THE INTERNATIONAL

REVIIEW OF RESEARCH IN

OPEN AND DISTANCE LEARNING

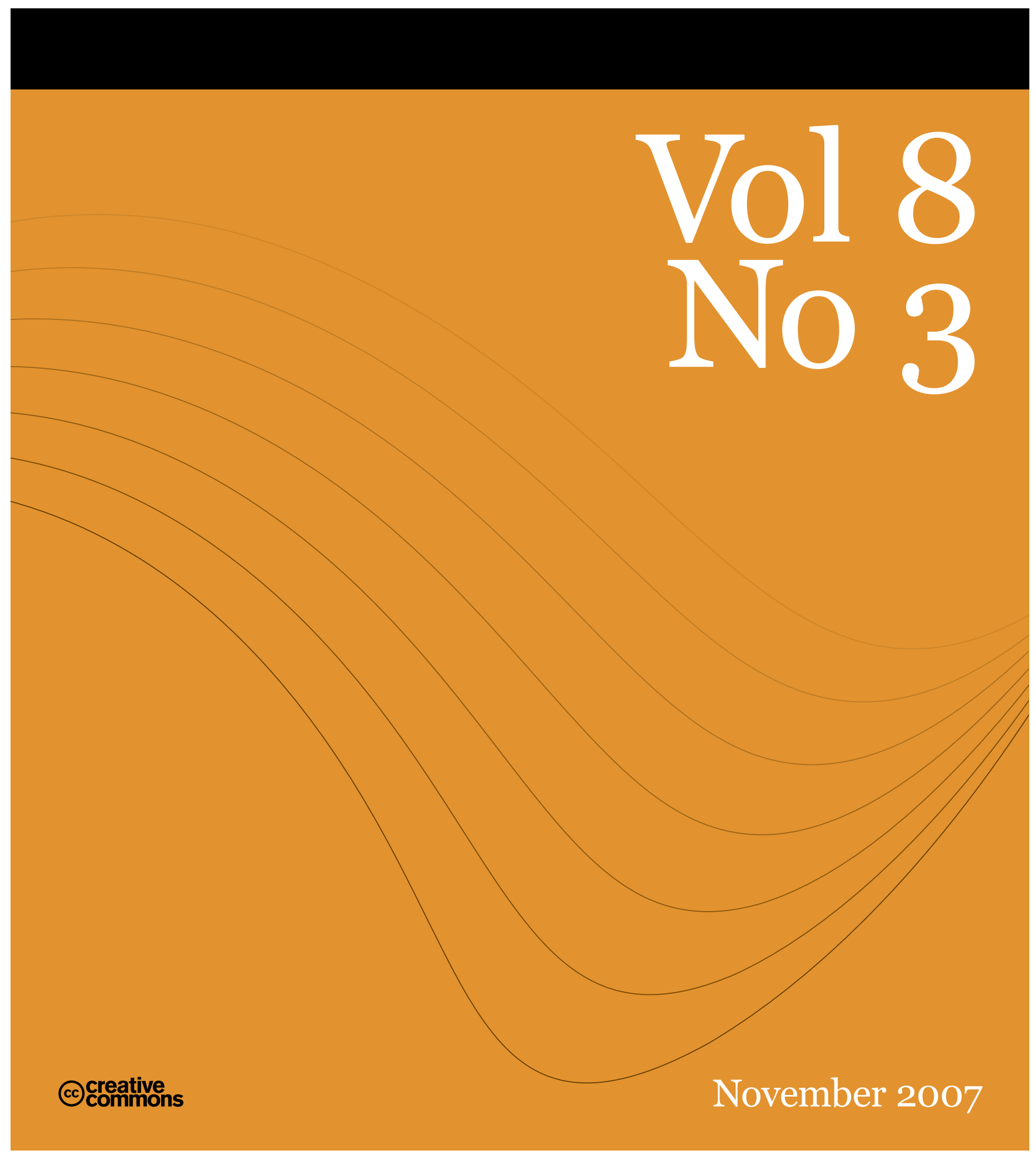


November -2007

\section{Editorial}

\section{Sabbaticals}

It has been my pleasure to be the acting editor of IRRODL while Dr. Terry Anderson has been on sabbatical leave. While the value and need for academic sabbaticals has been passionately debated for decades (and will likely continue to be debated for decades to come), within the academy most, if not all, academics understand both the value and need for a career pause.

An academic sabbatical is a prolonged leave, typically for one year after six years of continuous employment. Harvard University was the first to grant academics a sabbatical in 1880. The primary purpose was, and still is, to provide an opportunity for academics to fulfill a career goal (i.e., write a book, travel for research or an opportunity for collegial inter-visitations). The word 'sabbatical' has biblical origins connected to the practice of leaving land unplanted as a means of rejuvenation. The word originates from the Mosaic law of ancient Judea, during which farmers left land fallow for a year after six consecutive harvests. The spirit of rejuvenation and harvesting has remained unchanged within the academy. Similar to 'leaving the land unplanted,' academics 'leave the daily demands of university life' (e.g., teaching and service commitments) for an opportunity to regenerate new ideas and pursue professional growth.

In the next issue of IRRODL, Dr. Anderson will be returning to us 'refreshed and recharged.' I'm sure you'll join me in welcoming Dr. Anderson back and look forward to hearing about his new ideas!

Sincerely,

Heather Kanuka

Acting Editor, IRRODL

In this issue of IRRODL, we have a broad cross section of articles, book reviews, and rebroadcasted presentations called CIDER Sessions from the Canadian Institute of Distance Education Research.

First in our line-up is a paper entitled, Cross-Cultural Delivery of e-Learning Programmes: Perspectives from Hong Kong, by Wong Lap Sang. Wong examines a typically overlooked facet of e-learning, namely cultural hegemony. By examining Hong Kong's approach to education policy vis-à-vis the importation of cultural artifacts, Wong examines e-learning "from a critical-dialectical perspective.” In particular, he examines the cultural implications that Hong Kong faces from the cross-border importation of elearning courses and programs. As more and more universities seek to capitalize on new 
Heather Kanuka Editorial

Open Issue

Vol. 8, No. 3, November 2007

and foreign markets, and both learners and governments seek educational opportunity from global suppliers, cultural hegemony could very well present problems.

Next, we move to report of a study conducted at the University of California, Irvine. In Persistence in University Continuing Education Online Classes, Jia Frydenberg examines student persistence and attrition in online versus 'onground' classes. Clearly, attrition is a problem. What is interesting is that Frydenberg's study found that despite fairly consistent reports in the literature indicating higher drop outs for distance education students, this was not the case at the University of California, Irvine once the course has begun. Attrition in open and distance education is a critical factor, but studies such as Frydenberg show that attrition is multifaceted and often clouded by a host of confounding variables.

The next paper in this issue, Going the Distance: Towards a new professionalism for fulltime distance education faculty at the University of the Philippines, by Patricia Arinto addresses issues of training and professional development in distance education. Arinto's paper is interesting because she explores the literature grounded within the context of her own experiences teaching in a distance education faculty of a respected Filipino university.

Increasing access to educational opportunity is the driving motivation of much distance education programming. Access to Communication for the Deaf, Hard of Hearing, and ESL Students in Blended Courses, by Gary Long, Karen Vignare, Raychel Rappold, James Mallory, reports on how the online components of blended courses afford positive outcomes for deaf and hard of hearing ESL students.

Our next two papers examine open educational resources and open source software. The first paper by Mimi Miyoung Lee, Meng-Fen Grace Lin, and Curtis Bonk OOPS, Turning MIT Opencourseware into Chinese: An analysis of a community of practice of global translators, explores the dynamics of the open source community - specifically how volunteers negotiate 'obstacles' to bring the benefits of open courseware to the new audiences.

The next paper is entitled, The Emergence of Open-Source Software in North America by Guohua Pan and Curtis Bonk. This paper, is a companion piece published earlier this year in Insung Jung's Regional Focus Issue (IRRODL Vol .8 No. 1, 2007) on Changing Faces of Open and Distance Education in Asia.

Pedagogy is the basis of quality education, regardless of delivery method or technology used. In Identifying Effective Pedagogical Approaches for Online Workplace Training: A case study of the South African wood products manufacturing sector, Iain Macdonald, Mark Bullen and Robert Kozak report on an investigation of pedagogical techniques for workplace e-learning programs in the South African wood products manufacturing sector. 
Is our education system meeting the needs of today's and tomorrow's students? Our next article by David Annand, Re-organizing Universities for the Information Age examines this issue through the lens of organizational theory. It is an informative read for those interested in cost effectiveness and the administration of distance education systems.

Same Size Doesn't Fit All: Insights from research on listening skills at the University of the South Pacific (USP), by Rajni Chand explores how 'listening skills' - a subcomponent of a larger study skills course, is 'actually' being taught at a distance. This paper illustrates the apparent disconnect between teachers' perceptions of what they felt they were teaching versus students' perceptions of what they felt they were actually learning. It also examines the complexity of delivering a distance course across a very wide geographic region.

Next, we have three Research Notes papers. First in our line-up is an informative paper entitled: Combating HIV/AIDS Epidemic in Nigeria: Responses from National Open University of Nigeria (NOUN) by Ambe-Uva Terhemba. Effective response to HIV/AIDS clearly needs holistic policies that formally recognize and address the entire scope of this global pandemic - including its impact on universities and the people who work within them.

We then move on to Lessons from an International e-Learning Project by Paul Breen. While Breen points out that distance education projects rarely form part of any larger plan in Africa, so-called 'agenda free' assistance from western agencies or educators remains equally problematic. Those interested in the multifaceted potential for distance education projects in developing countries will find Breen provides interesting and critical insights.

Montana State University is the setting for our final article, Incorporating Screencasts in Online Teaching, by Elaine Peterson. Despite success in teaching a library course online, one component remained a problem for Montana State students: learning the Dewey Decimal Classification System. Peterson reports on the preliminary results of an intervention designed to address this challenge.

We then bring to you two book reviews on James Paul Gee's Good Video Games + Good Learning: Collected essays on video games, learning and literacy, reviewed by Sharon Stoerger; and Susan D'Antoni's The Virtual University - Models and Messages: Lessons from case studies, reviewed by Denis Mayer.

Finally, we wrap up this issue with rebroadcasts of the latest CIDER Sessions, hosted by the Canadian Institute for Distance Education Research. It's a large issue, so enjoy! 


\title{
Cross-Cultural Delivery of e-Learning Programmes: Perspectives from Hong Kong
}

\author{
Andrew Lap-sang Wong \\ School of Professional and Continuing Education (HKU SPACE) \\ The University of Hong Kong
}

\begin{abstract}
The growing popularity of e-learning may pose one of the greatest challenges currently facing traditional educational institutions. The questions often asked are how, rather than whether, to embrace this new form of instructional delivery and how to create an appropriate learning environment for the learners. Educational institutions in Hong Kong have the option of adopting programmes or learning materials developed in other parts of the world for local learners, or not. Such an approach of acquiring learning materials is not without risks in terms of the suitability of materials embedded with cultural contents 'foreign' to local learners, or in terms of the suitability of assumptions in the communication context. What are the issues involved in the globalization of education through e-learning? This paper explores - from a critical-dialectical perspective - the implications of globalization on educational policy through cross-border delivery of educational programmes by e-learning, with particular attention given to the threat of cultural imperialism. The paper concludes that Hong Kong seems to be coping with 'cultural imperialism' rather well because of its unique history of being a cross-road for East and West, and also with some recommendations to e-learning providers to mitigate the potential damage of cross-cultural delivery of e-learning.
\end{abstract}

\section{Introduction}

A casual survey of the media in Hong Kong, a Special Administrative Region of China, will create the impression of an exceptionally high occurrence of the word 'globalization.' Indeed, few other words in our contemporary vocabulary draw as much attention and controversy as 'globalization'. The context may be economic, environmental, or educational, but invariably the viewpoints will be polarized. Globalization is either depicted as the greatest force since the industrial revolution that created wonderful economic opportunities, improved standards of living and advanced civilization, or it is condemned as the vehicle of all forms of western economic exploitation and cultural imperialism. Such mixed and extremely opposite views are fueling a continuous debate over the merits or demerits of globalization, although such debates tend to be somewhat one-sided in the context of economic development in China, and certainly in Hong Kong. Economic growth takes a higher priority over other things for the country as a whole. In the educational and cultural arena, however, the debate tends to be more complicated by the added sensitivity of China in matters relating to ideology and culture. 
The phenomenon known as globalization is generally recognized to have its roots in the business world of about a century ago, as that is when international trade became more and more active (alongside a rapidly changing landscape of information and communication technology) and important to the economies of the world. The tremendous acceleration of trade volume has especially been propelled by the advances in information and communication technology (ICT) in the past quarter century or so. New ICT has brought about two major benefits to the market:

- information or knowledge has become much more portable and can be widely shared and communicated on the global internet platform, and;

- such improved access to information, especially scientific and business knowledge, has greatly facilitated innovation. Innovation is a key element in successful globalization.

Proponents of the globalization of education will point to the reduction of cultural isolation and the improved access to knowledge to support their claim, whilst opponents of globalization will protest the destruction of local culture by the unstoppable 'McDonaldization'. As Joseph Stiglitz pointed out, however, in his analysis of the different effects of economic globalization on different regions of the world:

Globalization itself is neither good nor bad. It has the power to do enormous good, and for the countries of East Asia, who have embraced globalization under their own terms, at their own pace it has been an enormous benefit, in spite of the setback of the 1997 crisis. But in much of the world it has not brought comparable benefits. (Stiglitz, 2003, p. 20)

This paper explores the implications of globalization on educational policy and politics from a critical-dialectical perspective, and also how the globalization of education could be embraced through cross-border delivery of educational programmes by e-learning, with particular attention given to dealing with the threat of cultural imperialism.

\section{Interdependency, Interconnectedness and Integration — The nature of globalization}

One of the greatest obstacles in studying globalization and understanding a discourse about globalization is the diverse definitions adopted in the literature. As Manuel Castells (1999) lamented about the nature of the debate of the information technology revolution, and of globalization, "As is always the case with a fundamental debate, it is most often framed ideologically and cast in simplistic terms" (p. 1). Indeed, there are probably as many definitions as researchers interested in the study of globalization. Their definitions largely reflect their theoretical perspectives (functionalist, humanist, radical functionalist, or radical humanist, among others) as well as their fields of study (economics, sociology, political science, or education, to name a few). Yet, the word 'globalization' always seems laden with strong emotions that imply either great opportunities and promises such as global prosperity, borderless education, democracy and the like, or merciless threats such as economic exploitation, political hegemony, widening of the economic divide, or the death of local culture. Obviously there are winners and losers in the process of globalization, so views on globalization will naturally be influenced by where one is positioned and how one has benefited (or otherwise) through the process. 
Some authors tend to refer to globalization as a mega-trend (one world) that has been powered by the much enhanced ICT which, in turn, makes information and knowledge much more readily available to anyone who is appropriately connected to it. Unlike the old days when one's life may only depend on others within a small isolated community, this interconnectedness or 'connectedness' referred to by Castells (1999) depends on improved access to information and improved capacity to communicate globally. It expands the network of interdependencies of each individual person or community tremendously. Giddens, as cited in Held (1991), defined globalization in terms of such connectedness as "the intensification of worldwide social relations which link distant localities in such a way that local happenings are shaped by events occurring many miles away and vice versa” (Held, 1991, p. 9).

This interconnectedness on a global scale is sometimes referred to as the 'Butterfly Effect.' Communities are no longer isolated like tribal villages in the Middle Ages, but are rather like what Marshall MacLuhan (1982) called the Global Village. Whilst the act of economic globalization such as outsourcing by a company in the United States affects the industrialization and urbanization of certain communities in India, the Indian's success in building-up a thriving outsourcing industry also affects the USA resulting in a rapid outflow of jobs in the labour market.

For others, globalization itself is a 'technology' that consists of certain sets of practices, largely drawn from the business sector, based on certain market ideology. These proponents argue that such sets of practices not only encroach on the freedom of individuals, but also on the capacity of nation states to control policies and politics and to influence the economics of their home market.

Jones (1998) defined globalization as "the organization and integration of economic activity at levels which transcend national borders and jurisdictions” (p. 143). Such economic integration is "achieved in particular through the establishment of a global market-place marked by free trade and a minimum of regulation” (p. 143). This last part about 'a minimum of regulation' may seem a little idealistic in the economic arena even with the best of efforts in intervention by international agencies such as the World Trade Organization (WTO), World Bank, and the International Monetary Fund. Nation states, including the behemoth of globalization, the United States of America, would want the benefits of globalization such as new capital and new markets without its negative effects of de-skilling of labour and resulting high unemployment. It is also true that in the global education market, with perhaps notable exceptions such as Hong Kong, barriers are often set-up to prevent the free flow of educational programmes, and talent, and sometimes even knowledge.

Kohler (1978) recognized this reality and saw globalization as an ongoing work in progress:

Fundamentally, it is the closer integration of the countries and peoples of the world which has been brought about by the enormous reduction of costs of transportation and communication, and the breaking down of artificial barriers to the flows of goods, services, capital, knowledge, and (to a lesser extent) people across borders. (Kohler, 1978 , p. 283)

Both definitions, however, seem to share the concept of integration. Unavoidably, integration implies standardization that demands achieving a certain level of uniformity; hence the Chinese translation of the word globalization renders 'the world becoming one system.' Here, perhaps, lies the heart of the problem with globalization in cultural terms: standardization, conformity and uniformity are very much at odds with multiculturalism and diversity. The 'integrators' might attempt to mitigate the negative effects of standardization by introducing flexibility or allowing 
some varieties in the process or standards expected. For example, personal computer makers might introduce different options to different groups of customers in different geographic regions. Such flexibility is always a trade-off to production efficiencies and is driven by market demand. In practice, such flexibilities tend to be limited and sometimes cosmetic, which are intended to gain some marketing angles rather than to provide real and substantial benefits.

Commodification or marketization of education, or the globalization of the knowledge economy, naturally epitomizes the tension of cultural resistance to globalization. The utopia of a 'borderless world' may very much be a Faustian bargain. As Morgan (2002) reminded us, the so-called 'borderless world' may only turn out to be a 'rootless world' because of 'the failure to take into account social realities and deep human preferences.

Another keyword often referred to in the debate of globalization is 'interdependency' of nation states. As Kohler (1978) suggested: "The process es of interdependence, interpenetration and intercommunication in the present era have made the entire humanity into one global society” (p. 283).

Similar to the effect of integration into one global system, such interdependency and interpenetration also tend to introduce either compromises or clashes between different ideologies, cultures, and political administrations. The most notable clashes of globalization with indigenous cultures and ideologies may be what Barber (1995) described as 'Jihad vs. McWorld' or the clash of 'tribalism' and 'globalism' where jihad represents the war against all others as practised in the name of the Islamic faith.

For the purpose of this paper, Knight's (2006) definition of globalization is adopted: A process that is increasing "the flow of people, culture, ideas, values, knowledge, technology and economy across borders, resulting in a more interconnected and interdependent world” (Knight, 2006, p. 18).

In education, the effect of globalization may be even more acutely felt by small states that aspire to become economically as successful as the industrialized countries. What are the key issues of globalization in education through cross-border delivery of e-learning that affect educational policies for a unique administrative region such as Hong Kong? As Rumble (2000) pointed out, it is the empowerment of learners, in terms of more choices, access to previously unavailable experts, high quality education, and the like that makes e-learning such an obvious commodity for globalization.

\section{Impact and Issues of Globalization}

Despite diverse opinion about the impact of globalization, there is general agreement on the issues arising from globalization. In the main, these issues fall into three broad categories:

\section{Economic: Income erosion and unemployment}

In economic terms, there are issues centred on damage caused by globalization of business with the free flow of goods, money, and people (workers or talent). Concerns include loss of jobs brought about by the inflow of inexpensive goods and services produced in foreign countries, and the outflow of capital and talent (brain drain). Current hot public debate in the USA is about the extensive out-sourcing of services such as income tax reporting and service call centres from the 
USA to countries like India, which has resulted in a massive loss of jobs and income for the American economy (estimated to reach \$US1.5 trillion by 2006). No wonder Burbules and Torres (2000) observed the result of economic restructuring brought about by globalization and argued that "[c]ontrary to Marx and Engel's prediction, the globalization of the economy has produced a unification of capital on a world scale, while workers and other subordinate groups have become more fragmented and divided” (p. 7).

Hong Kong , in this regard, seems to be one of the few territories to be standing somewhere in the middle on a world scale of globalization. As the 'freest economy' in the world, it is an open target of unchecked globalization of any goods and services. Hong Kong is also heavily involved in the business of exportation of goods, however, playing the role of a 'globalizer,' especially with respect to the Mainland of China. But in the process, it has lost practically all of its manufacturing industry to China. Since that happened, Hong Kong has realized it must develop its capability and market as an exporter of services.

In terms of educational services, this gradual shift of position from an importer to an exporter is a good example. As Cribbin (2002a) observed in 2002: “ Hong Kong is a fairly open market economy in educational services and light regulation to protect consumers from rogue operators appears to have allowed ... healthy market provisions to meet undoubted needs” (p. 452).

As analyzed in later sections of this paper, however, recent attention of Hong Kong - and particularly its tertiary education sector - seem to focus more and more on Hong Kong becoming an education hub, which essentially means becoming an exporter of education.

\section{Political: Influence and control erosion}

In political terms, some nation states may feel their sovereignty or control of their own destiny is eroding under globalization. Some authors take a radical view and say that as a result of globalization, most nation states are becoming declining autonomous decision-making bodies. In other words, there is an erosion of influence or even control. For example, joining the WTO has forced new members, such as China, to weaken their control on trade, foreign currency exchange, taxation, and other spheres of control and influence. In a more subtle way, the growing power of externally defined values resulting from globalization is further eroding these spheres of influence of local institutions and authorities and constraining their ability in policy making. Some might argue, however, that the nation state might be weakened by globalization, but that its influence is not weakened. In other words, the states may be more interdependent but are not powerless.

A case in point is the Hong Kong Government's introduction of a Non-Local Higher Education and Professional Education (Regulation) Ordinance in 1997. The Government could not stop or control the rapid growth in the number of overseas educational programmes in Hong Kong - or the number of students enrolled in them. In the interests of 'consumer protection,' however, the Ordinance gives the Government the power to demand that overseas institutions (the 'globalizers') demonstrate that the qualities of their overseas-delivered programmes are of the same standards as those delivered in the home countries. It also steers (influences) the institutions towards collaborating with local universities by exempting registration of collaborative programmes. 


\section{Cultural: Identity crisis}

In cultural terms, free flows of goods, services and people also means free-flows of ideology and the cultural settings behind and embedded in them. Goods, services and people are never really culturally neutral. Buying a Big Mac from a McDonald's restaurant is also buying the cultural features embedded in the promotion, packaging, and ambience of McDonald's. As Carnoy (2003) put it: "Globalization redefines culture because it stretches boundaries of time and space and [an] individual's relationship to them. It reduces the legitimacy of national political institutions to define modernity" (Carnoy, 2003, p.133).

The process of globalization tends to bring forth cultural standardization and homogeneity that naturally creates tension and fragmentation because of the likely rise of resistance forces in the local cultural movements. In the context of globalization through the cross-border delivery of elearning, there is also the danger of erosion of the community. The educational process of elearning is largely without the element of face-to-face contacts of teachers and students, leading to a social loss in a physical community. Mason (1998) warned about the potential damage elearning does to community, including undermining the physical experience of community and replacing it with the virtual communities.

There are, of course, opposing views. Rheingold (1993) praised the virtual communities, from which he was able to obtain precisely the information he needed to know. The 'well' gives him an "immense inner sense of security that comes with discovering that real people . . are available around the clock, if you need them" (p. 1). Harasim, Hiltz, Teles, and Turoff (1995) were also optimistic about the positive effect of electronic communication on the community. With the rapid growth of small online learning networks, small interest groups can be formed on a wide range of topics, which in their views made possible "a considerable improvement in the quality of life of the local community" (p. 247).

Another counter argument might be that in the process of professional development based on cross-cultural learning materials, if the learners are cognizant of the embedded bias, they become more aware of the relative strengths of their own culture vis-à-vis those that are foreign. They might even be able to develop stronger local programmes based on this appreciation.

\section{Globalization of Education: The Hong Kong perspective}

The word 'globalization' must be one of the favourite buzzwords used by the Hong Kong Government. Together with 'knowledge-based economy,' globalization has been mentioned so often in the Chief Executive's annual policy addresses in recent years that one might form the impression that Hong Kong, or at least the Hong Kong Government, is a radical 'globalist'. Indeed, this interpretation is clearly supported by the repeated appearance of certain government policy agenda items in the annual Chief Executive's Policy Address, such as transforming Hong Kong's economy into a knowledge-based economy, ambitious expansion of the tertiary education participation rate from 30 percent to 60 percent by 2010, exportation of educational and medical services, closer economic partnership with Greater Pearl River Delta Region, and so it goes.

From the perspectives of the Hong Kong institutions of higher learning, now is, indeed, a time of ample opportunities and challenges. The information age - powered by accelerated technological advancement over the past decade or so, which marked a new industrial revolution that has fundamentally changed the business world in a similar fashion - is also changing the higher 
education sector. This new industrial revolution has resulted in a new order focusing on knowledge as the prime asset of a corporation. We have therefore witnessed the formation of a knowledge-based global economy, more visible perhaps in America and Europe, but certainly an economy that is aspired to, and is beginning to, take shape in richer Asian nation states such as Singapore . Being one of the world's most open economies, Hong Kong also envisages becoming a vibrant knowledge-based economy. By aiming at 'moving towards a knowledge-based economy' (which implies a road to greater economic prosperity), the Hong Kong Government has adopted a very open educational policy, and at the same time has placed great pressure on the education system to reform. Over a short period of five years, the Hong Kong Government has made the following major policy or strategic decisions relating to education:

Enactment of a Non-Local Higher Education and Professional Education (Regulation) Ordinance from June 1997. The objective of the Ordinance is:

. . . to protect Hong Kong consumers by guarding against the marketing of substandard non-local higher and professional education courses conducted in Hong Kong. It also enhances Hong Kong's reputation as a community which values reliable and internationally recognized academic and professional standards

(see http://www.emb.gov.hk/index.aspx?langno=1\&nodeid=1251).

Essentially, the Ordinance requires registration of all overseas programmes offered in Hong Kong; unless these programmes are offered in collaboration with a local tertiary institution (Hong Kong has stringent controls on private tertiary institutions). Registration requirements, however, are not onerous, and actually legitimizes and facilitates the exportation or globalization of programmes of legitimate overseas institutions in Hong Kong. Additionally, it is perhaps important to note that all purely distance learning courses (including e-learning courses) are also exempt from registration.

As of April 30, 2007, and according to statistics provided by the Non-Local Course Registry (see http://www.emb.gov.hk/index.aspx?langno=1\&nodeid=1250 ), there were 1,101 overseas courses on the register, of which only 37 percent were registered without a local partner (programmes in collaboration with a local partner are exempted from registration and related scrutiny by Government). Whilst no statistics on student enrolment are available, current total enrolment is estimated to be in the region of 85,000 (about 42,000 in 1999). In terms of countries of origin of these courses (or programmes), the UK is the clear leader with a 47 percent and 63 percent share of registered and exempted courses, respectively.

Chief Executive Tung Chee Hwa announced in "The 2000 Policy Address" (Hong Kong Government, 2000 ) that, among the various policy objectives for Education and Manpower, Hong Kong should actively work "to develop Hong Kong into a regional center of excellence for higher education" (p. 5).

First, Chief Executive Tung Chee Hwa pointed out in his 2001 policy address (Hong Kong Government, 2001) that Hong Kong's economy was facing a major restructuring and transformation because of the global economic downturn and globalization of markets. Such a transformation was leading Hong Kong from an industrial economy to a knowledge-based economy. 
Second, severe funding cuts to the public tertiary institutions had resulted in almost all taught post-graduate programmes becoming self-funding in 2003. On one hand, having to charge market rates for these programmes has made overseas programmes much more competitive and attractive to local learners. On the other, the financial squeeze has forced local institutions to look for ways to expand their income base, including more aggressive exportation of their programmes, mainly to Mainland China.

Third, Chief Executive Tung Chee Hwa announced in his 2004 policy speech that Hong Kong should further develop its educational (and medical) services to serve people in the Mainland and elsewhere in Asia.

Fourth, the Chief Executive, in the Executive Council meeting of December 7, 2004, ordered a relaxation of immigration control in respect of institutions and programmes admitting non-local students. As outlined in the Education and Manpower Bureau paper (2005), the implementation of this new policy would take effect in the following areas:

- Increased quota for publicly-funded full-time programmes at sub-degree, degree and taught post-graduate levels, plus the admission of students from the Mainland, Macau, and Taiwan.

- Hong Kong institutions could now admit students from the Mainland, Macau, and Taiwan to the self-financing full-time programmes below post-graduate level, subject to a quota. There would be no quota at post-graduate level.

- For publicly-funded part-time programmes, students from the Mainland would be allowed to enter Hong Kong for locally accredited taught post-graduate programmes provided by the eight publicly-funded institutions up to 10 percent of the student number targets. There would be no quota for self-financing part-time programmes.

Fifth, the Hong Kong Trade Development Council , a quasi-NGO funded by the government, commissioned an independent study in 2005 to assess the demand for Hong Kong Higher Education in mainland China's major cities . The report (2005) concluded that there was great potential for exporting education, and that Hong Kong had the necessary strengths to be successful in attracting students from the Mainland.

Sixth, in July 2005, a Memorandum of Understanding was signed by representatives of the China Central Government's Education Ministry and Hong Kong that outlined the mutual recognition of higher educational awards. The Minister of Education also discussed with Hong Kong representatives a range of topics of mutual concern, such as taxation and expansion of the list of provinces that allow direct recruitment of students by Hong Kong-based institutions and recognition of Associate Degree qualifications for the purpose of articulation into universities in the Mainland.

Finally, on 21 June 2006, the Secretary of Education and Manpower, Professor Arthur Li (2006) provided some glimpses of the Hong Kong Government's intention in developing Hong Kong into a regional education hub. In his speech to the Legislative Council during the debate on the same subject, he argued for the need and the readiness of Hong Kong to become an educational hub. He also outlined various measures that the Government had been studying to support and facilitate such a development. The Government subsequently established a high-level steering 
committee, chaired by the Chief Secretary of the Hong Kong Government, to provide policy guidance in this development.

\section{Can Hong Kong Become Both a ‘Globalizee’ and a ‘Globalizer’?}

Higher educational institutions in Hong Kongare at the forefront of changes, and the core business of any higher educational institution is the creation and dissemination of knowledge. Any attempts by a society to transform itself into a knowledge-based economy, with rapidly growing demand for 're-skilling' or 'up-skilling,' creates ample opportunities for the higher education sector.

Nonetheless, it can also be the worst of times for weaker institutions in Hong Kong, when education is becoming more of a global marketplace without many barriers, especially if such education is delivered through e-learning. As competition will no longer be limited to between local institutions within the boundaries of one territory, or even one country as was the case in the not-so-distant past, higher educational institutions must face fierce competition for students, teachers, and even resources - globally, not just locally. World-class universities can easily extend their reach internationally and break the barrier of space, especially those from the United States, Britain, Australia, and Canada. For example, in addition to the thousands of students who leave Hong Kong to study abroad annually, Cribbin (2002b) estimated that in 1999 more than 42,000 students were also enroll ed in Hong Kong in both registered and exempted programmes offered by universities of these countries in collaboration with local educational institutions in 1999. With the rapid growth of demand for continuing education in the following years, current enrolment is believed to have at least doubled. At the moment, only a small percentage of these programmes involve e-learning, but clearly this can only grow as personal computers and broadband communication become more and more affordable.

Another reason to expect an increase in the growth of e-learning programmes offered by overseas institutions is the advantage that 'purely distance learning courses' are exempted from registration under the Non-local Higher and Professional Education (Regulation) Ordinance. In practical terms, even if the Hong Kong Government wished to regulate e-learning programmes, it would find it almost impossible unless the providers had a physical presence in Hong Kong. For these reasons, there is genuine concern that 'global universities' armed with their expertise in elearning can, and will, eventually grab a big chunk of this market.

Although these global universities offer technology-based education not yet widely available locally, understandably there is a fear that the Hong Kong public, which traditionally worships technology and reveres education, may regard taking up e-learning with an overseas institution as a trend worth embracing as Hong Kong progresses toward modernity. But is this assumption valid?

Another worrying side effect from all hype surrounding globalization and knowledge economy is that the Hong Kong Government seems to have an endless agenda of educational reforms covering pre-schools through to universities. Clearly such an agenda is motivated by a human capital development agenda in the interest of economic growth. The perception of the inevitability of globalization and the knowledge economy has been used to push such a government-directed education reform agenda. As Mok and Currie (2002) remarked: "Globalization discourse is used to facilitate the accomplishment of domestic purposes by creating a proper rationale or a legitimate claim for launching institutional reforms or to sustain a new discourse about the environment confronting institutions” (p. 274). 


\section{The threat of 'cultural imperialism'}

Many educators argue that the real threat of the globalization of education is not so much in economic terms but rather in cultural terms. Gayol and Schied (1997) warned about potential cultural imperialism in cross-cultural delivery of education:

. . . empiricist epistemologies and procedures derived from mainstream pedagogy serve as the basis for most distance education programs. Frequently, these models are used to produce educational programs delivered globally. Yet the ethical and cultural implications of this approach are rarely discussed in distance education literature. (Gayol \& Schied, 1997, p. 1)

There are at least two major sources for this threat of cultural imperialism.

\section{The dominance of the English language}

In the context of cultural ideology, language is not neutral. The language we use shapes our reality as different languages address and constitute the world in different ways. As Postman (1992) put it, "our most powerful ideological instrument is the technology of language itself” (p. 123). Its structure, form, linkage to history, and connotation relating to usage - and all contribute to the ideological structure of that language. This means when people speak two different languages, they actually see the world differently. But the real danger is that unless people have sufficient command of both languages, this difference is not normally noticeable, which is why the problem of communication between two cultures can be so difficult. To quote Postman again, "language has an ideological agenda that is apt to be hidden from view" (p. 124), which is why he called language the 'invisible technology.'

The dominance of English as the medium of instruction also means most e-learning courses carry cultural bias inherent in that language. According to Vilaweb, about 68.4 percent of all webpages surveyed (over 214 million pages) were in English (see http://cyberatlas.internet.com/big_picture/demographics/article/0,1323,5901 408521,00.html).

That implies not only that most e-learning is in English, but also most online references are in English. Online translators are trying to mitigate the problem, but the effect so far has been less than satisfactory.

Some argue that English being the dominant international language creates the environment for communication and improves understanding between two cultures. That may be true to some extent, but unfortunately the flow of culture tends to be one way and at best heavily asymmetrical, with English-speaking Anglo-Saxon-American culture dominating the flow.

Some educators believe that asynchronous communication of e-learning actually helps non-native speakers to follow and participate in online discussions, as language aids can be used before responding. As Mason (1994) pointed out, however, the pace of discussions is such that students working in their second language can find it hard to keep up and therefore tended to make shorter and fewer inputs. 


\section{The dominance of the Anglo-Saxon-American culture}

In the Hong Kong continuing education market, the United Kingdom is the clear leader in the import of education with a 47 percent and 63 percent share of all registered and exempted nonlocal courses, followed by Australia. The dominance of the Anglo-Saxon-American culture is almost self-evident.

In cyberspace, the American dominance is particularly overwhelming. Since over 68 percent of the webpages on the ubiquitous Internet are in English, if globalization of education is realized through the medium of the Web through the engine of e-learning, such globalization undoubtedly carries with it a distinctive dominance of the Anglo-Saxon-American culture.

Wilson, Qayyum and Boshier (1998) reported a 1996 survey that showed - of the 9.4 million host computers in the world - 60 percent were in the United States, which explains why most of the tools developed for the Web, such as browsers and search engines, are mostly in English. The implication is, "although cyberspace straddles oceans and continents, it is like a boomerang that keeps going back to the US” (p. 120).

Wilson and colleagues also experimented with three widely-used search engines to search 'online course' and found between 68 percent and 87 percent of the hits were American sites. This led these scholars to conclude that the United States has an undisputed dominance of Web education. That means most e-learning courses available contain American cultural assumptions relating to their family, democracy, religion, traditions, social fabrics, and structure: "The overwhelming US presence renders ‘American’ as the norm and the rest of the world as periphery” (1998, p. 119).

One might add that the dominance of Anglo-Saxon culture is really disproportionate to the sheer size of their related population. This is made possible because of the growing interdependence of nations and people in the world. Because it is the case of a minority race dominating a majority composed of all non-Anglo-Saxon races, however, Kohler (1978) called it a 'Global Apartheid' and suggested that such global apartheid had the characteristics of a minority occupying the 'pole of affluence,' with a disproportionately large share of economic and political power. Although economic development of the two groups is interdependent, their social integration is extremely difficult.

\section{Is ‘Cultural Imperialism’ All Negative?}

Some authors hold more positive views about globalization relating to the issue of cultural imperialism. Henry, Lingard, Rizvi, and Taylor (1999) argued that the effect of globalization depends much on how the forces of globalization were engaged to mitigate their worst consequences and were used to advantage. "Globalization is not necessarily a homogenizing force, but [it] also provides considerable opportunities for heterogeneity of cultural traditions to exist side by side” (Henry et al., 1999, p. 86).

Mok and Currie (2002) held similar views and saw that globalization may not necessarily reduce diversity as a result. "We should not treat globalization merely as a homogenization process.

Rather, we must appreciate the complex and dynamic interactions between global-regional-local forces and there is no reason to expect a dramatic decline in diversity” (p. 274). 
Luke and Luke (2000) also argued for the more positive outcomes of 'cultural imperialism' as they believed that new forms of cultural identity may be created. "Globalization has generated new kinds of identity, new forms of intercultural communication and new forms of community" (p. 282).

In other words, they believe that globalization is such a complex issue that countries on the receiving end may or may not appropriate Western cultures uncritically and the process of appropriation is not always uni-dimensional ('don’t other me'). As Kellner (2000) so powerfully argued: "Culture is an especially complex and contested terrain today as global cultures permeate local ones and new configurations emerge that synthesize both poles, providing contradictory forces of colonization and resistance, local homogenization and local hybrid forms and identities" (p. 305).

\section{Concluding Remarks and Recommendations}

Is globalization a real threat to culture and education? Is it possible to retain the benefits and avoid some of the evils at the same time?

\section{Hong Kong's Way of Blending Foreign Culture into the Local Culture}

Taking into consideration the above arguments from both sides of the fence, and judging from the limited coverage in the media, the general public of Hong Kong seems to be absorbing the blows of 'cultural imperialism' in a rather nonchalant manner.

First, the view that appropriation of western culture can result in a new form of culture may carry some truth in the Hong Kong context. One only needs to observe the popular practice of frequently mixing English words with Chinese words in pop music or as a common practice in the classrooms so that students can hardly carry on a reasonable flow of discussions in Chinese without using a substantial vocabulary of English words. Indeed, the local pop culture seems happy to embrace features of foreign cultures introduced by the globalization of goods, entertainment, or services into local culture to produce a new form (some authors refer to this process of hybridization and re-appropriation of Western culture as 'glocalization'). As a crossroad of Western and Asian culture, diversity in culture - especially as manifested in food, entertainment, and way of living in general — is appreciated and celebrated in Hong Kong.

Second, it may be of interest to note that the reverse is also happening with respect to the spreading of Hong Kong culture through the globalization of its entertainment products (TV soap operas, movies, pop music) into Asian countries, mainly in sub-communities of Chinese descent. Is this also cultural imperialism when such cultural influence is taking place between diasporic Chinese communities?

\section{Recommendations to Providers of e-Learning in Hong Kong}

How can we weigh the perceived benefits against the perceived harm generated from the globalization of education, particularly through the cross-border delivery of e-learning programmes? What can be done by local providers to at least mitigate the potential damages resulting from submissively swallowing cultural imperialism embedded in e-learning programmes imported to Hong Kong? Mason (1994) outlined three broad alternative attitudes and practices: 
- $\quad$ Try to tackle the problem by 1) making adaptations to the original course; 2) jointly redeveloping the course for cross-cultural delivery with the original overseas provider; or 3) creating a different version of the original course by translation into the local language.

- Try to develop a culturally neutral course or a 'culturally uni-dimensional' course (McLoughlin \& Oliver, 1999). But trying to create a generic course for all people might end up with a course that pleases nobody. As cited by McLoughlin and Oliver (1999), Henderson argued that instructional design cannot be culturally netural simply because the process of instructional design is is all about the creation of cultural identity.

- Try to argue that the cultural bias may encourage students to be independent in knowledge acquisition. This, however, is somewhat like stating 'caveat emptor' as a disclaimer.

For obvious reasons, therefore, only the first alternative is recommended to providers of elearning.

Admittedly e-learning is better suited for cross-cultural delivery than traditional distance learning courses because greater emphasis is placed on student interaction and reflection. Students from different cultural backgrounds have an environment for inter-cultural understanding and appreciation to remedy cultural bias in the course materials. The ideal solution, of course, is to redevelop with the target audience in mind, along with the full knowledge of the social and cultural grounding of that audience. McLoughlin and Oliver (1999) suggested that instructional designers for cross-culturally delivered programmes should begin with the epistemology of constructivist theories of learning, and to acknowledge that learning is socially-grounded and located within communities with particular cultures, values, and expectations.

In practical terms the best strategy to mitigate the potential harm of cultural bias inherent in the cross-border delivery of e-learning may involve the adoption of a combination of the three techniques of adaptation - the joint re-development and translation suggested in the first alternative. As designing a culturally neutral course is not considered practical, making a carefully planned adaptation with suitable modification and substitution of locally relevant materials, and at the same time providing appropriate warnings and guidance to students (including open discussions about the likely sensitive areas in the original materials) would seem a reasonable strategy to deal with this problem.

Care must also be taken to ensure that a communal atmosphere is maintained at all times. In addition to encouraging or directing students to make use of the usual communication facilities in CMC such as forum, chat rooms, and emails, additional activities may be necessary to foster a spirit of community. In the Hong Kong context, as the barrier of space is much less of a problem because of its compactness, a number of face-to-face meetings may be arranged for small group discussions or tutorials with the tutor to supplement the originally designed online activities. Employing a 'blended' or 'integrated' approach would likely be much preferred over the 'pure' ecourse.

For a territory that is moving towards a position to be both a 'globalizer' and 'globalizee' in education services, what would be a sensible public policy for Hong Kong regarding strategies in dealing with the threat of cultural imperialism embedded in cross-border delivery of e-learning educational services? 
This is a question that perhaps requires more debate - not only in academia, but also through careful consideration by the educational policy makers in Hong Kong.

\section{Note}

This article is based on a paper presented and discussed at the 4th Asia Pacific Conference on Continuing Education \& Lifelong Learning hosted by The University of Hong Kong, 6-8 December 2006. Some of the revisions made in the production of this article are based on discussions at the conference, for which I am very grateful to the participants.

\section{Acknowledgement}

I would like to thank Dr. Rex G. Sharman, Professor John Morgan, Dr. Zhang Weiyuan and three anonymous reviewers for their advice and helpful comments.

\section{References}

Barber, B. R. (1995). Jihad vs. McWorld: How globalism and tribalism are reshaping the world. New York: Ballantine Books.

Burbules, N. C., \& Torres, C. A. (2000). Globalization and Education: An introduction. In N. C. Burbules \& C. A. Torres (Eds.), Globalization and Education: Critical perspectives (pp. 126). New York and London: Routledge.

Carnoy, M. (2002). Globalization, development and the international knowledge economy. In D. Istance, H. G. Schuetze, \& T. Schuller (Eds.), International Perspectives o $n$ Lifelong Learning: From recurrent education to the knowledge society (pp. 129-140). Buckingham: Society for Research into Higher Education \& Open University Press.

Castells, M. (1999). Information technology, globalization and social development. DP114. Geneva: United Nations Research Institute for Social Development, Palais des Nations. Retrieved www.unrisd.org

Cribbin, J. (2002 a). Crossing Boarders: Continuing education in China and community colleges in Hong Kong . In J. Cribbin \& P. Kennedy (Eds .), Lifelong Learning in Action: Hong Kong practitioners’ perspectives (pp. 435-436). Hong Kong: Hong Kong University Press.

Cribbin, J. (2002 b). Competition and Collaboration: Hong Kong providers and partners. In J. Cribbin \& P. Kennedy (Eds .), Lifelong Learning in Action: Hong Kong practitioners' perspectives (pp. 35-56). Hong Kong: Hong Kong University Press.

Education and Manpower Branch, Hong Kong Government (2005), Developing Hong Kong as the regional education hub , CR 1/9/2041/93 . Hong Kong: Author.

Gayol, Y., \& Schied, F. M. (1997). Cultural Imperialism in the Virtual Classroom: Critical pedagogy in transnational distance education. Paper presented to the 18th conference of the International Council for Distance Education, State College, PA. 
Harasim, L., Hiltz, S. R., Teles, L., \& Turoff, M. (1995) Learning networks: A Field Guide to Teaching and Learning Online. Cambridge, MA.: MIT Press.

Held, D. (1991). Editor's introduction. In D. Held (Ed.), Political theory today (p. 9). Cambridge, MA.: Polity Press.

Henry, M., Lingard, B., Rizvi, F., \& Taylor, S. (1999). Working with/against globalization in education. Journal of Education Policy, 14(1), 85-97.

Hong Kong Government (2000). Policy Objectives - The 2000 Policy Address. Volume 1, Chapter 11, Education and Manpower Bureau Policy Objectives, Hong Kong. Author.

Hong Kong Government (2001). Building on our strengths, investing in our future - The 2001 policy address by the Chief Executive. Author.

Hong Kong Trade Development Council (2005). Export potential of Hong Kong's education services. Author.

Jones, P. W. (1998). Globalisation and Internationalism: Democratic prospects for world education. Comparative Education, 34(2). 143-155.

Kellner, D. (2000). Globalization and New Social Movements: Lessons for critical theory and pedagogy. In N. C. Burbules \& C. A. Torres (Eds.), Globalization and Education: Critical perspectives (pp. 299-323). New York and London: Routledge.

Knight, J. (2006). Higher Education Crossing Borders - A guide to the implications of the General Agreement on Trade in Services (GATS) for cross-border education. A Report prepared for the Commonwealth of Learning and UNESCO. Retrieved June 7, 2007 from: http://www.col.org/colweb/webdav/site/myjahiasite/shared/docs/GATS_web_nocover.pdf [excerpt http://www.col.org/colweb/site/pid/4059]

Kohler, G. (1978). Global apartheid. City? Institute for World Order, Inc.

Li, A. K. C. (2006). Speech to Legislative Council, 21 June 2006. [in Chinese] Retreived date http://www.info.gov.hk/gia/general/200606/21/P200606210257.htm

Luke, A., \& Luke, C. (2000). A situated perspective on cultural globalization. In N. C. Burbules \& C. A. Torres (Eds.), Globalization and Education: Critical perspectives (pp. 275-298). New York \& London: Routledge.

Mason, R. (1994). Distance education across national borders. In M. Thorpe \& D. Grugeon (Eds.), Open learning in the mainstream (pp. 297-308). Harlow, Essex: Longman Group Limited. Retrieved DATE as extracts in World Bank Global Distance, EDUCATIONET. http://wbweb4.worldbank.org/DistEd/Policy/Global/coll-03.html

Mason, R. (1998). Globalising education. London: Routledge.

McLoughlin, C., \& Oliver, R. (1999). Instructional Design for Cultural Difference: A case study of the indigenous online learning in a tertiary context. ASCITE99 Conference proceedings. 
Retrieved November 26, 2007 from:

http://www.ascilite.org.au/conferences/brisbane99/papers/mcloughlinoliver.pdf

Mok, J. K-H., \& Currie, J. (2002). Reflections on the impact of globalization on educational restructuring in Hong Kong. In J. K-H. Mok \& D. K-K. Chan (Eds.), Globalization and Education: The quest for quality education in Hong Kong (pp. 259-278). Hong Kong: Hong Kong University Press.

Morgan, W. J. (2002 May/June.). Globalisation, education, and the need for roots. Education Quarterly 34(4).

Non-Local Course Registry Homepage (n.d.). Retrieved November 1, 2007 from: http://www.ncr.edu.hk/eng/faq.asp

Postman, N . (1992). Technopoly: The surrender of culture to technology. New York: Vintage Books.

Rheingold, H. (1993). Retrieved from The Virtual Community

Rumble, G. (2000). The Globalization of Open and Flexible Learning: Consideration for planners and managers. Online Journal of Distance Learning Administration, 3(3), Winter. Retrieved DATE from http://www.westga.edu/ distance/ojdla/fall33/rumble33.html

Stiglitz , J. E. (2003). Globalization and its discontents. New York : Norton \& Company.

Wilson, M., Qayyum, A., \& Boshier, R. (1998). Worldwide America? Think globally, click locally. Distance Education, 19(1), 109-123.

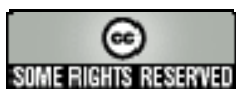




\title{
Persistence in University Continuing Education Online Classes
}

\author{
Jia Frydenberg \\ University of California Irvine, USA
}

\begin{abstract}
This study presents persistence and attrition data from two years of data collection. Over the eight quarters studied, the persistence rate in online courses was 79 percent. The persistence rate for similar onground courses was 84 percent. The drops for both course modalities were disaggregated by the time of the request for withdrawal: before course start, during the initial week, and during instruction. There was a significant difference between online and onground requests for withdrawals during the initial week. There was no significant difference between online and onground drop rates after the start of instruction, leading to the conclusion that differences in instruction online and onground was unlikely to be a major influencing factor in the student's decision to drop.
\end{abstract}

Keywords: persistence; attrition; online; distance learning

\section{Studies of Persistence}

The literature on student persistence has a long history. The outcome variable selected by the majority of the studies is the completion of a four-year or two-year formal degree, and the group whose behavior is studied is of traditional undergraduate age (18 - 22 years). The independent variables examined can be grouped into three broad and general categories (Tinto, 1993; Braxton, 2000; Tillman, 2002; Berge \& Huang, 2004): variables attributable to the 'individual persister/ non-persister,' variables within the institution, and variables related to the interaction between the individual and the institution. A few examples of such variables are listed below. 
Persistence in University Continuing Education Online Classes Frydenberg

Table 1. Commonly selected independent variables in persistence research

\begin{tabular}{|l|l|}
\hline The individual & - Prior academic preparation \\
& - Personality characteristics \\
& - Demographic variables \\
\hline The institution & - Allocation of funds \\
& - Orientation activities \\
\hline The interaction (between the individual and the institution) & - Academic integration \\
& - Social integration \\
\hline
\end{tabular}

Dropout rates are of concern because, as reported in Berge and Huang (2004) and referencing Tinto's (1982) work, "Historically, the percentage of students who dropout of brick and mortar higher education has held constant at between 40 - 45\% for the past 100 years” ( $₫ 2$ ).

The growing presence of adults on traditional campuses has led to an interest in research conducted to discover whether this group requires services with a different emphasis than do younger students. That they are different is not in question. Being older means they are more likely to have more external commitments, more financial resources, more likely to study parttime, more likely to have clearly defined goals, and a more acute ability to assess the perceived 'return-on-investment' they feel they are getting (or not getting) from their education (Bean \& Metzner, 1985; Kember, 1989; MacKinnon-Slaney, 1994). Yet, while the groups of learners may be different, the same categories of independent variables (the person, the institution, and the interaction between the two) guide our research.

With the explosion of distance learning as an option for people seeking both degrees and continuing professional education, a concern has been raised regarding whether this modality, or loosely collected group of modalities, shows a different pattern of persistence and attrition than do onground educational modalities. The National Center for Education Statistics reported that for the academic year 2000-2001, over three million students were pursuing their postsecondary education through distance learning in the United States (NCES, 2003). However, given this relatively recent phenomenon and the need for longitudinal and rigorously controlled studies to assess whether students who take all (or most) of their undergraduate or graduate degree work at a distance show a higher attrition rate than the 45 percent cited above (Tinto 1982), it is understandable that the unit of analysis in most research on retention in distance education tends to be an individual course, not a complete degree program.

Dropout rates do appear to be significantly higher in distance education courses as compared to traditional, onground course equivalents (Parker, 1999; Diaz, 2000). In the Distance Education Report issue of April 15, 2002, Jennifer Lorenzetti (2002) asserts, "Dropout rates vary but can range as high as 50\%” (p. 2). Individual characteristics and events in an individual's life have been predicted to influence persistence in distance learning programs (Powell, Conway, \& Ross, 1990; Tennant \& Pogson, 1995). Nonetheless, Kemp (2002) did not find significant correlations between life events and attrition in her study of a first-year degree course at Athabasca University. Perhaps unsurprisingly, prior academic success does appear to be predictive of persistence (Morris, Wu, \& Finnegan, 2005; Dupin-Bryant, 2004) in online as well as in onground classes. 
Changes in institutional support systems have been proposed to enhance persistence in academic course completion among adult learners at a distance as a result of analysis of individual characteristics (MacKinnon-Slaney, 1994; Castles, 2004). The authors of both these studies agree that more in-depth orientation to the educational program and ongoing proactive counseling would be desirable, and they predict that these could stem some of the dropout from distance education courses.

An important group of persistence theories and studies are those focusing on the quality of interaction between representatives of the institution and the students (Astin, 1971; Tinto, 1982). Faculty involvement appears to be crucial in student satisfaction, and satisfaction seems to be predictive of persistence (Astin, 1977; Pascarella, Terenzini, \& Wolfe, 1986). Of great interest to the field, would be studies comparing faculty involvement and instruction in reasonably comparable onground and online classes or, better yet, in complete degree programs.

\section{Where This Study Fits}

The present study describes persistence data collected over two years. Since the University of California Irvine divides the academic year into four quarters, this time frame covers the quarters, Spring 2004 through Winter 2006. The group studied is comprised of adults pursuing continuing professional education through University Extension. The unit of analysis is the individual course. Class sizes tend to be between 10 and 25 students. The independent variable falls under the category 'the institution,' and examines the point in time when a student drops the course.

It is a comparative study, gathering data from online and onground continuing professional education classes offered by UC Irvine Extension. The onground class sections are offered primarily in the evening as once-a-week, three-hour long meetings. A standard Extension class has 10 meetings of three hours and offers three continuing education credits for successful (evaluated) completion of the course objectives. The online classes also have fixed start- and enddates, and run the equivalent length of time (10 weeks), plus an extra week called 'Orientation Week,' which is described below. All classes are evaluated and graded with assignments tied to preset due dates, and a substantial percentage of the grade is based on participation in the online threaded discussions. Both the online and onground course sections are instructor-facilitated.

\section{Definitions}

One of the reasons for the scarcity of aggregable data from multiple university providers of online as well as onground learning may be a lack of consistency in defining attrition. As a result, we may be, as researchers at Brigham Young University propose, comparing 'apples and oranges' when we put onground and online programs side by side. In the unpublished article "Reevaluating Course Completion in Distance Education,” Howell, Laws, and Lindsay (2004) note that, "At . . . Brigham Young University nonstarters in traditional courses are not considered dropouts although they are considered dropouts for distance education courses” (p. 9).

Ormond Simpson expands this list of possible definitions of what 'dropout' might mean in his book "Supporting Students in Online, Open, and Distance Learning” (Simpson, 2002). He notes the following nine stages at which a student could potentially be considered a dropout (p. 168):

1. Inquirers who do not register for a course 
Persistence in University Continuing Education Online Classes

Frydenberg

2. Students who become dormant - they do not withdraw but they do not submit assignments

3. Students who 'actively' withdraw

4. Students who submit assignments but do not take the exam

5. Students who fail the exam outright

6. Students who fail for administrative reasons - not paying fees, etc.

7. Students who fail, are granted re-sits ${ }^{\underline{1}}$ and fail them

8. Students who fail, are granted re-sits but do not take them

9. Students who pass one course or module but do not reserve or register for another

In the present study, we have collapsed these categories into 4 stages. Although 'dormant' students (we call them 'MIA's') and students who stay on-task almost to the end and then fail in one way or another is an interesting issue to examine, they are not included in the present study ${ }^{2}$. In this investigation, we include only 'active drops.' Our time definitions are listed in Table 2.

Table 2. Definitions of dropout at different stages

\begin{tabular}{|l|l|}
\hline Registered & Student regis tered and paid for the class \\
\hline Drop prior to class start & Onground: Prior to first class meeting \\
\hline & Online: Prior to first day of " $\mathrm{O}$ " week \\
\hline Drop prior to start of instruction & Onground: Prior to first class meeting \\
\hline & Online: Prior to first day of instruction \\
\hline Enrolled & Onground: Enrolled day before first class meeting \\
\hline & Online: Enrolled day before start of "O" week \\
\hline Drop during week 1 & Onground: Within 7 days after the first class meeting \\
\hline & Online: During "O" week \\
\hline Drop after week 1 & Onground: After the first week of instruction \\
\hline & Online: After "O" $\mathrm{O}^{\text {"s }}$ week \\
\hline
\end{tabular}

Note. ' $O$ ' week means 'Orientation Week.' See the section on "Where this study fits."

\section{Online and Onground Persistence}

While growing rapidly, the online program at UC Irvine Extension still only served 366 out of the total 3,037 enrollments in the last quarter of data included in this study: Winter 2006 (12\%). Over the two years, the percentage is naturally even smaller: 1,847 / 27,815 (6.6\%). Table 3 compares total registrations with total active drops in onground and online course sections. 
Persistence in University Continuing Education Online Classes Frydenberg

Table 3: Total course registrations minus total drops

\begin{tabular}{|l|c|c|c|c|c|c|c|c|c|c|}
\hline & & $\begin{array}{c}\text { Spring } \\
\mathbf{2 0 0 4}\end{array}$ & $\begin{array}{c}\text { Summer } \\
\mathbf{2 0 0 4}\end{array}$ & $\begin{array}{c}\text { Fall } \\
\mathbf{2 0 0 4}\end{array}$ & $\begin{array}{c}\text { Winter } \\
\mathbf{2 0 0 5}\end{array}$ & $\begin{array}{c}\text { Spring } \\
\mathbf{2 0 0 5}\end{array}$ & $\begin{array}{c}\text { Summer } \\
\mathbf{2 0 0 5}\end{array}$ & $\begin{array}{c}\text { Fall } \\
\mathbf{2 0 0 5}\end{array}$ & $\begin{array}{c}\text { Winter } \\
\mathbf{2 0 0 6}\end{array}$ & $\begin{array}{c}\text { Two } \\
\text { Years }\end{array}$ \\
\hline $\begin{array}{l}\text { Total } \\
\text { registrations }\end{array}$ & & & & & & & & & & \\
\hline & Online & 148 & 194 & 210 & 284 & 310 & 335 & 381 & 461 & $\mathbf{2 , 3 2 3}$ \\
\hline & Onground & 5,119 & 4,171 & 5,170 & 4,696 & 3,843 & 2,598 & 4,148 & 3,138 & $\mathbf{3 2 , 8 8 3}$ \\
\hline Total drops & & & & & & & & & & \\
\hline & Online & 22 & 38 & 35 & 81 & 82 & 56 & 67 & 95 & $\begin{array}{c}\mathbf{4 7 6} \\
(\mathbf{2 1} \%)\end{array}$ \\
\hline & Onground & 742 & 596 & 837 & 667 & 612 & 453 & 694 & 467 & $\begin{array}{c}\mathbf{5 , 0 6 8} \\
(\mathbf{1 5} \%)\end{array}$ \\
\hline & & & & & & & & & & \\
\hline & Online & 126 & 156 & 175 & 203 & 228 & 279 & 314 & 366 & $\mathbf{1 , 8 4 7}$ \\
\hline & Onground & 4,337 & 3,575 & 4,333 & 4,029 & 3,231 & 2,145 & 3,454 & 2,671 & $\mathbf{2 7 , 8 1 5}$ \\
\hline
\end{tabular}

While there is some variation quarter over quarter, the persistence rates remain reasonably steady, both in the online and the onground program. Figures 1 and 2 show this consistency.

Figure 1. Drop pattern in online courses by quarter

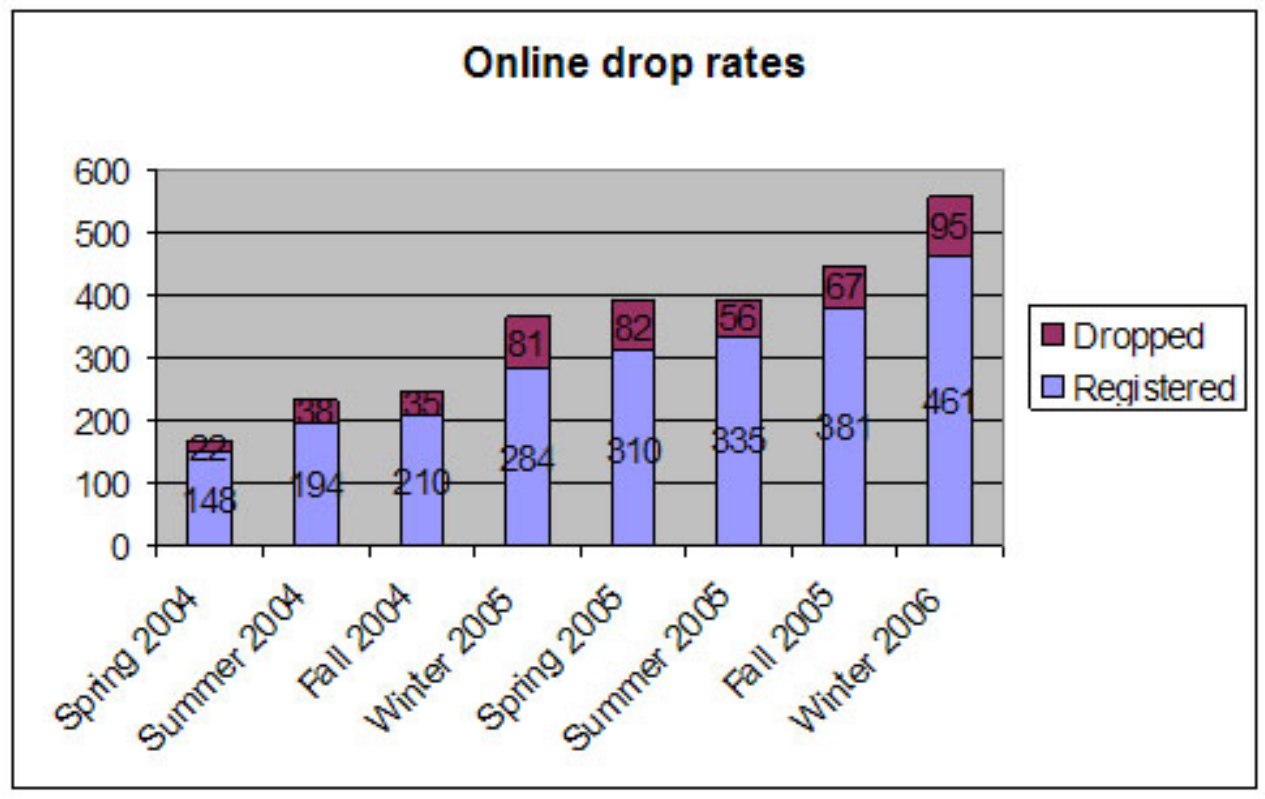


Figure 2. Drop pattern in onground courses by quarter

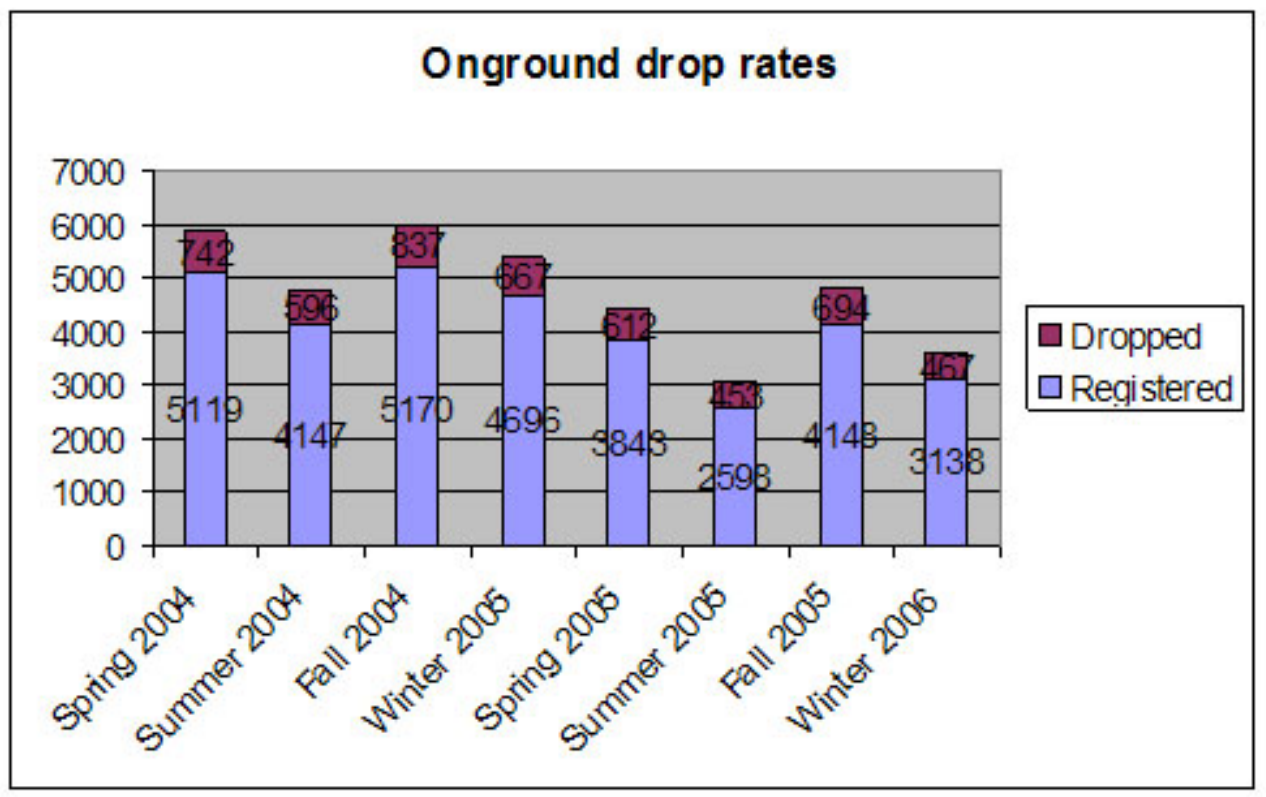

However, there is a marked difference in the percentage attrition between the large onground program (15\%) and the smaller online program (21\%). Table 4 shows that this difference is statistically significant.

Table 4: Comparison of online and onground persistence rates

\begin{tabular}{|c|c|c|c|}
\hline \multicolumn{4}{|c|}{ Two-Year Onground and Online drop rates } \\
\hline & Onground & Online & Total \\
Registered & 27,815 & 1,847 & 29,662 \\
Dropped & 5,068 & 476 & 5,544 \\
Total & 32,883 & 2,323 & 35,206 \\
\hline
\end{tabular}

Degrees of freedom: 1

Chi-square $=42.178$

$p$ is less than or equal to 0.001 .

The dis tribution is significant.

\section{Drop Patterns}

As described above, the onground students meet the educational facility (campus), the course content (syllabus and handouts), and the instructor at the same time at the initial class meeting. The online students, however, meet these potentially influencing factors gradually. During ' $O$ ' week, the facility (the virtual classroom) and all the content (syllabus, lessons, and assignments) are available for students to peruse. They meet the instructor the following week. Table 5 below shows the distribution of drops grouped by the time of dropping the course. 
Persistence in University Continuing Education Online Classes

Frydenberg

Table 5. Drop rates before class start, during first week / 'O' week, and after instructional start

\begin{tabular}{|l|c|c|c|c|}
\hline & Online & \% drop & Onground & \% drop \\
\hline Registered & 2323 & $5 \%$ & 32883 & $8 \%$ \\
\hline $\begin{array}{l}\text { Drop prior to } \\
\text { course start }\end{array}$ & 108 & $8 \%$ & 1165 & $4 \%$ \\
\hline $\begin{array}{l}\text { Drop during } \\
\text { week 1/ '0' } \\
\text { week }\end{array}$ & 185 & $8 \%$ & 1347 & $4 \%$ \\
\hline $\begin{array}{l}\text { Drop after week } \\
\text { 1/'0' week }\end{array}$ & 183 & & & \\
\hline
\end{tabular}

Degrees of freedom: 3

Chi-square $=197.625$

$p$ is less than or equal to 0.001

The distribution is significant

More onground than online students dropout prior to having met either the classroom, the course content, or the instruction/ instructor; however, the focus of this investigation is on the first week and subsequent weeks of the course.

\section{Drop Rates Before and After Meeting the Instruction/ Instructor}

To examine whether drop rates differed after instruction had begun (and after the students had 'met' either virtually or in person with the instructor), we collapsed the data from Table 5 by combining the 108 online drops prior to course start with the 185 online students who dropped during the ' $\mathrm{O}$ week.' These students all dropped before instruction had begun. For the onground students, the picture is reversed: those who dropped during week one were combined with those who dropped later in the quarter, because all of these students had then been exposed to instruction. As per Table 2 above, 'Drop during week 1' was defined as 'Drop during the 7 days after course start' in order to capture the same time frame as the seven days of the week of the online course orientation week. Table 6 shows this new distribution.

Table 6. Drop rates before and after start of instruction

\begin{tabular}{|l|c|c|c|c|}
\hline & Online & \% drop & Onground & $\%$ drop \\
\hline Total registrations & 2323 & & 32,883 & \\
\hline Drop prior to start of instruction & 293 & $13 \%$ & 2,556 & $8 \%$ \\
\hline Drop after start of instruction & 183 & $8 \%$ & 2,512 & $8 \%$ \\
\hline
\end{tabular}

By aggregating the data this way, an interesting pattern emerges. The percentage of people dropping out of classes after instruction has begun is essentially the same in online and onground classes. Recall from Table 5 above that in the online classes, only 5 percent dropout prior to having experienced any aspect of the course. However, given the 8 percent of online students who drop during 'Orientation Week,' this boosts the dropout rate to 13 percent prior to the start of instruction. We propose that it is probably not the instruction in the online classes that is the root cause of the higher dropout rate. 
This leaves us with the question of whether students' motivation to drop a course is related to the online content, to the technology, or, simply, to life interfering with their plans.

\section{The Reasons People Give for Dropping Out}

Adult students participating in continuing professional education are naturally surrounded by a different set of life pressures than college undergraduates. Whether life circumstances, such as workload pressures, are predictive of lack of persistence in educational endeavors is unclear in the literature. Tennant and Pogson (1995) found evidence to suggest that life circumstances and transitions was predictive, but Kemp (2002) reports that "For the most part, external commitments - in the form of personal, family, home, financial, and community commitments were not found to be significant predictors of persistence (or lack of persistence) in distance education” (p. 75).

As part of a larger effort for us to understand better why students who have registered for a class choose to drop, the UCI Extension student services office assigns each request for withdrawal a code to describe the reason for the drop. Withdrawal requests are accepted only in writing: by fax, email, or in person. There is no form to check off and giving a reason is voluntary, so the student services staff does a textual analysis of the request to assign it a drop code.

Table 7. Reasons given for requesting withdrawal from online courses

\begin{tabular}{|c|l|c|c|}
\hline Rank & \multicolumn{1}{|c|}{ REASONS } & 2-Year Trend & $\%$ \\
\hline 1 & Other Reason & 157 & $33 \%$ \\
\hline 2 & Transfer (transfer to another course) & 95 & $20 \%$ \\
\hline 3 & Work Schedule Conflict & 62 & $13 \%$ \\
\hline 4 & No Reason & 44 & $9 \%$ \\
\hline 5 & Changed Mind & 26 & $5 \%$ \\
\hline 6 & Other Schedule Conflict & 21 & $4 \%$ \\
\hline 7 & Not Satisfied & 20 & $4 \%$ \\
\hline 8 & Cancel (course canceled) & 19 & $4 \%$ \\
\hline 9 & No information & 13 & $3 \%$ \\
\hline 10 & Family & 13 & $3 \%$ \\
\hline 11 & Declined Credit Card & 6 & $1 \%$ \\
\hline & TOTAL & 476 & \\
\hline
\end{tabular}

If we combine reasons 1 and 4 above, which essentially means that the person requesting withdrawal either was not willing to give their reason or that none of the categories fit their reason, we get a total of 201. Unfortunately, this comprises almost 50 percent of our data. We can also reasonably combine 'Work Schedule Conflict' and 'Other Schedule Conflict,' resulting in a total of 83 people selecting this category. The 'Transfer' category may be transfer to another online course, it may be transfer to an onground course, or it may even be transferring from one quarter to another. That detail of data is not captured. Figure 3 details the top six categories, which account for 93 percent of the data. 
Persistence in University Continuing Education Online Classes Frydenberg

Figure 3. Distribution of drop reasons in online courses (top 6 reasons)

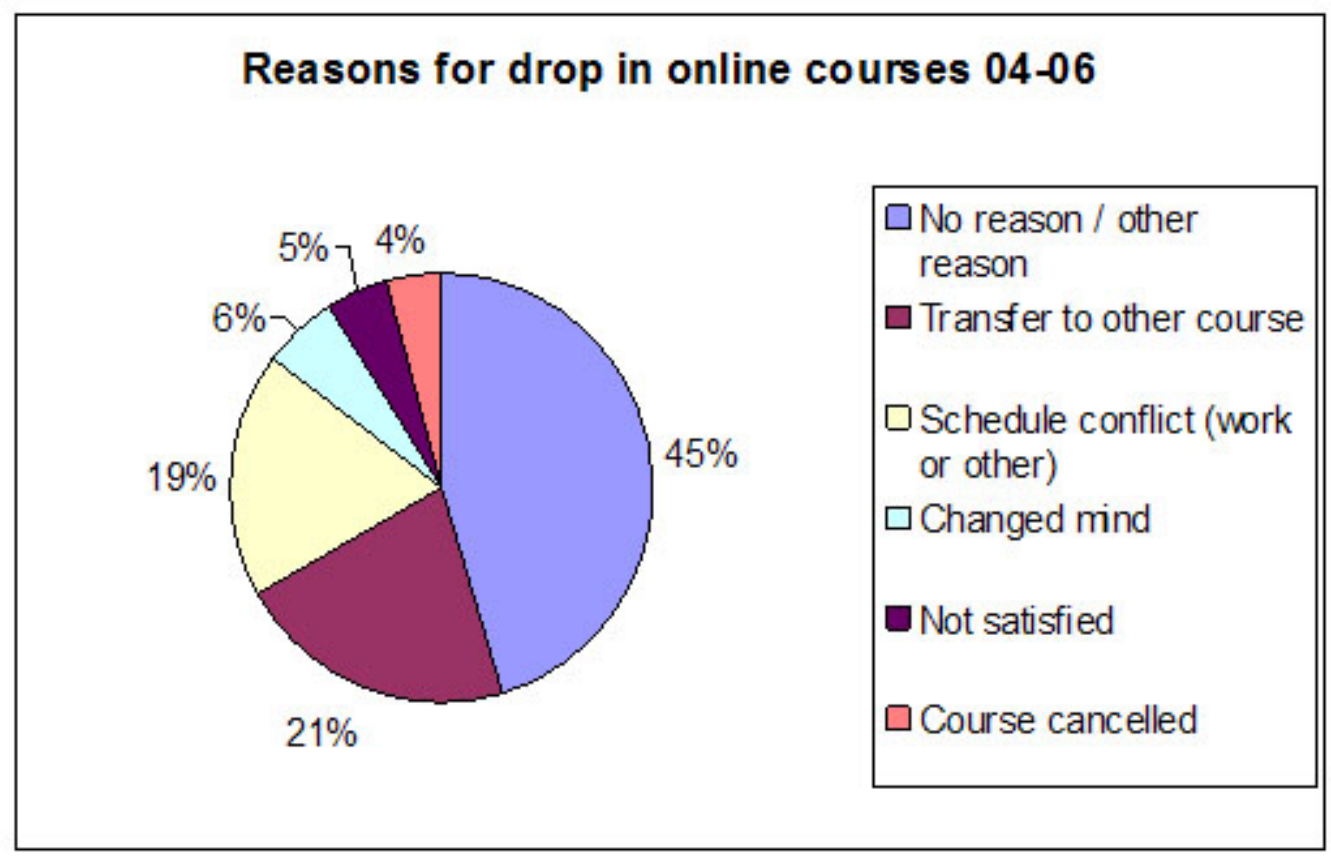

'Not Satisfied' accounts for 5 percent of this reduced data set. It does not appear that an expressed lack of satisfaction with the technology, with the instruction, or with the content of the online classes is the primary reason for dropping out. From the two-year data set above, one could draw the conclusion that 'life interfered.'

Table 8. Top three reasons for withdrawal from online classes, accounting for 85 percent of the data

\begin{tabular}{|l|l|}
\hline No reason / other reason & $45 \%$ \\
\hline Transfer to another course & $21 \%$ \\
\hline Schedule conflict & $19 \%$ \\
\hline
\end{tabular}

Comparable data exist for onground classes. For the same two-year period (Spring 2004 through Winter 2006): 
Persistence in University Continuing Education Online Classes Frydenberg

Table 9. Reasons given for requesting withdrawal from onground courses

\begin{tabular}{|c|l|c|c|}
\hline Rank & \multicolumn{1}{|c|}{ REASONS } & 2-Year Trend & $\%$ \\
\hline 1 & Cancel (course canceled) & 925 & $20 \%$ \\
\hline 2 & Other Reason & 803 & $17 \%$ \\
\hline 3 & Transfer (transfer to another course) & 738 & $16 \%$ \\
\hline 4 & Work Schedule Conflict & 696 & $15 \%$ \\
\hline 5 & No Reason & 430 & $9 \%$ \\
\hline 6 & Other Schedule Conflict & 313 & $7 \%$ \\
\hline 7 & Changed Mind & 237 & $5 \%$ \\
\hline 8 & Family & 129 & $3 \%$ \\
\hline 9 & Illness & 116 & $3 \%$ \\
\hline 10 & Wait List & 139 & $3 \%$ \\
\hline 11 & Not Satisfied & 71 & $2 \%$ \\
\hline 12 & Declined Credit Card & 12 & $0 \%$ \\
\hline 13 & Other & 5 & $0 \%$ \\
\hline & TOTAL & 4614 & \\
\hline
\end{tabular}

Collapsing the top categories as was carried out for the online courses, we get:

Figure 4. Distribution of drop reasons in onground courses (top 9 reasons)

\section{Reasons for drop in onground courses 04-06}

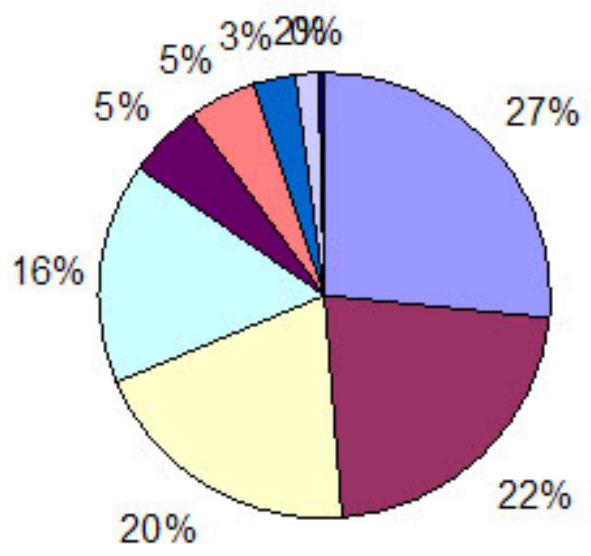

$\square$ No reason / other reason
$\square$ Schedule conflict
$\square$ Course cancelled
$\square$ Transfer to other course
$\square$ Family / Illness
$\square$ Changed mind
$\square$ Wait list
$\square$ Not satisfied
$\square$ Other


Persistence in University Continuing Education Online Classes Frydenberg

Table 10. Top four reasons for withdrawal from onground classes, accounting for 85 percent of the data

\begin{tabular}{|l|l|}
\hline No reason / other reason & $27 \%$ \\
\hline Schedule Conflict & $22 \%$ \\
\hline Course Cancelled & $20 \%$ \\
\hline Transfer & $16 \%$ \\
\hline
\end{tabular}

Side by side, the data appear this way:

Figure 5a, 5b. Comparing the reasons people give for withdrawal

\begin{tabular}{|l|l|}
\hline Reasons for drop in online courses $\mathbf{0 4 - 0 6}$ \\
$\begin{array}{l}\text { No reason / other } \\
\text { reason } \\
\square \text { Transfer to other course } \\
\square \text { Schedule conflict (work } \\
\text { or other) } \\
\square \text { Changed mind } \\
\text { Not satisfied } \\
\square \text { Course cancelled }\end{array}$ \\
\hline
\end{tabular}

Table 5a. 


\section{Reasons for drop in onground courses 04-06}

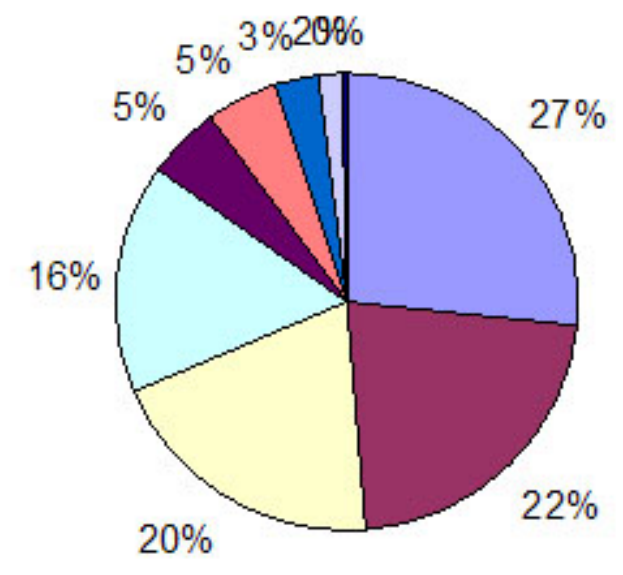

$\square$ No reason / other reason

$\square$ Schedule conflict

$\square$ Course cancelled

口Transfer to other course

- Family / IIIness

口Changed mind

口Wait list

$\square$ Not satisfied

- Other

\section{Table $5 b$.}

While different, there is a striking similarity. 'No/ Other Reason,' 'Transfer' to another course, and 'Schedule Conflict' lead both lists, accounting for 85 percent of the online courses and 65 percent of the onground courses. The large difference in the category 'Course Cancelled' between the two modalities is that we allow online courses to run with a much smaller class size than the onground courses and hence they are rarely cancelled. There is a difference in the category 'Not Satisfied,' - four percent $(n=20)$ students in online classes, and two percent $(n=71)$ students in the onground classes - but this is insufficient data from which to draw conclusions.

\section{Conclusions and Further Research}

When the unit of analysis is the individual course, we do not see the 45 percent dropout rate mentioned in Tinto (1982). The total drop rate in this two-year study, before instruction as well as after course start, is 21 percent in online classes and 16 percent in onground classes. In other words, 79 percent of online students and 84 percent of onground students in this study of adults pursuing continuing professional education did not actively withdraw from their courses.

Second, there is no striking difference in attrition after instruction has begun; in fact, there is no difference at all. This is interesting (and, I admit, surprising) because it would seem to be 'common sense' to hypothesize that the relationship between an unseen instructor (online classes) and one you can get physically close to (onground classes) would be likely to be associated with a different level of satisfaction with the education received. And satisfaction, as we saw in the introduction, has been shown to correlate with persistence. Perhaps the fact that we require online instructors to be actively participating in class asynchronous discussions online every 48 to 72 hours (depending on the course type) mitigates the lack of 'eyeball-to-eyeball' interaction? 
Third, student self-reports in giving a reason for requesting withdrawal from a class are largely similar. From that kind of evidence, we would draw the conclusion that it is life ('No Reason' and 'Schedule Conflict') that primarily interferes with the intent to complete a course. However, the large percentage of 'Transfer' among the online students does need to be investigated. Which courses did they transfer to? That is, did they transfer to another online course or from online to onground?

Fourth, something is going on during the 'Orientation Week' of the online classes. The attrition rate during that time period is twice that of onground classes. This enables us to focus our research. If we assume that life events occur equally at any period of the run of a course, the three remaining possibilities are that it could be something about the online course platform (or its very existence) as a virtual classroom, it could be the quality or amount of the online class content which substitutes for the content delivered by a live instructor, or it could be an issue of a student's expectations. Given that none of the participants in today's adult continuing education could possibly have formed expectations of the social and interactional structure of an online virtual class in their years of formal schooling, they may have unstated expectations of the online class that are different from what they meet. There is, after all, double the percentage of 'Not Satisfied' students requesting withdrawal in online versus onground classes. These blueprints for hypotheses will guide our future research at the University of California Irvine Distance Learning Center.

Finally, in order to be able to conduct cross-institutional studies and aggregate data in meaningful ways, we hope that the definitions of the time a student withdraws prove useful for other researchers.

\section{Note}

The author wishes to express her appreciation of the efforts of the University of California Irvine Extension Student Services staff in collecting the data that form the basis of this study.

\section{Foot Notes}

1. A 're-sit' is a person who is allowed to retake an exam

2. We do, however, have data on these students going back four quarters, and the issues of 'flunkout' in one way or another will be the subject of another article.

\section{References}

Astin, A. 1971. Predicting academic performance in college. New York: Free Press.

Astin, A. 1977. Four Critical Years: Effects of college on beliefs, attitudes, and knowledge. San Francisco: Jossey-Bass.

Bean, J., \& Metzner, B. (1985). A conceptual model of non-traditional undergraduate student attrition. Review of Educational Research, 55(4), 485-540.

Berge, Z., \& Huang, Y. (2004, May). A Model for Sustainable Student Retention: A holistic perspective on the student dropout problem with special attention to e-learning. 
Persistence in University Continuing Education Online Classes

Frydenberg

DEOSNEWS, 13(5). Retrieved October 21, 2007, from:

http://www.ed.psu.edu/acsde/deos/deosnews/deosnews13_5.pdf

Braxton, J. (2000). Reworking the student departure puzzle. Nashville, TN.: Vanderbilt University Press.

Castles, J. (2004). Persistence and the adult learner. Active Learning in Higher Education, 5(2), 166-179.

Diaz, D. (2002, May/ June). Commentary: Online drop rates revisited. The Technology Source. Retrieved October 23, 2007 from: http://technologysource.org/article/online_drop_rates_revisited/.

Dupin-Bryant, P. A. (2004). Pre-entry variables related to retention in online distance education. The American Journal of Distance Education, 18(4), 199-206.

Howell, S. L., Laws, R. D., \& Lindsay, N. K. (2004). Reevaluating Course Completion in Distance Education: Avoiding the comparison between apples and oranges. Unpublished handout at the University Continuing Education Association (UCEA) Conference, April 16, 2004. San Antonio Texas.

Kember, D. (1989). A longitudinal-process model of drop-out from distance education. The Journal of Higher Education , 60(3), 278-301.

Kemp, W. (2002). Persistence of adult learners in distance education. The American Journal of Distance Education, 16(2), 65-81.

Lorenzetti, J. (2002). Before They Drift Away: Two experts pool retention highlights. Distance Education Report, 6(8), 1-2.

MacKinnon-Slaney, F. (1994). The Adult Persistence in Learning Model: A road map to counseling services for adult learners. Journal of Counseling and Development , 72(3), 268-275.

Morris, L., Wu, S., \& Finnegan, C. (2005). Predicting retention in online general education courses. The American Journal of Distance Education, 19(1), 23-36.

NCES (2003). National Center for Education Statistics website. Retrieved October 23, 2007 from: http://nces.ed.gov/surveys/peqis/publications/2003017/

Parker, A. (1999). A study of variables that predict dropout from distance education. International Journal of Educational Technology, 1(2). Retrieved October 23, 2007 from: http://smi.curtin.edu.au/ijet/v1n2/parker/index.html

Pascarella, E., Terenzini, P., \& Wolfe, L. (1986). Orientation to college and freshman persistence/ withdrawal decisions. Journal of Higher Education, 57(2), 155-175. 
Powell, R., Conway, J., \& Ross. L. (1990). Effects of student predisposing characteristics on student success. Journal of Distance Education, 5(1). Retrieved October 23, 2007 from: http://cade.icaap.org/vol5.1/8_powell_et_al.html

Simpson, O. (2002). Supporting students in online, open, and distance learning. London: Kogan Page.

Tennant, M., \& Pogson, P. (1995). Learning and Change in the Adult Years: A developmental perspective. San Francisco: Jossey-Bass.

Tillman, C.A. Sr. (2002). Barriers to student persistence in higher education. Retrieved October 3, 2002 from: http://www.nazarene.org/ed_didache/vol2_1.html

Tinto, V. (1982). Limits of theory and practice in student attrition. Journal of Higher Education, 53(6), 687-700.

Tinto, V. (1993). Leaving College: Rethinking the causes and cures of student attrition (2nd edition). Chicago: University of Chicago Press.

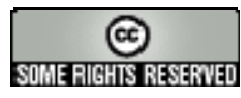




\title{
Going the Distance: Towards a new professionalism for full-time distance education faculty at the University of the Philippines
}

\author{
Patricia B. Arinto \\ University of the Philippines, Open University
}

\begin{abstract}
Several constraints influence the formation of a professional identity by full-time distance education faculty at the University of the Philippines. One of these is the marginalisation of distance education (DE) in the academy as a consequence of DE's identification with low status disciplines, as well as with developments in higher education that are undermining traditional academic identities. There are also constraints arising from the social organisation of distance education itself. The paper offers a (re)conceptualisation of academic professionalism for distance education faculty that is more responsive to the challenges that they face, and more empowering for themselves and the academic and other communities of which they are a part.
\end{abstract}

Keywords: Distance education faculty; academic professionalism; faculty development

\section{Introduction}

How do faculty of distance education (DE) institutions form a professional identity as members of the academic community when their very status as academics is in question and certain conventions of academic life are absent from the DE setting in which they operate? What models of academic professionalism can they look to, and perhaps emulate, when traditional academics norms and values are under challenge and are far from stable?

My interest in these questions is both personal and professional. In 1999, after 10 years of teaching in the Department of English and Comparative Literature in the University of the Philippines' (UP) flagship campus, I decided to join the faculty of the UP Open University (UPOU), which has the special mandate to deliver degree and non-degree programmes by distance education. Some of my (former) colleagues tried to dissuade me. At the time, UPOU was only four years old. Many in the UP System, especially in the more prestigious colleges, had opposed its establishment. Until recently, I sat on UPOU's Academic Personnel Board (APB), which recommends policies regarding the hiring, retention, promotion, and tenure of UPOU's regular (as opposed to affiliate and adjunct) faculty. My vantage point is that of a mid-level faculty member and administrator who has taught in both conventional education and DE settings. My socialisation into the academy took place in the former. Now I find myself in the privileged position of helping shape the professional identity of distance education faculty. 
When it was founded in 1995, UPOU did not have its own full-time faculty. Hoping to spare the new university doubts about the quality of its educational provision, University administrators decided that UPOU should simply rely on the faculty of the more established constituent universities of the UP System. Questions about quality, however, continued to be raised against UPOU by the other UP units. (Considered as the country's premier university, UP accepts only the top 2 percent of the entire college-bound population, chosen through competitive examinations.) At the same time, the development of its programmes was held back as the affiliate faculty on whom it relied, understandably enough, gave priority to their work in their home units.

For this reason, the UPOU administration lobbied to get, and eventually succeeded in acquiring, a core of regular faculty for each of UPOU's programmes. ${ }^{1}$ Today, UPOU has 17 regular or fulltime faculty members, aside from more than 200 affiliate and adjunct faculty members. Majority of the 17 faculty members are in their 30s and 40s, with the rank of Assistant Professor. Rankwise, they are in the lower half of the faculty hierarchy in the UP system. Aside from serving as course instructors and tutors, they have instructional design, project management, and program coordination responsibilities. Like other faculty members of the UP System, they are expected to prove themselves excellent in teaching and research in their respective fields of specialisation, and to establish a publication record.

The untenured UPOU faculty members' performance of these various roles and responsibilities is evaluated on an annual basis. The evaluation guidelines include detailed descriptions, checklists, and rubrics for assigning points to each performance criterion. On these bases, we have managed to identify the high-performers and put them on tenure track, and weed out those with below-par performance. Therefore it can be said that the performance evaluation works.

Or does it? Wading through the voluminous portfolios submitted for our scrutiny, I get the feeling that a great deal of what is important in the social formation of faculty members - their values and principles, the way they relate to their students and colleagues, the extent of their growth into their discipline and into university life - is not captured by the detailed documentation. Moreover, there is a sense that the portfolio is a gesture of compliance rather than an act of genuine reflection and self-assessment and, in some cases, that it is merely a product designed for the consumption of the Academic Personnel Board. For Shore and Wright (2000), these are the logical outcomes of audit practices in higher education: On the one hand, "[f]or many university lecturers, all this activity [of producing auditable records] appears superfluous to their real work and, indeed, the whole audit procedure takes on the feel of an artificial and staged performance" (p. 72). On the other hand, audit creates a "culture of compliance" and an "invitation to outward conformity" (p. 73).

Neither 'performativity' (with its suggestion of a valuing of form over substance) nor conformity (or lack of autonomy) seems to be desirable traits in academic professionals. Indeed, they are antithetical to the academic identity because it is traditionally conceived by academics. On the other hand, a number of writers (see Halsey, 1995; Readings, 1996; Trowler, 1998; Taylor, Barr \& Steele, 2002) observe that traditional academic values are being undermined and that academic professionalism is under attack. In this light, how faculty members of UPOU (and of DE institutions of this type) are to construct a professional identity is an important question to ask. 


\section{The Problem of Low Status}

Distance education institutions, like UPOU, tend to be considered inferior to conventional higher education institutions. According to Kirby (1988), distance education is often viewed by traditionalists as being "the ultimate erosion of academic standards" (quoted in Panda, 2004, p. 78). According to Black (1992), "Distance education is often viewed as second-best to classroom, face-to-face instruction” (quoted in Jones et al., 2002, p. 1).

Although UPOU is no longer openly criticized as being of lower quality than the non-DE units of the university, there continues to be doubt regarding the quality of its programs, its students, and its faculty. Recently, a graduate of UPOU's Associate in Arts program was denied admission into a Bachelor of Arts program of another UP unit in the flagship campus (UP Diliman) because DE courses are "not the same as" courses taught the conventional way. Of the faculty, it has been asked at the highest levels of the University administration whether teaching at a distance should receive the same teaching credit units as teaching face-to-face. In the other UP campuses, course development work done by their own faculty for UPOU is either not counted towards promotion or is given fewer points than other publication work.

DE practitioners have taken great pains to put in place a number of quality assurance mechanisms to satisfy expectations of excellence. They have also demonstrated through research and wellreasoned arguments that, for example, it is not physical distance but transactional distance that influences the quality of learning (Moore, 1993). Nonetheless doubts persist, as evidenced above.

It may be argued that the low regard for $\mathrm{DE}$ is not because distance education is inherently inferior, but because it is associated with disciplines that rank low in the academic hierarchy. First, education is considered "a low-status field" (Lagemann, 2000, p. 234) because it is a "soft applied" knowledge domain (Becher, 1989, p. 161). Second, majority of UPOU's program offerings are in fields that are also perceived to be "soft applied": social work, nursing, public administration, environmental management, and development communication.

Another reason for DE's low status in academia is its implication in the expansion of higher education that is threatening to radically alter the lives of academics in the heretofore elite universities (such as the University of the Philippines). The expansion of higher education, also called "massification," is manifest in the rapid increase in the number of colleges and universities and students seeking undergraduate and postgraduate degrees. The demographics of higher education registrants have changed as well (Henkel, 2000), to include significantly more adult learners and part-timers and/ or working students, for example. According to Enders (2000), this phenomenon arose in a political climate formed by "the [widespread] belief that substantial educational investment is needed . . . to ensure economic growth, the readiness to reduce inequality of opportunities in education, and the radical student protest of the 1960s” (pp. 8-9).

Unfortunately, the expansion took place without an increase in government funding for higher education. In fact, in many countries (including the Philippines) State support for colleges and universities is on the decline. Universities are expected to generate incomes from student enrolments and other private sources. In many institutions, diminished resources have resulted in higher student-faculty ratios (Henkel, 2000; Enders, 2000), reduced research funds (Enders, 2000), negligible salary increases if any, fewer tenured positions and increased hiring of lowerpaid part-time staff (Bryson \& Barnes, 2000). For academics, these are compounded by loss of status relative to other professions, as evidenced, for example, by lower incomes, loss of "a considerable proportion of its guild powers" due to increasing control of their performance by a 
new managerial class in higher education, and public criticism of higher education for its perceived failure to produce employable graduates as well as socially relevant research (Enders, 2000, p. 9).

Distance education is implicated in the massification of higher education in two ways. First, DE and the associated concepts of flexible learning and lifelong learning - is underpinned by social ideals of equality of opportunity and democratic participation. UPOU, for example, was established "to democratize access to quality higher education." Second, certain conceptions of $\mathrm{DE}$ are market-driven: it is touted as a cost-effective strategy for broadening the reach of education systems. Neither of these recommends distance education to elitist academics that either fear, or are suffering from, the negative impact of higher education expansion.

In UPOU's case, although enrolments have been kept low by the restriction imposed by the UP System administration against the offering of undergraduate programs, some quarters continue to accuse it of taking more than its fair share of a significantly reduced university budget. At the same time, it is being encouraged to be more entrepreneurial in its operations by offering continuing education programs that appeal to groups who can afford to pay.

\section{The Problem of Alienation}

Exacerbating the impact of a negative reputation are the feelings of loneliness and alienation that those who teach at a distance experience because of lack of interaction with fellow academics (Paul, 1987). This is true especially of small DE institutions like UPOU where there is only one full-time faculty member for each program (the remainder of a program's teaching staff are affiliate and adjunct faculty) and faculty members are dispersed in three locations: Manila, Diliman (1.5 hours away by car from Manila), and the headquarters in Los Baños (2.5 hours by car from either Manila or Diliman). Even those based in the same location do not share the same office space, or observe the same office hours.

Thus, for UPOU faculty it is difficult to develop the kind of professional knowledge that comes with interaction with colleagues and participation in complex situations in the workplace. Such knowledge, which is what the old-timers in the profession might have as opposed to the greenhorns or newcomers, would include not only

the language, tools, documents, images, symbols, well-defined roles, specified criteria, codified procedures, regulations, and contracts . . . but . . . also . . . implicit relations, tacit conventions, subtle cues, untold rules of thumb, recognizable intuitions, specific perceptions, well-tuned sensitivities, and shared world views. Most of these may never be articulated, yet they are unmistakable signs of membership in communities of practice and are critical to the success of their enterprises. (Wenger, 1998, p. 47)

This type of professional knowledge is learned not only during work activities, but also "at coffee breaks, over a beer after work, or at lunch” (Paré \& Le Maistre, 2004, p. 7). Here, communal lunches and coffee breaks are a metonym for what Beck and Young (2004) call "the creation of a professional habitus," which is "the intensive socialization into the values of a professional community and its standards of professional integrity, judgment, and loyalty” (p. 9).

Aside from being geographically dispersed, regular UPOU faculty is organized not into departments but into looser and bigger units called faculties. This could pose a problem to the 
formation of academic identities, especially for faculty members without prior experience of working (as academics) in a higher education institution. According to Taylor (1999), the key factor in the formation of academic identities is identification with one's discipline as embodied by one's department, and not identification with one's institution. Faculty members are expected to grow into their respective disciplines through formal and informal interaction with peers within departments. As Scott (1995) puts it, "departments . . . are much more than administrative units; they also institutionalise the intellectual values, cognitive structures and social practices of academic disciplines" (p. 160) and they "create the professional structures through which academic careers are realised” (p. 159).

A third reason for the alienation experienced by DE faculty could be the loss of control and autonomy, which is a consequence of the way that teaching at a distance is organized. Usually, a unified activity handled by one faculty member in conventional universities, teaching in distance education institutions is cut up into various phases: "course planning, design and development (writing and editing), preparation of assignments and assessment mechanisms, scripting for audio and video programmes, coordination of design and development processes, tutoring and counseling of students, course maintenance, training of people involved in the process of development and delivery, discipline-based and distance education research” (Panda, 2004, p. 79). These teaching roles are 'distributed' (Guri-Rosenblit, 1999): senior academics plan the courses and write the materials or modules; junior faculty oversee the production of materials, plan the assignment and assessment activities, serve as course coordinators during the course offering, and maintain the course; and mostly part-time lecturers serve as tutors and counsellors. For each of these sets of faculty, the situation is far from ideal.

The senior academics are the acknowledged experts and therefore enjoy considerable prestige. They too, however, have to defer to advice from the instructional designer, editor, and multimedia designer on how to present their subject matter. There is also the 'tyranny' of modularization itself. According to Beck and Young (2004), modularization has the effect of "eroding the intellectual authority of the subject specialists to control the content, sequencing and pacing of knowledge in their 'own' fields” (p. 10). For the faculty respondents in Henkel's study (2000), modularization "represented developments that diminished academics' sense of identity, loss of control or restricted autonomy and reduced expectations in terms of the nature of knowledge acquired by students in higher education” (p. 226).

For course coordinators or instructors, lack of autonomy is manifested in the hesitation to teach the course differently from the way it is written, for the purpose for example of clarifying relationships among ideas and incorporating new developments and concepts. At a recent instructional design workshop for UPOU's regular faculty, one instructor expressed surprise that instructors are 'allowed' to deviate from the original sequence of topics within a course or module and to augment the module with other material. According to Abrioux (2001), the rigid demarcation between course development and course delivery is making it difficult for faculty of single-mode DE universities (such as UPOU) to take advantage of opportunities for increased faculty control of courses, such as those resulting from the use of e-learning or online learning environments.

The part-time tutors are the least autonomous among the DE teaching staff. They are limited to answering students' queries, clarifying what is written in the modules, and marking assignments according to the marking guide given by the course coordinator or instructor. This way of teaching is dictated by a course 'delivery' model that is concerned with standardizing instruction by different tutors in different locations (learning centers). But Garrison and Shale (cited in 
Keegan, 1993) object to this equation of instruction with packaging knowledge, and of teaching with telling, as it can all too easily lead to the conclusion that "the [DE] teacher is a utility, a resource that can be used and then dispensed with” (Keegan, 1993, p. 125).

\section{The Question of Expertise}

The high percentage of part-time teaching staff (mostly tutors) in DE institutions (Guri-Rosenblit, 1999; Reeves, 2002) also impinges on the formation of academic identities by regular or full-time DE faculty. For one, the increase in size of this "academic underclass" (Taylor, 1999, pp. 103106) further entrenches the questionable hierarchy within the academy that undervalues regular DE faculty members in the first place, even as it now proposes to place them above the parttimers. This hierarchy, says Taylor (1999, p. 105), undermines "the more egalitarian assumptions of collegiality." Altbach (1997; cited in Taylor, 1999) asserts that the hierarchy is a caste system where, although they have similar research qualifications as the "tenured Brahmins," these "untouchables...[are] hired to teach a course or two, provided no benefits, often given no office space, and expected simply to show up to teach a class” (quoted in Taylor, 1999, p. 105).

Although Altbach insists that they have the same qualifications as tenured academics, it is also true that many of those hired to teach on a part-time basis "possess less knowledge and skills than traditional academics" (Guri-Rosenblit, 1999, p. 91). To address this gap, they undergo a training program that includes sessions with the course developers and course coordinators to familiarize them with the modules, and workshops on tutoring, marking assignments, and teaching online. Staff "trainability" is therefore important. For part-time staff, being valued for their trainability is perhaps less sinister than being considered as "disposable, rootless workers" (Castillo, 1997; quoted in Taylor, 1999, p. 104). It is not, however, more benign. For Bernstein (2000; quoted in Beck \& Young, 2004, p. 13), the concept of trainability suggests a 'short-term-ist' concept of life and work. Beck and Young (2004) elaborate: Trainability "declare[s] the inevitable obsolescence accumulated knowledge and prioritize the value of developing the skills and flexibility to acquire and put to use whatever is needed next” (p. 13). This has profound implications for the formation of professional identities:

Older forms of relations to knowledge enabled professional and academic identities to be centred in relatively stable identifications with (and loyalties to) clearly defined knowledge traditions which "partook of the sacred" yet which were linked to practices "in the world". However, as Bernstein observes, "there appears to be an emptiness in the concept of trainability, an emptiness which makes the concept self-referential and therefore excluding” (in the sense of having no intrinsic content that allows self-definition or self recognition). But if the concept is empty how does the actor recognise her/himself and others? Bernstein's answer is that this recognition is increasingly likely to be accomplished through "the materialities of consumption." In other words, relatively stable identities which previously were forged through subject loyalties are being progressively replaced by "temporary stabilities (constructed) out of the products of the market.” (Beck \& Young, 2004, p. 13)

Macdonald (1995) notes that one of the prerequisites of professionalism is the ability to make an exclusive claim to a knowledge base. Part-time DE tutors will be hard pressed to claim professionalism for themselves because: 1) they lack expertise in their subject areas or disciplines (Guri-Rosenblit, 1999); and 2) they do not have formal training in distance education theory and methods. 
Likewise, UPOU's full-time faculty cannot claim expertise. Most have completed only master's degrees; they have little or no experience of teaching at a university; and they have no training in and/or experience of distance education. Following academic tradition, they are expected to redress their lack of disciplinal expertise by engaging in disciplinal research and pursuing doctoral studies. Their lack of university teaching experience and knowledge of DE are supposed to be remedied by attendance in seminars, workshops, and conferences organized by UPOU. Some are given the opportunity to participate in online postgraduate courses (in distance education and technology-based distributed learning) offered by universities abroad.

However, the DE faculty development program outlined above suggests a dichotomy between the formation of disciplinal expertise on the one hand, and the development of competence (or knowhow) in distance education. The former is a long and formal educational process culminating in the conferment of a degree, while the latter is short-term, non-formal training.

\section{Towards a New Academic Professionalism}

The foregoing highlights the constraints to professional identity formation for UPOU's regular/ full-time faculty. This section offers a conceptualization of academic professionalism that takes these constraints - and the corollary opportunities - into account.

The academic professionalism that is proposed for UPOU faculty is based on the concept of democratic professionalism recommended by Furlong Barton, Miles, Whiting, and Whitty (1999) - that is, a professionalism founded on alliances between professionals and "excluded constituencies” (p. 175). In UPOU's case, these excluded constituencies consist of distance education students and would-be students, including adult learners and other groups that do not have access to campus-based higher education, and part-time teaching staff. Other important constituencies are academics from other units of the UP System, professional bodies including those seeking continuing professional development for their members, and other higher education institutions in the Philippines.

First, the professional identity of members of DE institutions like UPOU is necessarily based on a commitment to broadening access to higher education. To the charge that distance education has aided and abetted the massification of higher education, DE faculty must plead guilty - but without apology. While in many instances the expansion of higher education provision is complicit with marketization and the neo-liberal agenda, this does not invalidate the social democratic aspirations of broadening access to education, namely, the reduction of poverty and the promotion of equity, democratic participation, and social justice.

These are not antithetical to the concept of academic professionalism. According to Blomqvist (1997; in Taylor, 1999, p. 117), historically there have been two opposing foci for academic professionalism: autonomy and heteronomy. Autonomy refers to "academic freedom" and scholarship "pursued for its own sake, with its own organization, and a system of thought and rules that only academics can judge" (quoted in Taylor, 1999, p. 117). Heteronomy emphasises social responsibility: "teaching and research are pursued in ways which both respond to social needs and are valued in terms of their contributions to the 'social good'” (quoted in Taylor, 1999, p. 117).

Nevertheless, DE practitioners and institutions must disprove the false dichotomy between equity and quality. They owe this first of all to their students. Those who are concerned for genuine equity know that "equality of opportunity' must be accompanied by "equality of outcomes," 
which means that education must develop in individuals the capacity for full participation in social and economic life (Instance, Schnetze \& Schuller, 2002, p. 4). This kind of accountability that DE and other academics must espouse differs substantially from the "crude form of accountability" (Becher, 1989, p. 171) that performance appraisals and other new managerial practices in higher education tend to promote.

Closer attention to teaching effectiveness can also help to promote teaching as a worthwhile role for academics. Teaching has traditionally been undervalued in universities, compared to research (Boyer, 1990; Taylor, 1999; Reeves, 2002). Teaching, however, should itself be the subject of research. Boyer (1990) advocates the institution of a "scholarship of teaching" in universities, and its being accorded the same status as "the scholarship of discovery, the scholarship of integration, and the scholarship of application” (p. 16). Taylor calls for the development of a teaching-based identity based on "the development of a shared value-related educational knowledge base for academics" (p. 130). To combat the perception that teaching is "a "pre-professional" low-level competence which can, and should, be acquired "on-the-job”' (p. 130), he says academics must undergo "a formal process that engages in the task, i.e., identity work, of coming to identify, understand and recognise the values that might underpin it” (p. 128).

UPOU faculty can undertake rigorous research on teaching effectiveness and related topics like adult education, flexible delivery modes, and computer-supported learning. Research needs to be theory-based and not limited to mere data-gathering (Perraton, 2000; Saba, 2000; Anglin, 2002) so that it can help establish distance education as a legitimate area of academic endeavor (Garrison, 2000). UPOU faculty should also be involved in training programs for improving teaching effectiveness in other higher education institutions, as well as in continuing education programs requested by government and non-government organizations. (Note also the growing interest of scholarship of teaching and learning and its capacity to both inform and legitimize DE research).

Having faculty members participate in the organization and conduct of these activities gives them an opportunity to interact with their colleagues and to learn more systematically about distance education (because they must give a lecture about an aspect of it for example). It also gives them a chance to participate in the important task of institution building - that is, in promoting the institution as a centre of excellence. According to Henkel (2000), institutional work or "enterprise," with its function of "structural integration," can combine with disciplinal work to "constitute a strong source of identity for academics" (p. 20). Working on institution-wide projects can also help develop what Kerr (1994) calls “academic citizenship.” For Kerr, academic citizenship, which includes "observance of the code of academic ethics" and "willingness to participate in shared governance" of the university (Kerr, 1994, p. 149), is an essential aspect of academic professionalism.

Regarding the development of a discipline-based identity for UPOU faculty, encompassing the development not only of expertise but also of the "relational [academic] values of collegiality, peer-based review and recognition" (Taylor, 1999, p. 119), the way forward appears to lie in establishing collaborative networks, for example in the form of project and research teams, with existing departments in the other UP units. Cross-disciplinal collaboration can likewise be encouraged. That UPOU faculty are organized into "faculties" rather than departments is an advantage in this case. As Scott reminds us, "looser academic structures . . . built around theme categories such as . . . environmental sciences" (p. 159) are "open environment[s] where knowledge producers/ users mingle” (p. 160) and form the alliances required for transdisciplinary academic work. 
An alliance between the regular/ full-time faculty of UPOU and the part-time teaching staff also must be forged for both practical and ethical reasons. The practical concern is that the regular faculty members constitute a minority, not only with respect to the rest of the UP faculty, but even within UPOU where the non-academic staff outnumber them (by approximately 5 to 1 ). The ethical, and more important, consideration is recognition of the fact that academic work is complex and is the collective effort of everyone in the university, including part-time tutors and non-academic staff (Blackmore \& Blackwell, 2003). This is also why University leaders must provide "equal and appropriate support" to part-time staff (Blackmore \& Blackwell, 2003, p. 24).

Finally, an important aspect of the professional identities of UPOU's regular faculty might come from "vocational links" (Blackmore \& Blackwell, 2003, p. 20) or professional affiliations. For example, the regular faculty member responsible for the nursing program at UPOU is a certified nurse and member of nursing organizations; the clinical psychologist is a member of the national organization of psychiatrists; and some of us are members of the Philippine e-Learning Society.

\section{Conclusion}

Because it is a complex undertaking, professional identity formation for UPOU's regular faculty requires collaboration between the faculty themselves and UPOU leaders, who are themselves academics. The academic professionalism described above must be forged from various alliances. Thus, unless faculty and academic leaders work together, there is danger of developing a "fragmented professionalism" that could "divide and weaken the academic community" (Blackmore \& Blackwell, 2003, p. 22).

Moreover, developing academic professionalism requires that academics reposition themselves (and find their bearings) in the rapidly changing landscape of higher education. For Nixon and colleagues (1997) academics must

... shift . . .away from "professionalism” as the ideology of service and specialist expertise; away from "professionalism" where the status of the occupation is at stake; and towards a "professionalism" which focuses on the quality of practice in contexts that require radically altered relations of power and control. (quoted in Taylor, 1999, p. 115)

Academics in general can no longer invoke professional privilege. Various challenges to the academy have called into question the validity of academics' claims to autonomy and exclusivity. Once considered to be the "key profession” (Perkin, 1969), academics are now being sidelined.

Faculty of distance education institutions, like UPOU, are twice removed from the centre. Paradoxically, however, i $\mathrm{n}$ being in the margins of mainstream academia, academics working in DE units like UPOU are strategically positioned to craft professional identities that are based on traditional as well as emergent academic values, such as expertise, scholarship, collegiality, reflexivity, and engagement. They have the opportunity to form professional identities that take into account the complexities of contemporary university life, and that are potentially empowering for themselves and for the communities of which they are a part. 


\section{End Notes}

In his study of two Canadian distance universities, Abrioux (2006) found that one of the critical issues in the survival and success of a DE institution is having its own full-time academic staff. "Academics are considered as the primary relationship builders across universities" and the credibility of a university without its own faculty is "severely undermined" (p. 43).

\section{References}

Abrioux, D. (2001). Guest editorial. International Review of Research in Open and Distance Learning, 1(2). Retrieved November 14, 2007 from: http://www.irrodl.org/index.php/irrodl/article/view/16/352

Abrioux, D. (2006). Strategic Issues in Single and Dual-mode Distance Education: The organization blending of two Canadian universities. Retrieved June 8, 2007 from: http://www.col.org/colweb/webdav/site/myjahiasite/shared/docs/06SingleDualDE_Canada. pdf

Ainley, P. (1994). Degrees of Difference: Higher education in the 1990s. London: Lawrence \& Wishart.

Anglin, G. J. (2002). Education and Research in Distance Education: Implications for research. In C. Vrasidos \& G. V. Glass (Eds.), D istance education and distributed learning (pp. 157180). Greenwich, CT.: Information Age Publishing.

Armstrong, F. (1996). Teaching and Learning at a Distance: Redefining the role of the teacher. In Hedge, N. (Ed.), Going the Distance: Teaching, learning and researching in distance education (pp. 77-97). University of Sheffield Division of Education.

Barnett, R. (2003). Beyond all Reason: Living with ideology in the university. Milton Keynes: SRHE and the Open University Press.

Barnett, R. (2000). Realizing the university in an age of supercomplexity. Milton Keynes: SRHE and the Open University Press.

Becher, T. (1989). Academic Tribes and Territories: Intellectual enquiry and the culture of the disciplines. Milton Keynes: SRHE and the Open University Press.

Beck, J., \& Young, M. F. D. (2005). The Assault on the Professions and the Restructuring of Academic and Professional Identities: A Bernsteinian analysis. British Journal of Sociology of Education, 26(2), 183-197.

Blackmore, P., \& Blackwell, R. (2003). Academic roles and relationships. In R. Blackwell \& P. Blackmore (Eds.), T owards strategic staff development in higher education. Milton Keynes: SRHE and Open University Press.

Boyer, E. L. (1990). Scholarship Reconsidered: Priorities of the professoriate. Princeton, NJ.: The Carnegie Foundation for the Advancement of Teaching. 
Bryson, C., \& Barnes, N. (2000). The casualisation of employment in higher education in the United Kingdom. In M. Tight (Ed.), Academic Work and L ife: What it means to be an academic and how this is changing. New York: Elsevier Science.

Enders, J. (2000). Academic Staff in Europe: Changing employment and working conditions. In M. Tight (Ed.), Academic Work and L ife: What it means to be an academic and how this is changing. New York: Elsevier Science.

Fillitz, T. (2000). Academia: Same pressures, same conditions of work? In M. Strathern, (Ed.), Audit Cultures: Anthropological studies in accountability, ethics and the academy. London: Routledge.

Furlong, J., Barton, L., Miles, S., Whiting, C., \& Whitty, G. (2000). Teacher Education in Transition: Re-forming professionalism? Buckingham: Open University Press.

Garrison, R. (2000). Theoretical Challenges for Distance Education in the 21st Century: A shift from structural to transactional issues. International Review of Research in Open and Distance Learning, 1(1). Retrieved November 14, 2007 from: http://www.irrodl.org/index.php/irrodl/article/view/2/333

Guri-Rosenblit, S. (1999). Distance and Campus Universities: Tensions and interactions. A comparative study of five countries. International Association of Universities and Elsevier Science.

Halsey, A. H. (1995). Decline of Donnish Dominion: British academic professions in the twentieth century. Oxford: Clarendon Press.

Henkel, M. (2000). Academic identities and policy change in higher education. London and Philadelphia: Jessica Kingsley Publishers.

Instance, D., Schnetze, H. G., \& Schuller, T. (Eds.). (2002). International Perspectives on Lifelong Learning: From recurrent education to the knowledge society. Milton Keynes: SRHE and Open University Press.

Jevons, F. (1987). Distance Education and Campus-based Education: Parity of esteem. In P. Smith \& M. Kelly (Eds.), Distance education and the mainstream (pp. 12-23). New York: Croom Helm.

Keegan, D. (1993). Reintegration of the teaching acts. In D. Keegan (Ed.), Theoretical principles of distance education. London: Routledge.

Kerr, C. (1994). Higher Education Cannot Escape History: Issues for the 21 st century. Albany, NY.: State University of New York Press.

Lagemann, E. C. (2000). An Elusive Science: The troubling history of education research. Chicago and London: The University of Chicago Press.

Lave, J., \& Wenger, E. (1991). Situated Learning: Legitimate peripheral participation. Cambridge: Cambridge University Press. 
Leh, A. S., \& Jobin, A. (2002). Striving for quality control in distance education. In C. D., Maddux, J. Ewing-Taylor, \& D. Lamont-Johnson (Eds.), Distance Education: Issues and concerns (pp. 87-102). Binghamton, NY.: The Haworth Press.

Macdonald, K. M. (1995). The sociology of the professions. London: Sage.

Moore, M. G. (1993). Theory of transactional distance. In D. Keegan (Ed.), Theoretical principles of distance education. London: Routledge.

Morley, L. (2003). Quality and power in higher education. Buckingham: Open University Press.

Nedvek, B. P. (1999). Information technology and changing roles in the academy. In J. Brennan, J. Fredowitz, M. Huber, \& T. Shah (Eds.), What K ind of University?: International perspectives on knowledge, participation and governance (pp. 171-192). Milton Keynes: The Society for Research into Higher Education and Open University Press.

Panda, S. (2004). People: Staffing, development and management. In H. Perraton \& H. Lentell (Eds.), Policy for open and distance learning (pp. 76-99). London and New York: Routledge Falmer.

Paré, A., \& Le Maistre, C. (2004). Learning Through Complex Participation: Distributed mentoring in communities of practice. In P. Tynjälä, J. Välimaa \& G. Boulton-Lewis (Eds.), Higher Education and Working L ife: Collaborations, confrontations and challenges.

Paul, R. (1987). Staff Development Needs for Universities: Mainstream and distance education. In P. Smith \& M. Kelly (Eds.), Distance education and the mainstream (pp. 139-155). New York: Croom Helm.

Perkin, H. (1969). Key profession. London: Routledge \& Kegan Paul.

Perraton, H. (2000). Rethinking the research agenda. International Review of Research in Open and Distance Learning, 1(1). Retrieved November 14, 2007 from: http://www.irrodl.org/index.php/irrodl/article/view/5/338

Readings , B. (1996). The university in ruins. Cambridge, MA.: Harvard University Press.

Reeves, T. C. (2002). Distance Education and the Professorate: The issue of productivity. In C. Vrasidos \& G. V. Glass (Eds.), Distance education and distributed learning (pp. 135-156). Greenwich, CT.: Information Age Publishing.

Saba, F. (2000). Research in Distance Education: A status report. International Review of Research in Open and Distance Learning, 1(1). Retrieved November 14, 2007 from: http://www.irrodl.org/index.php/irrodl/article/view/4/337

Scott, P. (1995). The meanings of mass higher education. Milton Keynes: SRHE and the Open University Press. 
Shore, C., \& Wright, S. (2000). Coercive Accountability: The rise of audit cultures in higher education. In M. Strathern (Ed.), Audit Cultures: Anthropological studies in accountability, ethics and the academy. London: Routledge.

Taylor, P. (1999). Making Sense of Academic L ife: Academics, universities and change. Milton Keynes: SRHE and the Open University Press.

Taylor, R.; Barr, J., \& Steele, T. (2002). For a radical higher education. Milton Keynes: SRHE and the Open University Press.

Trowler, P. R. (1998). Academics responding to change. New higher education frameworks and academic cultures. Milton Keynes: SRHE and the Open University Press.

Walker, R. (2002). Is There Anyone There? The embodiment of knowledge in virtual environments. In C. Vrasidos \& G. V. Glass. (Eds.), Distance education and distributed learning (pp. 94-114). Greenwich, CT.: Information Age Publishing.

Wenger, E. (1998). Communities of practice: Learning, meaning, and identity. Cambridge: Cambridge University Press.

Williams, P. E. (2003). Roles and competencies for distance education programs in higher education institutions. The American Journal of Distance Education, 17(1), 45-57. 
November - 2007

\title{
Access to Communication for Deaf, Hard-of- Hearing and ESL Students in Blended Learning Courses
}

\author{
Gary L. Long \\ National Technical Institute for the Deaf \\ Rochester Institute of Technology, USA \\ Karen Vignare \\ Michigan State University, USA \\ Raychel P. Rappold \\ Online Learning \\ Rochester Institute of Technology, USA \\ Jim Mallory \\ National Technical Institute for the Deaf \\ Rochester Institute of Technology, USA
}

\begin{abstract}
In an effort to better understand student perceptions of communication in blended (online and traditional) learning courses, a 22 item questionnaire was developed and sent to all students registered for these courses at a large technology-focused college during three quarters of instruction. The respondents were divided into four groups: 1) hearing, 2) deaf, 3) hard-of-hearing $(\mathrm{D} / \mathrm{HH})$, and 3) English as a second language (ESL). Their perceptions of communication and the blended learning experience were examined. While the hearing and ESL students were positive about blended learning, the findings indicated that deaf and hard-of-hearing students reported that both the quality and quantity of their interactions with the professor and other students was greatly improved by the inclusion of an online component. ESL and hearing students were also positive about the blended experience; but the greatest benefit to communication access was observed by students with a hearing loss.
\end{abstract}

Keywords: Blended learning; deaf and hard-of-hearing students; online learning; learning community; cooperative learning

\section{Introduction}

Deaf students' struggles with reading, writing, and communication in the classroom have been well documented by many researchers over the past 20 years (Long \& Beil, 2005; Antia, Reed, \& 
Kreimeyer, 2005; Mallory \& Long, 2002; Johnson \& Johnson, 1986; Karchmer \& Mitchell, 2003). The need exists for technologies that will help deaf students to interact directly with their hearing peers. As Dansereau (1988) found in a program of research on cooperative learning, interaction and communication with peers, instructors, and experts produce the quickest, longest lasting and most transferable learning outcomes. Deaf and hard-of-hearing (D/HH) students in mainstream classes currently use the assistance of a third party, either a sign language interpreter or a voice-to-print 'captionist' to facilitate communication with hearing instructors and peers. While helping to provide access to the information, these systems are seen as lacking the clarity and immediacy of direct one-to-one communication (Long \& Beil, 2005; Foster, Long, \& Snell, 1999). With the advent of distance learning technology, email, instant messaging and discussion boards, there is now the opportunity for deaf and hard-of-hearing students to interact directly with their hearing peers and instructors without the message going through a third party. The present study examined student interactions and satisfaction with instructional delivery in blended learning courses where online communication is incorporated into traditional lecture classes.

\section{In-Class versus Online Learning}

When deaf and hard-of-hearing learners attend traditional in-class instruction, they typically do so with the assistance of sign language interpreters. However, the transfer of information from hearing instructors (who do not know sign language) through interpreters is a major concern to deaf and hard-of-hearing students. Long and Beil (2005) found that deaf adults in traditional learning environments often feel left out of classroom communication. Because of the lag that exists between the delivery of the information by the instructor and the signing of the content by the interpreter, deaf and hard-of-hearing learners report difficulty responding to the instructor's questions or asking a timely question. They feel out of sync with the instruction and, if the classroom pace is fairly quick, they do not feel comfortable stopping the flow to ask a question of clarification. In a study of main-streamed college students, Foster, Long and Snell, (1999) found that deaf and hard-of-hearing students often feel isolated or left out of the interactions that occur with other students and the instructor in the classroom.

In contrast to traditional lecture classes, online learning provides discussion boards, chat rooms, and other opportunities for both synchronous and asynchronous discussions related to the topic at hand. Inclusion of the online format slows the synchronous pace and allows the deaf, hard-ofhearing, and ESL students, more time to compose a response or ask a relevant question. Blended learning is a combination of traditional live classroom activities and online activities. Blended learning aims to join the best of classroom teaching and learning with the best of online teaching and learning. Interest in blended learning is growing as more universities become accustomed to using a courseware management system, and as academic leaders increasingly endorse active cooperative learning and the effective use of instructional technology. Some educational researchers see blended learning as a 'transformative' process for the university (Garrison \& Kanuka, 2004). The Rochester Institute of Technology (RIT) Online Learning instructional model defines a blended course as any course in which approximately 25 percent to 50 percent of classroom lectures and other seat time are replaced by instructor-guided online learning activities such as virtual team projects, synchronous chat sessions, and asynchronous discussions (Humbert \& Vignare, 2004). Blended learning courses that use online technologies to enable collaboration should improve quality and quantity of interaction between faculty and students, and students and students (Shea, Pickett, \& Pelz, 2003). 


\section{Review of the Literature}

The deaf and hard-of-hearing students enrolled in college face a multitude of barriers to inclusion in the classroom (Stinson \& Liu, 1999). In the online classroom however, the barriers tend to be lower and primarily focus on whether the student has the intellectual capability to participate (Mallory \& Long, 2003; 2002). It is important to build an understanding of the issues surrounding accessibility for $\mathrm{D} / \mathrm{HH}$ students, especially those focused around the use and spread of educational technologies.

Many legal and ethical discussions have taken place since the late 1980s on regulatory rules and standards required by legislation. Norm Coombs (as cited in Schmetzke, 2001) provides us with reasons why educators should be proactive in meeting the needs of students with disabilities.

First, ethically speaking, it simply is the right thing to do. Second, it is the economically sensible thing to do-considering the extra cost involved in producing alternative versions of instructional materials. Third, it is the selfish thing to do: With advancing age, as our senses grow weaker and our mobility decreases, we all stand a good chance of becoming beneficiaries of a barrier-free information infrastructure. (\$ 8)

While there is no doubt that it is good policy to provide a barrier-free classroom, the issues of accessibility often fail to include inclusive classroom communication (Schenker \& Scadden, 2002). One of the pedagogical strengths of online learning is the ability to provide a barrier-free or more level playing field for all students in the classroom (Harasim, Hiltz, Teles, \& Turroff, 1995). This environment, where communications are open to all - faculty to students and students to students - is conducive to deaf, hard-of-hearing, and English as a second language (ESL) students. In the traditional classroom, all communication is triangulated through the interpreter or others (Lang, 2002). Deaf students often feel they are behind the classroom dialogue and often do not wish to ask questions or interject thoughts (Long \& Beil, 2005). In online asynchronous learning environment, traditional classroom communication barriers are minimized (Richardson, Long, \& Woodley, 2003). While online learning presents opportunities to lower communication barriers for $\mathrm{D} / \mathrm{HH}$ and ESL students, most traditional-aged students who attend a residential university expect to attend classes in a classroom (Lang, 2002). The expectation of classroom attendance includes the D/HH students (Lang, 2002). The opportunity to meld the two learning environments presents itself through the blended learning format.

The online learning environment can help build a community of learners who cooperatively share ideas, knowledge, and opinions. Learning theory prominently recognizes the value of learning communities and the importance of cooperative learning for long-term retention of information (Dansereau, 1988; Phillips \& Soltis, 2004). While no doubt the traditional classroom is a learning community where cooperative learning can occur, it is clear that it is difficult to engage all learners in the community during a discussion. Stinson and Liu (1999) found that the development of a learning community was problematic for D/HH students.

Recent discussion has emphasized the importance of deep meaningful learning that is associated with hypothesis construction, problem solving, and conceptual organization, in contrast to memorization and retention of facts (Iran-Nejad, 1990; Pintrich, Marx, \& Boyle, 1993). While this kind of learning can occur in individual seatwork, it is more likely to take place in group activities. Often, the inability of $\mathrm{D} / \mathrm{HH}$ and hearing students to communicate easily and directly makes group participation difficult for the $\mathrm{D} / \mathrm{HH}$ member, even with an interpreter. 
Research by Long and Beil (2005, p. 6) has found that if communication breaks down, students are "less likely to become engaged, active learners," and the exchange of ideas is limited. In a study of US and Thai ESL students studying information technology and collaborating on a group project, Sarker (2005) found that both the US and the Thai students perceived more learning and information were transmitted by the US members of the team, even though capability and experience levels were equal. Sarker suggests this resulted from a communication/ language barrier, because the language medium was English. Although the Thai members of the team could potentially have contributed to the whole team's learning, it was perceived by both sides that they did not contribute in proportion to their potential. Even the Thai team members felt they had not been able to make a substantial contribution to the team's learning outcomes. Sarker stated that it is possible the Thai team members experienced frustration with the language barrier and could not share their knowledge effectively. In the same way, deaf students in a predominantly hearing setting and ESL students in an English environment may experience similar feelings of not being able to contribute to the group's learning, even though they have knowledge they would like to share. This underscores the necessity of providing a method of communication wherein all group members feel they can express themselves and are able to clearly communicate their ideas to their peers and receive feedback.

Liu, Moore, Graham, and Lee (2003) reviewed 21 journals and 246 articles related to computer use in the ESL classroom. They found 70 research-based articles that focused on the use of computer technology to support second and foreign language learning, many of which addressed the use of computer-mediated communication in the classroom. Since deaf students' struggles with English reading and writing are akin to those of English language learners (Antia, et al., 2005), strategies proven by research to improve the writing and language use of English language learners may also be beneficial to deaf students. Liu and colleagues (2003) found that "computer mediated communication seems to promote meaningful human interaction that can foster the language learning process” (p. 252). Computer-mediated communication has also been found to reduce anxiety about writing and increase the perception of social integration (Bishop, Taylor, \& Froy, 2000; Hertz-Lazarowitz \& Bar-Natan, 2001). Thus online communication may provide secondary language development benefits as well as important social interaction benefits.

\section{Inclusive Classrooms at the Rochester Institute for Technology}

The National Technical Institute for the Deaf (NTID) is located at the Rochester Institute for Technology (RIT). NTID is a leading undergraduate college whose primary mission is to provide post-secondary education to students who are deaf or hard of hearing. All NTID students are allowed to enroll in RIT courses provided they have the academic skills to do so. RIT has a significant commitment to creating an inclusive learning environment. In the past these efforts have relied primarily on having classroom interpreters for professors who do not sign. More recent efforts have included technologies like C-Print, a real-time, voice-to-print captioning system that utilizes trained 'captionists' in the classroom. RIT has also been a pioneer in distance learning. All distance learning courses must meet standards that make the classroom accessible to D/HH students.

With over 16,000 students and just over 1,100 D/HH students enrolled, approximately 50 percent of the D/HH students are taking mainstreamed RIT classes during each quarter. At NTID, students' services include smaller classes, faculty who can sign American Sign Language without interpreters, and aides. Their transition to RIT courses while still supported with note takers, voice-to-print captionists, and/ or interpreters, can still be difficult for students. There is constant and continual service and education provided to faculty on how to integrate $\mathrm{D} / \mathrm{HH}$ learners into 
the classroom (see www.rit.edu/classact). RIT's commitment to support and recognize students with disabilities, especially D/HH students, extends to its distance learning courses as well. The Online Learning department makes it clear to distance faculty that all new course processes and new materials must be designed to be accessible. All audio and video material must be captioned, even when the video is streamed.

\section{Blended Learning Survey}

The first year (2003-2004), a blended learning pilot program was introduced at the Rochester Institute of Technology; no demographic questions were asked of student participants in year one, but the initial results of the students' satisfaction survey seemed to mirror data reported by Dziuban, Hartman, Moskal, Sorg, and Truman (2004) at the University of Central Florida. Course completion rates were just over 95 percent, and nearly 70 percent of the students said they liked blended learning. During in-depth interviews, faculty indicated that they felt energized by redesigning their courses for a blended learning format.

The second year survey (2004-2005) continued to ask many of the satisfaction Likert-type questions, but was expanded to investigate the perceptions of deaf, hard-of-hearing, and ESL students enrolled in blended learning courses. Since classroom communication has been a significant challenge for the deaf and hard-of-hearing students, we were focused on the ease of communication for these students with their hearing peers and instructors. Hearing student and ESL student reactions to the blended format were also examined.

\section{Method}

\section{Procedure}

A 22 item "Blended End of Course Survey" was designed by the authors to explore student perceptions of communication in the blended learning instructional format. The questionnaire consisted of 16 Likert items, two open-ended questions, and four demographic items. Details of each follow:

- Two types of Likert items were used in this study. The first asked students to rate their agreement with specific statements using this five-point scale: $(5=$ Strongly Agree, $4=$ Agree, 3 = Neutral, 2 = Disagree, $1=$ Strongly Disagree). Examples of these items include: "I learned more about my fellow students because part of this course was online", and "I interacted more with fellow students because part of this course was online.” The second type of Likert question asked students to compare their level of interaction in this blended course to more traditional courses that meet only in the classroom using this five-point scale: $(5=$ Increased, $4=$ Somewhat Increased, $3=$ No Difference, 2 = Somewhat Decreased, 1 = Decreased). Examples of these ratings include: "The amount of interaction with other students" and "The quality of your interaction with the professor.”

- Open-ended questions allowed participants to type in a response in response boxes following each item, in their own words. The two open-ended questions were: "If more courses were offered like this (ones that meet in the classroom and online) what changes would you recommend" and "What did you like best about this course?" 
- Finally, the survey asked students to provide demographic information about: student workload (full or part-time); hearing status (hearing, hard-of-hearing or deaf); level of program (graduate or undergraduate); and whether English is a second language (Yes or No).

The Blended End of Course Survey was sent to 1,713 students who were enrolled in blended learning courses at the Rochester Ins 'titute of Technology during one academic year (2004-2005). Clipboard, a system for design and delivery of questionnaires, was used for the set-up of the survey, and each student was sent a live link via email and asked to access the survey by selecting the link. Students who responded were entered into a draw for a US \$50 gift certificate at the campus bookstore. Nine hundred and eight $(n=908)$ students responded to the survey, yielding a response rate of 53 percent.

\section{Participants}

Approximately 68 percent of the respondents were male and 32 percent female. The vast majority (96\%) were full-time students, while 4 percent were enrolled part-time. Eighty-five percent of the respondents were enrolled in undergraduate programs, and 15 percent were in graduate school. Thirty-six $(n=36)$ of the respondents were deaf, 28 were hard-of-hearing and 84 hearing students indicated that English was their second language. The remaining 760 students constituted the (non ESL) hearing student group.

\section{Results}

The following section summarizes our findings related to: 'Communication with Peers,' 'Communication with Instructors,' and 'Overall Satisfaction' with the blended learning experience.

\section{Communication with Peers}

Of particular interest in this study is how students perceived the ease of communication with their fellow students. The following questions relate to peer interactions. The stated percentage is the total number of individuals who indicated that they either Agreed or Strongly Agreed with each statement.

Table 1. Peer Interactions Online

\begin{tabular}{lcccc}
\hline & Deaf & $\begin{array}{c}\text { Hard-of- } \\
\text { Hearing }\end{array}$ & ESL & Hearing \\
\hline $\begin{array}{l}\text { Ilearned more about my fellow students because part of } \\
\text { this class was online. }\end{array}$ & $73 \%$ & $52 \%$ & $36 \%$ & $30 \%$ \\
$\begin{array}{l}\text { I interacted more with other students because part of } \\
\text { this course being online. }\end{array}$ & $51 \%$ & $39 \%$ & $29 \%$ & $30 \%$ \\
\hline
\end{tabular}

Note: ESL and Hearing students were primarily neutral about their level of communication with peers.

In their responses to these items, deaf and hard-of-hearing students indicated that they interacted and learned more about their peers because of the online format of the course. The online format provided a mechanism for deaf and hard-of-hearing students to have direct communication with 
their hearing peers. The ESL students said that they learned more about their fellow students, but were similar to other hearing students in terms of the amount of interaction.

The following questions ask students to compare the online course to traditional lecture courses and rate the amount and quality of interaction with other students. The stated percentage is for the number of individuals who indicated that the amount and quality of interaction either Somewhat Increased or Increased with the blended learning courses.

Table 2. Amount and Quality of Increased Interaction with Peers

\begin{tabular}{lcccc}
\hline & Deaf & $\begin{array}{c}\text { Hard-of- } \\
\text { Hearing }\end{array}$ & ESL & Hearing \\
\hline The amount of your interaction with other students. & $61 \%$ & $61 \%$ & $41 \%$ & $38 \%$ \\
The quality of your interaction with other students. & $61 \%$ & $61 \%$ & $36 \%$ & $34 \%$ \\
\hline
\end{tabular}

Note: ESL and Hearing students were primarily neutral about their level of communication with peers.

The most striking finding in the above items is that the deaf and hard-of-hearing students report a significant increase in the amount and quality of the interaction with peers when the blended course is compared to more traditional in-class instruction. The ESL students are just a little more positive than hearing students about online communication with peers. But the deaf and hard-ofhearing students are very positive regarding the benefits of adding an online component to a course. The following quotes, taken from the open-ended questions, by the deaf and hard-ofhearing students help to clarify this benefit:

"I think the online discussion is the best [part of] this class."

"I like the discussion board and being able to say my opinion. I think it was much more easier for me to stand up for the Social Issues that were presented than in person."

"[I like] learning about other students who are in this class and their opinion and beliefs about the things we learn in class!”

"I liked how I was able to interact more with other students, especially the hearing."

“At least I get to read about other students' thoughts and opinions about the assigned readings and assignments. It allows room for learning and increased knowledge.”

"I learned lots of stuff from the students who are in my class."

"Neutrality and respect regardless of race and disability. Only respect you receive is from knowledge and opinions not based on your appearances.” 
Thus the deaf and hard-of-hearing students felt that the online portion of these courses added to the ease of communication with their peers. The online experiences increased opportunities for sharing their opinions and actively participating in cooperative, peer learning.

\section{Communication with Instructors}

The ease of communication between the instructor and the students in the course are examined in the following questions. The stated percentage is for the number of individuals who indicated that the amount and quality of the interactions with the instructor either Somewhat Increased or Increased with this online course.

Table 3. Increased Communication with Instructor(s)

\begin{tabular}{lcccc}
\hline & Deaf & $\begin{array}{c}\text { Hard-of- } \\
\text { Hearing }\end{array}$ & ESL & Hearing \\
\hline The amount of your interaction with the professor. & $67 \%$ & $35 \%$ & $35 \%$ & $29 \%$ \\
& & & & \\
The quality of your interaction with the professor. & $67 \%$ & $48 \%$ & $39 \%$ & $30 \%$ \\
\hline
\end{tabular}

Note: ESL and Hearing students were mostly neutral about their level of communication with Instructors.

Deaf students were the group that reported that the online format led to the greatest increase in interaction with their instructors when compared to traditional in-class instruction. In comparison, approximately one-third of the 'other' students reported increased interaction with the instructor, whereas two-thirds of the deaf students indicated that the online format led to increased interactions with the instructor.

Deaf and hard-of-hearing students were very positive about the quality of interaction with their instructors when online interaction is present. Sixty-seven percent of the deaf students and 48 percent of the hard-of-hearing students said that the quality of the interactions with the faculty improved in online courses. The ESL and hearing students reported similar perceptions, with 39 percent and 30 percent respectively saying that the online format increased the quality of interactions with their instructors. The following quotes from deaf and hard-of-hearing students clearly articulate their perspective on communication with the instructor and interaction with course content.

"Since no interpreters are [available for] night classes, it is more convenient for me to communicate with teacher and students online."

"I seemed to have a greater voice in lending my opinion and questions regarding the topics in which I have received a great amount of feedback.”

"There was better motivation to read the course materials as well as search for our own perceptions and feelings regarding certain topics and being able to write it all down where everyone had a place to say something about it.” 
"The study of cultural differences and applying it to my life was interesting, and the use of online postings was much more interactive for me."

"More availability with the instructor. . ."

While many students said there were communication advantages to having online access to the instructor, the majority of the deaf students said it increased the amount and quality of those interactions.

\section{Overall Satisfaction with the Blended Learning Experience}

While the prior sections of this paper focused on communication with instructors and peers, this section examines overall student satisfaction with the blended learning experience. The following questions relate to student satisfaction with the blended learning format. The stated percentage is the total number of individuals who either Agreed or Strongly Agreed with each statement.

Table 4. Overall Satisfaction

\begin{tabular}{|c|c|c|c|c|}
\hline & Deaf & $\begin{array}{l}\text { Hard-of- } \\
\text { Hearing }\end{array}$ & ESL & Hearing \\
\hline $\begin{array}{l}\text { I like having part of the course online and part of it in } \\
\text { the classroom. }\end{array}$ & $79 \%$ & $74 \%$ & $55 \%$ & $62 \%$ \\
\hline I like leaming from online activities. & $76 \%$ & $61 \%$ & $42 \%$ & $51 \%$ \\
\hline $\begin{array}{l}\text { Other students should have the opportunity to take a } \\
\text { class like this in the future. }\end{array}$ & $82 \%$ & $74 \%$ & $49 \%$ & $56 \%$ \\
\hline
\end{tabular}

Note: While ESL and Hearing students were positive about their level of satisfaction with blended leaming, their second choice by an overwhelming percent was neutral, not negative.

Overall student reaction to blended learning was very positive, with the majority of students saying that they liked having part of the course online and that they enjoyed learning from online activities. The deaf and hard-of-hearing students generated the most positive ratings, however. Between 60 and 80 percent of the deaf and hard-of-hearing students reported that they liked having part of the class online, they were able to learn from the online activities, and believed that other students should have the opportunity to take a blended learning course. The hearing students were slightly more positive about the online experience than were the ESL students; however, both groups reported to benefit from the experience. The following quotes focus on the perceived advantages of blended learning by deaf and hard-of-hearing students.

"I like the part where we can take part of the course in and out of the classroom."

"I would say that (it) is fun to do project but I (would) rather try online for credit because I live off campus and (am) sick of going to class to learn something new, I would like to get online and learn something new that mean time is gonna be flexible which is much better." 
"I have more time at home to think about the questions."

"I like the discussion board the best."

"The fact that the course was combined with online time really allowed me to manage my time better. It is always a long day for me, so it takes a lot of stress away for me to be able to not go to class every time."

"[There is] flexibility in when to meet for class and [how to use] my own time."

"I can say this course is more independent for the students."

Along with the benefits of communication ease, deaf and hard-of-hearing students point to the flexibility of the schedule and the sense of independence as important advantages of the blended learning format. Similar comments were made by the hearing and ESL students in this study.

\section{Conclusion}

Students at RIT were positive about courses that used a blended learning format. When subgroups of students were examined, the deaf and hard-of-hearing students were the most positive. In traditional classes, these students are faced with the challenge of peer and teacher interactions filtered through a third party, specifically an interpreter or captionist. Students with a hearing loss are sometimes concerned that the intervention of the third party in the communication process may in some way distort the message. At times they feel that what they are signing is not being accurately represented to their instructors and peers. At other times, they feel that the interpreter may not have the content knowledge or 'sign skills' needed to accurately convey the lecture contents. To the deaf and hard-of-hearing student in the classroom, there is always the concern that part of the message is being lost. When the message is interpreted, there is always the added challenge of the lag that occurs. When this lag occurs in the classroom, the deaf and hard-ofhearing students are always behind their hearing peers in reception of the message. This lag often leads to difficulty responding to the instructor's questions or reluctance to stop the class to ask a clarification question. Thus deaf and hard-of-hearing students, at times, are not actively engaged in communication in mainstream classes.

A limitation of the present study is that the communication preferences of deaf and hard-ofhearing participants were not identified. Some of the students may have relied on sign language for communication, while others used speech and lip reading. Student communication preference may be related to satisfaction with the online learning experience and should be included in subsequent research. However, in the present study, in both groups of students with hearing loss, those who saw themselves as 'deaf' and those who saw themselves as 'hard-of-hearing' reported a benefit to communication access with the inclusion of an online component in a course.

The results of this study indicate that the blended learning instructional format offers some appealing advantages for students with hearing loss. The addition of discussion boards and other online tools that facilitate written communication provide tools for deaf and hard-of-hearing students to interact directly with hearing instructors and peers. Often questions are posted and students are asked to share their answers or opinions based on their reading of course materials and personal experience. Because of the online format, students with a hearing loss do not need to go through a third party to respond and they have direct access to the thinking of their hearing peers. They also have more time to compose their response than they do in a traditional lecture 
class. This allows for the free sharing of opinions and ideas by students who are typically challenged to do so in a traditional class. Students also are able to process and learn from the ideas and opinions of their classmates and instructors without the information going through a third party. In some ways, providing an option for online communication helped level the playing field and allowed the deaf and hard-of-hearing students greater ease of communication with peers and instructors. This may be why over 75 percent of the students with hearing loss said that other students should have the opportunity to take a class like this in the future.

\section{References}

Antia, S., Reed, S., \& Kreimeyer, K. (2005). Written language of deaf and hard-of-hearing students in public schools. Journal of Deaf Studies and Deaf Education, 10 (3), 244-255.

Bishop, J. M., Taylor, L., \& Froy, F. (2000). Computer-mediated communication use by the deaf and hard-of-hearing. Kybernetes, 29(9/10), 1078-1086.

Dansereau, D. (1988). Cooperative Learning Strategies. In C. E. Weinstein, E. T. Goetz, \& P. A. Alexander (Eds.), Learning and Study Strategies: Issues in assessment, instruction and evaluation (pp. 103-129). San Diego, CA: Academic Press.

Dziuban, C., Hartman, J., Moskal, P., Sorg, S., \& Truman, B. (2004). Three ALN Modalities: An institutional perspective. In J. Bourne \& J. C. Moore (Eds.), Elements of Quality Online Education: Into the Mainstream (pp. 127-148). Needham, MA: Sloan Center for Online Education.

Foster, S., Long, G., \& Snell, K. (1999). Inclusive instruction and learning for deaf students in postsecondary education. Journal of Deaf Studies and Deaf Education, 4(3), 225-235.

Garrison, D. R., \& Kanuka, H. (2004). Blended Learning: Uncovering its transformative potential in higher education. The Internet and Higher Education, 7(2), 95-105.

Harasim, L., Hiltz, S. R., Teles, L. \& Turroff, M. (1995). Learning Networks: A field guide to teaching and learning online. Cambridge, MA: MIT Press.

Hertz-Lazarowitz, R., \& Bar-Natan, I. (2001). Writing development of Arab and Jewish students using Cooperative Learning (CL) and Computer-Mediated Communication (CMC). Computers \& Education, 39(1), 19-36.

Humbert, J., \& Vignare, K. (2004). RIT introduces blended learning - successfully! In J. C. Moore (Ed.), Elements of Quality Online Education: Engaging communities, wisdom from the Sloan Consortium, Volume 2 in the 'Wisdom Series.' Needham, MA: Sloan Center for Online Education.

Iran-Nejad, A. (1990). Active and dynamic self-regulation of learning processes. Review of Educational Research, 60 (4), 573-602.

Johnson, D., \& Johnson, R. (1986). Mainstreaming Hearing Impaired Students: The effect of effort in communicating on cooperation and interpersonal attraction. The Journal of Psychology, 119(1), 31-44. 
Karchmer, M., \& Mitchell, R. (2003). Demographic and achievement characteristics of deaf and hard-of-hearing students. In M. Marschark \& P. Spencer (Eds.), Oxford Handbook of Deaf Studies, Language and Education (pp. 21-37). New York: Oxford.

Lang, H. (2002). Higher education for deaf students: Research priorities for the new millennium. Journal of Deaf Education and Deaf Studies, 7 (4), 267-280.

Liu, M., Moore, Z., Graham, L., \& Lee, S. (2003). A Look at the Research on Computer-based Technology Use in Second Language Learning: A review of the literature from 1990-2000. Journal of Research on Technology in Education, 34(3), 250-273.

Long, G., \& Beil, D. (2005). The importance of direct communication during continuing education workshops for deaf and hard-of-hearing professionals. Journal of Postsecondary Education and Disability. 18(1), 5-11.

Mallory, J. R., \& Long, G. L. (2003). Learning preferences for deaf and hard of hearing remote, online learners. Paper presented at the Instructional Technology and Education of the Deaf Supporting Learners symposium, Rochester, NY. Retrieved October 24, 2007 from: http://www.rit.edu/ techsym/

Mallory, J., \& Long, G. (2002). Postsecondary Education Programs Network (PEPNet). Kansas City, MO. Retrieved October 24, 2007 from: http://sunsite.utk.edu/cod/pec/other.html

National Technical Institute for the Deaf (n.d.) Class Act homepage: Rochester Institute of Technology. Retrieved October 24, 2007 from: http://www.rit.edu/ classact/

Phillips, D. C., \& Soltis, J. F. (2004). Perspectives on learning (4th edition). New York: Teachers College Press.

Pintrich, C. J., Marx, R. W., \& Boyle, R. A. (1993). Beyond 'Cold' Conceptual Change: The role of motivational beliefs and classroom contextual factors in the process of conceptual change. Review of Educational Research, 63, 167-199.

Richardson, J., Long, G., \& Woodley, A. (2003). Academic engagement and perceptions of quality in distance education. Open Learning, 18(3), 223-244.

Sarker, S. (2005). Knowledge transfer and collaboration in distributed U.S.-Thai teams. Journal of Computer Mediated Communication, 10(4). Retrieved October 24, 2007 from: http://jcmc.indiana.edu/vol10/issue4/sarker.html

Schenker, K., \& Scadden, L. (2002). The design of accessible distance education environments that use collaborative learning. Journal of Information Technologies and Disabilities, 8 (1). Retrieved October 24, 2007 from: http://www.rit.edu/ easi/itd/itdv08n1/scadden.htm

Schmetzke, A. (2001). Online distance education - "Anytime, Anywhere” but not for everyone. Journal of Information Technology and Disabilities, 7 (2). Retrieved October 24, 2007 from: http://www.rit.edu/ easi/itd/itdv07n2/axel.htm 
Access to Communication for Deaf, Hard-of-Hearing and ESL Students in Blended Learning Courses Long, Vignare, Rappold \& Mallory

Shea, P., Pickett, A., \& Pelz, W. (2003). A follow up investigation of "teacher presence" in the SUNY Learning Network. Journal of Asynchronous Learning Networks, 7(2), 61-80.

Stinson, M., \& Liu, Y. (1999). Participation of deaf and hard-of-hearing students in classes with hearing students. Journal of Deaf Studies and Deaf Education, 4 (3), 190-202.

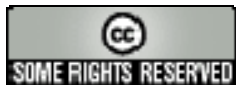




\title{
OOPS, Turning MIT Opencourseware into Chinese: An analysis of a community of practice of global translators
}

\author{
Mimi Miyoung Lee \\ University of Houston \\ USA \\ Meng-Fen Grace Lin \\ University of Houston \\ USA \\ Curtis J. Bonk \\ Indiana University at Bloomington \\ USA
}

\begin{abstract}
An all-volunteer organization called the Opensource Opencourseware Prototype System (OOPS), headquartered in Taiwan, was initially designed to translate open source materials from MIT OpenCourseWare (OCW) site into Chinese. Given the recent plethora of open educational resources (OER), such as the OCW, the growing use of such resources by the world community, and the emergence of online global education communities to localize resources such as the OOPS, a key goal of this research was to understand how the OOPS members negotiate meanings and form a collective identity in this cross-continent online community. To help with our explorations and analyses within the OOPS translation community, several core principles from Etienne Wenger's concept of Communities of Practice (COP) guided our analyses, including mutual engagement, joint enterprise, shared repertoire, reification, and overall identity of the community. In this paper, we detail how each of these key components was uniquely manifested within the OOPS. Three issues appeared central to the emergence, success, and challenges of the community such as OOPS: 1) strong, stable, and fairly democratic leadership; 2) participation incentives; and 3) online storytelling or opportunities to share one's translation successes, struggles, and advice within an asynchronous discussion forum. While an extremely high level of enthusiasm among the OOPS members underpinned the success of the OOPS, discussion continues on issues related to quality control, purpose and scope, and forms of legitimate participation. This study, therefore, provides an initial window into the emergence and functioning of an online global education COP in the OER movement. Future research directions related to online global educational communities are discussed.
\end{abstract}

Keywords: Open educational resources (OER), OpenCourseWare (OCW); communities of practice (CoP); global education; Opensource Opencourseware Prototype System (OOPS); 
OOPS, Turning MIT Opencourseware into Chinese: An analysis of a community of practice of global translators

Lee, Lin \& Bonk

opensource; volunteer translators; reification; mutual engagement; joint enterprise; shared repertoire; MIT; global translation; asynchronous discussion threads; Chinese; China; Taiwan

\section{Introduction}

During the past decade, online collaborative technologies combined with a shift in educational practices toward sharing educational contents, have created global educational opportunities never witnessed before in the history of human civilization. These opportunities have supported a change in dispositions to share among renowned institutions and established educational scholars. This shift has already resulted in innovative learning possibilities for every connected citizen on this planet. As individuals and funding agencies recognize some of these opportunities and events, even more far reaching global exchanges and learning outcomes can be developed, tested, combined, and promoted. In partial response to these trends, we examine an Open Educational Resources (OER) community, with the goal of understanding how members negotiate meanings and form a collective identity in this cross-continent online community.

This study focuses on an all-volunteer organization called Opensource Opencourseware Prototype System (OOPS). The OOPS community was a brainchild of Lucifer Chu, whose passion and vision for providing Chinese/ Taiwanese version of opencourseware made OOPS possible (Phipps, 2005). Lucifer, known simply as 'Luc,' represents the strong leadership felt by members of the OOPS in that most of the community's major events are initiated with his ideas. As the Chinese translator of The Lord of the Rings and the founder of Fantasy Foundation, Luc has been a well known entrepreneur and promoter since 2002; his stated purpose is "to promote fantasy arts in the Great China area, cultivate our own Tolkien and J.K. Rowling, and encourage the sharing of knowledge and creative thinking” (Lin, 2006, p. 24). For example, the Fantasy Foundation has been promoting activities such as annual fantasy art competitions and summer fantasy art camps. In addition, it has been hosting several online forums where fantasy arts fans and creators can interact and exchange ideas. Luc's life story shaped his motivation and inspiration for creating OOPS. His diverse experience also provided him with the ability to start and spread the OOPS project.

In OOPS, we were interested in understanding how the members negotiate meaning and establish their sense of identity through various members of this organization. Using the participant dialogues from the OOPS's electronic bulletin board followed by participant interviews, we explored many characteristics of this unique community through the theoretical framework of Communities of Practice proposed nearly a decade ago by Wenger (1998). Our analysis of the OOPS data presents an example of a unique application of Wenger's framework to a growing and vital segment of the global education field. As such, we detail specific aspects of Wenger's model that apply to the OOPS setting. The OOPS project was initially designed to translate open source materials from Massachusetts Institute of Technology (MIT) OpenCourseWare (OCW) site into Chinese and Taiwanese. The most unique aspect of the OOPS is that it originated as a group comprised solely of volunteers of Chinese and Taiwanese speakers from various regions of the world. In the conception of the project, the participants' collective identity as a 'grassroots movement' and the technology enabling the formation of an online network amongst diverse groups of 'Chinese' speakers played a key role in its success. The emergence of a community of practice (COP) composed of volunteer members for the purpose of global education is highly unique, but will likely become increasingly common as access to the Internet, and the plethora of open educational resources within it, increases around the globe. This particular study, therefore, is significant in providing an initial window into how such a global education COP forms and later thrives. 
OOPS, Turning MIT Opencourseware into Chinese: An analysis of a community of practice of global translators

Lee, Lin \& Bonk

The negotiation of meaning in this community takes place on two levels: 1) the act of translation of the MIT contents, and 2) the act of 'interpretation' of their practice of translation. Much of this negotiation is centered on understanding the process of translation as well as sustaining the OOPS as an effective volunteer organization. Focusing on the formation of and the activities within the OOPS community, this paper presents a story of the efforts and work behind this unique community and how the participants make sense of their work as a part of a larger open courseware initiative. As indicated, we utilize Wenger's (1998) ideas related to communities of practice to frame our analysis and discussion.

The paper is organized in the following way: first, a selective overview of the theoretical discussion around communities of practice is introduced. Second, data from the study is presented where the analysis shows the key components of community of practice as manifested uniquely within OOPS. Third, the interpretations on these findings are presented along with future implications for both the OOPS and other similar communities.

\section{Framing the Study}

\section{Communities of Practice}

Recent learning theories emphasize the importance of collaboration, interaction, and discussion in learning. In social theories of learning, which ideas related to communities of practice are based on, learning is best understood from analyzing participation in social enterprises (Thomas, 2005). These social enterprises need not be physical ones, however. In fact, with the emergence of online communities, scholars have increasingly focused their attention on the variables impacting the effectiveness of virtual communities (Bonk, Wisher, \& Nigrelli, 2004; Castells, 2001; Jones, 1997; Rheingold, 2000; Smith \& Kollock, 1999). Wenger's (1998) Communities of Practice framework has been employed to better inform studies of such electronic communities. Communities of practice are groups of people who share a passion or concern for something they do. They learn by engaging in the practice and improving it through interactions with others in the community (Wenger, 1998).

A significant amount of studies have been conducted on various aspects of communities of practice. For instance, some scholars in the COP field have provided overviews of the research (Johnson, 2001) and delineated key principles or components of a COP (Bonk, Wisher \& Nigrelli, 2004). In a recent book chapter, Bonk and colleagues (2004) listed ten key principles of a community of practice (e.g., sharing goals, trust and respect, shared history, identity, shared spaces for idea negotiation, influence, autonomy, team collaboration, personal fulfillment, and events embedded in real world practices, and rewards, acknowledgements, and fulfilling personal needs) and the associated online technologies and activities that can support their development. For example, a sense of shared goals, purpose, and mission can be facilitated through activities to create team or community logos and mottos, or vision statements as well as technologies such as help systems, online calendars, site announcements, and streaming videos from community leaders discussing the mission of the community. The development of community identity, sustaining diverse membership, and the growth of expertise in the community, might be fostered through celebration of individual and team accomplishments in that community as well as global chats among the members and other special events. To help develop such identity, there might be synchronous group meetings as well as a designated website or portal for the community to which members could contribute as well as get needed information and knowledge from. 
OOPS, Turning MIT Opencourseware into Chinese: An analysis of a community of practice of global translators

Lee, Lin \& Bonk

As indicated earlier, since Wenger's landmark book, there has been much research in the field of virtual online communities. Other COP-related research has addressed issues and typologies of virtual communities of practice (Baek \& Barab, 2005; Barab, Kling \& Gray, 2004; Dubé, Bourhis \& Jacob, 2006; 2005), motivations for participation (Wasko \& Faraj, 2000), aspects of voluntary communities of practice (Donaldson, Lank \& Maher, 2005), components of global knowledge sharing (Pan \& Leidner, 2003; Donaldson, Lank \& Maher, 2005), and COP success factors (McDermott, 2001). Still other COP scholars have begun to offer a critical discussion related to designing online communities of practice (Schwen \& Hara, 2003).

Schwen and Hara (2003) mention that COPs foster the articulation of "everyday problems of dilemmas of practice” (p. 167). Hara and Kling's (2002) study of two public defender offices revealed that communities of practice display a sense of shared vision, a supportive culture when problems or issues arise, a great deal of worker autonomy, professional identity, a common practice or set of work procedures, and opportunities to share meaning and collectively build knowledge. Importantly, as will become clear later in this paper, many of these same principles, activities, and technologies are evident in the OOPS community. As everyday practices are often used to exhibit the formation of communities, we will focus on the three dimensions of practice: 1) mutual engagement, 2) a joint enterprise, and 3) a shared repertoire as they are manifested in the community of OOPS (Wenger, 1998). In the following section, we provide an overview of the Opencourseware movement and a brief history of the OOPS project.

\section{OpenCourseWare (OCW) movement}

Initiated by MIT and its faculty in their effort to provide free and open educational materials to learners around the world, the Opencourseware (OCW) movement represents the new movement to help advance education at the global level. In the case of MIT, the OCW provides visitors with course syllabi, lecture notes, and course calendars for over 1,000 courses. Most of these courses include supplemental materials such as multimedia simulations, problem sets and their solutions, past exams, reading lists, sample student projects, and a selection of video lectures. With its first announcement in April 2001, the MIT OCW pilot site opened to the public in September 2002 and offered 32 courses initially. The site was officially launched in September 2003 with 500 courses online. In 2004, the site received almost 120 million hits from visitors in more than 210 countries, territories, and city-states around the globe.

Many other OCW initiatives have been inspired by the success of the MIT OCW initiative. Utah State University (n.d.) launched its OCW in March 2005, followed by Johns Hopkins Bloomberg School of Public Health in April 2005. These two institutions added additional course materials to MIT's offerings, making the current OCW collection unique around the world. Internationally, six of Japan's top schools also announced their OCW in May, 2005, expanded to ten in June 2007. Other international institutions such as Paris Technology, Universia (i.e., a consortium of universities in Spain and Portugal) have begun their involvements as well (Atkins, Brown \& Hammond, 2007). The growth of the OCW movement has been so fast and far reaching, that the 'OpenCourseWare Consortium' was established in summer of 2006 to keep track of all of OCW developments underway and facilitate the communication and international development of OCW. Its mission statement (OCW, n.d.) reads, "The mission of the OpenCourseWare Consortium is to advance education and empower people worldwide through opencourseware” (ף 2). The OCW Consortium's website tracks the rapid growth of its members, emerging issues, hot discussion topics, and the latest OCW related news. According to an MIT report in June 2006, over 350 of the online MIT courses had been translated and at least 70 mirror sites existed 
OOPS, Turning MIT Opencourseware into Chinese: An analysis of a community of practice of global translators

Lee, Lin \& Bonk

globally. In addition, the MIT course materials had already been translated into at least 10 different languages, including Chinese, Spanish, and Portuguese.

\section{OOPS project}

OOPS is an independent grass roots project, headquartered in Taiwan, designed to translate and adopt Opencourseware OCW for the Great China Region, referring commonly as China, Taiwan, and Hong Kong. The most distinguishing characteristic of OOPS is that the project is mainly run by volunteers in various disciplines, recruited from all over the world (see Figure 1). These volunteers choose ('adopt') courses and translate them.

Figure 1. The Opensource Opencourseware Prototype System (OOPS) volunteers

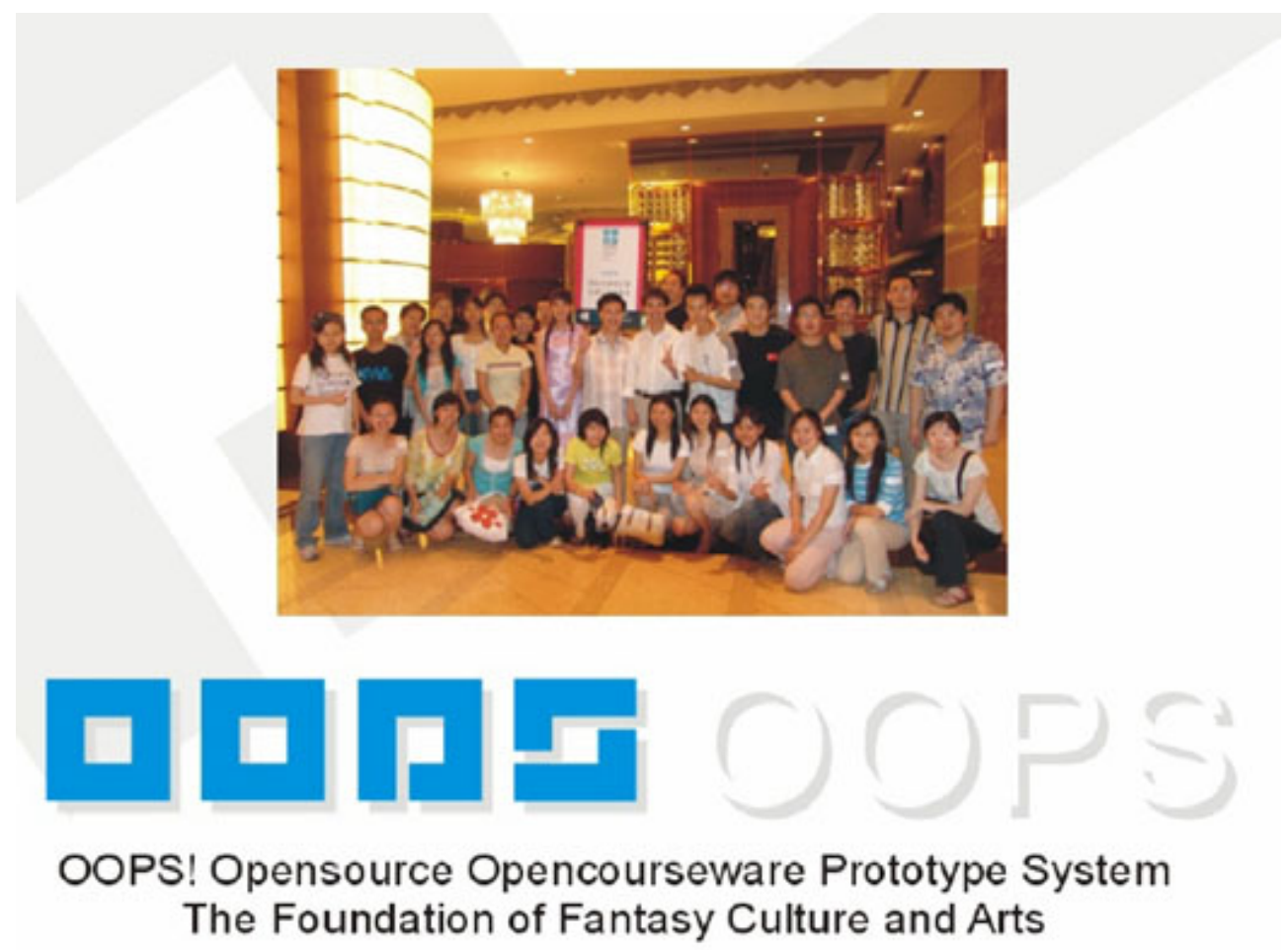

In February 2004, the entire MIT OCW site was copied to a local server hosted in Taiwan, signaling the beginning of OOPS (see Figure 2). Through media coverage, bulletin board postings, and forwarded emails, OOPS quickly attracted volunteer translators in cyberspace. After more than three years of operation, OOPS currently includes materials from MIT, Johns Hopkins Bloomberg School of Public Health, Utah State University, Tufts University, Paris Technology, Japan OCWs, Harvard Extension Schools' podcasts, Public Library of Science, and a unique collection from Professor Harry Bhadeshia's (n.d.) education materials from the Phase Transformations and Complex Properties Research Group. In addition to adding more materials for translation, in late 2006, OOPS successfully secured a two-year grant from the Hewlett Foundation, one of the major funding agencies in the OER movement. This funding clearly acknowledged OOPS' contribution to and growing influence in the global education community. In June 2007, OOPS hosted its first international conference on OCW and e-learning in Taiwan. In this conference, OOPS not only invited OER pioneers to share their first-hand experience with 
OOPS, Turning MIT Opencourseware into Chinese: An analysis of a community of practice of global translators

Lee, Lin \& Bonk

the Taiwanese educational community, it also functioned as a showcase for the three-years of progress and contributions related to OOPS.

Figure 2. MIT OCW mirror site in Chinese
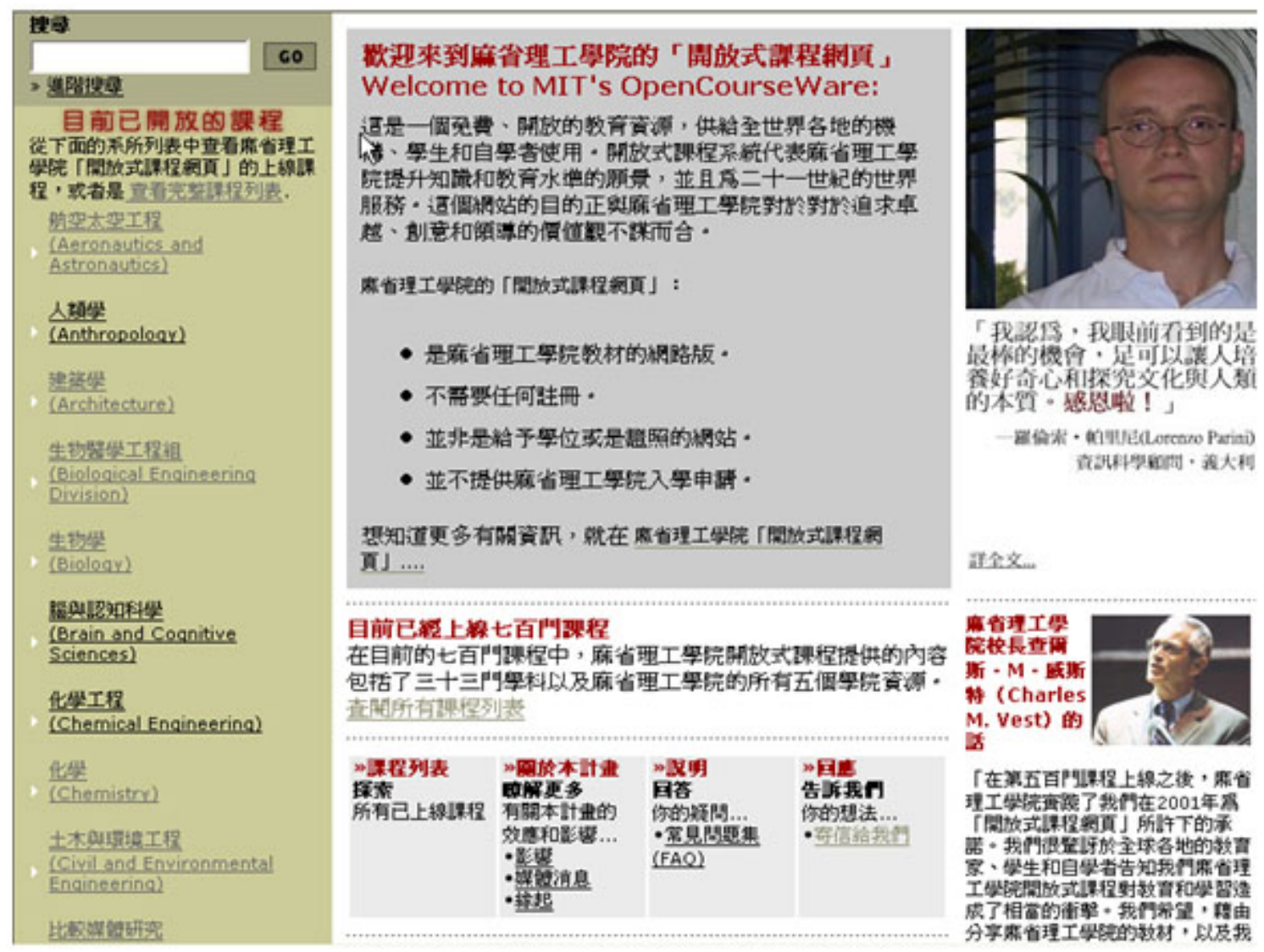

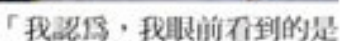

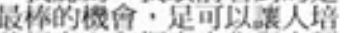
好命心和探究文化與人衫

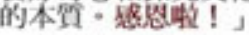

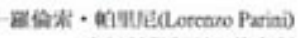

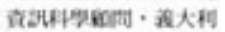

珪金.

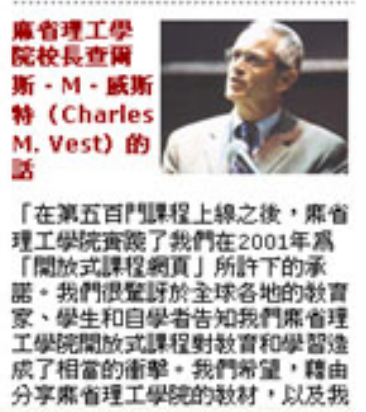

As shown in Figure 3, as of September 2005, of the 1,100 MIT OCW courses, 660 had been adopted for translation at Level One (text), 305 were adopted for Level Two translation (text, video, and audio), 55 courses were completed, and 80 had yet to be adopted. By January 1, 2007 the translation of nearly half of the 1,100 courses had been completed by a network of over 2,200 volunteer translators from more than 22 countries (Lucifer Chu, personal communication, July 18, 2007). 
OOPS, Turning MIT Opencourseware into Chinese: An analysis of a community of practice of global translators

Lee, Lin \& Bonk

Figure 3. OOPS course adoption and completion of MIT OCW courses

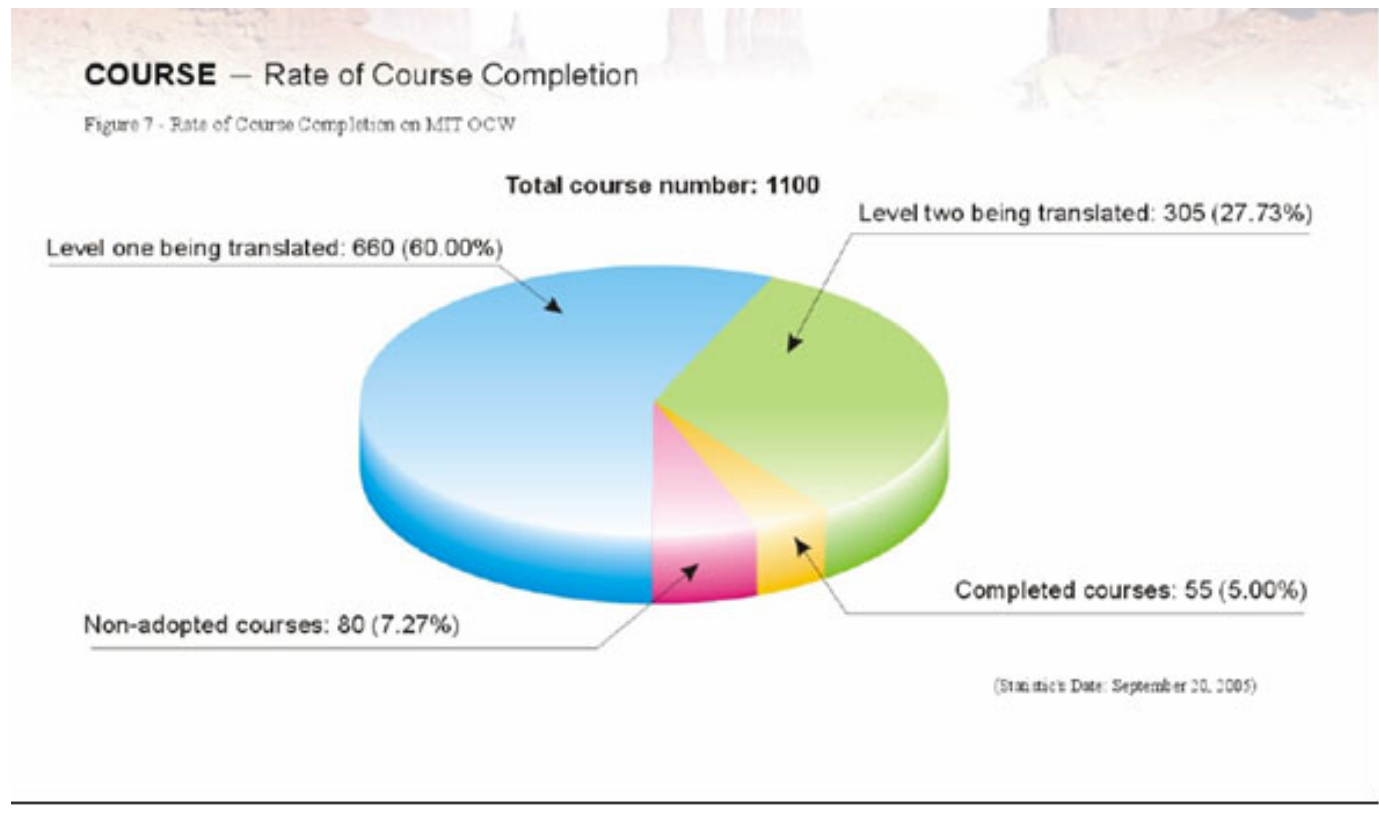

\section{Data Collection and Analysis}

For this paper, three data sources were used: 1) the OOPS online discussion forum, 2) the project website (see Figure 4), and 3) interviews with five participants. This data was originally collected by the second author, and the analysis was later conducted by all the authors using content analysis and story-thread analysis (Lin, 2005) as well as coding methods used in reconstructive analysis (Carspecken, 1996). Content analysis was conducted for online conversations posted between February 2004 and January 2005. A total of 734 threads, or 2,977 responses, were categorized into emerging story lines. These story lines formed the basic understanding of the ecology of this community, which was used as the starting point for participant interviews. 
OOPS, Turning MIT Opencourseware into Chinese: An analysis of a community of practice of global translators

Lee, Lin \& Bonk

Figure 4. List of MIT courses adopted by OOPS volunteers and progress updates

Opensource Opencourseware Prototype System

Opensource Opencourseware Prototype System

開放式課程計劃 www.myOOPS.org

开放式课程计划www.myOOPS.org

Home | I want to volunteer | List of Courses | FAQS | Discussion (Chinese)

\section{List of Courses}

\begin{tabular}{|c|c|c|c|c|c|}
\hline Course ID & Course Name & Professor & $\begin{array}{c}\text { Total }= \\
\text { of } \\
\text { lectures }\end{array}$ & $\begin{array}{c}\text { of } \\
\text { lectures } \\
\text { transcribed }\end{array}$ & $\begin{array}{c}\text { of } \\
\text { lectures } \\
\text { proofread }\end{array}$ \\
\hline \multicolumn{6}{|c|}{ List of courses with complete video and/or audio } \\
\hline usu & Anthropology of Religion & Prof. Richley Crapo & 10 & & \\
\hline 6.002 & Circuits and Electronics & Prof. Anant Agarwal & 26 & 2 & 2 \\
\hline 18.03 & Differential Equations & $\begin{array}{l}\text { Prof. Haynes Miller } \\
\text { Prof. Arthur Mattuck }\end{array}$ & 33 & 2 & 1 \\
\hline EE123 (Berkeley) & Digital Signal Processing & Prof. Avideh Zakhor & 30 & 30 & 30 \\
\hline HST.SOS (audio) & Genomics and Computational Biology & Prof. George Church & 22 & & \\
\hline HST.512 (audio) & Genomic Medicine & $\begin{array}{l}\text { Prof. Isaac Samuel } \\
\text { Kohane et. al. }\end{array}$ & 20 & & \\
\hline 7.012 & Introduction to Biology & $\begin{array}{l}\text { Prof. Eric Lander } \\
\text { Prof. Robert Weinberg } \\
\text { Dr. Claudette Gardel }\end{array}$ & 35 & 6 & 4 \\
\hline 3.091 & Introduction to Solid State Chemistry & Prof. Donald Sadoway & 35 & 1 & \\
\hline 18.06 & Linear Algebra & Prof. Gilbert Strang & 34 & 18 & 11 \\
\hline 18.085 & Mathematical Methods for Engineers & Prof. Gilbert Strang & 32 & & \\
\hline
\end{tabular}

Participant interviews were primarily conducted between April 2005 and December 2005, with some follow-ups via emails or online chats. Participants were invited based on: 1) the second author's first-hand involvement and observation with the community, 2) the second author's contacts with some of the participants during the volunteer activities, and 3) the understanding gained in the above mentioned content analyses. The number of interviews and the duration of each interviews varied, depending mainly on the availability and enthusiasm of each participant. Some participants were interviewed via Skype (a free online phone service). Such online conversations typically lasted over two hours. Other participants communicated mainly via emails during the research period. A series of interviews with two of the participants were conducted mainly through online chats, some of which lasted a few minutes and some lasted more than an hour.

Trustworthiness was established mainly through the following measures: 1) data triangulation that included data sources such as interviews, online postings, and newsletters from project website, 2) peer debriefing that included discussions of interpretations and conclusions between two authors and with other researchers, and 3) member checking that included sharing documents with the participants. As noted, Wenger's ideas regarding communities of practices guided our analyses. In the following sections, we explore the issues related to mutual engagement, reification, joint enterprise, shared repertoire, legitimate participation, collective identity and harmony, sustaining membership, and leadership in the OOPS community. As will become increasingly evident, each of these respective principles is a vital component of the productivity and livelihood of the OOPS community. 


\section{Communities of Practice in Action}

\section{Mutual Engagement}

\section{"Knowledge is power"}

We learn by participating in the specific, local practices, which in turn are negotiated within broader discourses. In this sense, "the act of knowing involves an interaction between the local and the global” (Wenger, 1998, p.141). The globalization of open educational resources originally shared in one language (e.g., English), such as the MIT Opencourseware initiative, epitomizes such local-global interactions. As a prime example, the OOPS community and their project of translation are engaged in the act of making that link between the Chinese speaking population and the available opencoursewares - i.e., bringing globalized content to local populations. The meaning of the practice of translation and localization of the global contents is discussed, questioned, and further negotiated through the narratives of these volunteer participants.

As a volunteer group, the OOPS community shows an extremely high level of enthusiasm and engagement which can be explained by the organization's grassroots history. The mission statement declared on the homepage indicated:

We wanted to use the spirit of an open source to challenge the groundbreaking idea of knowledge sharing. Our goal is to let more people enjoy the shared knowledge (OOPS Homepage, 2007).

On the discussion forum and through interviews, a sense of idealism among the volunteers was apparent. The OOPS members view their work as an extremely innovative project and take great pride in their participation in 'opening doors' to new information for the enormous non-English speaking Chinese population, contributing to more fair distribution of knowledge and power. For example, the following two excerpts were quoted from OOPS' online discussion forum when volunteers were asked to share their view about OOPS.

As someone once said, "Knowledge is power." .. . I believe that this "power" should be made available fairly and equally to all. It should go to those with the will and the ability to make the best use of it, not just tothose born [the] to right parents. When it is hoarded by a few, social inequality and disharmony result. In addition, knowledge is one of the few commodities that increase the further [if] it is shared. (Ms. J.)

In addition, providing the educational materials whose contents were created by a university of international renown seemed to give a sense of empowerment to these volunteers. Given that Chinese culture holds top tier universities in the United States in especially high regard, there is additional motivation to lend one's talents to such a project. As noted in the quote below, such sentiments are apparent in Mr. A's views about the key role or function of the OOPS.

Make the 'treasure bank' for worldwide Chinese; do our best to equalize access to knowledge; use our skills to promote global prosperity; use technology to create a new knowledge-based society. (Mr. A.) 
OOPS, Turning MIT Opencourseware into Chinese: An analysis of a community of practice of global translators

Lee, Lin \& Bonk

Quoting the line from Spiderman, "with great powers comes greater responsibility,” Lucifer Chu, the founder of OOPS, shared his view about OOPS and called on the volunteers to assume greater social responsibility. Luc's view about the power of knowledge was revealed and supported by the enthusiastic volunteers.

\section{Linked activities in online and offline platforms}

Volunteers' apparent subscription to the goal of OOPS was vocally expressed via the online forum used in OOPS. As Wenger (1998) emphasized, different forms of reification at the organizational level help sustain the energy and help build the collective sense of identity as a group - in effect, the tools, symbols, stories, terminology, and concepts used in a COP reify the practice of it. It was clear from our observations that the OOPS project had such a process of reification. Reification in OOPS helped support the high level of enthusiasm and sense of devotion among the volunteers who entered it. That is, having an electronic forum served as a channel of reification by providing a common place to share and exchange dialogues. Members utilized the online forum for information exchanges, ask questions, and debate hot issues. This would be a good example of reification process being "reappropriated into a local process in order to become meaningful" (Wenger, 1998, p. 60). In addition to utilizing an online forum, OOPS made extensive effort to promote project ideas through traditional media such as radio, TV, and newspapers. All these activities were frequently reported on the project website, online forum, and monthly newsletter sent to subscribers via email.

\section{Joint Enterprise}

\section{Translation quality}

Another key aspect of Wenger's vision for effective creation and sustainability of a COP involves joint enterprise. In a negotiated enterprise, individual situations and responses to such situations will vary among the members; however, member responses to their conditions will be highly interconnected because they are engaged together in the joint enterprise of the practice, bringing a sense of "real and livable" (Wenger, 1998, p.78-79) form to it. In the OOPS project, the practice of translation presented different situations and various individual problems. The responses, however, were closely connected through the community's process of defining the meaning of translation. Aspects of this joint enterprise within the OOPS community could be seen in the example of negotiating translation quality.

With its pride as a volunteer community OOPS has an open-door policy in accepting any volunteers who are willing to participate. For this reason, there have been consistent concerns regarding quality control since it came into existence. In response to this, OOPS established some rules regarding its review process in July 2004, several months into the birth of the organization. The review process requires that each piece of translation work go through the translator and an editor before publishing it online. In other words, OOPS utilizes a pre-publishing review model, a model quite different from that of Wikipedia where edits are done after the entry is posted online. Even with the implementation of this review process, the issue of translation quality was still the most discussed topic in the online forum, continuously manifesting members' concerns. Here are examples of opposing views taken from the forum. 
Wrong knowledge is worse than no knowledge.

[F]or those Chinese who come here just to learn, it would be extremely difficult to achieve any learning with this translation quality.

[I]f quality is to be top priority, OOPS must slow down the translation production process, including assessing the abilities of the translators and the editors.

At the root of the issue of translation quality lies the question of whose knowledge is prioritized and why. How should it be determined and who should determine it? The increasing negotiation of meaning regarding these issues among the members of the OOPS community was evident in the online forum. The two additional issues concerning the quality management within OOPS had to do with informing the visitors of the stages of translation and accommodating the visitors from different regions with different dialects and/ or terminologies (Lin \& Lee, 2006). About the first issue of how quality should be determined and who should determine it, Luc made his position clear:

All web pages are published with both the original English and the Chinese translations. . . All readers are proofreaders. For us, there will never be a finalized version. Everything is forever up for discussion, and modification. (Lin, 2006, p. 14)

The conversation with Mr. A. revealed a different view. When asked if a review by a university professor could guarantee the translation quality, Mr. A. responded in strong affirmative that institutions like the China Academy of Sciences and universities have been regarded as the highest academic standard.

During the interviews, there were some suggestions for establishing standards to help the quality issues in translation. Mr. A., for instance, approached the quality issue through standardizing the terms and concepts and argued for the need for standards "set by the authority." Ms. D., on the other hand, pointed to the editors about the current problems with the translation quality.

To be frank with you, I'm worried about the quality of our editors. I had an unpleasant experience with one of them who actually made my translation look worse. .; . As a result, I ignored 99\% of his revisions not out of arrogance but my principles in keeping the quality of translation. (Ms. D.)

Ms. D. here shares her frustration about an incident where she felt her work was edited to a lower quality. She subsequently asked Luc to remove the aforementioned volunteer editor's name from the editors list. Whether relying on the outside authority (Mr. A.) or getting better editors (Ms. D.), conversations related to improving quality continued in the OOPS forum. Unfortunately, no one was able to propose a final answer to this ever-evolving issue.

The act of translation is an effort to contextualize the meaning into the local culture. It is crucial for volunteers to first understand the meaning of the words (the first level of localization) and then be able to deliver it to the readers within their realm of language (the second level of localization). As participants in the various stages of the translation process define the joint enterprise, their responses to and interpretations of these processes were always being negotiated. In the case of the OOPS project, this negotiation can be explained on two levels: 1) the negotiation of meaning taking place in the very act of translation (definition of words, phrases, 
OOPS, Turning MIT Opencourseware into Chinese: An analysis of a community of practice of global translators

Lee, Lin \& Bonk

idioms), and 2) the negotiation of processes in defining the repertoire of the enterprise. Both processes are collective by nature and reveal the full complexity of mutual engagement (Wenger, 1998). Situations would arise that call for the community's negotiated response to the issues ranging from determining word definitions to more macro issues, such as the possibility of quality control within the project. In the next section, we discuss actual examples of 'negotiated response to the situation' shown in the OOPS.

\section{Right to Criticize? Issues of membership and legitimate 'participation'}

The fact that the membership within the OOPS was based purely on a volunteer basis resulted in some interesting findings. Ms. D., for example, recounted a story where she got extremely angry about the comment of an outsider criticizing the community's lack of quality control. In her defense of the OOPS community, Ms. D. stressed the autonomy of group participation that "nobody force[d]" the volunteers into anything. She went on to emphasize the fact that the volunteers "are not even forced to finish the translation once [they] adopt a course" (Lin, 2006, p. 134). Ironically, the high level of autonomy that defines the sense of a volunteer group, such as OOPS, seemed to act as an impediment to an effective management of quality. Sometimes members of the OOPS community did not seem to take open criticism very well, however constructive it might be. The situation can be seen as an example where "tight bonds can become exclusive and present an insurmountable barrier to entry” (Wenger, McDermott \& Snyder, 2002, p.144). Questions about the quality issues were, at times, interpreted by the translators as personal attacks on their efforts. "I think his comment is an insult to our volunteers" (Ms. D.). She sarcastically called this a "let-us-find-fault activity."

I feel like a group of people going to a basketball game. He would complain how bad the players are playing. If so, why don't you come down and play the game yourself? (Ms. D)

As shown in the example above, a sense of defensiveness was evident that "if you are not participating, you don't have any right to criticize" (Italics ours). The sentiment was based on the fact that the OOPS was already doing everything it could with limited resources, and it needed more volunteers who would 'actually work' rather than provide ideas to make it better. In this sense, the OOPS participants that were interviewed seem to clearly regard the core participation (i.e., translating MIT courses or facilitating the process of translation) as the only legitimate participation within it. An outsider's critique and suggestions were considered 'lip service' and clearly not as a form of 'real' participation. Does an 'outsider' have to earn their right to comment only through actually 'doing' the translation? Can criticism be considered peripheral yet a form of legitimate participation?

In effect, the OOPS community does not seem to recognize that critiques from outsiders, though peripheral, should be seen as participation influencing the identity and sustainability of the community. Criticism and suggestions should be used to bolster the community and make it more useful for additional audiences or uses. As the quote below makes evident, the second author, in her extensive analysis of the OOPS (Lin, 2005), also pondered this issue,

I wholeheartedly agreed with Ms. D. in the notion that outsiders may not be able to understand, due to the lack of hands-on experience, certain aspects of OOPS. However, can I not just enjoy watching a basketball game without really knowing how to play? This reminded me of Wikipedia. Do people who consider 
Wikipedia as a reference source need to have the knowledge and skill to question the credibility of it?

As emphasized by Wenger (1998), "communities of practice can connect with the rest of the world by providing peripheral experiences" (p. 117). It is important to offer them "various forms of casual but legitimate access to a practice without subjecting them to the demands of full membership," which can be interpreted as the community's ability to have "multiple levels of involvement" (p.117). In this sense, the OOPS community should be able to consider any critique of 'outsiders' as a peripheral form of participation. Their criticism, seen this way, is a first step toward promoting the inbound trajectories, increasing "the degree of permeability" (p. 117) and eventually drawing more full participation from the interested public.

\section{Shared Repertoire}

\section{Logo voting and collective identity}

This community was fashioned by Luc Chu and has been sustained under his strong and steadfast leadership. In many instances, he single-handedly promoted the mission of OOPS resulting in enthusiastic responses from many volunteers from all over the world. His personal charisma and name value were directly responsible for the formation of the OOPS. As shown in the name and logo voting illustrated below, Luc was always the one to initiate the major events calling for the whole community's participation. There was a clear recognition of his leadership and an overall support from the community. In June 19, 2004, Luc created a new thread on the OOPS forum titled "Our name" where he announced, for the first time, the name "OOPS" (see Figure 5). In this forum, Luc wrote:

I contemplated for a while and came up with this name ... this way, it is easier to introduce OOPS to others. We are looking for volunteers who are willing to design a logo for us. We could have a voting later. (Lin, 2006, p. 111)

Figure 5. The OOPS Logo

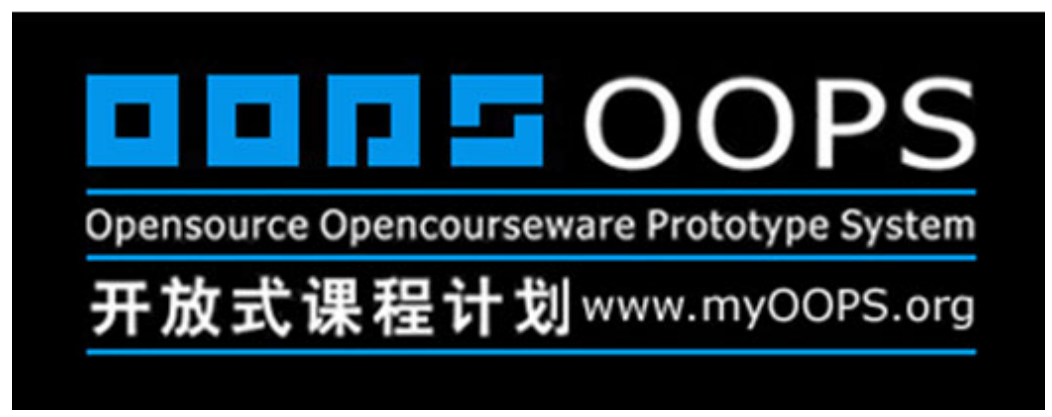

Over the following weeks, many discussions were exchanged. Some participants questioned the appropriateness of the name OOPS; they believed members should think twice about the possible name before even designing a logo. Other participants focused on what the name OOPS meant and if it truly reflected on the inherent mission. The discussion quickly evolved into the design itself where several artist volunteers shared their conceptualization of a logo. The OOPS logo was selected through a community vote which took place in the course of 10 days and right before the planned meeting among the OOPS volunteers worldwide on August 15, 2004. 
Lee, Lin \& Bonk

The logo-voting event originated from the discussions about group identity (i.e., a key aspect of a COP, mentioned earlier) and simultaneously forced group members to more deeply reflect on just what their identity should be. 'Who are we?' the volunteers asked themselves; they could not easily come to an agreement, however. In response to this dilemma, Luc requested that the volunteers submit a logo design and gave a month to do so. Six designs went into voting stage where participants engaged in a friendly campaigning of their favorite design.

The questions and answers between Luc and the other volunteers during this event revealed his hopes and visions of the group's future. He did this by explaining the parts of the acronym OOPS, as well as clarifying any questions that the members had during this process. For example, the second author remembers a conversation with Luc that started out as his reply to her questions about using the term 'courseware.' While the current effort is only focused on the translation of the MIT 'courses,' Luc was envisioning the possibility of Chinese/ Taiwanese open courses in the future. The group took what is regarded as 'advanced' contents from MIT, but he also had high hopes for cross-cultural exchanges: "I wish in the next stage, MIT can get some from OOPS" (Lin, 2006, p. 105). As the group was focused on establishing its sense of identity, the importance of 'branding' was echoed throughout the logo selection process as shown in one participant's posting below.

[A] non-profit organization also needs a strong branding . . . on the Internet, branding becomes even more vital. When we do not have a physical place, the network becomes [where] the organization locates. . . A charitable organization's logo should represent the organization's vision. (Participant posting)

In this sense, the name OOPS not only defined the values and practice of the group currently, it served as a reification of the future direction that could be shared by the whole community. As dissemination of opencourse materials was also a large part of the OOPS' mission, Luc and others saw the need for a good visual identification system and thought it crucial to work toward the branding of their name and logo.

During these discussions about the group name and the branding issues, an interesting incident occurred that revealed the OOPS's attitude or disposition toward conflict avoidance. When Luc created a new thread on the discussion forum, titled "Our name" introducing the name OOPS, someone quickly posted a reply by saying, "Logo is a form of visual communication. Maybe we could incorporate the image of Taiwan, to promote Taiwan to the world, of the image of tolerance (technology + humanity + beautiful island).” Immediately following this message was a jolting one-liner from a volunteer from Mainland China; " Taiwan is not a country." The posting below by Mr. A. is a good representation of the community’s sentiment regarding this incident.

Everyone, stop. If we keep at this issue, there will be trouble. Let's not get to that point. We are from two different places, different social environment, different education [system], and different political party. However, what we are doing collaboratively is for the benefits of the larger Chinese community, not for the debates of the two- China. Can we leave this discussion out? Let's not talk politics...I suggest logo should not carry any political implication. Even though this is a Taiwanese-based project, its goal is for the global Chinese. (Mr. A., italics ours) 


\section{On collective identity and the focus on harmony}

The fact that sensitive issues were avoided and purposefully moved out of discussions points to this community's current emphasis on harmony. When a sensitive topic such as the issue of 'China/Taiwan' arose, the community chose to avoid it and strictly adhered to issues of translation. Similarly, in late 2004, there was an incident where discussions about quality became overheated and quickly turned into flaming between Luc and an anonymous visitor. Luc deleted those 'inappropriate' postings immediately. When questioned later, he regretted that the incident occurred, but empathized that he could not allow some minor disagreements collapse the entire community, a phenomenon he had witnessed first hand in another online community. Such actions are in line with Smith's (1999) finding that people whose view of community is that of harmony and homogeneity see conflict as being disruptive to social integration. They usually try to manage the sources of conflict or argument for greater system unity (Deutsch, 1973; Filley, 1975 cited in Smith, 1999). This tendency toward community harmony is due to the commonly mistaken assumption of peaceful coexistence and mutual support at all times in communities of practice (Wenger, 1998). What is more important for the evolution and maintenance of the COP, however, is for disagreements and challenges to be considered as legitimate forms of participation (Wenger, 1998). This view of disagreements and challenges is not present in the current state of OOPS. On the contrary, OOPS seems to emphasize the importance of politeness in communication.

\section{Discussion}

As shown above, the OOPS community is alive with principles Wenger laid out a decade ago regarding communities of practice. As an example, volunteer translators are quickly recognized as legitimate participants in the translation process. Mutual engagement is seen in the online discussions and interactions among the many volunteer translators of OOPS. They are highly focused to translate MIT course documents to Chinese, thereby providing educational value for the world, which coincidentally, is free and openly accessible. That is their joint mission or enterprise - to better the world. And why not? Knowledge from MIT is, indeed, very powerful, whether it be from courses in chemistry, physics, history, economics, literature, environmental sciences, engineering, architecture, or some other area. There are millions of people who could benefit for the efforts of OOPS community members.

At the same time, they have support from other OOPS members in the online discussion forums. Such forums and associated stories related to difficulties or successes in course translation help reify the OOPS community. In these stories, they share their ideas, successes, tricks of the trade, problems, and overall experiences with each other. OOPS participants might also discuss the quality of the products that they are producing and begin to establish community standards and norms. And when combined with Luc's leadership and decision-making, there is a collective identity and sense of peaceful harmony within the OOPS community. It is a welcoming environment where members can vote on logos, names, and other issues of the community. Despite this democratic flavor, tensions, challenges, and controversial issues are avoided in favor of producing courses for the greater good of society.

Three issues seem key to the sustainability and success of this community: 1) the leadership by Luc Chu within OOPS, 2) the incentives for continued participation within OOPS, and 3) the opportunities for storytelling that can provide support or scaffolds for new OOPS volunteers while capturing the knowledge of experienced ones. It is interesting to point out that each of these 
three areas relate, in some way, to the recognition of the members of the OOPS community - the more senior or experienced individuals as well as the newcomers. It is people that matter and that, in effect, make up any COP. We explore each of these three issues below.

\section{On Leadership}

The common thread that binds all these different aspects of the OOPS as a community, is Luc's leadership whose vision and effort, as mentioned earlier, founded the organization. It was also clear throughout our study that he very much valued the harmony of the OOPS community. One example of such effort is seen by his earlier censoring of potentially controversial topics -i.e., when he removed some postings from the online discussion forum. Such instances of censorship, however, can prevent "occasions for the production of new meanings" (Wenger, 1998, p. 84). Despite the need for some controversy and debate to promote the generation of new meanings, it seems that an online community of volunteers such as OOPS needs a clear and strong leader to cultivate peace and mutual understanding. As with any community, there is perhaps a tension between the stability such leadership offers and the unrestricted or free flow of thoughts and ideas.

\section{On Participation and Incentives}

Judging from the findings, it looks like the very nature of the OOPS as a volunteer organization at times can work against productivity. Because the participants were mostly volunteers, they focus mainly on participation itself. This explains why they tended to move toward the 'easier' tasks (the first level translation of MIT courses - text only) than the 'harder' tasks (the second level translation/ editing - text, audio, and video translation). This was a key reason behind the quality 'problem.' Some measures have been taken to mitigate this problem, however. Luc recently hired several editors whose work will be compensated monetarily so that more difficult course components can be translated and quality standards can be better modeled and established. These editors will help Luc with some of the difficult decision-making within OOPS. Of course, when the community empowers people to make decisions, add to community resources, celebrate accomplishments, and impact on the shared history of the COP as it unfolds, then productivity and performance can be peaked and members of the COP can start to gel, and foster feelings of shared identity and purpose, and coalesce members respective talents and interests.

\section{On Storytelling}

As Orr (1990) points out, "details of practice" are "part of the information circulating in the community memory" (p. 170). In the case of the OOPS, the act of storytelling among the members becomes a crucial means toward establishing the collective memory and shared repertoire. The telling and sharing of stories about their own processes of translation is vitally important to the community for many reasons, including: 1) helping to diagnose the state of trouble concerning emerging problems or situations, and 2) acting as repositories of accumulated wisdom (Brown \& Duguid, 1991). Narratives are central to the growth and survival of communities since they help in "finding or creating meaning in an inherently ambiguous situation" (Orr, 1990, p. 176). In OOPS, the discussion forum serves as the gateway for members to share the repertoires of their practices and form a sense of collective identity as volunteer translators. In order to capture a vast amount of postings and interactions in the OOPS discussion forum, Lin (2005) used a unique method of analysis called "story thread analysis" where 'a 
thread' of postings is used as a unit of analysis. Such methods can document the emergence of a COP as well as its struggles, challenges, key participants, successes, and pressing issues.

At indicated, the OOPS has been highly successful in recruiting new volunteers. The community, however, needs a better system for sustaining old members as many volunteers come for a short stint and then promptly leave. When they depart, so too leaves a valuable knowledge base for translating documents, emotional supports, and perhaps even some of the historical or organizational memory of this COP. While many OOPS participants used the online discussion forum within it to post questions and share their stories, the community could benefit from a more organized archival system capturing and passing down these valuable stories. In this way, participants can have a shared point of reference where the history of mutual engagement is captured. Along these same lines, what seems currently lacking within the OOPS are ways of documenting OOPS policies, procedures, events, and overall history. Such documentation would enhance the sense of identity and shared history within the OOPS, as well as other key principles of a COP.

\section{Future Directions and Implications}

There are many directions for additional research in this area. For instance, other studies might attempt to document key principles or features that were lacking in global education or knowledge sharing communities of volunteers that ceased to exist. Other research might compare COP principles in volunteer and non-volunteer communities where the goal is the creation, dissemination, compilation, or translation of globally shared educational resources. Still other investigations in this area might attempt to document the creative spark or initial impetus for such a COP so that the innovative spirit, ideas, and energy as well as the associated positive individual and community changes can perhaps be promoted in other communities, countries, or regions lacking such initiatives or wishing to advance upon what already has been initiated.

Wherever the research in this area heads, projects, such as OOPS, have massive implications for the open and distance learning field. For instance, they provide a means to repurpose existing online learning materials for those previously lacking of such educational resources and opportunities. With the global translation of educational materials from prestigious colleges, universities, institutions, and organizations in North America, Europe, Asia, and elsewhere, online learners who previously were left at the back door of education can now do much more than peek inside; they can interact with advanced learning materials and share such access with their friends and family. With MIT courses already available in Mandarin as well as English, a huge portion of the world's population can study such materials asynchronously and, perhaps, debate ideas synchronously with their friends, as well as those who they may never physically meet. This is only the tip of the iceberg since translation efforts to still other languages are currently pushing such learning possibilities even further.

Another benefit for the field of open and distance learning is to create a discussion about what resources are most beneficial or important for an online course. As more courses are translated, bottlenecks and inefficiencies in the learning and instructional design process become more apparent. At the same time, global translation will foster greater experimentation with the delivery of online courses and programs. For instance, while there are accreditation, licensing, copyright, and other related issues that need to be addressed, bold and charismatic leaders, such as Lucifer Chu, can create the innovative partnerships necessary for translated courses from MIT and other universities to someday be re-packaged into certificate and other degree programs in 
Taiwan, mainland China, or other countries. Even without such partnerships, a plethora of novel online and distance learning course experiences are already possible.

Of course, once translated, the online course materials are always there. Within minutes of inspiration, adult learners in Beijing, Shanghai, Hong Kong, Hsinchu, or Taipei, can decide to access and learn from courses originally created at MIT. Learners can proceed to learn flexibly, as time allows. When this occurs, translated OCW materials could inspire individuals who have work and family responsibilities to pursue educational opportunities that they previously thought impossible. Enhanced learning is only part of the equation; learning from MIT courses (as well as those from other colleges and universities) could also boost learners' self-esteem and sense of self-worth. At a societal level, the process of translation and the sharing of rich educational materials can foster, and support international relations between east and west and between participating countries or parties. Clearly, mankind benefits as educational opportunities from projects like MIT's OCW and the OOPS are made available to all.

Finally, there are vast implications for the translators. Their shear involvement in projects, such as the OOPS, increases their awareness of online learning resources and can transform their own educational outlooks, appetites, and fire new ambitions. At the same time, OOPS translators may be downloading, translating, and sharing documents as a way of reifying their own practices. They might also use it as a means of promoting their highly unique community of practice to potential translators and support personnel, thereby expanding their joint enterprise. The 'metaawareness' of the importance of sharing and discussing documents within their own community of practice may nudge OOPS translators from local document editing concerns into a higher level of awareness related to educating other translators. As this process of reification occurs, projects such as the OOPS - under the visionary leadership of people like Lucifer Chu - are laying the foundation for other global online educational opportunities and translation communities. Research on such communities during the next few years should prove exciting and critical for the global online open education movement.

\section{Concluding Remarks}

The OOPS is a unique project that has the potential to impact more than one billion people. With the continued expansion and use of Internet technologies and resources for education and training of hundreds of millions of people around the world each day, open educational resources (OER) such as the MIT Opencourseware project and projects like the OOPS which significantly expand upon its original focus, will no doubt play an increasing role in educating the citizenry of this planet. Understanding how such communities are established, cultivated, and sustained perhaps is among the most vital and complex issues that can be addressed today by educators, politicians, and, of course, the learners of this small planet (Wenger, 2004). The coming decade will undoubtedly witness the emergence of innumerable communities of online learners, instructors, translators, instructional designers, and other stakeholders in the OER movement. It is not too surprising that these forms of online communities are not yet fully understood given that such global educational activities were never previously possible; at least not at the speed and intensity that such events are occurring today.

In response to the massive spike in online educational opportunities and global sharing taking place today through many different types and levels of virtual communities, we have attempted to provide a window on one such online community - the OOPS. As some of the earlier quotes and comments indicate, not all aspects of the OOPS community are evolving at a same speed - areas that can be interpreted as a sign of mature community coexist with areas that need to be improved 
OOPS, Turning MIT Opencourseware into Chinese: An analysis of a community of practice of global translators

Lee, Lin \& Bonk

into a mature community. Of course, as alluded earlier, much more needs to be researched and better understood. This is a start. Hopefully, others will become excited by the opportunities and challenges of free and open educational resources, and make their own respective contributions whether it is from a personal course one teaches or a translation of the course materials and resources of someone else. At the same time, those in administrative positions have the power to consider the sharing of entire programs or course catalogs with the world community. In any of these situations, educational progress will have been made and new possibilities will have arisen. As new global education volunteer communities emerge, one can look at the OOPS project for inspiration and modeling of something truly unique and important taking place in education today.

\section{References}

Atkins, D., Brown, J. S., \& Hammond, A. (2007). A Review of the Open Educational Resources (OER) Movement: Achievement, challenges and new opportunities. Retrieved July 15, 2007, from http://www.hewlett.org/Programs/Education/OER/OpenContent/Hewlett+OER+Report.ht $\underline{\mathrm{m}}$

Baek, E. O., \& Barab, S. (2005). A study of dynamic design dualities in a web-supported community of practice for teachers. Educational Technology \& Society, 8(4), 161-177

Barab, S. A., Kling, R., \& Gray, J. H. (Eds.). (2004). Designing for virtual communities in the service of learning. New York: Cambridge University Press.

Bhadeshia, H. (n.d.). Professor Harry Professor Harry Bhadeshia's Phase Transformations and Complex Properties Research Group homepage. Retrieved October 24, 2007 from: http://www.msm.cam.ac.uk/phase-trans/Bhadeshia.html

Bonk, C. J., Wisher, R. A., \& Nigrelli, M. L. (2004). Learning communities, communities of practice: Principles, technologies, and examples. In K. Littleton, D. Miell \& D. Faulkner (Eds.), Learning to collaborate, collaborating to learn (pp. 199-219). Hauppauge, NY.: Nova Science Publishers.

Brown, J. S., \& Duguid, P. (1991). Organizational learning and communities of Practice: Toward a unified view of working, learning, and innovation. Organizational Science, 2(1), 40-57.

Carspecken, P. (1996). Critical Ethnography in Educational Research: A theoretical and practical guide. New York: Routledge.

Castells, M. (2001). Internet Galaxy: Reflections on the Internet, business and society. Oxford: Blackwell.

Chu, Lucifer. Personal communication, July 18, 2007.

Donaldson, A., Lank, E., \& Maher, J. (2005). Connecting through communities: How a voluntary organization is influencing healthcare policy and practice. Journal of Change

Management, 5(1), 71-86. 
OOPS, Turning MIT Opencourseware into Chinese: An analysis of a community of practice of global translators

Lee, Lin \& Bonk

Dubé, L., Bourhis, A., \& Jacob, R. (2006). Towards a Typology of Virtual Communities of Practice, Interdisciplinary Journal of Information, Knowledge, and Management, 1, 6993.

Dubé, L., Bourhis, A., \& Jacob, R. (2005). The impact of structural characteristics on the launching of intentionally formed virtual communities of practice. Journal of Organizational Change Management, 18(2), 145-166.

Hara, N., \& Kling, R. (2002). Communities of practice with and without information technology. Paper presented at the American Society of Information Science and Technology, Philadelphia, PA.

Japan Open Courseware Consortium (n.d.). Japan's Open Courseware Consortium OCW homepage. Retrieved October 21, 2007 from: http://www.jocw.jp/

John Hopkins University (n.d.). Johns Hopkins Bloomberg School of Public Health's OCW. Retrieved October 21, 2007 from: http://ocw.jhsph.edu

Johnson. C. (2001). A survey of current research on online communities of practice. Internet and Higher Education, 4(1), 45-60.

Jones, S. (1997). Virtual culture: Identity and communication in cybersociety. Thousand Oaks , CA.: Sage.

Lin, M. F. (2005). Story Thread Analysis: Storied lives in an online community of practice. International Journal of Instructional Technology \& Distance Learning, 2(9), 61-82.

Lin, M. F. (2006). Building Communities and Sharing Knowledge: A narrative of the formation, development and sustainability of OOPS. Unpublished doctoral dissertation, University of Houston, Houston.

Lin, M. F, \& Lee, M. (2006). E-learning Localized: The case of the OOPS project. In A. Edmundson (Ed.), Globalization in Education: Improving education quality through cross-cultural dialogue (pp. 168-186). Hershey, PA.: Idea Group.

McDermott, R. (2001). How to design live community events. Knowledge Management Review, 4(4), 103-117.

OCW Consortium (n.d.). Open CourseWare Consortium homepage. Retrieved October 21, 2007 from: http://www.ocwconsortium.org/

OOPS (2007). OOPS (Opensource Opencourseware Prototype System) homepage. Retrieved November 9, 2007 from http://www.myoops.org/twocw/

Orr, J. (1990). Sharing Knowledge, Celebrating Identity: Community memory in a service culture. In D. Middleton \& D. Edwards (Eds.), Collective remembering (pp. 169-189). London: Sage. 
OOPS, Turning MIT Opencourseware into Chinese: An analysis of a community of practice of global translators

Lee, Lin \& Bonk

Pan, S. L., \& Leidner, D. E. (2003). Bridging communities of practice with information technology in pursuit of global knowledge sharing. Journal of Strategic Information Systems, 12 (1), 71-88.

Paris Technology (n.d.) ParisTech graduate school homepage. Retrieved October 24, 2007 from: http://graduateschool.paristech.org/

Phipps, G. (2005, May 6). Turning Fantasy into a Reality that Helps Others: Lucifer Chu's obscure interest in fantasy novels ended up making him an unlikely millionaire. Taipei Times, p. 8. Retrieved October 21, 2007 from: http://www.taipeitimes.com/News/feat/archives/2005/03/06/2003225764/print

Public Library of Science (n.d.). Public Library of Science homepage. Retrieved October 24, 2007 from: http://www.plos.org/

Rheingold, H. (2000). The Virtual Community: Homesteading on the electronic frontier. Cambridge, MA: MIT Press.

Schwen, T. M., \& Hara, N. (2003). Community of Practice: A metaphor for online design? The Information Society , 19(3). 257-270.

Smith, M., \& Kollock, P. (Eds.). (1999). Communities in cyberspace. London: Routledge.

Thomas, A. (2005). Children Online: Learning in a virtual community of practice. E-Learning, 2(1), 27-38. Retrieved October 24, 2007 from: http://dx.doi.org/10.2304/elea.2005.2.1.3

Tufts University (n.d.). Tufts University’s OCW. Retrieved October 22, 2007 from: http://ocw.tufts.edu/

Utah State University (n.d.). Utah State University’s OCW homepage. Retrieved October 21, 2007 from: http://ocw.usu.edu

Wasko, M. M., \& Faraj, S. (2000).'It is What One Does': Why people participate and help others in electronic communities of practice. Journal of Strategic Information Systems, 9(2-3), 155-173.

Wenger, E. (1998). Communities of Practice: learning, meaning, and identity. New York: Cambridge University Press.

Wenger, E. (2004). Learning for a Small Planet: A research agenda. Retrieved July 15, 2007 from: http://www.learninghistories.nl/documents/learning\%20for\%20a\%20small\%20planet.pdf

Wenger, E., McDermott, R., \& Snyder, W. M. (2002). A Guide to Managing Knowledge: Cultivating communities of practice. Boston, MA.: Harvard Business School Press.

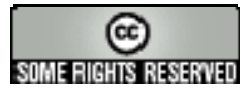


November - 2007

\title{
The Emergence of Open-Source Software in North America
}

\author{
Guohua Pan \\ MacEwan College, Canada \\ Curtis J. Bonk \\ Indiana University, USA
}

\begin{abstract}
Unlike conventional models of software development, the open source model is based on the collaborative efforts of users who are also co-developers of the software. Interest in open source software has grown exponentially in recent years. A Google search for the phrase open source in early 2005 returned 28.8 million webpage hits, while less than two years later that number had jumped to 376 million. This paper discusses the origin of the term open source and the key tenets of the open source software development model. In addition, it analyzes the merits and drawbacks of using this model and discusses the advantages and disadvantages of applying the model in higher education. Importantly, examples are provided of computer software, and course management systems in particular, developed using the open source model. Also included are brief analyses of the Linux operating system, and two open source course management systems, Sakai and Moodle, as well as the uPortal. A timeline of major open source projects of significance in North America is provided. The paper concludes with a discussion of the potential for applying the open source software development model to open and distance education.
\end{abstract}

Keywords: open source, Bazaar model, redistribution, untapped resources

\section{Introduction}

In recent years interest in open source has grown exponentially. In mid January, 2005 a Google search of the phrase open source returned approximately 28.8 million webpage hits (Kapor, 2005). That number jumped significantly to 376 million when a Google search was conducted on October 12, 2006. Given recently difficult monetary times, there is keen interest in higher education and corporate training related to the use of open source software. Some organizations and institutions are choosing such tools as podcasting, wikis, and blogs for their glamour and excitement, as well as open source tools and systems in more mundane areas such as financial systems, enrollment services, and learning management systems.

The open source model of software development, which increased in visibility after Raymond (1997) published his essay "The Cathedral and the Bazaar," provides an approach to software development that is different from the conventional model of software development. As 
indicated, it promises great potential for the public at large, and for higher education in particular, to use software extensively for effective learning and instruction. Linux has been frequently cited as one of the most successful examples of open source software. A number of colleges and universities in North America have been developing course management software and associated services using an open source development model.

Not surprisingly, there are many questions raised concerning the open source movement. For instance, what is open source? How does it work? And what are the implications of the open source development model for learning in general, open and distance education in particular? In seeking to explore some of the answers to those questions, a literature review on open source and learning was conducted . We conducted an extensive Web search on open source and open source learning management systems. We visited the websites of open source learning management systems that we felt were of high importance in open source movement. We interviewed some prominent figures of the open source movement and administrators of some open source management systems for information not available on their websites. We analyzed three examples of course management software developed by colleges and universities in North America using the open source model.

\section{Open Source Software Development}

The label open source code first drew media attention at a strategy session held in Palo Alto, California on February 3, 1998, after Netscape's announcement of the release of Navigator's source code for its Web browser Mozilla (Wikipedia, 2006). Instead of the word 'free' that appears confrontational to business world, Christine Peterson, one of the influential figures of open source movement at the session came up with the pragmatic and business friendly label 'open source.' Also at the session were people in leadership roles in the open source movement, including Todd Anderson, Larry Augustin, John Hall, Sam Ockman, and Eric S. Raymond (Eric Raymond, personal communication, January 31, 2006). The term open source has since been widely adopted to mean any computer software program whose source code is free to its licensed users for use, modification, and redistribution. In effect, open source refers to a product, usually an original computer software program that is "of or relating to source code that is available to the public" either partially or in whole (Answers.com, 2005a). This definition of open source deals only with the juridical category of software licenses, that is, with the terms of distribution and redistribution of the software.

More interesting than pinning down a definition of it however, is the development process surrounding open source software. An open source software product differs from commercial software in that an open source software product, tool, or system is "created by a development community rather than a single vendor" and that the users are individuals working independently or affiliated with participating organizations to rewrite the source code (Answers.com, 2005a). Under the open source development model, the licensed users are potential developers who contribute to the development of the open source software code by rewriting the original code. The modified version is revised and then released frequently for further modification. As such, the "source code of open source software is free and available to anyone who would like to use it or modify it for their own purposes" (Answers.com, 2005b). One interesting and unique aspect about open source software is that an organization does not have to wait for a new release of the software for new functions and features. Instead, it can add desired features to the existing program itself. Moreover, the organization can redistribute copies of either the original or the modified program (Wheeler, 2006). 
In summary, Johnson (2005) paraphrases the following criteria for open source definition:

1. Free Redistribution - Copies of the software can be made at no cost.

2. Source Code - The source code must be distributed with the original work, as well as all derived works.

3. Derived Works - Modifications are allowed; however, it is not required that the derived work be subject to the same license terms as the original work.

4. Integrity of the Author's Source Code - Modifications to the original work may be restricted only if the distribution of patches is allowed. Derived works may be required to carry a different name or version number from the original software.

5. No Discrimination Against Persons or Groups - Discrimination against any person or group of persons is not allowed.

6. No Discrimination Against Fields of Endeavor - Restrictions preventing use of the software by a certain business or area of research are not allowed.

7. Distribution of License - Any terms should apply automatically without written authorization.

8. License Must Not Be Specific to a Product - Rights attached to a program must not depend on that program being part of a specific software distribution.

9. License Must Not Contaminate Other Software - Restrictions on other software distributed with the licensed software are not allowed.

There are various advantages of open source. One of the advantages is that it motivates innovation - original source code provides a base for the receivers to begin with while frequent discussion of code improvement results in idea exchanges essential to innovation. In an open source world, original ideas illuminate the receivers' world and provide the spark and motivation to others in the community or conversation to do better.

Another frequently cited advantage is that open source makes available the talent of the world (Johnson, 2005; Kapor, 2005; Robles, 2005; Room 17, 2005; Wheeler, 2006). It is a way to lever those untapped resources because, as Bill Joy, one of the founders of Sun Microsystems stated, "most of the smart people in the world work somewhere else." Since a new software release is frequently conducted immediately after any significant changes are made and anyone can participate in the development and modification of the code, open source is believed to be "fundamentally a more efficient as well as democratic way of developing software" (Kapor, 2005, p. 72).

A third advantage is that open source reduces the cost and helps to create a sustainable economy wherein co-developers' participation in code development is free. This third advantage may be of particular significance to higher education institutions and will be discussed later in this paper.

What makes open source may also break it, however. In open source, the quality of the product is often at risk because anyone can download source code, work on it, and redistribute the 'finished' product. Since there are no guarantees that this new code is of high quality and without problems, the finished product is thus at the mercy of the co-developers' reputation. Equally problematic, the open source product is often left unattended to or forgotten once the original developer decides to no longer fund it and offloads this product as open source for the world community (e.g., e-education for Jones Knowledge, Inc.). As a toddler in the information age, this open source movement is analogous to the old wild west where there were few fences and spotty law enforcement with lots of cowboys on the move looking for greener pastures (Kapor, 2005). A few 
such cowboys rise in fame, but most are faint memories or sudden tragedies of some rival gang. Dead links act like grave stones reminding us of their short existence and untimely deaths.

Another disadvantage is the hidden cost. In many cases there is no technical infrastructure to support some critical requirement or function in the open source product. Additional modifications, and, in effect, more money and other resources, are therefore needed not only to keep the project running but to make others aware of it and enlist their support and services.

\section{The Bazaar Model}

It has been widely accepted that the visibility of the open source development model has been substantially raised since Raymond (1997) put forward the concept of the Bazaar development model (Kapor, 2005; Kivekäs, 2005; Morin, 1998; Robles, 2005; Room 17, 2005; Wheeler, 2006). In his essay "The Cathedral and the Bazaar," Raymond (1997) postulates a new model of software development. He calls this new model or approach the "bazaar model" to distinguish it from the traditional "cathedral model" of software development. In the cathedral model, the software development process is centralized and there is a relatively strong control over who can submit patches to the code and how they are integrated, as well as a rigorous plan for code releases. Under this model, source code is available with each software release, but code developed between releases is restricted to an exclusive group of developers (Wikipedia, 2006).

In contrast to the cathedral model, the central thesis of the bazaar model is that the development of software is distributed and transparent. According to Raymond (1997), users of the operating system are potential developers with different agendas and approaches. Raymond notes that, in effect, the source code of the prototype software is open and released as early as possible to attract co-developers, even though it may have limited functionalities. Besides, the software is released whenever significant changes are made such that the product evolves in an incremental way, enabling co-developers and users to modify and debug it. Other features of the bazaar model include the co-existence of several versions; for example, a production version that is stable, and a development version that is unstable but supplies all the latest functionality. Last but not least, a dynamic decision making structure exists in either a formal or an informal fashion to make strategic decisions (Kivekäs, 2005; Morin, 1998; Raymond, 1997; Robles, 2005).

A criticism of the bazaar model is its oversimplification - any open source project appears the same and will be completed, whether the project is a large scale one with millions of lines of code or a more modest one with thousands of lines (Bezroukov, 2005a). The reality is that the bazaar model is difficult to reproduce and even tough er to predict where it is headed. As a result, there is continued uncertainty as to whether it will ultimately lead to success or failure. In part, this tension arises due to the fact that extremely few projects will excite sufficient interest for software developers to continue working beyond their normal 8-12 hour work (days) (Robles, 2005; Room 17, 2005).

One of the bazaar model's tenets, according to Raymond (1997), is that "given enough eyeballs, all bugs are shallow" ( $\$ 1$ ). This is particularly problematic in the case of kernel development, because the number of highly eager and available co-developers is just one of the necessary factors for successfully debugging a complex system. In terms of Linux, a kernel consists of the core code of the operating system which is responsible for providing secure access to the machine's hardware and to various computer processes. 


\section{Linux and Other Open Source Projects}

Linux, a free computer operating system, has been repeatedly cited as one of the earliest open source projects, and, more importantly, one of the most successful open source models. A key reason for this success is that it presently is the only viable alternative to Microsoft's WindowsNT (Bezroukov, 2005a, 2005b; Johnson, 2005; Machado \& Thompson, 2005 ; Raymond, 1997; Robles, 2005). Linus Torvalds, from Finland, is the creator of Linux. Linux Kernel 1.0, the heart of all Linux systems, was developed and released under the GNU General Public License in 1994. Its source code is freely available to everyone. Amazingly, based on this kernel, hundreds of companies and organizations and an equal number of individuals have released their own versions of the Linux operating system (Linux Online, 2005).

Distributed code development is one of the most frequently cited advantages in the development of Linux. Based on the Linux kernel, the code is re-written by the co-developers who are also licensed users across the world. This distributed development process allows the Linux to tap a talent pool from across the planet with minimal cost while addressing the problems of individual users. Of course, it is the Internet which actually makes this globally-based and locally-focused development process possible.

Another reason for the success of Linux is its large user base. A key reason for the widespread use of Linux is because it can be downloaded for free. And for people, institutions, or organizations unable to download it because of bandwidth, Internet accessibility, or other related issues, it can be obtained from a retailer such as the CD-ROM Shop in Canada for less than CDN \$20. The large number of users has meant that there are a plethora of needs, which forces the development of Linux to become more sophisticated. At the same time, Linux was PC friendly from the beginning, enabling its user base to grow along with the increasing popularity of the PC.

Another critical factor contributing to the success of Linux is the frequent releases of new Linux versions and the parallel debugging by a huge army of co-developers. This creative development process is akin to a Delphi approach or effect wherein the new code is based on the average opinion of many equally expert observers and is deemed to be more reliable than the opinion of one randomly-chosen individual expert observer. There is always an able person or team who amidst the mass of talented co-developers can fix a tricky problem (Raymond, 1997). Duplication is minimized in Linux since fixes or patches are propagated and fed-back as quickly as possible so that any inefficiency resulting from the duplication of parallel debugging is limited, if not eliminated (Raymond, 1997). At the same time, parallel development in Linux is feasible because over half of the code in Linux developed by co-developers correspond to device drivers, which typically are relatively independent of the code kernel (Godfrey \& Tu, 2001). Of course, more critical fixes occur when co-developers are involved in developing a significant change to the code corresponding to the heart of kernel.

Other challenges in using Linux include the necessary technical skills required for a user to run Linux system at its optimum as well as the maintenance costs and security measures to protect the computer from malicious attempts (Pfaffenberger, 2000).

\section{Open Source in Higher Education}

Higher education institutions, and in particular colleges and universities, are places wherein innovation and the free exchange of ideas are fostered (Hilton, 2005). Universities play a central 
role in the creation of new knowledge as well as the transmission, distribution, and ultimate application of it within the economy and society as a whole (Hilton, 2005).

Along with the massive use of information technology (IT) in the classroom, higher education is facing severe financial constraints because an institution's base budget is not only for licensing fees, but also for training and support required for application software (Rhodes, 1999; Wheeler, 2006). For example, in a survey of IT executives from 52 colleges and universities on IT-related issues, the executives responded that pricing and scalability were the most important factors when buying course management systems for their institutions and they all expressed their dissatisfaction with the cost of course management systems from vendors such as WebCT and Blackboard (Hartrey \& Fallon, 2005).

An option for an institution to achieve sustainable economics is to limit changes related to application software so as to reduce the institution's total spending on IT; fewer changes to track and announce, training events, and orientation sessions. Yet, colleges and universities are noted for extensive networks of widely dispersed and talented individuals who are motivated to develop innovative tools, resources, and pedagogical methods, especially those online. As a result, software applications that are constraining or offer limited opportunities for experimentation or creativity are unlikely to be applauded within higher education institutions (Rhodes, 1999).

- Universities and colleges are constantly facing the plethora of challenges and tensions related to utilizing resources that are financially sustainable and, perhaps more importantly, also have underlying standards, while simultaneously developing creative products or software application programs that push the frontiers of the possible (Rhodes, 1999; Wheeler, 2004). A new business model is needed in higher education, and in all educational settings, to address these dual challenges - to utilize the sound products that exist while allocating resources to develop custom products where what is available is insufficient or inferior. The success of Linux, and, more importantly, the model of open source application development on which Linux is developed, appears to be a highly valuable solution for colleges and universities (Johnson, 2005; Raymond, 1997; Wheeler, 2006).

- Following the open source development model of Linux and backed by like-minded software vendors and IT foundations, higher education institutions in North America initiated various open source projects that focus mostly on course management systems and related systems and tools. Some popular and widely known open source tools used in higher education are detailed in Table 1.

Analogous to a 'greenhouse' for growing open source projects, colleges and universities have begun to embrace the open source development model resulting in many new and exciting open source projects and products (Abel, 2005; Wheeler, 2004). One striking feature of those open source projects, as Table 1 illustrates, is that they are mostly open source course management systems, student electronic portfolios, or student information systems that seem specially developed for those in higher education with limited applicability to corporate and government training settings (Abel, 2005). In addition, most well known open source projects in higher education have been undertaken collaboratively by several institutions. Perhaps such development efforts not only utilize the hard work, experiences, and thought power of these institutions but also the ethical models of higher education where strong, collaborative communities of sharing and idea exchange are the norm, instead of hiding one's ideas from competitors (Abel, 2005). 
The Emergence of Open-Source Software in North America Pan \& Bonk

Table 1. The open-source offerings in North America

\begin{tabular}{|c|c|c|}
\hline Project & Institution(s) & URL \\
\hline Apache & Apache Software Foundation & http://www.apache.org/ \\
\hline Atutor & University of Toronto & http://www.atutor.ca/index.php \\
\hline Bazaar & Athabasca University & $\begin{array}{l}\text { http://klaatu.pc.athabascau.ca/cgi- } \\
\text { bin/b7/main.pl?rid=1 }\end{array}$ \\
\hline Chandler OSAF & $\begin{array}{l}\text { Open Source Applications } \\
\text { Foundation }\end{array}$ & http://www.osafoundation.org/ \\
\hline DSPACE & $\begin{array}{l}\text { MIT Libraries and Hewlett- } \\
\text { Packard (HP) }\end{array}$ & http://www.dspace.org/ \\
\hline FEDORA & Cornell and Virginia & http://www.fedora.info \\
\hline Globus & $\begin{array}{l}\text { Argonne National Laboratory, } \\
\text { Chicago, Southern California } \\
\text { Information Sciences Institute, } \\
\text { Edinburgh, Swedish Royal } \\
\text { Institute of Technology, and } \\
\text { Northern Illinois }\end{array}$ & http://globus.org \\
\hline Haystack & MIT & $\underline{\text { http://haystack.lcs.mit.edu }}$ \\
\hline LionShare & $\begin{array}{l}\text { Penn State, MIT Open } \\
\text { Knowledge Initiative, Simon } \\
\text { Fraser, and the Internet2 P2P } \\
\text { Working Group }\end{array}$ & http://lionshare.its.psu.edu/main/ \\
\hline$L R N$ & & \\
\hline Moodle & Moodle partners & http://www.moodle.org \\
\hline $\begin{array}{l}\text { OKI (Open } \\
\text { Knowledge } \\
\text { Initiative) }\end{array}$ & MIT & http://web.mit.edu/oki/ \\
\hline opensourceCMS & $\begin{array}{l}\text { The Open Source Collective, } \\
\text { Inc. }\end{array}$ & https://www.opensourcehost.com/mos452/ \\
\hline $\begin{array}{l}\text { OSPI (Open } \\
\text { Source Portfolio } \\
\text { Initiative) }\end{array}$ & $\begin{array}{l}\text { Carnegie Foundation for the } \\
\text { advancement of teaching, } \\
\text { Delaware, Minnesota, Rhode } \\
\text { Island, and the r-smart group, }\end{array}$ & http://www.osportfolio.org/ \\
\hline PKI & Dartmouth College & $\underline{\text { http://www.dartmouth.edu/ pkilab }}$ \\
\hline Sakai & $\begin{array}{l}\text { Indiana , Michigan, MIT, } \\
\text { Stanford }\end{array}$ & http://www.sakaiproject.org/ \\
\hline Shibboleth & $\begin{array}{l}\text { Brown, Carnegie Mellon, } \\
\text { Columbia, The Ohio State, } \\
\text { Internet2 and the NSF } \\
\text { Middleware Initiative }\end{array}$ & $\underline{\text { http://shibboleth.internet2.edu/ }}$ \\
\hline Uportal & $\begin{array}{l}\text { JA-SIG members Princeton, } \\
\text { UBC, Boston College, } \\
\text { Delaware, and Sun } \\
\text { Microsystems }\end{array}$ & http://www.uportal.org/ \\
\hline $\begin{array}{l}\text { Visual } \\
\text { Understanding } \\
\text { Environment } \\
\text { (VUE) }\end{array}$ & $\begin{array}{l}\text { Tufts University, the Mellon } \\
\text { Foundation }\end{array}$ & $\underline{\text { http://vue.tccs.tufts.edu/ }}$ \\
\hline WeBWorK & University of Rochester & http://webwork.math.rochester.edu/ \\
\hline
\end{tabular}




\begin{tabular}{lll}
\hline $\begin{array}{l}\text { Whiteboard } \\
\text { Wikipedia }\end{array}$ & $\begin{array}{l}\text { SourceForge } \\
\text { Wikipedia, the free } \\
\text { encyclopedia }\end{array}$ & http://whiteboard.sourceforge.net/ \\
\end{tabular}

Note: Table 1 is derived from 3waynet Inc. and the Commonwealth of Learning, 2003; Abel, 2005; Coppola \& Neelley, 2005; Farrell, 2003; Wheeler, 2004; Wikipedia, 2005.

Of the tens of open source projects outlined in Table 1, uPortal is often cited as a successful model (Coppola \& Neelley, 2004; Wheeler, 2004; Yanosky, Harris, \& Zastrocky, 2003). uPortalis a free, sharable "common portal reference framework," which includes “ a set of technical specifications, and software” (Gleason, 2001, p.15).

The framework provides a J2EE portal server (container) and well-defined interfaces that will permit individual institutions to customize the institutional portal by plugging in components in a well-defined and usable manner. The portal specification provides single, sign-on plug-and-play, providing both ease of use (removing the need to sign-on each time an application is accessed) and the ability to implement single sign-on in a way appropriate to the situation. The portal specification defines interfaces for the content suppliers (publishers), allowing for smooth integration of channels and applications. (Gleason, 2001, p.15)

The participating institutions of uPortal are both consumers and developers in that they can publish the content through their institutional portal while consuming the content of interest published on uPortal. An institutional portal may be described as a virtual university, or a onestop service station consisting of "applications that provide a single, intuitive, and personalized gateway to access and to integrate campus-specific information and applications with unstructured data from on and off campus" (Gleason, 2001, p. 14). Typical applications delivered via the portal include campus administrative systems, library information systems, and learning management systems. uPortal is built with Java, XML, JSP and J2EE. There are over 90 participating institutions across the world, including universities from North America: Athabasca University, University of British Columbia, University of Calgary, Columbia University, Cornell University, Dalhousie University, Duke, Memorial, Princeton, University of Saskatchewan, and Yale. Also participating are those in Bristol, Edinburgh, Nottingham, Oslo, and Stockholm within Europe, as well as universities in Hong Kong (i.e., University of Science and Technology), Japan (i.e., Nagoya), New Zealand (i.e., Auckland University of Technology), and Vietnam (i.e., Vietnam National) (uPortal, 2006).

Sakai is another popular open source example in higher education. The Sakai Project is a community source project to produce an open source collaboration and learning environment (CLE). The founding institutions and organizations in the Sakai project include Indiana University, MIT, Stanford University, the Open Knowledge Initiative (OKI), the University of Michigan, and the uPortal Consortium with the support of the Andrew W. Mellon Foundation and the Hewlett Foundation. Following the community source model, each participating institution contributes to the Sakai project by developing "the Sakai application framework and associated CMS tools and components that are designed to work together" ( Sakai, 2005). Specifically, Sakai course management system incorporates the best features of the existing course management systems of CHEF developed by University of Michigan, CourseWork by Stanford, Oncourse by Indiana, and Stellar by MIT, as well as their development experiences. Using that experience, these four institutions have partnered their resources, code, and modules to build even more robust and valuable course management systems, testing and examination software, and other tools for universities around the world. Those applications aim to address the 
common and unique needs of the participating institutions ( Sakai, 2005). Recent data indicate that the number of participants is growing fast with 97 participating institutions in just two years ( Sakai, 2006).

Moodle, an acronym for the Modular Object-Oriented Dynamic Learning Environment, i s yet another popular open source software package designed to help educators create quality online courses (Moodle, 2005a; Wikipedia, 2005 ). Like other open source software, Moodle is free to download, use, modify, and even distribute and sell (under GNU General Public License), all with no license fee. According to information at the Moodle website, one of the main advantages of Moodle over other systems is its strong grounding in social constructionist pedagogy embedded in the features that "support role sharing, allow(ing) each participant to be a teacher as well as a learner” ( Wikipedia, 2005). Instead of being the ultimate source of knowledge or sage, an instructor can role model the type of class culture that they seek to implement and attempt to personally connect with students while addressing their individual needs and experiences. In addition, the instructor in Moodle can moderate or facilitate discussions and activities in ways that help students negotiate ideas and socially interact to meet course learning goals (Coppola \& Neelley, 2005; Moodle, 2005a; Wikipedia, 2005).

Moodle operates without modification on FreeBSD, Linux, Mac OS X, NetWare, Unix, Windows, and any other system that supports PHP, including most Web host providers. Data is stored in a single database: MySQL and PostgreSQL are best supported, but it can also be used with Access, Interbase, ODBC, and Oracle ( Moodle, 2005b; Wikipedia, 2005) .

As of October 17, 2006, Moodle was available in 75 languages, with 1 7,095 sites from 160 countries that had, in fact, registered their Moodle installation (Moodle, 2006). It has been reported that the largest single Moodle site holds over 6,000 courses and enrolls over 45,000 students, and the Moodle installation at Open University of the UK is built for their 200,000 users. (Coppola \& Neelley, 2005; Moodle, 2005a; Wikipedia, 2005).

Although there is increasing interesting in research on open source (Carey \& Gleason, 2006; Downes, 2006a; Hepburn \& Buley, 2006; Huang, Dong, \& Ge, 2006; Iiyoshi, Richardson, \& McGrath, 2006; Quamen, 2006; Stephenson, 2006; Wiley, 2006), most of what we now know about open source is descriptive information about how it works and why it is an important trend. There is limited, if any, information about what implications it has for open and distance learning.

\section{Milestones of, and Approach to,}

\section{the Open Source Movement in North America}

Long before open source became a label to denote collaborative efforts for computer software development in 1998, the socially diverse production model was exercised by engineers and computer scientists when they used open standards such as the Internet Request for Comments (RFC) in their development of the Internet in 1969. RFC consists of a series of notes, policies, and/ or protocols for the Internet (Internet Mail Standard, 2006; RFC.net, 2006; Wikipedia, 2006).

A further look into the approaches of the open source projects reveals that in North America, open source is more an individual initiative derived from personal needs with minimal government support. The free software movement upon which open source is built, for example, 
was initiated by Richard Stallman, a computer programmer who quit his full time job at MIT to develop GNU, the first open source project. Another example is Linux. Linus Torvalds was a university computer science student when he released Linux 0.01, the first computer operating system licensed under GNU General Public License. Linux was the first open source software that became a viable competitor to proprietary software such as the Microsoft Windows system. As a third example, Martin Dougiamas from Western Australia spearheaded the development of the Moodle course management system when he became unhappy with the WebCT and other standard CMS products.

Table 2. Important Open Source Projects in North America

\begin{tabular}{|c|c|c|c|}
\hline Time & Sponsor & Project & Significance \\
\hline 1969 & Internet Society & $\begin{array}{l}\text { Request for } \\
\text { Comments ( RFC) }\end{array}$ & $\begin{array}{l}\text { The de facto exercise of first } \\
\text { open source software } \\
\text { development. }\end{array}$ \\
\hline 1983 & Richard Stallman & GNU project & $\begin{array}{l}\text { Start of free software } \\
\text { movement, on which open } \\
\text { source is built. }\end{array}$ \\
\hline 1991 & Linus Torvalds & Linux & $\begin{array}{l}\text { First viable open source } \\
\text { operating system under } G N U \text {. }\end{array}$ \\
\hline 1995 & Apache Software Foundation & $\begin{array}{l}\text { Apache } \\
\text { Server }\end{array}$ & $\begin{array}{l}\text { Apache was the only viable } \\
\text { open source alternative to the } \\
\text { Netscape web server in } 1995 .\end{array}$ \\
\hline 1995 & $\begin{array}{l}\text { Profs. Arnold Pizer and } \\
\text { Michael Gage at the University } \\
\text { of Rochester }\end{array}$ & WeBWork & $\begin{array}{l}\text { Written in both Perl and LaTeX } \\
\text { code, WeBWork individualizes } \\
\text { problems, provides students } \\
\text { with immediate feedback, } \\
\text { encourages students to make } \\
\text { multiple attempts, and provides } \\
\text { instructors with real-time } \\
\text { statistics for lesson plan } \\
\text { customization. }\end{array}$ \\
\hline 1998 & Mozilla Organization & $\begin{array}{l}\text { Mozilla Application } \\
\text { Suite }\end{array}$ & $\begin{array}{l}\text { First Web browser to release its } \\
\text { source code. }\end{array}$ \\
\hline 1999 & Martin Dougiamas & Moodle & $\begin{array}{l}\text { An open source eLearning } \\
\text { platform that supports social } \\
\text { constructivist epistemology. }\end{array}$ \\
\hline 2000 & $\begin{array}{l}\text { JA-SIG, the Java in } \\
\text { Administration Special Interest } \\
\text { Group, JA-SIG member } \\
\text { institutions }\end{array}$ & uPortal & $\begin{array}{l}\text { A set of Java classes and } \\
\text { XML/XSL documents that can } \\
\text { be customized to produce a } \\
\text { portal for use on campus. }\end{array}$ \\
\hline 2000 & $\begin{array}{l}\text { Bertelsmann Foundation, the } \\
\text { Heinz Nixdorf Foundation, the } \\
\text { Sal. Oppenheim Foundation } \\
\text { and the Department of Science } \\
\text { and Research of the State of } \\
\text { Northrhine-Westphalia }\end{array}$ & ILIAS & $\begin{array}{l}\text { first free software LMS that has } \\
\text { reached SCORM } 1.2 \\
\text { Conformance Level LMS- } \\
\text { RTE3, guaranteeing platform } \\
\text { independent re-use of contents. }\end{array}$ \\
\hline 2001 & $\begin{array}{l}\text { Wikipedia, the free } \\
\text { encyclopedia }\end{array}$ & Wikipedia & $\begin{array}{l}\text { First multi-lingual Web-based } \\
\text { free-content encyclopedia } \\
\text { collaboratively written by }\end{array}$ \\
\hline
\end{tabular}




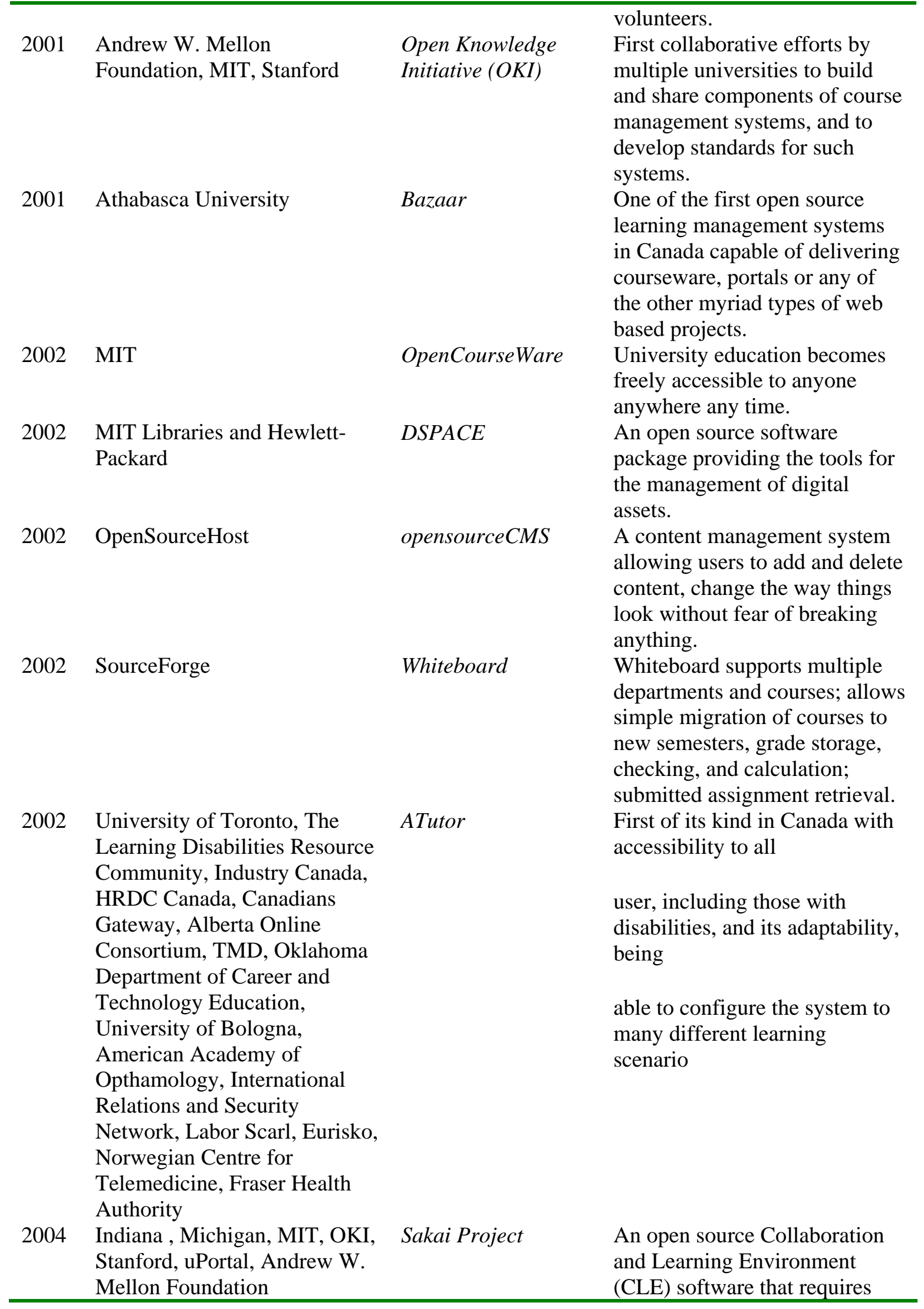




\section{The Open Source Development's Relation With, and Contribution to, Open and Distance Learning}

The 'gift culture' and distributed development might be one of open source development's contributions to open and distance learning. Raymond (1997) notes that, in effect, the source code of the prototype software is open and freely available to the users who are potential codevelopers, even though the source code only has limited functionalities. While the gift culture allows people to access source code freely, distributed development calls those same people, in one way or another, to participate in improving the prototype such that it becomes sophisticated (i.e., with more and stable functionalities). This is a give-and-take process that creates an obligation for people to give back when a gift is given; the values and beliefs of the giver may also be passed on to the recipients. It thus binds people together. As Weber (2004) notes, "the artifact being gifted is not just a functional widget but carries with it some of the giver” (p. 149). This gift culture and distributed development is further manifested in the Open Source Initiative's (2006) introduction to the idea of open source: "When programmers can read, redistribute, and modify the source code for a piece of software, the software evolves. People improve it, people adapt it, people fix bugs.”

This practice of gift culture and distributed development in open source can also be - and may have already been - practiced in open and distance learning. Participants in an online discussion, for example, can post their ideas on a given topic freely while reading peers' ideas on the same topic. The posting of such honest appraisals, supports, and advice is an example of social as well as cognitive presence wherein learners project themselves into a community of inquiry as real people (Rourke \& Anderson, 2002). Their ideas, albeit incomplete and perhaps unsophisticated, function in the same manner as the source code with limited functionalities in open source. Through the same give-and-take practice, that is, by referring to peers' postings, commenting on peer postings, and being commented on by peers, what were once incomplete and shallow ideas now become increasingly complete and sophisticated. In addition to such volunteer contributions, however, motivational measures, such as reputation and/ or status within the system or community, may be utilized to encourage and reward students' contributions to the continued refinement of ideas, as what happened in open source software development. And a mechanism may be established such that people would not feel comfortable if they did not contribute, or contributed even a little. Enabled by the Net, this open source model provides "expanded opportunities for students to plunge ever deeper" into learning and affords "a near limitless means for students to grow their knowledge” ( Anderson, 2004, \13). 
The gift culture and distributed development in open source also shows that it is feasible and effective to build and consolidate an online community. As the evolution of Linux manifests into a community of 'knowledge sharing,' each person will be working on and improving the software. When this occurs, developers and co-developers can increasingly look at things from similar paradigms, and interact with each other and negotiate meanings out of "a common ground of interest and understanding" (Bonk \& Cunningham, 1998, p. 31). This means that meaning must be accepted by the members in the community of practice before it is considered valid. Although each member has their own preference to, or belief in, each and everything, there is a set of important core understandings that members of the community share in common. These shared understandings consist of the norms, values, attitudes, beliefs, and paradigms, or in other words, the culture, in this community of practice. The culture, albeit implicit, thus helps build and consolidates subsequently a community of practice that is grounded on the same experience the members of this community of practice share, and a concomitant knowledge as how they should be able to perform (Cole, 1996; Fisher, Giaccardo, Eden, Sugimoto, \& Ye 2005; Mahoney, 2004).

A community of practice is possible and feasible in open and distance learning too. The values of and beliefs in sharing and distributed development, or the culture, are promoted and reinforced while open and distance learners share their ideas with peers, comment on peers' ideas, and defend their own. Typically, such transactions occur through asynchronous communication tools and are grounded in existing knowledge contexts (Anderson, 2004). Consciously or unconsciously, such open and distance learners use the language and act in ways that are acceptable to them. A culture, thus, begins to form that unites the learners and makes them feel an increasingly sense of belonging to each other.

At the same time, the expanded possibilities afforded by open source model ca $\mathrm{n}$ be overwhelming . It remains a challenge to maintain open and distance learners' interest and commitment to the projects they are in because of the spontaneity feature of participation .

\section{Conclusion}

This paper reviewed the definitions and connotations of open source and the bazaar model of software development. In contrast to software development, acquisition, and use in the past, the two most striking features of the open source development model are distributed development of software and free redistribution of the software copies. As a result, Linux, an open source operating system, is seen as a viable alternative to Microsoft's Windows system. Equally significant, the Internet appears to have been shifting from being a medium for information transmission and consumption to that of a platform through which content is created, shared, remixed, repurposed, and passed along by its participants to potential users (Downes, 2006b).

Like many open source advocates, we discuss uPortal, Sakai, and Moodle, three popular open source projects that are being undertaken by higher education institutions in North America in response to their dual challenges of developing sustainable economics and advancing innovation for application software and other related products in higher education. Given these open source trends of the past decade, and especially the past few years, there are many exciting opportunities for research and development within higher education across the human reaches of this particular planet and beyond.

The 'gift culture' and distributed development enable the success of open source software, such as Linux, and help to build and consolidate a community of practice of open source software developers. This gift culture and distributed development can, and may have already been, 
mirrored in open and distance learning practice, while they may also help to build and reinforce a community of open and distance learners. The spontaneity and expanded possibilities of the open source model can also impact open and distance learners adversely.

\section{References}

3waynet Inc. and the Commonwealth of Learning. (2003, June). COL LMS Open Source. Retrieved October 18, 2006 from: http://www.col.org/colweb/webdav/site/myjahiasite/shared/docs/03LMSOpenSource.pdf

Abel, R. (2005, May 25). Will open source software become an important institutional strategy in higher education? Alliance for Higher Education Competitive website. Retrieved October 31, 2007 from: http://www.a-hec.org/research/indepth_articles/open_source0505/open_source0505_toc.html

Anderson, T. (2004). Toward a theory of online learning. In T. Anderson \& F. Elloumni (Eds.) ,Theory and practice of online learning. Athabasca, AB.: Athabasca University Press. Retrieved October 31, 2007 from: http://cde.athabascau.ca/online_book/ch2.html

Answers.com (2005a). 'Open source movement' from Answers.com website. Retrieved November 1, 2007 from: http://www.answers.com/open-source\&r=67

Answers.com (2005b). 'Open source’ from Answers.com website. Retrieved October 31, 2007 from: http://www.answers.com/open-source\&r=67

Bezroukov, N. (2005a). Open source software development as a special type of academic research (Critique of Vulgar Raymond). First Monday, 4(10), Retrieved November 1, 2007 from: http://firstmonday.org/issues/issue4 10/bezroukov/

Bezroukov, N. (2005b). A second look at the cathedral and the Bazaar. First Monday 4(12), Retrieved November 1, 2007 from: http://firstmonday.org/issues/issue4_12/bezroukov/

Bonk, C. J., \& Cunningham, D. J. (1998). Searching for learner-centered, constructivist, and sociocultural components of collaborative educational learning tools. In Curtis J. Bonk \& Kira S. King (Eds.), Electronic Collaborators: Learner-centered technologies for literacy, apprenticeship, and discourse (pp. 25-50). Mahwah, NJ.: Erlbaum.

Carey, P., \& Gleason, B. (2006). Vision 2010: The future of higher education business and learning applications. Innovate, 3(1). Retrieved October 31, 2007 from: http://www.innovateonline.info/index.php?view=article\&id=314

Cole, M. (1996). Cultural Psychology: A once and future discipline. Cambridge, MA.: Harvard University Press.

Coppola, C., \& Neelley, E. (2004). Open source - opens learning. The R-Smart Group. Retrieved October 31, 2007 from: http://www.rsmart.com/assets/OpenSourceOpensLearningJuly2004.pdf 
Downes, S. (2006a). Places to Go: Intute. Innovate, 3(1). Retrieved October 31, 2007 from: http://www.innovateonline.info/index.php?view=article\&id=398

Downes, S. (2006b). E-learning 2.0. eLearn Magazine. Retrieved October 31, 2007 from: http://www.elearnmag.org/subpage.cfm?section=articles\&article=29-1

Farrell, G . M. (2003, October). A Virtual university for small states of the Commonwealth. Vancouver: The Commonwealth of Learning.

Fisher, G., Giaccardo, E., Eden, H., Sugimoto, M., \& Ye, Y. (2005). Beyond binary choices: Integrating individual and social creativity. International Journal of Human-Computer Studies, 63(4), 482-512.

Gleason, B. W. (2001, June 26). uPortal: A common portal reference framework. Syllabus,14(12), 14-15. Retrieved October 31, 2007 from: http://www.campus-

technology.com/article.asp?id=4136

Godfrey, M. W., \& Tu, Q. (2000). Evolution in open source software: A case study. Retrieved October 31, 2007 from: http://turingmachine.org/opensource/papers/godfrey2000.pdf

Hartrey, P. L., \& Fallon, M. A. C. (2004, November 30). IT issues \& Strategic viewpoints in higher education. Campus Technology. Retrieved November 1, 2007 from:

http://www.campus-technology.com/article.asp?id=10308

Hepburn, G., \& Buley, J. (2006). Getting Open Source Software into Schools: Strategies and challenges. Innovate, 3(1). Retrieved October 31, 2007 from:

http://www.innovateonline.info/index.php?view=article\&id=323

Hilton, J. L. (2005). In praise of sharing. EDUCAUSE Review, 40(3), 72-73.

Huang, K., Dong, Y., \& Ge, X. (2006). From, by, and for the OSSD: Software engineering education using an open source software approach and ideal. Innovate, 3(1). Retrieved October 31, 2007 from: http://www.innovateonline.info/index.php?view=article\&id=32

Iiyoshi, T., Richardson, C., \& McGrath, O. (2006). Harnessing open technologies to promote open educational knowledge sharing. Innovate, 3(1). Retrieved October 31, 2007 from: http://www.innovateonline.info/index.php?view=article\&id=339\&highlight=Iiyoshi

Internet Mail Standard (2006). RFCs and Internet Drafts. Internet Mail Consortium webpage. Retrieved October 31, 2007 from: http://www.imc.org/mail-standards.html

Johnson, K. (2005). A descriptive process model for open-source software development. Retrieved December 16, 2005, from http://sern.ucalgary.ca/students/theses/KimJohnson/chapter2.htm

Kapor, M. (2005). How is open source special? EDUCAUSE Review,40(2), 72-73. 
The Emergence of Open-Source Software in North America Pan \& Bonk

Kivekäs, O. (2005). The Bazaar methodology of software development. Proceedings at Research Seminar on Open Source and Free Software, University of Helsinki, Department of Computer Science, May 15, Helsinki, Finland.

Linux Online (2005). What is Linux? Retrieved November 1, 2007 from: http://www.linux.org/info/index.html

Machado, C., \& Thompson, K. (2005). The adoption of open sources within higher education in Europe and a dissemination case study. Turkish Online Journal of Distance Education, 6(1). Retrieved November 1, 2007 from: http://tojde.anadolu.edu.tr/tojde17/articles/carlos.htm

Mahoney, M. J. (2004). Constructivism. Retrieved February 12, 2006, from http://www.constructivism123.com

Moodle (2005a). Moodle website. Retrieved November 1, 2007 from: http://moodle.org/

Moodle (2005b). Moodle UTF-8 language packs. Retrieved November 1, 2007 from: http://download.moodle.org/lang/?MoodleSession=8b50ac297a877da6658fb575189e95f2

Moodle (2006). Moodle community. Retrieved November 1, 2007 from: http://moodle.org/

Morin, R. (1998, January). Of cathedral and Bazaar. SunExpert Magazine, 9(1). Retrieved November 1, 2007 from: http://www.macperl.com/depts/articles/OCaB.html

Open Source Initiative (2006). Introduction. Open Source Initiative website. Retrieved December 28, 2006 from: http://opensource.org/node/104

Pfaffenberger, B. (2000, March 2). Linux in Higher Education: Open source, open minds, social justice. Retrieved November 1, 2007 from: http://www.linuxjournal.com/article/5071

Quamen, H. (2006). Looking Toward the Future: A case study of open source software in the humanities. Innovate, 3(1). Retrieved October 31, 2007 from: http://www.innovateonline.info/index.php?view=article\&id=325

Raymond, E. (1997). The cathedral and the Bazaar. Retrieved December 9, 2005 from http://www.catb.org/ esr/writings/cathedral-bazaar/cathedral-bazaar/index.html

RFC.net (2006). What is an RFC? RFC.Net website. Retrieved October 31, 2007 from: http://www.rfc.net/

Rhodes, F. (1999). The Gilion declaration. Retrieved December 26, 2005, from http://www.glion.org/?a=6202\&p=1512

Robles, G. (2004). A software engineering approach to Libre software. Germany: Open Source Jahrbuch. Retrieved December 16, 2005, from http://www.opensourcejahrbuch.de/2004/pdfs/III-3-Robles.pdf 
Room 17. (2005). Bazaar source. Retrieved November 1, 2007 from: http://www.room17.com/ramblings/bazaar_src.shtml

Rourke, L., \& Anderson, T. (2002). Using Web-based, group communication systems to support case study learning at a distance. International Review of Research Open and Distance Learning, 3(2), Retrieved November 1, 2007 from: http://www.irrodl.org/index.php/irrodl/article/view/107/186

Sakai (2005). About Sakai. Retrieved October 31, 2007 from: http://www.sakaiproject.org/index.php?option=com content\&task=view\&id=103\&Itemid= $\underline{208}$

Sakai (2006). The Sakai Partners Program . Retrieved October 17, 2006, from http://sakaiproject.org/index.php?option=com_content\&task=view\&id=233\&Itemid=462

Stephenson, R. (2006). Open source/Open course learning: Lessons for educators from free and open source software. Innovate, 3(1). Retrieved October 17, 2006, from http://www.innovateonline.info/index.php?view=article\&id=345

uPortal (2006). uPortal in Production. Retrieved October 31, 2007 from: http://uportal.org/whoprod.html

Weber, S. (2004). The success of open source. Cambridge, MA.: Harvard University Press.

Wheeler, B. (2004). Open source 2007: How did this happen? EDUCAUSE Review, 39(4), 12-27.

Wheeler, D. (2006, April 16). Why open source software / free software (OSS/FS, FLOSS, or FOSS)? Look at the numbers! Retrieved November 1, 2007 from: http://www.dwheeler.com/oss_fs_why.html

Wikipedia (2005). 'Wikipedia’ wiki entry. Retrieved November 1, 2007 from: http://en.wikipedia.org/wiki/Wikipedia

Wiley, D. (2006). Open source, openness, and higher education. Innovate, 3(1). Retrieved November 1, 2007 from: http://www.innovateonline.info/index.php?view=article\&id=354

Yanosky, R., Harris, M., \& Zastrocky, M. (2003). Higher-education E-learning meets open source. Gartner.com website. Retrieved December 28, 2005 from: http://www4.gartner.com/LogNReg/manualLogin 
November - 2007

\title{
Identifying Effective Pedagogical Approaches for Online Workplace Training: A case study of the South African wood products manufacturing sector
}

\author{
Ian S. Macdonald \\ University of British Columbia, Canada \\ Mark Bullen \\ British Columbia Institute of Technology, Canada \\ R. A. Kozak \\ University of British Columbia, Canada
}

\begin{abstract}
This study investigated appropriate pedagogical techniques for workplace e-learning programs in the South African wood products (furniture) manufacturing sector. The study found that learners responded favourably to constructivist teaching approaches, such as asynchronous discussions, open-ended task-based activities, and assignments incorporating authentic, real-world examples. Learners viewed constructivist activities to be more useful than quizzes and traditional essaybased assignments, as they allowed new concepts to be learned in context and were perceived to promote deeper understanding of the subject matter. Nevertheless, they valued the inclusion of a blend of pedagogical approaches in the course design, as this enabled them to approach and analyze new concepts in an assortment of ways. Learners placed importance on regular interaction with other learners and course instructors, and were strongly in favour of including face-to-face components in Web-based courses.
\end{abstract}

Keywords : e-learning; pedagogy; constructivism; workplace learners; corporate training; learning activities

\section{Introduction}

South Africa has one of the best-developed economies and highest standards of living in Africa, and its Internet infrastructure - although poor compared to western industrialised nations - is well-established in African terms (World Bank, 2000). Despite these advantages, it shares many of the challenges that its economically less-fortunate neighbours experience. These include extreme poverty among a large percentage of the population and an unemployment rate that has recently been estimated at 41.2 per cent $^{1}$ (Streak \& van der Westhuizen, 2004). Given the availability of environmentally-certified plantation forest resources, the forest products industry in South Africa offers a potential opportunity to address poverty and unemployment by increasing the domestic production of wood products such as furniture. A major barrier to achieving such 
Identifying Effective Pedagogical Approaches for Online Workplace Training:

A case study of the South African wood products manufacturing sector

Macdonald, Bullen, \& Kozak

growth, however, is a lack of appropriate skills; South Africa's Forest Industry Education and Training Authority states that "78 per cent of the forest industry workforce is either semi- or unskilled, and there are critical shortages of craft or skilled workers, technicians, and professional managers" (FIETA, 2006). New post-secondary and tertiary education programs are being developed in response to this problem, and e-learning is being considered as a delivery mode for industry training programs because it allows for flexible study schedules and eliminates the need for employees to leave the workplace and incur costly travel expenses. Two pilot e-learning courses on forestry for undergraduate learners have been offered by the University of Stellenbosch, South Africa, and students responded favourably to the e-learning format (Längin, Lewark, \& Ackerman, 2004). The results suggest that e-learning may also be an appropriate format for corporate workplace training, which has prompted the present study.

Using a qualitative approach, this research project investigated various pedagogical approaches in order to determine the most appropriate ways of conducting online workplace training in the South African wooden furniture sector. More specifically, it explored whether constructivist teaching and learning was an effective approach. The principal research question of the study was "Is constructivist teaching and learning an effective pedagogical approach for use in Webbased training for adult workplace learners in South Africa?” In addition, a number of secondary questions relating to corporate support for workplace e-learning, adequacy of computer infrastructure in South Africa, and computer literacy requirements were posed, though these are not discussed in this article.

Adult learners are likely to be relatively unfamiliar with constructivist methods of instruction instead, they can be expected to be much more familiar with didactic teaching approaches which are prevalent in traditional school and university environments (Akerlind \& Trevin, 1995). However, if the rationale for the constructivist approach is clearly explained, and learners are given sufficient opportunity to become comfortable with this style of instruction, it is believed that the approach can be both meaningful and effective.

\section{Research Methods}

A qualitative case study approach was selected for this study in order to obtain detailed information in a flexible, semi-structured interview format, and to allow for complex interactional variables that typically occur in learning environments to be taken into account (Cronbach, 1975). A quantitative study of learners enrolled in several courses was deemed inappropriate because it would not allow the researcher to frame problems as open-ended questions (Patton, 1990) or to probe issues which had not been anticipated during the questionnaire design process. Furthermore, the teaching and learning methods employed in the various courses would not be uniform and it would be impossible, in practical terms, to ensure that consistent approaches were being used across all courses. It was decided to adapt a specific e-learning course as the focus of the study so that the researcher was able to control and manipulate all of the key variables related to course design, including the course content, types of learning activities used, presentation of content, assessment criteria, student workload, and the timing of the course. In doing so, the researcher was able to ensure that a diverse range of teaching and learning activities were present for participants to experience and comment upon, so that the project would be as informative as possible.

The course selected for use as the research vehicle was an online, first-year undergraduate course, developed at the Faculty of Forestry, University of British Columbia. This course was intended to introduce students to what is known as the forest products value chain, beginning with the 
Identifying Effective Pedagogical Approaches for Online Workplace Training:

A case study of the South African wood products manufacturing sector

Macdonald, Bullen, \& Kozak

planting and management of forests, introducing the taxonomy of wood products, and then subsequently discussing all of the key manufacturing stages through to the global trade in forest products and the various issues and interrelationships along the supply chain. The course is delivered using the WebCT course management system.

A group of 20 South African workplace learners were selected to participate in the course, which was 14 weeks in duration. This sample size was chosen as it was manageable enough to allow for detailed, one-on-one interviews with each participant to be conducted before and after the course, yet still yielded a varied range of opinions and experiences. During the course, WebCT server logs, quiz scores, and grades for other assessed activities were monitored by the researcher ${ }^{2}$. Candidates for the study were identified with the help of regional human resources managers. Participants were required to have computer experience and to be working in occupations that were relevant to the subject matter of the course being offered. While human resources managers disseminated information about the course to suitable candidates, participation was voluntary. Consent forms were obtained from all of the participants, and the study was reviewed and approved by The University of British Columbia's Ethics Board.

\section{Adaptation of the E-learning Course}

To prepare for the study, the course content was substantially adapted and augmented so that it was germane to South African participants. In addition, a pedagogical redesign was undertaken with the aim of providing as wide a variety of teaching and learning activities as possible within the same course, while still maintaining a learning environment in which learners could progress comfortably. This involved changing the order of course modules, as some types of content lent themselves more readily to a particular pedagogical approach. It was decided that creating five discrete modules, each based upon a different learning theory and with no common elements, would confuse learners, and consequently, render the study of little use as a framework for evaluating appropriate pedagogies. For this reason, a more gradual, phased tactic was employed, in which a behaviourist approach in the first part of the course led toward a more constructivist, learner-centred approach in the latter half. The behaviourist approach was chosen for the early part of the course because this is the teaching style that is predominantly and traditionally employed in classroom instruction in schools and higher education. It was anticipated that familiarity with this style of instruction would build learner confidence in the early stages of the course. Module-by-module, learning activities were designed to progress smoothly toward a more constructivist approach, with more loosely defined tasks and greater freedom for the students to play a more direct role in their own learning. A constructivist approach - the focus of one of the key research questions of this study - was used in the later modules. Cognitivist principles guided the creation of optional self-test exercises used at various points in the course.

Table 1 describes the pedagogical approaches and learning activities employed in the course. The course did not represent a perfectly linear progression from a behavioural to a constructivist approach, since course content often lends itself to one pedagogical approach more so than another (Tennyson, 2002). A series of short quizzes were created within the WebCT electronic quiz tool, and these were integrated into the first two modules of the course, which were contentdriven and involved highly-structured learning activities testing declarative and procedural knowledge. Online discussion questions were posed in Modules 4 and 5, and were designed to encourage learners to relate personal experiences and perspectives to the course content as a means of developing knowledge in context. Each module contained a major assignment - in the early modules, these focused on testing comprehension of information supplied in the online course text, while later modules promoted independent research and the social exchange of ideas 
Identifying Effective Pedagogical Approaches for Online Workplace Training: A case study of the South African wood products manufacturing sector

Macdonald, Bullen, \& Kozak

to achieve authentic project-based tasks. Modules 1 and 3 also contained short optional exercises within the online text pages that encouraged learners to augment the information presented in the online text pages with their own relevant experiences.

Table 1. Pedagogical Approaches and Learning Activities employed in the Course

\begin{tabular}{|c|c|c|}
\hline Module & Pedagogical Approach & Learning Activities \\
\hline $\begin{array}{l}\text { 1. Forest } \\
\text { Management } \\
\text { Issues and } \\
\text { Practices }\end{array}$ & $\begin{array}{l}\text { Followed a behavioural/ } \\
\text { transmissive approach that } \\
\text { promoted leaming in small, } \\
\text { controlled steps and relied } \\
\text { on a designated source of } \\
\text { content information (course } \\
\text { website, supporting PDF } \\
\text { documents). Emphasis on } \\
\text { acquisition of declarative } \\
\text { and procedural, rather than } \\
\text { contextual, knowledge. } \\
\text { Assessed activities measured } \\
\text { internalisation of predefined } \\
\text { set of facts (those supplied } \\
\text { in course website). } \\
\text { Cognitivist principles, in } \\
\text { which new information is } \\
\text { related to prior knowledge } \\
\text { and experience, guided the } \\
\text { creation of optional } \\
\text { exercises provided within } \\
\text { the text. }\end{array}$ & $\begin{array}{l}\text { Short quizzes consisting } \\
\text { predominantly of multiple-choice } \\
\text { questions to test recall of declarative } \\
\text { knowledge (assessed). Exercises } \\
\text { relating personal experience and } \\
\text { opinions to course content (optional, } \\
\text { unassessed). } \\
\text { Assignment 1- review and } \\
\text { summarise values, issues, and } \\
\text { conflicts related to forestry in South } \\
\text { Africa based upon reading a } \\
\text { government website and White } \\
\text { Paper (assessed). }\end{array}$ \\
\hline $\begin{array}{l}\text { 2. Taxonomy of } \\
\text { Wood Products }\end{array}$ & $\begin{array}{l}\text { Followed the behavioural } \\
\text { approach described above. }\end{array}$ & $\begin{array}{l}\text { Short quizzes consisting } \\
\text { predominantly of multiple-choice } \\
\text { questions to test recall of declarative } \\
\text { knowledge (assessed). } \\
\text { Assignment } 2 \text { - provide point-form } \\
\text { answers to a list of questions based } \\
\text { directly upon online course text } \\
\text { (assessed). }\end{array}$ \\
\hline
\end{tabular}


Identifying Effective Pedagogical Approaches for Online Workplace Training: A case study of the South African wood products manufacturing sector

Macdonald, Bullen, \& Kozak

\begin{tabular}{|c|c|c|}
\hline $\begin{array}{l}\text { 3. Primary } \\
\text { Processing of } \\
\text { Wood Products }\end{array}$ & $\begin{array}{l}\text { Transition point between } \\
\text { primarily behaviourist } \\
\text { approach of first two } \\
\text { modules and more } \\
\text { constructivist approach of } \\
\text { Modules } 4 \text { and } 5 \text {. Assessed } \\
\text { quizzes no longer included, } \\
\text { but sets of self-test questions } \\
\text { provided as means of } \\
\text { flagging core concepts that } \\
\text { learners were required to } \\
\text { learn. Assignment tested } \\
\text { leamers' ability to link } \\
\text { concepts introduced in } \\
\text { online text to real-world } \\
\text { contexts, setting the scene } \\
\text { for more flexible and } \\
\text { authentic learning tasks in } \\
\text { later modules. }\end{array}$ & $\begin{array}{l}\text { Self-test questions at end of each } \\
\text { section of content allow learners to } \\
\text { verify whether they can recall key } \\
\text { facts and concepts (unassessed). } \\
\text { Assignment } 3 \text { - describe all of the } \\
\text { main stages in the manufacture of } \\
\text { solid lumber, starting with the } \\
\text { felling of the tree (from online text). } \\
\text { Suggest ways that occurrences at } \\
\text { each stage in the process could } \\
\text { affect the quality of the final product } \\
\text { or of a downstream value-added } \\
\text { product. }\end{array}$ \\
\hline $\begin{array}{l}\text { 4. Secondary } \\
\text { Processing of } \\
\text { Wood Products }\end{array}$ & $\begin{array}{l}\text { Employed a constructivist } \\
\text { approach, still with some } \\
\text { direct instruction (HTML } \\
\text { pages of course content), but } \\
\text { with encouragement and } \\
\text { opportunity for leamers to } \\
\text { go beyond the information } \\
\text { given. Greater emphasis and } \\
\text { validity given to individual } \\
\text { opinions and experience and } \\
\text { third-party online } \\
\text { information sources, versus } \\
\text { the dominance of 'official' } \\
\text { facts provided in the online } \\
\text { course text. Social } \\
\text { interaction and exchange of } \\
\text { information with peers } \\
\text { facilitated via the discussion } \\
\text { forum. }\end{array}$ & $\begin{array}{l}\text { Discussion questions asked learners } \\
\text { to: } 1 \text {. provide opinions on the } \\
\text { meaning of the term "value-added } \\
\text { product" using examples from own } \\
\text { industry, and; } 2 \text {. weigh the economic } \\
\text { versus social impacts of factory } \\
\text { automation in South Africa. } \\
\text { Assignment } 4 \text {-leam ers asked to } \\
\text { conduct independent research that } \\
\text { considered authentic variables in the } \\
\text { furniture manufacturing process, } \\
\text { using suggested Web links and } \\
\text { reputable websites of their choice as } \\
\text { sources of information. }\end{array}$ \\
\hline
\end{tabular}


Identifying Effective Pedagogical Approaches for Online Workplace Training: A case study of the South African wood products manufacturing sector

Macdonald, Bullen, \& Kozak

\begin{tabular}{|c|c|c|}
\hline $\begin{array}{l}\text { 5. Global Trade } \\
\text { in Forest } \\
\text { Products }\end{array}$ & $\begin{array}{l}\text { Employed a social } \\
\text { constructivist approach, } \\
\text { incorporating authentic, } \\
\text { project-based activities and } \\
\text { collaborative leaming, but } \\
\text { based upon well-structured } \\
\text { content and objectives. } \\
\text { Leamers given even greater } \\
\text { flexibility in shaping their } \\
\text { own learning, and } \\
\text { authenticity was } \\
\text { emphasised. Discussion } \\
\text { forum questions allowed } \\
\text { learners to share opinions } \\
\text { and leam from differing } \\
\text { experiences and perspectives } \\
\text { of their peers. Final } \\
\text { assignment was team-based } \\
\text { activity resembling a task } \\
\text { that managers may be asked } \\
\text { to do in the workplace, and } \\
\text { encouraging practical } \\
\text { application of knowledge } \\
\text { gained during the course } \\
\text { within a real-world context. } \\
\text { Chat tools and discussion } \\
\text { forums provided as a means } \\
\text { for groups to communicate } \\
\text { and collaborate. }\end{array}$ & $\begin{array}{l}\text { Discussion questions asked leamers } \\
\text { to: } 1 \text {. exchange opinions on Africa's } \\
\text { future role in global forest products } \\
\text { trade, and; } 2 \text {. comment on a market } \\
\text { analysis report on the South African } \\
\text { furmiture sector. } \\
\text { Assignment } 5 \text {-in pre-assigned } \\
\text { groups of three, leamers asked to put } \\
\text { themselves in the role of } \\
\text { entrepreneurs developing a new } \\
\text { business venture. Leamers were } \\
\text { tasked with creating a mini product } \\
\text { development plan, incorporating } \\
\text { knowledge gained throughout the } \\
\text { course. }\end{array}$ \\
\hline
\end{tabular}

\section{Technological Considerations}

In choosing how information should be presented in the course, it was decided not to rely upon media or applications that required high bandwidth (video, animated simulations, audio) as it was foreseen that this would cause accessibility problems for some learners due to slow modem connections and poor bandwidth. Presentation of content was achieved through text-based HTML pages supported by photos, diagrams, and charts. Supplementary resources, such as third-party reports, were converted to the Adobe PDF document format and optimized such that the file size was as small as possible before posting them on the course website.

\section{Selection of Study Participants}

In selecting a group of learners to participate in the study, it was deemed important to minimize variation with respect to access to technology and corporate policies towards training. For this reason, all of the learners were selected from one large, diversified company. The company chosen was Steinhoff Africa Group Services Ltd., the largest employer in South Africa's wood 
Identifying Effective Pedagogical Approaches for Online Workplace Training:

A case study of the South African wood products manufacturing sector

Macdonald, Bullen, \& Kozak

products sector, with 32 manufacturing facilities dispersed throughout the country. The company actively encourages and sponsors training and further education for its management-track employees, and was interested in evaluating the potential use of e-learning as a training tool because of the challenge of providing standardized training across multiple sites and in many different countries (Geldenhuys, 2004).

Study participants were selected with the assistance of human resources managers within the company. Candidates were recruited on a voluntary basis, but were required to be working in roles in which the course subject matter would be relevant and beneficial, and to have access to and experience in using a computer. The participants were employed in eight manufacturing facilities located close to the three major urban centres of South Africa: Johannesburg, Cape Town, and Durban.

\section{Data Collection}

In June 2005, approximately three weeks before the course began, pre-course interviews, between one hour and 90 minutes in duration, were conducted with all 20 learners at their workplaces. The objective of the pre-course interviews was to obtain a detailed understanding of the learner group in terms of educational and career histories, personalities, experiences with computers and the Internet, and attitudes and beliefs about teaching and learning. Upon the completion of the elearning course in October 2005, the researcher once again scheduled interviews of a similar length at each learner's workplace. The objective of the exit interviews was to obtain detailed qualitative data on the appropriateness of the various learning activities, assess the perceived level of difficulty of the various activities for learners, identify aspects that were particularly challenging or rewarding, and ascertain how well the various learning activities were perceived by the learners to have helped them to learn the materials. Eighteen learners were interviewed in person, and the remaining two, who had been unable to meet with the researcher due to illness and job-related commitments, were later interviewed by telephone. Six human resources and training managers, who between them were responsible for all eight of the factory locations involved in the study, were also interviewed at this time. WebCT server logs were also monitored during the course, but are not reported here as they did not yield useful data in terms of the effectiveness of pedagogical approaches.

\section{Research Findings}

\section{Learner Profiles}

Participants were fluent English speakers employed in supervisory, management-track, or management roles. Learners had varying degrees of familiarity with the course subject matter, depending on their backgrounds and the types of factories in which they were employed. All participants had adequate computer skills, and most used a computer daily. Some learners were unfamiliar with performing information searches on the Internet and using tools such as chat and discussion forums. None had any prior experience with e-learning, but half had taken at least one correspondence course. Learners who had taken correspondence courses generally liked the flexibility afforded by distance learning, but disliked the lack of interaction and tutor support.

Participants tended to place importance on practical learning outcomes and learning that could be readily applied in personal and professional contexts. A possible reason for this is that people who are attracted to careers in manufacturing favour acquisition of such practical knowledge as 
Identifying Effective Pedagogical Approaches for Online Workplace Training:

A case study of the South African wood products manufacturing sector

Macdonald, Bullen, \& Kozak

they have to solve hands-on problems on the factory floor on a daily basis (Felder \& Silverman, 1988). Learners' responses may also have been influenced by the fact that much of the training that they have done is sponsored by their employer and is vocationally-oriented.

As a group, learners described themselves as more outgoing than reserved, much more experimental than traditional, and more flexible than perfectionist. Learners' epistemological outlook was measured by calculating an average score for each respondent based upon their level of agreement or disagreement with a series of 24 statements on the nature of knowledge and learning. The group leaned more towards constructivist tenets than behaviourist, though not strongly so.

\section{Evaluating the Success of Learning Activities Used}

Upon completion of the course, learners identified specific benefits and drawbacks for each learning activity, but overall saw the mix of activities as appropriate. The inclusion of a variety of differing learning tasks helped to stimulate and maintain the interest of learners and promote engagement. These findings support the work of Tennyson (2002), Mishra (2002), and Sfard (1998), who each advocate instructional design models that borrow from multiple theories of learning to match the most appropriate learning activities to the learning task at hand. Approaching the same concepts through different modalities may also strengthen learners' understanding of the course material, and Spiro, Feltovich, Jacobson, and Coulson (1991) suggest that "revisiting the same material, at different times, in rearranged contexts, for different purposes, and from different conceptual perspectives is essential for attaining the goals of advanced knowledge acquisition” (p.28).

The perceived advantages of each learning task/activity are summarised in Table 2, and further discussion of specific benefits and drawbacks is provided below. 
Identifying Effective Pedagogical Approaches for Online Workplace Training: A case study of the South African wood products manufacturing sector Macdonald, Bullen, \& Kozak

Table 2: Participants' Opinions on Perceived Benefits of Learning Activities

\begin{tabular}{|c|c|}
\hline Learning Activity & Perceived Benefits \\
\hline Quizzes & $\begin{array}{l}\text { - Useful for generating keywords or phrases that } \\
\text { can prompt recall of main concepts } \\
\text { - Require leamers to carefully read course content } \\
\text { - Reinforce what leamers have already read and } \\
\text { aid retention } \\
\text { - Prepare leamers for more complex assignments }\end{array}$ \\
\hline Self-test (optional) exercises & $\begin{array}{l}\text { - Promote deeper understanding of new concepts } \\
\text { - Help relate new concepts to personal experience } \\
\text { or real-world contexts } \\
\text { - Can take on an interactive dimension if leamers } \\
\text { are asked to generate questions for each other to } \\
\text { answer }\end{array}$ \\
\hline $\begin{array}{l}\text { Tasks incorporating external } \\
\text { online resources }\end{array}$ & $\begin{array}{l}\text { - Are interesting and motivating in so much as } \\
\text { extemal resources are authentic } \\
\text { - Expand learmers' perspectives on concepts } \\
\text { covered in the course } \\
\text { - Introduce learners to the availability of a wide } \\
\text { range of readily-acces sible information resources } \\
\text { - Validate and reinforce information in course text } \\
\text { - Enhance the online research skills of learmers }\end{array}$ \\
\hline $\begin{array}{l}\text { Tasks incorporating choice } \\
\text { of topic/area of focus }\end{array}$ & $\begin{array}{l}\text { - Are motivating and interesting as a result of } \\
\text { having a choice on what to write about } \\
\text { - Can focus on topics of personal interest or } \\
\text { relevant to their own work }\end{array}$ \\
\hline Discussions & $\begin{array}{l}\text { - Address issues not covered in course content } \\
\text { - Promote a deeper understanding of issues that are } \\
\text { only mentioned in the course } \\
\text { - Place concepts within the context of learners' } \\
\text { own opinions and experiences, making them } \\
\text { more memorable } \\
\text { - Help learers to understand concepts within a } \\
\text { real-world context } \\
\text { - Alter or reinforce learners' perspectives by } \\
\text { offering alternative opinions } \\
\text { - Can be used as a means for learners to discuss } \\
\text { questions or problems with each other }\end{array}$ \\
\hline Group work & $\begin{array}{l}\text { - Is interesting and motivating because of the } \\
\text { authentic nature of the activity } \\
\text { - Provides opportunities to share knowledge and } \\
\text { perspectives with colleagues from other factories }\end{array}$ \\
\hline Face-to-face meetings & $\begin{array}{l}\text { - Motivate learners to keep up with course } \\
\text { requirements } \\
\text { - Facilitate the coordination of group work } \\
\text { - Allow for human contact and natural interaction } \\
\text { with peers }\end{array}$ \\
\hline
\end{tabular}


Identifying Effective Pedagogical Approaches for Online Workplace Training:

A case study of the South African wood products manufacturing sector

Macdonald, Bullen, \& Kozak

Most learners found that the short online quizzes were useful in encouraging them to carefully read and review the online course text, and they were also seen to be helpful in building a base of knowledge that could be expanded upon through more complex assignments that required higherorder thinking. Several learners proposed that short quizzes also generated keywords that triggered the recall of the main concepts covered in the course text. This function is similar to that described by Ausubel (1968), who proposes that memory is organised in a hierarchical structure in which anchoring ideas - the strongest and most inclusive concepts within an individual's cognitive structure - provide points for new information to enter and to be assimilated into that structure. If the online course text is structured carefully so that basic concepts are covered first and augmented by more sophisticated material, it is possible to structure quizzes such that questions trigger recall of (and thus, reinforce) the anchoring ideas of the course.

An alternative role for quizzes in online courses is to prepare students for the coming module of content rather than to serve as a review of the content just covered. For example, students could be asked their opinions on various issues related to a topic that will be discussed in an upcoming module. Model answers could provide summaries of the differing perspectives on each of these issues, serving as an introduction to the concepts to be covered in the module. This approach encourages learners to reflect upon their existing knowledge and ideas relevant to the new content to be covered. In doing so, learners are encouraged to relate new information to their relevant existing knowledge and experience (Ausubel, 1960).

The optional self-test questions and exercises in the online text were regarded by learners to be useful in providing ways to relate the concepts being discussed to personal experiences. Participants stated that the most important role of such questions was to make them 'stop and think' about a given concept in greater depth than would be achieved simply by reading course notes. While time-strapped learners skipped over such exercises to focus instead on the assessed tasks, the inclusion of such questions within the course text appears to be a simple and effective means of promoting a deeper understanding of important concepts for those learners with the time and interest to take advantage of them.

Learners saw many benefits in pursuing tasks that incorporated the use of external Web-based sources of information. The authentic nature of third-party websites was noted as a motivating factor, and such sources served to validate, reinforce, and enhance the online course text or provide useful alternative perspectives. Activities involving external Web resources also enhanced learners' skills in conducting Internet-based research, and opened learners' eyes to the wealth of information available to them online. The perceived drawback of such activities was the greater time requirement, as learners typically reported that finding and evaluating information from online sources was much more time-consuming than writing an assignment based on information in the online course text. The need for extra time was exacerbated by the slow download speeds of many South African websites and company networks. For this reason, it may be prudent for course designers, in certain contexts, to restrict the number of learning tasks in any one course that require learners to access external websites. A possible time-saving solution is to post excerpts or copies of documents from external sites on the course Web server and link them to the course text. While this would be more convenient for some learners, it does reduce the perceived authenticity of the information source, and prevents learners from developing Internetbased research skills. This trade-off is one that must be carefully considered by the instructional designer.

Online asynchronous discussions were seen as a stimulating way of allowing learners to consider a range of perspectives beyond that of the course author. The discussions provided a means for 
Identifying Effective Pedagogical Approaches for Online Workplace Training:

A case study of the South African wood products manufacturing sector

Macdonald, Bullen, \& Kozak

topics introduced in the course text to be explored in greater depth, and for new issues to be raised and debated. Learners saw significant value in having to frame the concepts raised in the course within the context of their own experience and opinions, and stated that doing so made those concepts more memorable. Reading the differing perspectives of peers was also regarded as worthwhile, as it reinforced or altered learners' own views and often augmented their knowledge. Lastly, the discussion forum was seen as a medium through which learners could help each other with any problems that they were experiencing during the course.

The group assignment was found by most learners to be a useful and appropriate learning activity, and the authentic nature and interactive dimension of the task drew positive comments similar to those made about the discussion forum and use of external Web-based resources. Many learners, however, were discouraged by the complexities involved in communicating with team members who were based in other locations. Learners who were already very busy now had to deal with the differing working hours of group members at other factories. This could be mitigated by creating groups composed of learners based in the same location, so that face-to-face group meetings could occur. Organizing learners into groups earlier in the course to allow more time for preparation may also be prudent.

Most of the study participants suggested that the course could be improved by including a faceto-face meeting component. In addition to simplifying the logistics of group work, holding meetings of course participants in each region may increase motivation to complete assessed tasks on time, and would create the human interaction that is lacking in pure e-learning courses. For a course of three to four months, one meeting per month may be sufficient to yield such benefits. Dagada and Jakovljevic (2004) found that South African facilitators of e-learning courses favoured this kind of blended learning approach, and South African researchers, van der Westhuizen and Krige (2003), also found that participants involved in e-learning expressed a strong desire for face-to-face interaction.

These findings suggest that e-learning can be made more effective when combined with other methods of educational delivery, and this concept is supported by writers such as Gray (2006) who proposes an instructional design model that links instructional delivery methods with the various stages in the learning process and the educational goals that must be met at each stage.

Although there was a general consensus that a mix of learning activities was beneficial, learners did not have a unanimous view on how the course should be structured. The structure used in this study, in which a familiar behavioural approach at the beginning transitions to a constructivist model in the later stages, may be appropriate where learners are taking an e-learning course for the first time. Many learners, however, suggested that short-answer quizzes should be included in all of the modules in order to prepare learners for more open-ended assignments. The choice of learning activities employed should also be dependent on the content and desired learning outcomes for each module.

\section{Conclusions and Recommendations}

This study found that learning activities designed according to the constructivist philosophy are appropriate for online training of adult learners in the South African wood products (furniture) industry. Although such activities were seen to be more time-consuming than short quizzes or assignments based on course notes only, they were believed to promote deeper understanding and better retention of new concepts. 
Identifying Effective Pedagogical Approaches for Online Workplace Training:

A case study of the South African wood products manufacturing sector

Macdonald, Bullen, \& Kozak

The learners who participated in this study tended to place greater importance on practical outcomes than on purely theoretical knowledge. To achieve practical outcomes, it is necessary to apply new knowledge in context, and a dominant belief among constructivist educators is that learning activities must reflect the complex problems that individuals are required to deal with in real life (Driscoll, 2000). The course involved many opportunities for learners to relate concepts introduced in the course to the context of real-world industry issues and to their own personal experiences and those of their peers. This may have been one of the key reasons why such activities were highly valued by the group. Learners regarded quizzes and summary-type assignments as helpful when trying to commit new facts to memory, but constructivist activities were seen to be essential for turning those facts into actionable knowledge. This concept is supported by Brown, Collins, and Duguid (1989), who propose that, if learning is not done within the context of meaningful activity, knowledge will remain untapped even when relevant problems present themselves.

Constructivist activities should not be employed to the exclusion of other approaches, however. Each of the learning activities employed in the course yielded specific benefits, and instructional designers should exploit these to create learning environments that stimulate and engage workplace learners. Based on this case study of South African workplace learners, the following recommendations (with their implications for pedagogy and instructional design) are proposed as a summary of the findings:

1. Workplace e-learning courses should include a mix of tasks and activities that encourage learners to approach new concepts in a variety of ways.

2. Constructivist activities should be used to enable learners to link new knowledge to realworld contexts. For situations in which learners are not familiar with the constructivist approach, the course should begin with behaviourist/ didactic activities in the early stages and move in incremental steps toward constructivist methods.

3. Authentic tasks and research based on external Web research should be included, but instructional designers should carefully consider the time demands on learners when planning overall workloads.

4. Ample opportunities for interaction between students should be created.

5. Face-to-face meetings should be included to minimise isolation and procrastination and to facilitate group work.

This study has considered the specific case of learners involved in manufacturing roles within the South African wood products industry. As mentioned above, the learners' enthusiasm for constructivist pedagogical approaches may be partially attributable to the practical nature of their jobs and their desire to quickly implement newly-gained knowledge to improve workplace performance. Further research comparing workplace learners in a variety of sectors would be useful to ascertain the relative important of such factors in the success of constructivist teaching and learning methods.

\section{Limitations of the Study}

This study is limited by a number of factors. The qualitative approach used is an appropriate means of collecting detailed information on learner attitudes and experiences, but the small 
Identifying Effective Pedagogical Approaches for Online Workplace Training:

A case study of the South African wood products manufacturing sector

Macdonald, Bullen, \& Kozak

sample size means that the results are not statistically meaningful. For this reason, judgments about the usefulness and credibility of the results must be left to the researcher and the reader (Eisner, 1991).

In qualitative research, sampling errors can arise from insufficient breadth in sampling, distortions due to changes over time, or lack of depth in data collection at each site (Patton, 1990). To address the risk of insufficient breadth in sampling, participants from a number of locations, demographic profiles, and job roles were asked to participate in the study. Learning technologies and information and communication technologies change rapidly and, while this study attempted to focus on pedagogical and organisational factors rather than technology itself, it was inherently influenced by such changes. The study attempted to ensure that robust data was collected through the detailed in-depth interviews conducted with each participant.

A limitation of the pilot e-learning course itself is that it was not accredited by the Ministry of Education in South Africa, since it was not feasible to undertake a lengthy application process for the purpose of a one-time, three-month pilot course. This factor may have resulted in lower levels of learner motivation than if the course had been accredited. Lastly, the "pilot program" nature of the course may also have tempted some learners to take the course less seriously than would have been the case if the course had been a training program offered regularly by the company or another external training provider.

\section{Acknowledgements}

The authors would like to thank all of the adult learners who participated in the study, Mr. Craig Stewart at Steinhoff Africa Group Services, and Professor David Cohen, author of the course used in the study. We would also like to acknowledge the funding support of Canadian International Development Agency.

\section{Foot Notes}

1. Although the official Statistics South Africa unemployment figure for the same year was $27.8 \%$, the expanded definition, which includes unemployed people who have given up looking for work, is more commonly cited.

2. To ensure impartiality, grading of participants' assessed work was done by other faculty members at the University of British Columbia and the University of Stellenbosch.

\section{References}

Akerlind, G., \& Trevitt, C. (1995). Enhancing Learning Through Technology: When students resist the change. Proceedings of ASCILITE 95 - Learning with Technology, 3-7 December, Melbourne, Australia.

Ausubel, D. (1960). The use of advance organizers in the learning and retention of meaningful verbal material. Journal of Educational Psychology, 51, 267-272.

Ausubel, D. (1968). Educational Psychology: A cognitive view. New York: Holt, Rinehart \& Winston. 
Identifying Effective Pedagogical Approaches for Online Workplace Training: A case study of the South African wood products manufacturing sector

Macdonald, Bullen, \& Kozak

Brown, J., Collins, A., \& Duguid, P. (1989). Situated cognition and the culture of learning. Educational Researcher, 18(1), 32-42.

Cronbach, L. J. (1975). Beyond the two disciplines of scientific psychology. American Psychologist, 30(2), 116-127.

Dagada, R., \& Jakovljevic, M. (2004). Where have all the trainers gone? E-learning strategies and tools in the corporate training environment. Proceedings of the 2004 annual research conference of the South African Institute of Computer Scientists and Information Technologists on IT Research in Developing Countries. Stellenbosch: South Africa.

Driscoll, M. P. (2000). Psychology of learning for instruction. Needham Heights, MA.: Allyn \& Bacon.

Eisner, E. W. (1991). The Enlightened Eye: Qualitative inquiry and the enhancement of educational practice. New York: Macmillan.

FIETA (2006).Website of Forest Industries Education \& Training Authority (FIETA). Retrieved April 9, 2006 from: http://www.fieta.org.za

Felder, R., \& Silverman, L. (1988). Learning and teaching styles in engineering education. Engineering Education, 78(7), 674-681.

Geldenhuys, J. (2004). Personal telephone conversation, September, 6, 2004.

Gray, C. (2006). Blended Learning: Why everything old is new again - but better. Learning Circuits. Retrieved May 15, 2007 from: http://www.learningcircuits.org/2006/March/gray.htm

Längin, D., Lewark, S. \& Ackerman , P. (2004). Internet-based learning in higher forestry education. UNASYLVA: Forestry Journal of the FAO, 216, 39-44. Retrieved May 8, 2006 from: http://www.fao.org/forestry/site/unasylva/en

Mishra, S. (2002). A design framework for online learning environments. British Journal of Educational Technology, 33(4), 493-496.

Patton, M. Q. (1990). Qualitative evaluation and research methods (2nd ed.). Newbury Park, CA: Sage.

Sfard A. (1998). On two metaphors for learning and the danger of choosing just one. Educational Researcher, 27(2), 4-13.

Spiro, R. J., Feltovich, P. J., Jacobson, M. J., \& Coulson, R. L., (1991). Cognitive Flexibility, Constructivism, and Hypertext: Random access instruction for advanced knowledge acquisition in ill-structured domains. Educational Technology, 31(5), 24-33.

Streak, J., \& van der Westhuizen, C. (2004). Fitting the Pieces Together: A composite view of the government's strategy to ASSIST THE UNEMPLOYED in South Africa 1994 - 2004. 
Identifying Effective Pedagogical Approaches for Online Workplace Training: A case study of the South African wood products manufacturing sector

Macdonald, Bullen, \& Kozak

Institute for Democracy in South Africa, October 12, 2004. Retrieved April 9, 2006 from: http://www.idasa.org.za.

Tennyson, R. D. (2002). Linking learning theories to instructional design. Educational Technology, 42(6), 7-12.

van der Westhuizen, D., \& Krige, H. (2003). Ending the divide between online learning and classroom instruction using a blended learning approach. In P. Kommers \& G. Richards (Eds.), Proceedings of World Conference on Educational Multimedia, Hypermedia and Telecommunications 2003 (p. 2527-2528). Chesapeake, VA: AACE. Retrieved February 28, 2006 from: http://www.editlib.org

World Bank (2000). The digital divide and the World Bank Group. Washington, D.C.: World Bank.

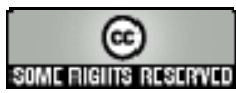


November - 2007

\title{
Re-organizing Universities for the Information Age
}

\author{
David Annand \\ Athabasca University - Canada’s Open University
}

\begin{abstract}
University education is still generally conducted within pre-Industrial Age organizational structures. As a result of their inability to evolve the predominant cohort-based classroom structure to more cost-effectively meet the aspirations of burgeoning worldwide populations for higher education, universities may see substantial organizational changes imposed on them over the next decades by external forces. Emergent forms of university organizational structures are examined that may affect this needed transformation.
\end{abstract}

Keywords: Fordism; industrialization; innovation; Luddite; university change

\section{Introduction}

Peters (2004) noted that paced, cohort-based education continues to be the norm in both traditional and dual-mode universities, even with the advent of online education. This format facilitates communication among learners and between learner and instructor . Peters noted, however, that expert forecasts of trends in online learning suggest an increasing emphasis on digitized instructional material. As a consequence, learning can be more autonomous and selfdirected. This is similar to the independent study form of distance education more predominant in the European experience. Historically, independent study represents a distinct break with classroom-based academic tradition because it is text-based rather than orally based. It is technically mediated and must be carefully planned and structured. Methods of presenting and acquiring knowledge differ from traditional universities. Learners must organize their learning independently, taking over some of the roles of the instructor. They must be more critically reflective in their learning, as there is little or no external intervention, even with the advent of what Peters describes as 'network-based distance education' - learning that provides access to digital media and the Internet, and allows new forms of learning through searching, evaluating, managing, and retrieving material.

A likely consequence of the increased emphasis on digitized media will be to increase learner demand for autonomy, particularly self-pacing - that is the ability to proceed through a course of studies without reference to a pre-determined schedule or other learners. Despite hopes that social interaction incorporating more characteristics of face-to-face instruction will be facilitated in the 'post-industrial' adult distance education era, facilitating significant learner-to-learner interaction requires cohorts of students to move through a course of studies at the same pace. As a result, requirements of social interaction conflict with learner autonomy. 
Re-organizing Universities for the Information Age

Annand

\section{Theoretical Divide over the Role of Interpersonal Communication}

The imposition of pacing as a necessary precursor for virtually all sustained two-way communication at a distance and the unavoidable restriction on learner autonomy that this produces has been at the centre of a relatively distinct divide among theorists since the 1990s. One view represented by Holmberg (1989) and Keegan (1990) conceptualized the important distinguishing feature of distance education as being organizational forms that facilitate learner independence and autonomy through flexible, self-paced learning. On the other hand, others like Garrison (1997) proposed that the advent of cost-effective two-way mediated communication in distance education had shifted emphasis away from these organizational issues toward the educational transaction itself. Significant and frequent interaction between instructor and learner, and among learners, had become the enabling - if not the essential - learning feature of distance education.

The debate remains unsettled. Operationally, though, organizational issues rather than learning theory significantly determine practice. Underlying beliefs about the relative importance of learner autonomy versus social interaction in the learning process are largely informed by adult educators' experiences within particular organizational structures. Since classroom-based learning predominates in universities, paced, cohort-based forms of learning are almost universally established in the electronic learning environment, as this is easier to support within the processes of the organization. In turn, adult learning theories predicated on paced learning is emphasized. The centrality of human-to-human interaction in current online learning theory like social constructivism exemplifies this phenomenon, even when it is clear that this may not even be the preferred learning mode for adult learners given a choice between self-pacing and group interaction (Anderson, Annand, \& Wark, 2005). To be efficacious, a particular educational theory needs to not only consider pedagogical benefits, but also balance these against learner preferences and perhaps most importantly for the future, relative cost. Replicating paced, cohort-based learning in the virtual environment means that industrialized forms of distance education predicated on independent learning are still largely ignored or disparaged, even though these are scalable and more cost effective.

Anderson (2003) posited the following equivalency theorem:

Deep and meaningful formal learning is supported as long as one of the three forms of interaction (student-teacher; student-student; student-content) is at a high level. The other two may be offered at minimal levels, or even eliminated, without degrading the educational experience. High levels of more than one of these three modes will likely provide a more satisfying educational experience, though these experiences may not be as cost or time effective as less interactive learning sequences. (p. 5)

It is this possibility that one form of learning can be substituted effectively for another, and the resultant need to consider cost/ benefit trade-offs more closely, that should encourage educators to consider more carefully how online learning is organized.

\section{Universities as Pre-industrial Organizations}

Despite growing demand for university education worldwide, and society's increasing desire, directly and through government agency, for increased value for privately and publicly-expended 
Re-organizing Universities for the Information Age

Annand

educational funds, the manner in which most universities conduct central aspects of the education process has not yet been fundamentally altered since pre-modernity. Some writers dispute this. Rumble (1998) noted that during the latter half of the 20th century, traditional universities have grown increasingly large and therefore bureaucratic. This has affected the role of academics, and decreased their ability to influence the learning process. Other factors also affect this role - the 'massification' of higher education; an emphasis on market responsiveness and entrepreneurialism; the rise of a professional managerial class in higher education; and an increasing dichotomy between teaching and research duties. Rumble and Latchem (2004) stated that distinctions between traditional and distance university education have decreased as traditional campuses move to reduce costs - by reducing dialogue between instructor and students (that is, by raising class size) and by imposing more bureaucratic rigour. This reduces the ability to respond to individual student needs. As a result, university teaching has evolved from a communal activity where the worker (academic) directly controlled the process of work, to a more highly organized, bureaucratic process involving many individuals. Effects on academics include de-skilling and loss of control over the educational process - effects similar to those imposed on labourers by the factory system during the Industrial Revolution. In turn, this has led to the diminution of the teaching craft.

These assertions should be challenged, however. Values, processes, and structures underlying the oral, classroom-based educational transaction within universities have not changed for several centuries. Learning continues to revolve around fixed start and end dates, cohort-based learning, and a craft-like approach to learning where one faculty member oversees most aspects of a student's learning experience for a specified time period. The vast majority of universities are still very much vertically integrated organizations with faculty and students clustered on campuses, even with the increasing use of Internet-based learning. Classes are still scheduled to permit a more efficient pursuit of other faculty activities like research and university service. Competitive advantage is often achieved by effectively marshalling faculty resources in one geographical location and by restricting competition through the accreditation process. Though bureaucratic structures have allowed universities to become large and more complex, the fundamental means of learning within the academy has not changed in centuries. In fact, it more closely resembles organizational forms common to merchant capitalism rather than those brought about by the Industrial Revolution.

Merchant capitalism became a significant economic force in Western Europe between the 11th and 16th centuries, depending on region. Merchants acted as intermediaries between buyers and sellers in a relatively straightforward exchange of simple goods and services. They financed their own operations, purchased raw materials, and distributed these to cottage workers. The workers significantly controlled the production process, working independently and at their own pace. Several problems arose with the system. Quality standards and production schedules were difficult to maintain. Increased demand for cloth led to shortages of workers in manufacturing districts and drove up costs. The era drew to a close around 1800, giving way to industrial capitalism and its attendant features - the factory system, incorporation of new technology like steam power and metal machines, and mass production as opposed to artisanship.

In the university, however, these industrializing characteristics were largely eschewed in favour of tradition. Most technological advances of the day could not be adapted easily to the classroom. Perhaps more fundamentally, growing direct public funding of universities insulated the academy from these industrializing effects. The exception to this was the formation of dedicated distance education universities. Peters (1983) argued that first and second generations of distance education introduced industrialized processes to adult learning starting as early as the mid-1800s. 
Re-organizing Universities for the Information Age

Annand

These processes included division of labour, managerialism, mechanization, capital-intensive technology, and an assembly-line mindset. Instructional tasks like curriculum design, content preparation, student support, formative assessment, and examination were divided up so that these could be undertaken by different people. Relying first on printed instructional packages and later digitized instructional media, industrialized forms of distance education became less subjective and craft-like than traditional, classroom-based university education.

Though followed by other phases, it is these industrialized characteristics that remain at the core of what Taylor (2001) described as the most recent incarnation of distance education, a fifth generation he dubbed 'Intelligent Flexible Learning.' Besides the relatively commonplace features found in most online learning systems, fifth generation distance education also incorporates business technologies that streamline instructional material production and student service functions. These permit multiple types of media outputs from a single source document, and provide student access through online portals to automated business processes and academic advice, for example. Most importantly, individually tailored services can be provided to an increasing number of learners with the same economic resources by using knowledge management software to reduce the need for direct, human interaction in the teaching and learning process. As Adria and Chowdhury (2002) noted, these software capabilities can be further leveraged by reassigning duties traditionally performed by academics, like student advising and general administrative information, to Call Centre personnel.

Critics of all forms of industrialized distance education term it 'Fordist,' and disparage it as a valid educational form, and generally consider it antithetical to desirable teaching and learning processes. As Stevens (1996) observed, its practitioners are accused of neocolonialism because it is purported to exclude, marginalize, and objectify learners and educators, to provide tacit support for globalization, and to diminish the teaching craft. Even post-Fordist paradigms that make industrialized education processes more flexible and humane, have not adequately nor fundamentally addressed the deficiencies of Fordism.

The problem with most criticisms leveled against industrialized distance education is that they can be applied equally to any form of university organization. Tendencies to be influenced by technology-based knowledge interests and politically motivated bureaucracies are certainly not unique to industrialized distance-based universities. The unexamined massification of both distance and campus-based higher education can result in the objectification of students. Education for transformation and democratic participation are principles embraced, and as a result, such practices are incorporated into the teaching processes of some faculty within industrialized distance education institutions, as well as at conventional campuses, albeit only sometimes for the latter. Niche marketing of university degrees, particularly in foreign jurisdictions, is practiced by a number of campus-based universities with physical presences in these offshore locales.

Furthermore, faculty in both classroom and distance-based university education often welcome the assignation to more mundane academic duties, like marking. Faculty at traditional universities moving into online education often benefit from the use of instructional designers, graphic artists, and editors, who contribute expertise to the online course production processes. It is the increased possibilities of instructional media and communications within the electronic environment that requires additional expertise, and this need not strip academics of their core academic responsibilities even in an industrialized setting. 
Re-organizing Universities for the Information Age

Annand

The opposition to industrialized distance education echoes sentiments voiced by Luddites as the textile industry of England evolved into the Industrial Age, and gives credence to the suggestion that most universities' organizational forms pre-date the Industrial Revolution. The Luddite rebellion of the early 19 th century was an organic and spontaneous movement based in the English Midlands. It is estimated that there were, for instance, 100 to 150 "General Ludds" leaders of small bands of insurrectionists. The rebellion took place primarily in three counties Lancastershire, Yorkshire, and Nottinghamshire - and at various times during the years 1811 and 1812. The large geographic size of the affected English countryside, and the fact that communication was by word of mouth, makes the organization and coordination of the rebellion even more remarkable. Groups of loosely organized cottage-based textile workers destroyed large stocking frames housed in textile factories and in the homes of several master craftsmen. These machines produced less-expensive stockings than those produced by skilled home-based knitters. Despite the generally pejorative tone now attached to the term, Luddites were overall an intelligent, well-disciplined, courageous group of people who acted on their convictions and at their own peril. They were not bungling Neanderthals as they are now often portrayed, but the focal point of the collision of old and new value systems created by emergent industrialization.

As Kennedy (1997) opined, and contrary to popular perception, the Luddites' destruction of certain types of machinery was a means to maintain a culture rather than a labour tactic. Luddites were not opposed to mechanization in all its forms. They embraced technology that reduced toilsome aspects of work, or enhanced output and quality of goods in their cottage-based industry. They identified with the past, and had a strong sense of relationship and community within their villages. They were opposed to technology that forced people into factory servitude, replaced workers with machines, deprived artisans of pride in their skills, produced allegedly inferior products, abolished set prices, and introduced free markets.

Neo-Luddites in the academy may have the same desire to control the nature of change in their work environments. A sense of loss of craft, fear of dislocation for students and faculty, and an assumption that re-organization may break down the bonds of academic community and result in the loss of control over the educative process seems to significantly inform today's opposition to some forms of technological change within the academy. If people matter more than technology, and machines are useful only if they contribute to a greater human (rather than economic) good, changes that are perceived threats to these ideals are opposed.

\section{The Innovation Imperative}

These sentiments have been amply reflected in the literature. The larger question is whether the perceived negative effects are probable, and if not, whether the academy can successfully resist the industrialization of higher education. Perhaps they can. Faculty associations and academic decision making bodies continue to hold considerable influence and are invariably a voice for incremental reform rather than radical restructuring. Continued evolution to cohort-based online learning at traditional universities may reduce the need for expensive physical infrastructure and thus reduce overall costs and external pressures to re-organize.

Realistically, though, most publicly funded universities still appear unwilling or unable to change the way that they operate in any fundamental way. Publicly funded universities in particular are generally ill equipped to handle major organizational change in almost all countries. At the same time, capacity constraints are becoming more severe because of serious, deepening shortages of academic and professional staff in developed countries' universities. Where university access is less problematic, classroom space is limited and infrastructure is aging. 
Much like the Industrial Revolution before it, rapid technological change in the Information Age has to date created significant, fundamental change in virtually all sectors of society except education. This may not remain the case for long. A confluence of factors puts increasing pressure on university systems worldwide to change.

Dhanarajan (2001) estimated that there are over three billion adolescents and adults who are under-literate, illiterate, or in need of retraining. Moe (2002) reported that there are only 10 countries that presently provide higher education to one-third or more of their college-age populations. Demographics indicate that absolute numbers of students, the number of students as a percentage of total population, and average age of students, will increase over the next 25 years. Population growth, increased economic activity, and growing demand for white-collar workers will create an unequalled demand for higher education. Based on much the same data, Daniel, Kanwar, and Uvalic-Trumbic (2006) predicted that a 'tectonic shift' will transform the map of higher education worldwide - the growth of universities in the developing world. Spreading connectivity allied with the massive creation of open-source educational resources may soon allow economies of scale and the attendant radical reduction in costs necessary for higher education to serve the four billion people at the bottom of the world's economic pyramid.

The missing factor in this analysis, however, is the need for university re-organization. Taylor's fifth generation learning model may replicate in the virtual learning environment two key attributes that accounted for the initial successes of distance education - flexibility for students and value creation for the institution, primarily in the form of reduced costs and enhanced services (as compared to traditional, campus-based universities). To the extent that Anderson's (2003) equivalency theorem holds, a less recognized corollary of Taylor's (2001) analysis is that universities incorporating high-quality digitized instructional media into well-structured learning experiences also can disaggregate student cohorts in favour of individualized learning and still provide focused group interaction for specific purposes within a self-paced learning experience. In this way, economies of scale can be realized, costs can be reduced, the overall quality of the learning experience can be maintained, and more learner autonomy can be facilitated. Most importantly, technologically-enabled, industrialized, yet responsive organizational structures can be established to meet the future demand for university education.

The public university sector could be radically altered by this combination of environmental pressures and new possibilities for organizing, particularly when understood in the context of innovation theory. According to Christensen and Raynor (2003), disruptive innovations occur when a simpler, more convenient, or less expensive product that may appeal to a new or previously unattractive customer base is introduced, generally by a new entrant in the market. This type of innovation also gradually pulls customers away from existing firms, starting with those who are most easily satisfied. The disruptive business model succeeds because the higher volumes of customers that are created by innovative, less costly approaches allow reasonable returns to be earned at lower prices by new firms.

Three litmus tests were proposed to determine whether an idea has disruptive potential. First, does the product or service appeal to a large group of people who previously have not had the money, equipment, or skill to use the product or service, or who have to travel to inconvenient locations? Second, is there a group of people at the low end of the market who would purchase the disruptive technology if it costs less, even if performance might be lower but still acceptable? Third, does the innovation disrupt all firms in the industry? Though Christensen and Raynor (2003) deal with innovation in a free market economy, this phenomenon is equally valid in any system where resources are scarce and good financial stewardship is required - for example, in 
Re-organizing Universities for the Information Age

Annand

the state-funded higher education sector. In this particular example, innovation permits the same level of resources to be allocated more efficiently to serve a larger number of students, or allows tuition to be reduced.

Historically, distance-based universities would almost certainly qualify as disruptive innovators, given their lower cost structure and flexibility that appeals to learners who can not attend traditional universities because of work, family, or other commitments. This advantage is not negated even with the introduction of Web-based learning in virtually all universities. In the electronic age, campus-based universities and even dedicated distance education institutions that do not take advantage of less expensive and newer organizational forms and operational processes now made possible by rapid improvements in the electronic technologies of fifth generation distance education, risk being supplanted by a few online university education providers that can get the model right.

Van Dusen (2000) used the term 'millennial restructuralism' to describe a view whereby radical restructuring of the academy is necessary to respond more rapidly to changing social, demographic, and economic pressures. A necessary component of this view is the removal of traditional constraints of learning - time and place. Concomitantly, new learning technologies adopted by appropriately reorganized institutions should be used to create significantly new approaches to the process and management of higher education, and not merely augment the classroom-based, faculty-centred model of most university education.

Unfortunately, a s Hilsberg (2004) noted, new technologies are considered within most universities only to the extent that they might incrementally improve the cohort-based, paced educational process in both traditional and online environments, without regard for how technology coupled with organizational reform might transform the educative process. Research conducted by Irele (2005) identified major issues and challenged the assumption that online education could be widely accepted and integrated into the mainstream of higher education. Peters (2004) provides further insight into the tensions that arise when distance education systems are introduced within traditional universities. He stated,

They have to deal and come to terms with fixed academic structures and conventions which are normally resistant to change and restrict flexibility. They have to assert themselves when trying to innovate and modernize not only the learning-teaching system, but also the mission and the sense of direction of the institution in order to adapt it to the requirements of a rapidly changing society. (p. 146)

\section{Prognosis}

It is these generally inflexible characteristics of the traditional academy that do not bode well for its future. It seems clear that growing demand for higher education cannot be met within a controlled paradigm like the present, conventional university system. This when combined with a worldwide entrepreneurial culture, the growing correlation between education and quality of life, and the increasingly strategic role of knowledge in determining the prosperity and security of nations, threaten the virtual monopoly of not-for-profit universities over the certification of higher learning. This would be unfortunate. It is quite possible to envision universities where technologically-facilitated educative processes are structured in significantly different, less expensive, and yet still-effective ways, but where academic freedom and research remain highly valued. These attributes can be maintained by retaining the autonomous, faculty-centred governance structures of publicly funded, not-for-profit universities; by strengthening the role of 
Re-organizing Universities for the Information Age

Annand

regional and national accreditation bodies; and by encouraging continued state funding of higher education. In effect, these measures retain barriers to entry from private competitors in the interest of supporting the demonstrable public good of publicly funded, research-supporting universities.

The generally silent struggle underway within the academy to determine the appropriate means to employ technology - using it to either fundamentally change the way education is delivered to students, or using it to augment the traditional way that higher education has been conducted by replicating the classroom in an electronic environment - is far from resolved. If creatively implemented, significant transformative change may be realized within current academic structures. However, heightened aspirations of a burgeoning world population, coupled with a growing perception that development of more affordable, widely-accessible education systems is desirable because civilized societies should provide their citizens with the education they need throughout their lives, create pressure on the academy to change perhaps too quickly. It is still unclear whether resistance to change within the academy constitutes anything other than rearguard action. Irresistible technological, economic, and social imperatives seem about to impose significant change on the conduct of higher education worldwide.

\section{References}

Adria, M., \& Chowdhury, S. (2002). Making room for the call center. Information Systems Management, 19(1), 71-80.

Anderson, T. (2003). Getting the Mix Right Again: An updated and theoretical rationale for interaction. The International Review of Research in Open and Distance Learning, 4(2). Retrieved January 27, 2007 from: http://www.irrodl.org/index.php/irrodl/article/view/149/230

Anderson, T., Annand, D., \& Wark, N. (2005). The search for learning community in learnerpaced distance education programming or "Having your cake and eating it, too!" Australian Journal of Educational Technology, 21(2), 222-241. Retrieved January 27, 2007 from: http://www.ascilite.org.au/ajet/ajet21/res/anderson.html

Christensen, C., \& Raynor, M. (2003). The Innovator's Solution. Boston: Harvard Business School Press.

Daniel, J., Kanwar, A., \& Uvalic-Trumbic, S. (2006, July/ August). A tectonic shift in global higher education. Change. Retrieved January 27, 2007 from: http://www.carnegiefoundation.org/change/sub.asp?key=98\&subkey=1841

Dhanarajan, R. (2001). Distance Education: Promise, performance and potential. Open Learning 16(1), 61-68

Garrison, R. (1997). Computer Conferencing: The post-industrial age of distance education . Open Learning, 12(2), 3-11.

Hilsberg, T. (2004). Comments in closing ICDE plenary session. 21st ICDE World Conference on Open Learning \& Distance Education, February 20-24, 2004, Hong Kong. 
Re-organizing Universities for the Information Age

Annand

Holmberg, B. (1989). Theory and practice of distance education. London: Routledge.

Irele, M. (2005). Can distance education be mainstreamed? Online Journal of Distance Learning Administration, 8(2). Retrieved January 27, 2007 from:

http://www.westga.edu/\%7Edistance/ojdla/summer82/irele82.htm

Keegan, D. (1990). The foundations of distance education (2nd ed.). London: Routledge.

Kennedy, P. (Producer). (1997, Feb. 17). Luddites and friends. Ideas [Radio Program]. Toronto: Canadian Broadcasting Corporation. Retrieved November 8, 2007 from:

http://www.cbc.ca/ideas/features/luddites/index.html

Moe, M. (2002). Emerging Trends in Post Secondary Education -The view to 2012. Driving Post-Secondary Education Conference. Washington, DC. December 9, 2002. Retrieved January 28, 2007 from: at http://www.usdla.org/ppt/THINKEQUITY.ppt

Peters, O. (2004). Distance Education in Transition. New trends and challenges (4th ed.). Oldenburg : Bibliotheks-und Informationssytems der Universitat Oldenburg.

Peters, O. (1983). Distance teaching and industrial production: A comparative interpretation in outline. In D. Seward, D. Keegan, and B. Holmberg, (Eds.), Distance Education: International perspectives (pp. 95-113). New York: Routledge.

Rumble, G. (1998). Academic Work in the Information Age: A speculative essay. Journal of Information Technology for Teacher Education, 7(1), 129-145.

Rumble, G., \& Latchem, C. (2004). Organisational models for distance and open learning. In H. Perraton and H. Lentell (Eds.), Policy for open and distance learning. London:

RoutledgeFalmer.

Stevens, K. (1996). Have the shifting sands of Fordism resulted in ground lost or ground gained for distance education? Distance Education, 17(2), 247-266.

Taylor, J. (2001). Fifth Generation Distance Education. Keynote Address presented at the 20 th ICDE World Conference, April, 2001, Düsseldorf, Germany.

Van Dusen, G. (2000). Digital Dilemma: Issues of access, cost, and quality in media-enhanced and distance education. San Francisco: Jossey-Bass.

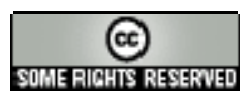




\title{
Same Size Doesn't Fit All: Insights from research on listening skills at the University of the South Pacific (USP)
}

\author{
Rajni K. Chand \\ University of Otago, New Zealand
}

\begin{abstract}
Listening skills research has tended to focus on strategy use in classrooms and on theory and practice of second language (L2) teachers. This study examined the teachers' and learners' perceptions of listening skills in non-classroom learning situations. Five $(n=5)$ study skills teachers and 19 former learners in a distance study skills course at the University of the South Pacific (USP) were interviewed for this study. The interviews with the study skills teachers sought their expectations of their learners' listening strategies, their views about the learners they taught, and the skills their learners used for listening. Former learners were similarly questioned about their perceptions of listening strategies they were taught and used. Data was collected and managed using NVivo, a computer assisted qualitative data analysis software. Besides revealing strategies that distance learners reported using their learning listening skills, the study identified a number of differences in views presented by researchers and L2 teachers, as well as differences in perceptions on listening skills between L2 teachers and L2 learners. The paper concludes that there exists a discrepancy between research and the practice of researchers, L2 teachers, and L2 learners on what works. The author also recommends further research in this area is needed, because research examining classroom-based learning situations will likely not apply to, nor fully inform, distance learning contexts.
\end{abstract}

Keywords: Distance learning; listening strategies; University of the South Pacific (USP); learning strategies; learner perceptions; teacher perceptions

\section{Introduction}

This paper aims to shed light on learners' and teachers' perceptions of language learning strategies (LLS) used for listening skills. It does so by using findings from a recent study conducted at University of the South Pacific (USP), which sought to examine the 'listening needs' of distance students for most of whom English is a second language.

The larger project collected views from four groups at USP: former and present students enrolled in a study skills course offered at a distance by USP, study skills teachers who taught the course, and course teachers taking distance courses. Other forms of data collection included questionnaires which were distributed to two groups of learners and course material analysis. The focus of this paper will be on the former learners' and teachers' perceptions of the students' 
Same Size Doesn't Fit All: Insights from research on listening skills at the University of the South Pacific (USP) Chand

listening skills, and specifically the differences reported by these two groups. Additionally, this paper aims to compare the findings with research by Berne $(1995,1996,1998)$ and reviews by Mendelsohn (2001a, 2001b), which show that teachers rarely refer to studies conducted on listening to inform their practice, and that they tend not to spell-out the strategies they want students to use in their classrooms.

This paper first provides readers with the current theoretical background on listening skills, language learning strategies, learners' and teachers' perceptions of language learning strategies, and the researchers' views on classroom practices. Next, the background to the study is presented, which includes participant details, and data collection methods and analysis used. This will be followed by discussion of the results, conclusion, limitations of the study, and possible directions for future research.

\section{Theoretical Background}

Listening plays an important role in language learning (Anderson \& Lynch, 1988; Dunkel, 1991; Rost, 1990; Rubin, 1994) and is possibly the most essential language skill (Oxford, 1993). It is also "the least explicit of the four language skills" (Vandergrift, 2004, p. 1) - speaking, listening, reading and writing: the four academic skills - because it is the most difficult to observe. Research on 'listening' began with Rankin (1930) who found listening to be the most frequently used mode of communication amongst humans. According to Brown (1987), research on listening as a field of inquiry began in the 1940s with the pioneering work of Nichols, who initiated the change to a communication programme with the encouragement of the National Council of Teachers of English in the United States. From the 1950s until the late 1970s, studies of listening focussed on the pedagogical and assessment aspects of listening, such as listening comprehension and critical listening (Feyten, 1991). Since the 1980s, studies related to listening strategies began to emerge. Early studies on language learning and listening strategies are discussed by O'Malley and Chamot (1989), Oxford (1990), and Rubin and Thompson (1994).

Foreshadowing the research findings of this study, language learning strategies are also of importance in learning study skills. According to Chamot (2005), learning strategies are procedures that facilitate learning and are conscious and goal-driven. Examining students' learning strategies can help gain insight into the metacognitive, cognitive, social, and affective strategies used by second language (L2) students. Less successful students can be taught strategies to help them become better language learners (Chamot, 2005, p. 112). Studies of language learning strategies began in the1970s with the work of Rubin (1975) and Stern (1975), who reported on the strategies used by successful L2 learners. Other studies followed that looked at student characteristics and strategic techniques used for effective language learning (O'Malley \& Chamot, 1990; O’Malley, Chamot, Manzanzres, Kupper \& Russo, 1985; Takeuchi, 2003). Studies of less successful students showed that, like their more successful student counterparts, they too used learning strategies frequently, but in a less effective manner (Chamot \& El-Dinary, 1999; Khaldieh, 2000; Vandergrift, 1997a, 1997b, 2003). A number of other factors such as the concept of 'will' (Leontiev, 1981), 'learning stamina' (Strevens, 1978), and 'learner persistence' (Schumann, 1980) were also claimed to be affecting second language acquisition.

According to Mendelsohn (2001a) and Berne (1998), however, studies on listening skills have not yet reached the classroom, and research has yet to be conducted in the classroom. Even after nearly a decade, studies on listening skills remains limited. Teachers rarely refer to studies

conducted on listening to inform their practice. Moreover, teachers typically do not spell out the strategies or the expectations that they expect from their students. Indeed, both Berne (1996, 
1998) and Mendelsohn (2001a) discuss the mismatch between the researchers' focus and actual classroom practice on listening skills. Berne's (1996) study, for instance, compares the questions addressed by second language (L2) researchers and those addressed by classroom instructors. Berne's study reveals limited overlap between issues that interested both the researchers and the classroom instructors. Berne (1996) reviewed studies conducted on L2 listening, and she interviewed nine language instructors. Her study shows that classroom instructors seldom, if ever, refer to 'listening research' to inform their practice, because the research did not provide answers to their questions, such as the effectiveness of different types of activities, and the relationship between listening and other skills. Similarly, Mendelsohn (2001b) discusses the differences between the researchers' and the teachers' research agendas. Teachers have issues that arise from the observations they make from their classroom experiences, while researchers usually focus on issues they find interesting and feel are worth investigating. This gap in the research agenda, according to Mendelsohn (2001b), can be bridged if teachers themselves undertake classroombased research, or when researchers teach in classrooms for a while and can fully appreciate what is really at issue in the classroom.

Related to research in the classroom, Griffiths and Parr (2001), Nunan (1986), Hawkey (2006), and O'Malley et al. (1985) examine the differences between language learners' and teachers' perceptions of language learning, and what actually is happening in the classroom. Griffiths and Parr (2001) discuss a study that showed parallel results to that of Nunan's (1986) study. Like Nunan's research, the Griffiths and Parr study which examined students' and teachers' perceptions of language learning strategies used, revealed discrepancies between students' and teachers' perceptions. While teachers believed that the students used memory strategies the most and were less reliant on cognitive strategies, students, on the other hand, reported that they primarily used social strategies and memory strategies the least - the exact opposite of what teachers believed they used.

Nunan $(1986,2000)$ also discussed the mismatch between teachers' and learners' expectations of the classroom. Using interviews and classroom observation as research tools, Nunan probed teachers' perceptions of what they felt is important in the learning process. While teachers believed in using communicative oriented activities, students, on the other hand, were found to value traditional learning activities more. Of the 10 learning activities researched by Nunan, only one (i.e., conversation) was selected by both teachers and students as important in the learning process.

Hawkey's (2006) study, which employed quantitative and qualitative data collection methods, also found differences between teachers' and students' perceptions of activities that took place in their classrooms. While both groups agreed on the importance of communicative approaches for language learning, both the teachers and students reported differences in the way they perceived grammar and pair work in their classes.

O'Malley and colleagues (1985) similarly found differences between teachers' beliefs on students' use of language learning strategies in the classroom versus students' perception of language learning strategies used. While students reported using a variety of language learning strategies, teachers "were generally unaware of their students' strategies" (p.20).

The recognition of the importance of language learning strategies began in 1975, and since then various frameworks to examine learners' reported language learning strategies have been designed. Oxford's (1990) Strategy Inventory for Language Learning, and O'Malley and colleagues' (1985) list of language learning strategies are two such frameworks. This study uses 
the description of language learning strategies put forth by O'Malley and colleagues (1985) and adapts it for discussing listening strategies in this paper.

Insights from research and views expressed by Berne (1996), Griffiths and Parr (2001), Hawkey (2006), Mendelsohn (2001a), Nunan (1986), and O’Malley and colleagues (1985) support the points expressed earlier - that a discrepancy does exist between research and actual practice in the classroom. The next section provides the background of the study reported in this paper.

\section{Background of the Study}

USP serves a region of approximately 33 million square kilometres (Bolabola \& Wah, 1995, p. 2) and spans five time zones. The countries served by USP range from the small coral atolls of Kiribati, Marshall Islands, Tokelau and Tuvalu, to the single island countries of Nauru and Niue, and volcanic groups of islands of Fiji, Solomon Islands, Vanuatu, and Samoa (Bolabola \& Wah, 1995) (see Appendix A for a map of the USP region). USP also serves a multicultural region, which can roughly be divided into three major, though often overlapping, ethnic groups. The Micronesia group of the North Pacific, the Melanesian group of the west, and the Polynesian group of the east, which altogether represent about 60 cultures and 235 languages. USP students either study full time at its main campus in Suva, Fiji, or they enrol in courses in the distance mode, which are administered from any one of 15 centres (Fiji has three centres; and Vanuatu two). Most USP programmes are offered by distance. In some cases, however, learners must travel to the campus in Suva to complete their studies.

Students who enrol in distance courses offered by USP's regional centres typically take courses that are primarily print-based, with student support offered from satellite, centre-based and/ or via visiting tutorials offered closer to the students' place of residence. Students enrolled in courses offered at a distance use their closest tutorial centre to interact with their course tutors and lecturers. Thus for most USP students studying at a distance their actual 'learning' takes place in typically remote and primarily asynchronous environments. Some courses, such as law courses for instance, require students to have an Internet connection to access the online material. And although other courses do not specify per say, it is generally expected that students have at their disposal the facilities and resources they need to complete their course-related work (i.e., a place to study, etc.). All learners enrolled in USP's certificate, diploma, and degree programmes are expected to enrol in a 'study skills course'. Moreover, the study skills course must be taken early on and concurrently with their programme of study. Thus, student enrolled for USP distance courses have at their disposal the study facilities provided by USP's centres, or they can study independently using print-based course materials. This, however, clearly indicates an imbalance in how USP's various facilities are used by students enrolled in the exact same course. In sum, some students use the facilities, while others rarely, if ever, use the facilities.

USP, however, expects its students to acquire the basic skills to cope with the academic demands of tertiary education via enrolment in its study skills course. The listening skills component of USP's study skills course - which is the focus of this report - is taught using learning materials comprised of course books and audio-taped materials. Centre-based and the satellite tutorials are held every three weeks during the semester; attendance at these tutorials is not compulsory however (see Appendix B for the study schedule for the study skills course).

The listening skills section of USP's study skills course, which comprises approximately three weeks of the semester, is designed so that students must listen to segments of two audiotapes 
(with or without pre-listening activities), after which they are given questions to test their understanding of what was said on these audio-tapes.

The first listening activity takes place in week 5 (Unit 5) of the semester. In this activity, students are expected to listen to a tape recording of a USP lecturer discussing an article in the course materials; the lecturer takes the students through the article paragraph by paragraph. This is a reading and interpreting text activity. There is also a reflective exercise wherein students are asked to predict and evaluate information in this article.

In week 11 (Unit 9) of the semester, students are provided with videos on seminar presentations. To access and watch these videos, however, students must travel to USP's centre libraries; these videos primarily contain information on their seminar presentations.

During final listening activity, which takes place in week 12 (Unit 10), students were asked to listen to Tape 2, containing recordings of two lectures. While listening to these lectures, learners are asked to practice note taking and pay close attention to transitional words, or signals. Students are also given pre- and post-listening activities based on these lectures.

Solutions are provided at the back of the course books for all these listening activities. There are no course assignments or grading, however, to test students' comprehension of the listening component of USP's study skills course. The students, however, are expected to submit an audiotaped seminar presentation for assessment as part of their coursework.

The teachers teaching the study skills are based at various USP regional centres. These teachers either had to travel to remote locations to conduct their tutorials; or the students themselves travelled to their closest centre, where the teachers conduct weekly tutorials. All the teachers interviewed were L2 teachers, and all reported that they were aware of technical facilities and learning opportunities offered by USP. Although USP's students were expected to use these centres and take part in the opportunities offered by the University, not all students, however, used these facilities, citing distance as a primary deterrent. With these differences in mind, this study aimed to investigate the teachers' and students' perceptions of the training opportunities offered to students to further develop their listening skills needed to successfully engage in higher education. The following questions served as a guide for the study:

1. What are the study skills teachers' expectations in terms of students' listening strategies?

2. What are the students' perceptions of listening strategies imparted in the distance study skills course offered by USP?

3. How are students' listening strategies and their teachers' expectations of students' listening strategies interrelated?

4. What is the role of distance study skills course at USP, and how successful is this course in fulfilling the listening needs of its students?

\section{Participants}

Five $(n=5)$ study skills teachers from various USP campuses and centres and 19 former learners, formed the sample of this study. Other interviews conducted with current students enrolled in the study skills course and course teachers, together with questionnaires and course material analysis, 
became part of the larger study mentioned in the introduction of this paper; this information, however, is not reported here (see Appendix $\mathrm{C}$ for details of the teachers and learners selected for interview).

Letters were sent to all the centre directors informing them of the larger project. The sample $(n=$ 5 teachers; $n=19$ learners) were contacted, with the assistance of the directors and study skills teachers based at the centres. Pre-set interview days were selected to coincide with the distance course tutorial dates. All 19 learners had completed the study skills course at a distance. Two $(n=$ 2) learners had studied at home in isolation and were solely dependent on the print and tapes provided in the course materials. The remainder of the students $(n=17)$ had either attended the satellite tutorials, or had face-to-face contact with their tutors at the centre-based tutorials offered by USP.

\section{Data Management and Analysis}

Data for the study was collected between July and August 2005 during visits to three centres of USP and at its Suva campus. The interviews, 30 to 45 minutes in duration, were conducted and transcribed by the researcher. All interviews were semi-structured and all began by obtaining participants' background and educational details. The second section of the interview dealt with the questions related to listening skills, such as:

- The participants' understanding of 'listening skills'.

- The strategies students used for listening and for overcoming listening difficulties encountered.

- The strategies study skills teachers used to encourage their students to use for listening.

- Students' and teachers' perception of their grasp, difficulties, and experiences of attending to the listening skills component of USP's study skills course offered at a distance.

All interviews were tape-recorded, transcribed, and coded. The research methodology used was similar to that of grounded theory (Glaser \& Strauss, 1967), which was deemed useful by the author as this method allows the "researcher to develop a theoretical account of the general features of a topic, while simultaneously grounding the account in empirical observations or data" (Martin \& Turner, 1986, p. 141). This approach was determined to be particularly useful because to date there seems to have been no research carried out examining teaching listening skills to L2 learners studying at a distance. Data collection, coding, and analysis proceeded recursively, beginning with the early stages of research being open-ended and becoming more directed with each emerging concept. The concepts were organised by recurring themes, which then became part of a set of categories that linked a number of concepts. Axial coding (Strauss \& Corbin, 1977) was employed to define the connections between subcategories, which, in turn, were used to construct a comprehensive scheme. The interview transcripts were then re-examined and recoded using this scheme to determine the set of categories and concepts to cover as much of the data as possible. NVivo, a computer assisted qualitative data analysis software programme, was used to highlight specific words and phrases that formed part of the concepts or themes. A list of all concepts or themes and subcategories, together with their occurrences in the transcripts, was subsequently created. This approach is similar to the traditional copy and paste procedure of data coding, but takes less time and saves making multiple copies of transcripts. 
Same Size Doesn't Fit All: Insights from research on listening skills at the University of the South Pacific (USP)

Chand

\section{Findings}

The themes that emerged from the interviews showed a mismatch between views expressed by the teachers versus that of the students. The remainder of this paper, therefore, will discuss these themes within the context of the theoretical insights expressed by Berne (1996), Mendelsohn (2001a, 2001b), and discrepancies on language learning strategies as explored by Griffiths and Parr (2001), Nunan (1986) and O’Malley and colleagues (1985).

This paper will focus first on the views of the teachers, followed by that of the students. All names reported are pseudonyms and all quotation(s) are verbatim unless otherwise indicated. The interviewee's pseudonym and the date the interview took place follow each interview quote.

\section{Views of the Study Skills Teachers}

The themes that emerged are: 1) the study skills teachers' listening skills expectations from the students; 2) the use of listening skills in the course; 3 ) the support they gave to their students in terms of building listening skills; 4) their views on distance teaching at USP; and 4) the impact of accent and the academic levels of students.

\section{Listening Skills Expectations}

During the interviews, the study skills teachers talked about what listening skills they anticipated to develop in their students. According to the teachers interviewed, students were expected to comprehend basic written/ read and spoken/ heard information while taking the course. "I think the learners should be able to get things at the same time as they are listening" (Judy, 3/08/2005). Similarly, Morgan expected his students to bring comprehension skills to the course. "They should be able to comprehend - that is very important because without that ability to comprehend we will not be able to listen well - and secondly, they have to be attentive" (Morgan, 6/08/2005).

Apart from expecting basic listening comprehension skills from their students, the study skills teachers expected them to have basic listening skills in order to learn what was being taught in the course. "I think they should first of all be able listen, have that capacity to be able to listen to a 50-minute lecture, or a one hour lecture" (Sahil, 27/07/2005).

Hence, the teachers indicated that the students needed to bring with them basic skills - that is comprehension, interest, and a willingness to learn, prior to taking the course - all basic skills from which students need to build upon and develop higher level listening skills demanded of tertiary studies.

\section{Listening Skills in Study Skills Course}

During the interviews, the teachers interviewed talked about the amount of time they spent teaching listening skills to their students. Since all tutorials at the centres were only held once a week and were only one hour long, all the teachers interviewed unanimously cited 'time limitations' as a major factor that impeded their ability to teach.

Not so much emphasis on listening though I would say (pause) but speaking yes certainly and as far as listening is concerned when they are doing the last 
assignment the seminar presentation may be there it could count (pause) like when students are doing their presentations. (Uma, 13/08/2005)

Wendy, who travelled to remote areas to conduct tutorials using school classrooms hired for the purpose, cited both lack of time and inadequate facilities as a problem.

You can't conduct these listening classes with them because there is this lack of the facilities that you need. The only listening they do is when I talk to them and they write down whatever they can. That's the best they can do. And our time factor because we have to cover six, five to six schools in a day we can't. . . It's quite difficult but we make the most of it. Listening, well we don't have too much of it. Even speaking we don't have too much that really if we do may be $10 \%$. (Wendy, 5/08/2005)

Morgan, who taught at a USP centre, also reported facing similar time constraints.

Well we only have one hour for the tutorial and basically we have group activities and there are times where they are sitting in groups and they exchange ideas, lecture methods but we are not doing much as far as listening is concerned. (Morgan, 6/08/2005)

Thus, the teachers indicated lack of time and facilities, along with limited contact with the learners, as detrimental to their teaching the listening skills component of USP's study skills course.

\section{Support Given to Learners}

Study skills teachers reported on their situation in relation to the support provided to USP students studying at a distance and what they personally did to assist their students in developing their listening skills. Support provided for these students studying at a distance, however, differed from centre to centre. Wendy, the tutor based at the Labasa centre in Fiji, travelled to remote areas and outer islands to conduct her tutorials. While in Lautoka, the other centre in Fiji, the students enrolled in the study skills course travelled from nearby towns to attend the tutorials. Similarly, Judy, the tutor based in Vanuatu, conducted tutorials only for those students in Vila area; however, she did not travel to the outer islands to conduct tutorials. Those students who attended centre-based tutorials were the ones the teachers knew better. During the interviews, the teachers tended to focus on those students they had contact with, and thus they tended to describe their experiences based on teaching those students they had actually met.

The remainder of the students - specifically those who did not attend the face-to-face tutorials offered - had no contact with the teachers, because they studied the print and audio-based materials on their own. Teachers made little mention about these students during the interviews. The teachers, however, were very much aware of these student's learning situations: "But we also have those police men posted in these areas. We have agricultural offices, prison officers, army officers, and police men round the region in the police posts" (Wendy, 5/08/2005). "The type of learners, we get the ones who are fresh from the high schools, those working, mature students, I get that range" (Judy, 3/08/2005). 


\section{Distance Teaching}

All study skills teachers interviewed indicated that they knew how distance teaching was carried out at USP. Additionally, all teachers interviewed indicated that they were university graduates, had secondary as well as tertiary teaching experience in the region, and all were experienced L2 teachers. These teachers reported also being aware of the differences in the facilities, opportunities, and resources made available to their students. Perhaps understandably, these teachers' reported experiences varied depending on their location. The centre-based tutors, for example, only conducted face-to-face tutorials, while the teacher based at USP's Suva campus conducted satellite tutorials, had limited email communication with learners, and visited other centres to conduct tutorials. On occasion, learners from the Suva area visited him for consultation. Overall, the study skills teachers interviewed tended to relate their experiences of teaching this course in terms of interaction with those students who came to see them versus those who did not. Those students who had no contact with their teacher, were typically only known by their enrolment identification numbers. These same teachers, however, voiced their concerns about these 'unseen, unheard' students. Nonetheless, they still tended to focus more on their experiences of teaching those students who attended their tutorials - and even then, interaction was reported as lacking.

Wendy, for example, linked the lack of resources and time available for the face-to-face tutorials to the lack of interaction she faced during her tutorial visits.

Very little interaction because the most you can spend is one hour. That's how much they allow us. I try to unload a lot of things and at the end of which they will ask questions but only a few will ask. The other problem too is not many ask questions. They just will practically accept what comes and that is a problem. (Wendy, 5/08/2005)

According to Judy, who was a Pacific Islander herself, this lack of interaction was associated with the perceived passive nature of Pacific learners.

I encourage them to speak actively, but I find that the Melanesian students are very passive listeners, they absorb everything you say, hold on tightly to it, and they don't think around it. So they just sit there and absorb everything that you say. You ask them if they have a question, one or two very brave ones will ask questions. The rest just stick by what you say. (Judy, 3/08/2005)

Sahil, who conducted satellite tutorials, saw distance - in other words the remoteness of students - as a problem:

The distant learners are a different breed of students altogether; you don't get to see them all the time. So you don't get to really form that rapport with them and when you conduct the satellite tutorials there are very little interaction from students. You are one doing most of the talking and when you ask them if there is any question they will ask very few content questions. (Sahil, 27/07/2005) 


\section{Accent and Academic Level}

Judy conducted tutorials for the learners residing in Vila, Vanuatu. The students she taught all had different educational backgrounds and attainment levels. While some students had dropped out of high school after year 10, some were high school graduates. All her students nonetheless had completed USP's pre-degree courses. Moreover, most of her students were mature, some of whom were enrolled in USP's distance Law programme, or in some other USP programme of study. Judy felt that the students she dealt with generally lacked listening skills - fundamental shortcomings that she felt was primarily due to their differing academic attainment levels or difficulties with spoken accents. "Sometimes they probably don't understand because of accent perhaps, depends on who are speaking and just the level of language that we are using, so they don't understand and that is maybe why they can't take notes" (Judy, 3/08/2005).

All study skills teachers interviewed indicated they were aware of listening skills they needed to teach; all indicated that they knew how listening skills should be taught; and all had certain expectations in terms of their students' prerequisite academic skills. There were, however, marked differences in how these teachers were teaching these listening skills in the study skills course. As such, it is logical to assume that the support they provided to learners would differ as well. The next section reports on former students' past experiences of the 'listening skills' component of the study skills course.

\section{Views of the Students}

Themes emerging from the interviews with past learners were: 1) their self-perception of listening skills, and 2) the strategies they used for facilitating listening.

\section{Self-perception of listening skills}

When students were questioned on their own perceptions of listening skills taught, they responded in a variety of ways. Most students tended to answer this question in relation to the study skills course they took. Their responses ranged from "becoming a better listener" to "still developing the skill."

My own listening skills after completing the course I find myself in a better position than before. (Albert, 8/08/2005)

I listened to the cassette on interpreting texts and I am glad because when you interpret text and it is all very complicated and jumbled, I am now able to jot down the points, link ideas. I manage to interpret text and get down basically what it is all about and try not to be overwhelmed by all the big words. (Thelma, $5 / 08 / 2005)$

The next section reports on the strategies students used, as well as what they said they 'did' when they encountered difficulties during listening.

\section{Strategies for Facilitating Listening}

The former students interviewed for this study, tended to talk about their listening strategies within the context of their study skills course, as well as in their everyday experiences of using 
listening skills. Depending on their profession, the students interviewed reported using varying degrees of listening skills. Those who had jobs that required them to interact with others, or who needed to interview people, mentioned their extensive use of listening skills. Those students, who were still enrolled in other courses, indicated that they required these listening skills for these courses.

The learning strategies framework developed by O’Malley and colleagues (1985) was used as a guide to discuss and explore the strategies students use. Metacognitive strategies include advance organisers, selective attention, and self-evaluation (O'Malley \& Chamot, 1990). Cognitive strategies, as discussed in the literature, include repetition, translation, note taking, conceptualisation, inference, elaboration, and clarification (O'Malley, Chamot, \& Kữpper, 1989; Oxford, 1990). Social mediation strategy involves cooperation with peers for information (O’Malley \& Chamot, 1990).

\section{Metacognitive Strategies}

Students have described the strategies they used, and such strategies can be aligned to the four 'metacognitive strategies' described by O'Malley and Chamot (1990): advance organiser; direct attention; comprehension and evaluation; and selective attention.

\section{Advance organiser}

I think before I go to or have to listen to any topic I do a bit of research on the topic and then I listen so that when I am listening I am able to pick out what is important and what's just the additional, so I take down notes at the same time. (Thelma, 5/08/2005)

\section{Directed attention}

I just listen closely, make notes as I am listening to specific or main text, terms and pick up specific words and create an image for what the person is saying. (Albert, 8/08/2005)

\section{Comprehension and evaluation}

When I am listening to someone talking, I pick out what I can remember and what I think is the key point they are trying to say and then later when I sit back by myself I try to analyse and remember or recall. (Jane, 4/08/2005)

\section{Selective attention}

What I learnt was to listen for example like first of all, so I think oh I see that is one of the points then I need to take note of that. And then they say secondly the other point, I take note of that. (Ian, 4/08/2005) 


\section{Cognitive Strategies}

The students interviewed reported that they used a number of cognitive strategies: translation; seeking clarification; repetition; note taking; and visualization.

\section{Translation}

At times I had to translate them in my language to help me understand and follow the words. I used to translate, listen slowly - trying to follow the conversation. (Tevita, 16/08/2005)

\section{Seeking clarification}

If I was given the opportunity I would ask straight after the talking. If I didn't get the time I think I will have to sit back and think. (Jane, 4/08/2005)

As a student, if I face difficulties for instance during satellite tutorials, I go back and request for a copy of the cassette and listen to it again and then I refer to my notes and for sure it helps. (Thelma, 5/08/2005)

\section{Repetition}

When I am not a good listener than I'll go to an empty room, read and repeat until I understand. (Lily, 5/08/2005)

\section{Note-taking}

I can get the main ideas; take down the main points, taking notes. (Albert, $8 / 08 / 2005)$

\section{Visualisation}

I would pick up specific words, create an image for what the person is saying. (Albert, 8/08/2005)

\section{Social Mediation}

Those students who had opportunities - or made the effort - to attend tutorials, or knew other students enrolled in the same course as them, reported that they used social strategies.

\section{Cooperation}

I ask my classmates or the one sitting beside for what the lecturer is saying. (Ian, $4 / 08 / 2005)$

As discussed earlier, while those students interviewed were enrolled in the same distance study skills course, each had different opportunities and facilities available to them. All students enrolled in the study skills course offered at USP's Vanuatu campus, for example, could have 
attended the centre-based and/ or satellite tutorials available in that region. The Vanuatu campus students, therefore, had available to them opportunities to discuss their problems face-to-face with their tutors. These students also practised and delivered their seminar presentations during these sessions. Learners living in Fiji also had access to similar facilities - centre-based tutorials, satellite tutorials, or visiting tutorials offered by USP's Suva campus. Learners from other parts of Vanuatu and those living in remote areas of the other countries that USP serves, however, did not have easy access to such opportunities primarily due to distance involved. Regardless of the differences in the facilities, opportunities, and course materials made available, all students interviewed for this study reported that they were aware of the listening skills taught, and that they use these listening skills and strategies to help in their learning.

The next section discusses the association of these issues with prior research on listening skills.

\section{Discussion}

The interviews reported here of study skills teachers and those former students who had taken study skills courses, revealed four areas associated with 'listening skills:

1) Differences in the views of L2 teachers and L2 students

2) Differences in the L2 teachers' and L2 students' views about learning strategies

3) Differences in the views expressed by L2 researchers and L2 teachers

4) Lack of research examining 'listening skills' taught at a distance

\section{Differences in views of the L2 teachers and L2 students}

The first issue raised in this paper was the apparent differences between L2 teachers' and L2 students' perceptions of listening skills. Hawkey (2006) examined the perceptual differences of teachers and students of language learning in the same classroom setting. Nunan $(1986,2000)$ also discussed the differing expectations held by these two groups. Griffiths and Parr (2001) and O'Malley and colleagues (1985) discuss differences in the perceptions teachers and students have about language learning strategies. Since the 'listening strategies' explored in this study are based on the language learning strategies framework of O’Malley et al. (1985), this framework will be used to examine the strategies teachers and learners reported using. As indicated, the sample of this study comprised 5 teachers and 19 students, all of whom reported differences in views on listening strategies taught and learned. While the study skills teachers expected their students to bring certain baseline skills to the classroom, they also indicated that 'anonymity' created by the distance mode did result in problems. For example, the teachers interviewed indicated that they expected their students to take notes, listen for information, and involve themselves in discussions and queries; the students, on the other hand, did not report these same expectations as being imparted by the teachers.

Nonetheless, all students interviewed had successfully completed the study skills course - with or without their teachers' support - and all indicated that they were aware of what skills they needed to assist and enhance their learning. They also indicated they felt comfortable with the level of independence the distance mode offered them in their learning path. The study skills teachers, on the other hand, felt that their students lacked the skills, that they needed more support, and were 
generally not up to the level necessary, mostly because English was not their first language. During the interviews, however, none of the students discussed these problems associated with the language. Thus, differences in views about skills and expectations can be seen in this study.

\section{Differences in L2 Teachers' and L2 Students' Views on Learning Strategies}

The second 'issue' revealed from this study is that of the reported listening strategies USP students say they use. While USP's study skills teachers reported that they faced limitations in terms of teaching the 'listening skills' component of the study skills course and indicated that they felt the students still lacked needed 'listening skills', the students, on the other hand, reported on the various metacognitive, cognitive, and social mediation strategies they used to develop their listening skills. Data from the student interviews revealed a mixture of the three strategies students reported employing. The study skills teachers, however, indicated little awareness of the strategies that the students themselves reported they were using. Moreover, the students reported using a variety of strategies, even though in most cases they had studied at a distance and mostly in isolation.

\section{Differences in the views of $L 2$ researchers and $L 2$ teachers}

This study confirms earlier research findings examining differences in the views expressed by L2 researchers and L2 teachers. Berne's (1996, 1998) and Mendelsohn's (2001a, 2001b,) studies found that L2 teachers made little use of listening research to inform their teaching L2 courses in classroom settings. These studies also found that the teachers rarely discussed research on listening with their colleagues. Additionally, the teachers rarely spelled out to their students the learning strategies they wanted them to use in the classroom. USP's study skills teachers were found to hold similar views and reaffirm those views expressed by Berne (1996) who found that teachers do not refer to listening research since they believe that such studies do not provide the answers they need for effective teaching in the classrooms. As Mendelsohn (2001b) found, studies conducted by researchers have not reached the classroom, primarily because many of the researchers have never themselves worked in a classroom. According to Mendelsohn, studies should be conducted by the teachers themselves, or by researchers who are actively involved in the classrooms. Even though the study reported here examines a very different 'distance education' situation, at USP the mismatch between researchers' and practitioners' views on theory and practice is manifest.

\section{Lack of research on listening skills taught by distance}

According to Vandergrift (2004), listening skills are difficult to observe in a learning environment and equally difficult to define. Moreover, learning listening skills can be a very stressful experience for students learning a second language simply because they are often unable to process information quickly enough to understand (Goh \& Taib, 2006). Nonetheless, studies on listening skills, whether in terms of 'listening comprehension' (Hadley, 2001; Lund, 1990) or 'listening strategies' used (Goh, 2002; O'Malley \& Chamot, 1990) have been conducted in real classrooms settings, or situations (i.e., tutorials) wherein teachers and students can interact faceto-face. The factor that distinguishes this study from earlier studies is that the students being taught and undergoing the learning process, are enrolled in study skills courses offered at USP by the distance mode. In short, the students that comprise the sample of this study are or were studying remotely and asynchronously. While all these studies looked at factors affecting L2 
students' listening skills, none have specifically examined students' learning listening skills at a distance. Thus, it is logical to suggest that the insights from research conducted in physical classroom settings cannot be fully applied to students learning at a distance. For this reason alone, it remains difficult to compare distance students' experiences of learning listening strategies based on literature garnered from research conducted in physical face-to-face classroom research settings.

\section{Conclusion}

Vandergrift, Goh, Mareschal and Tafaghodtari (2006) have examined the shift of research interest towards listening comprehension. More recent studies have focused on learners' self-reporting of their understanding and awareness of processes involved in listening in a second language. Vandergrift and colleagues (2006) believe that the students' awareness of the strategies used can have a positive influence on their listening development. In this study, students enrolled in USP distance programmes of study showed an awareness of strategies used, while the USP teachers, on the other hand, reported differing views, based primarily on their lack of contact with distance students. This disconnect suggests that USP's teachers, whether they teach in classrooms or at a distance, must strive to become more aware of their students' learning processes. To overcome this apparent mismatch manifest between the views of researchers, classroom teachers, and students, it is suggested the teachers themselves should be encouraged to conduct research in the classrooms.

Previous studies have mostly explored students' enrolled in study skills courses in a face-to-face learning environment or they have looked at students who learnt foreign languages by distance (Doughty \& Long, 2003). According to Boyle (1995), however, very few published reports report on study skills taught by distance. Additionally, most current distance education research studies tend to report on the use of new technology, online learning, multi-media language learning, and regular contact between learners and teachers (Harris, 2003; Harsh and Sadiq, 2002; Strambi \& Bouvet, 2003). There remains, however, a large body of students whose situation demands that they still must study at a distance using traditional approaches to distance education delivery such as is the case of those students enrolled in USP. Due to this lack of comparative literature in the field of distance education on this topic, an attempt was made here to compare the USP research reported here with similar studies conducted in other fields such as 'listening skills' and 'learner strategies.'

\section{Limitations}

This study shed light on a particular group of teachers and students in a particular educational setting. The sample of this study used only a small group of teachers and learners from USP. A larger sample, with more differences in the method of course delivery and learners from other countries served by USP, may have revealed more insights or revealed other perceptual differences. Regardless, the study achieved its objective, by contributing to an understanding of teachers' expectations and learners' perceptions of the listening skills in a distance education setting.

\section{Future Research}

Future research on teachers' expectation and learners' perception of language learning strategies, perhaps, should focus on distance learners due to the explosive growth taking place in this 
educational sector. It would be useful for researchers from universities, like USP, to conduct further research to acquire a better understanding of learners' strategy use, skills awareness, and teachers' views about students who are learning via distance education modes of course delivery. Such research would also help to fill the gap between research and practice, a problem as indicated by Berne (1996), Hawkey (2006), Mendelsohn (2001a), and Nunan (1986), and which has been discussed in this study. The University of the South Pacific serves a vast region in which multi-media, advanced technology, face-to-face learning, and regular contact with learners remains a largely unattainable dream for most students and educators. Reflective revision of all stakeholders' views is therefore necessary, so that those students who study by traditional distance education methods of course delivery are not overlooked or ignored by researchers, teachers, or students.

\section{References}

Anderson, A., \& Lynch, T. (1988). Listening. Oxford: Oxford University Press.

Berne , J. E. (1998). Examining the relationship between L2 listening research, pedagogical theory, and practice. Foreign Language Annals, 31(2), 169-190.

Berne , J. E. (1996). Current Trends in L2 listening Comprehension Research: Are researchers and language instructors on the same wavelength? Minnesota Language Review, 24(3), 610 .

Berne , J. E. (1995). How does varying pre-listening activities affect second language listening comprehension? Hispania, 78(2), 316-329.

Bolabola, C., \& Wah, R. (Eds.) (1995). South Pacific women in distance education. Studies from the countries of the University of the South Pacific. Suva: University of the South Pacific and the Commonwealth of Learning.

Brown, J. I. (1987). Listening - Ubiquitous yet obscure. Journal of the International Listening Association, 1, 3-14.

Boyle, R. (1995). Language Teaching at a Distance: From the first generation model to the third. System, 23(3), 283-294.

Chamot, A. U. (2005). Language Learning Strategy Instruction: Current issues and research. Annual Review of Applied Linguistics, 25, 112-130.

Chamot, A. U., \& El-Dinary, P. B. (1999). Children's learning strategies in immersion classrooms. The Modern Language Journal, 83(3), 319-341.

Doughty, C. J., \& Long, M. H. (2003). Optimal psycholinguistic environments for distance foreign language learning. Language Learning and Technology, 7(3), 50-80.

Dunkel, P. (1991). Listening in the Native and Second/ Foreign Language: Towards an integration of research and practice. TESOL Quarterly, 25(3), 431-457. 
Same Size Doesn't Fit All: Insights from research on listening skills at the University of the South Pacific (USP) Chand

Feyten, C. M. (1991). The Power of Listening Ability: An overlooked dimension in language acquisition. The Modern Language Journal, 75(2), 173-180.

Glaser, B. G., \& Strauss, A. L. (1967). The Discovery of Grounded Lheory: Strategies for qualitative research, New York: Aldine.

Griffiths, C., \& Parr, J. (2001). Language-Learning Strategies: Theory and perception. ELT Journal, 55(3), 247-254.

Goh, C. C. M. (2002). Exploring listening comprehension tactics and their interaction patterns. System, 30, 185-206.

Goh, C., \& Taib, Y. (2006). Metacognitive instruction in listening for young learners. ELT Journal, 60(3), 222-232.

Hadley, O. A. (2001). Teaching language in context. (3rd. edition).Toronto: Heinle \& Heinle.

Harris, V. (2003). Adapting classroom-based strategy instruction to a distance learning context. TESL-EJ, 7(2). Retrieved July 18, 2005 from: http://writing.berkeley.edu/TESLEJ/ej26/a1.html

Harsh, O. K., \& Sadiq, S. M. (2002). Role of Delivery, Course Design and Teacher-Student Interaction: Observations of adult distance education and traditional on- campus education. International Review of Research in Open and Distance Learning, 3(2). Retrieved May 9, 2006 from: http://www.irrodl.org/index.php/irrodl/article/viewArticle/92/171

Hawkey, R. (2006). Teacher and learner perceptions of language learning activity. ELT Journal, $60(3), 242-252$.

Leontiev, A. (1981). Psychology and the language learning process. Oxford: Pergamon.

Lund, R. J. (1990). A taxonomy for teaching second language listening. Foreign Language Annals, 23, 105-115.

Khaldieh, S. A. (2000). Learning strategies and the writing processes of proficient vs. lessproficient learners of Arabic. Foreign Language Annals, 33(5), 522-533.

Khan, V. (2005). LL114:English for Academic Purposes, Introduction and Assignments, Semester 2. Suva: DFL Support Centre, USP.

Map of USP . (n.d.). Map of the University of the South Pacific service area: November 20, 2004 from: http://www.usp.ac.fj/uspnet

Martin, P. Y., \& Turner, B. A. (1986). Grounded theory and organisational research. The Journal of Applied Behavioural Science, 22(2), 141-157.

Mendelsohn, D. J. (2001a). Listening Comprehension: We've come a long way, but.... Contact, 27(2), 33-40. 
Same Size Doesn't Fit All: Insights from research on listening skills at the University of the South Pacific (USP) Chand

Mendelsohn, D. J. (2001b). Teaching is for researchers, too. TESOL Matters, 11(4), Retrieved August 10, 2006 from:

http://www.tesol.org/s tesol/sec document.asp?CID=194\&DID=908

Nunan, D. (1986). Communicative Language Teaching: The learner's view. Paper presented at 1986 RELC Regional Seminar, Singapore . 21-26 April.

Nunan, D. (2000). Seven hypotheses about language teaching and learning. Plenary presentation, 2000 TESOL Convention, Vancouver. 14-18 March.

O’Malley, J. M., \& Chamot, A. U. (1990). Learning strategies in second language acquisition. Cambridge: Cambridge University Press.

O’Malley, J. M, Chamot, A. U., \& Kữpper, L. (1989). Listening comprehension strategies in second language acquisition. Applied Linguistics, 10(4), 418-437.

O’Malley, J. M., Chamot, A. U., Manzanzres, G. S., Kupper, L., \& Russo, R. P. (1985). Learning strategies used by beginning and intermediate ESL students. Language Learning, 35(1), 2146.

Oxford, R. (1990). Language Learning Strategies: What every teacher should know. Rowley MA.: Newbury House.

Oxford , R. (1993). Research update on teaching L2 listening. System, 21(2), 205-211.

Rankin, P. T. (1930). Listening Ability: Its importance, measurement, and development. Chicago Schools Journal, 147-179.

Rost, M. (1990). Listening in language learning. London: Longman.

Rubin, J. (1975). What the "good language learner" can teach us. TESOL Quarterly, 9(1), 41-51.

Rubin, J. (1994). A review of second language listening comprehension research. Modern Language Journal, 78(2), 199-221.

Rubin, J., \& Thompson, I. (1994). How to be a more successful language learner. (2nd. Ed.). Boston: Heinle \& Heinle.

Schumann, F. (1980). Diary of a >anguage Learner: A further analysis. In R. Scarcella \& S. Krashen (Eds.), Research in second language acquisition (pp. 51-57). Rowley, MA.: Newbury House.

Stern, H. H. (1975). What can we learn from the good language learner? Canadian Modern Language Review, 31, 304-318.

Strambi, A., \& Bouvet, E. (2003). Flexibility and Interaction at a Distance: A mixed-mode environment for language learning. Language Learning and Technology, 7(3), 81-102.

Strauss, A. L., \& Corbin, J. M. (1977). Grounded theory in practice. Thousand Oaks, CA.: Sage. 
Same Size Doesn't Fit All: Insights from research on listening skills at the University of the South Pacific (USP)

Chand

Strevens, P. (1978). New orientations in the teaching of English. Oxford: Oxford University Press.

Takeuchi, O. (2003). What Can We Learn from Good Language Learners: A qualitative study in the Japanese foreign language context. System, 31(3), 385-392.

University of the South Pacific. (2004). A vision to the year 2020. Background papers. Suva: The University of the South Pacific.

Vandergrift, L. (1997a). The Comprehension Strategies of Second Language (French) Listeners: A descriptive study. Foreign Language Annals, 30(3), 387-409.

Vandergrift, L. (1997b). The Cinderella of Communication Strategies: Reception strategies in interactive listening. Modern Language Journal, 81(4), 494-505.

Vandergrift, L. (2003). Orchestrating Strategy Use: Towards a model of the skilled L2 listener. Language Learning, 53, 461-494.

Vandergrift, L. (2004). Listening to learn or learning to listen? Annual Review of Applied Linguistics, 24, 3-25.

Vandergrift, L., Goh, C., Mareschal, C., \& Tafaghodtari, M. (2006). The Metacognitive Awareness Listening Questionnaire: Development and validation. Language Learning, 53(3), 431-462. 


\section{Appendix A}

Map of USP Region

USP Member Countries: Cook Islands, Fiji, Kiribati, Marshall Islands, Nauru, Niue, Samoa, Solomon Islands, Tokelau, Tonga, Tuvalu and Vanuatu.

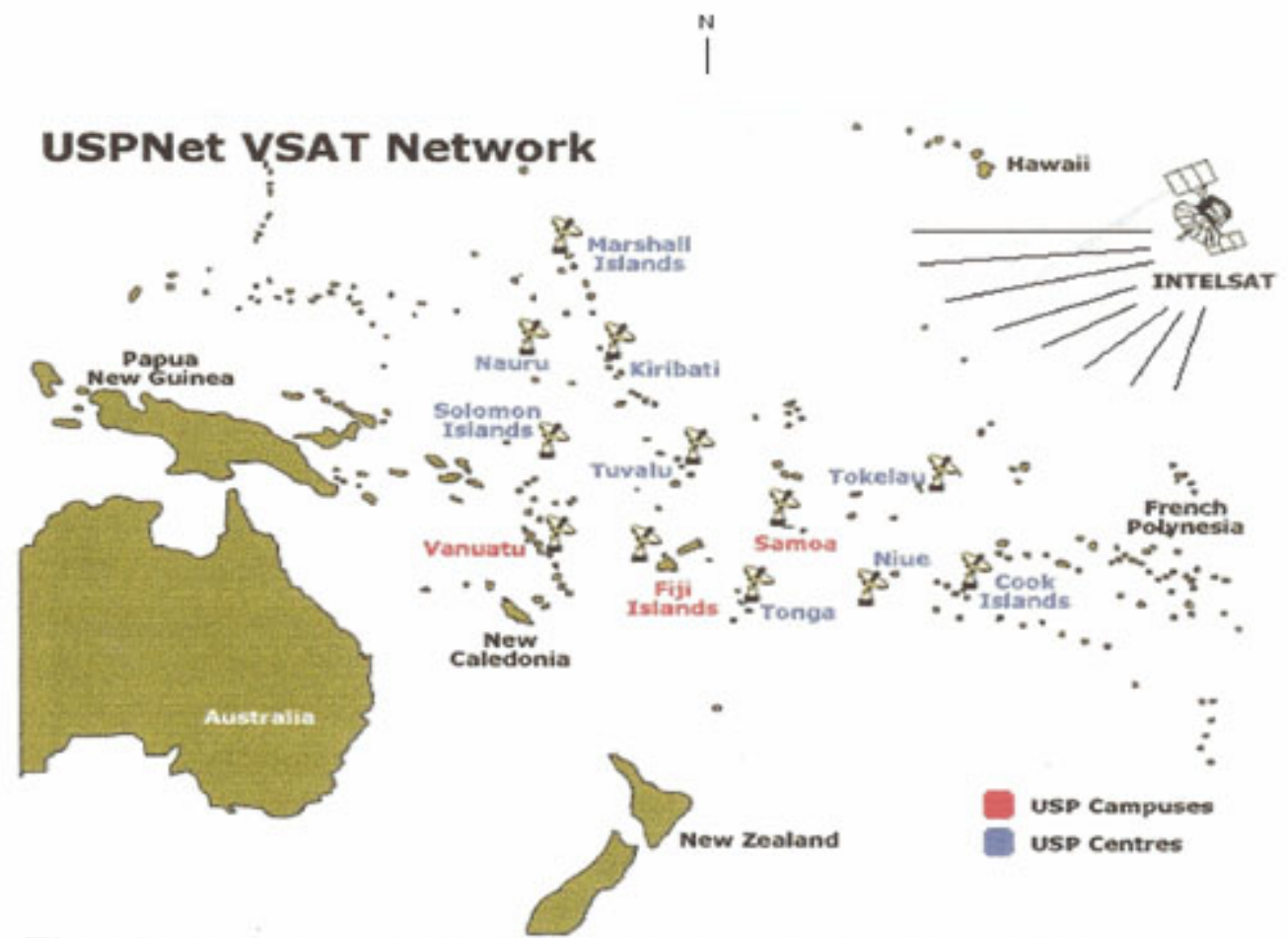

(Fig. 1 shows the location of the various countries and the satellite communication system). 
Same Size Doesn't Fit All: Insights from research on listening skills at the University of the South Pacific (USP) Chand

\section{Appendix B}

Study Skills course, Semester 2, 2005 Schedule

\begin{tabular}{|c|c|c|}
\hline Week No. and date & Unit & Assignments and tutorials \\
\hline 1: 11-15 July & 1: Writing I: Getting started & \\
\hline 2: 18-22 July & $\begin{array}{l}\text { 2: Writing II: Continuing the } \\
\text { process }\end{array}$ & $\begin{array}{l}\text { Satellite tutorial: Thursday } 21 \\
\text { July } 2005-6-7 \mathrm{pm}\end{array}$ \\
\hline 3: 25-29 July & 3: Research & \\
\hline 4: 1-5 August & 4: Reading & \\
\hline 5: 8-12 August & $\begin{array}{l}\text { 5: Rea ding and interpreting } \\
\text { texts (Listen to Tape } 1 \text { : } \\
\text { Reading and interpreting text) }\end{array}$ & \\
\hline 6: 15-19 August & $\begin{array}{l}\text { 6: Taking notes from writing } \\
\text { sources }\end{array}$ & $\begin{array}{l}\text { Satellite tutorial: Thursday } 18 \\
\text { August 2005: } 6-7 \mathrm{pm}\end{array}$ \\
\hline $7: 22-26$ August & 7: Writing III: Presentation & $\begin{array}{l}\text { Assignment } 1 \text { due: } 26 \text { August } \\
2005\end{array}$ \\
\hline 29August- 2 September & Mid-Semester Break & \\
\hline 8: 5-9 September & $\begin{array}{l}\text { Mid-Semester Test: } 7 \\
\text { September }\end{array}$ & $5.00 \mathrm{pm}$ local time \\
\hline 9: 12-16 September & 8: Report writing & $\begin{array}{l}\text { Satellite tutorial: Thursday } 15 \\
\text { September } 2005: 6-7 \mathrm{pm}\end{array}$ \\
\hline 10: $19-23$ September & 8: Report writing & \\
\hline 11: 26-30 September & $\begin{array}{l}\text { 9: Seminar presentation (View } \\
\text { videotape available at USP } \\
\text { Centre). Use the blank tape for } \\
\text { recording your seminar } \\
\text { presentation. }\end{array}$ & \\
\hline $12: 3-7$ October & $\begin{array}{l}\text { 10: Listening to lectures and } \\
\text { taking notes (Listen to Tape } 2 \text { : } \\
\text { Listening to lectures) }\end{array}$ & $\begin{array}{l}\text { Assignment } 2 \text { due: } 3 \text { October } \\
2005 \\
\text { Satellite tutorial: Thursday } 6 \\
\text { October } 2005: 6-7 \mathrm{pm}\end{array}$ \\
\hline 13: $10-14$ October & Revision & $\begin{array}{l}\text { Assignment } 3 \text { due: } 14 \text { October } \\
2005\end{array}$ \\
\hline 14: 17-21 October & Revision & $\begin{array}{l}\text { Satellite tutorial: Thursday } 20 \\
\text { October } 2005: 6-7 \mathrm{pm}\end{array}$ \\
\hline $\begin{array}{l}15: 24-28 \text { October } \\
16: 31 \text { October- } 4 \text { November } \\
17: 7-11 \text { November }\end{array}$ & $\begin{array}{l}\text { Study Break } \\
\text { Examinations: Check with } \\
\text { examination exact time and }\end{array}$ & $\begin{array}{l}\text { your USP Centre for the } \\
\text { date of your }\end{array}$ \\
\hline \multicolumn{3}{|c|}{ Material supplied for the course: } \\
\hline
\end{tabular}


Same Size Doesn't Fit All: Insights from research on listening skills at the University of the South Pacific (USP) Chand

\section{Appendix C}

Details of the teachers of other subjects selected for interview

\begin{tabular}{lllll}
\hline & Name & Gender & $\begin{array}{l}\text { Teaching Experience } \\
\text { (Specifically SST) }\end{array}$ & Location \\
1 & Judy & Female & 10 years & Vila, Vanuatu \\
2 & Morgan & Male & 5 years & Labasa, Fiji \\
3 & Sahil & Male & 4 years & Suva, Fiji \\
4 & Uma & Female & 5 years & Lautoka, Fiji \\
5 & Wendy & Female & 3 years & Labasa, Fiji \\
\hline
\end{tabular}

Details of the past learners selected for the interview

\begin{tabular}{llllll}
\hline & Name & $\begin{array}{l}\text { Place (centre of } \\
\text { enrolment) }\end{array}$ & Gender & Programme & Profession \\
1 & Pravin $\#$ & Suva & Male & $\begin{array}{l}\text { Dip Legal } \\
\text { Studies }\end{array}$ & Prosecution Office \\
2 & Tevita $*$ & Suva & Male & BEd Primary & Teacher \\
3 & Francis * & Suva & Female & Bed Primary & Teacher \\
4 & Vidya $\#$ & Labasa & Female & BA & Domestic Duties \\
5 & Thelma $\#$ & Labasa & Female & LLB & Joumalist/student \\
6 & Priya & Labasa & Female & BA GCE & Student \\
7 & Una & Labasa & Female & BEd & Student \\
8 & Lote & Labasa & Female & BA & Student \\
9 & Kamal & Lautoka & Female & BA GCE & Student \\
10 & Nisha & Lautoka & Female & BA & Student \\
11 & Nita $\#$ & Lautoka & Female & BEd & Teacher \\
12 & Sheena $\#$ & Lautoka & Female & BEd & Teacher \\
13 & Kumar $\#$ & Lautoka & Male & BEd & Teacher \\
14 & Jane & Vila, Vanuatu & Female & BA & Library \\
& & & & & Assistant/student \\
15 & Albert & Vila, Vanuatu & Male & LLB & Student \\
16 & Martin & Vila, Vanuatu & Male & LLB & Student \\
17 & Ian & Vila, Vanuatu & Male & MBBS & Student \\
18 & Leni & Vila, Vanuatu & Male & LLB & Church \\
& & & & & Minister/student \\
19 & Luke & Vila, Vanuatu & Male & LLB & Student \\
\hline
\end{tabular}

Note: * could not get to tutorial ses sions because of distance

\# could not attend all tutorial sessions due to work commitments

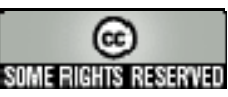




\title{
Combating HIV/AIDS Epidemic in Nigeria: Responses from National Open University of Nigeria (NOUN)
}

\author{
Terhemba Nom Ambe-Uva \\ National Open University of Nigeria
}

\begin{abstract}
Universities have come under serious attack because of their lackluster response to HIV/AIDS. This article examines the response of National Open University of Nigeria (NOUN) and its strategic responses in combating HIV/AIDS epidemic. This is achieved by examining NOUN's basic structures that position the University to respond to the epidemic; and second, by assessing HIV/AIDS strategies and policy framework the University has put in place. An interpretative epistemological stance was used for this study, and a qualitative research involving focus group discussion (FGD) and analysis of secondary data was carried out. Results showed that NOUN has identified the impact the epidemic has on the university, although it has yet to institutionalize an HIV/AIDS policy. NOUN's Draft Service Charter, however, has identified the fight against HIV/AIDS as a core mandate of the University, and the introduction of HIV/AIDS certification programs can be viewed as proactive policies in response to the epidemic. Results of this study are discussed in terms of their relevance to future research and the impact such policy frameworks may have on combating the epidemic, both within the University and the wider community.
\end{abstract}

Keywords: National Open University of Nigeria; HIV/AIDS; epidemic; institutional policy; basic structures; Nigeria

\section{Introduction}

The article is part of a larger endeavor, the aim that was to explore the response of National Open University of Nigeria (NOUN) in combating the Human Immunodeficiency Virus (HIV) and Acquired Immune Deficiency Syndrome (AIDS) epidemic. While an earlier study (Peters \& Olugbemiro, 2005) focused on the efficacy of the introduction of Post Graduate Diploma (PGD) program in HIV/AIDS Education and Management at NOUN in fighting the HIV/AIDS epidemic, the study reported here focused on the strength of distance education (DE) in fighting the epidemic. Specifically, it analysed various policy frameworks put in place, and measured both staff and students' perceptions about the University’s response to HIV/AIDS.

A recent study by Peters and Olugbemiro (2005) shows that the introduction of an HIV/AIDS program at NOUN would contribute to raising the level of awareness in the different segments of the Nigerian society, stimulate research, and create research networks on HIV/AIDS in Nigeria. It 
Ambe-Uva

also notes that the program would facilitate human resource capacity building and support positive behavioral changes. An earlier study by Aderinoye and Ojokheta (2004) investigated the links between DE and HIV/AIDS. This study shows that DE in Nigeria and throughout the continent of Africa is helping to democratize and spread knowledge, even to those living in remote, marginalized, and isolated communities. The Aderinoye and Ojokheta study also acknowledged that DE has helped individuals to acquire basic literacy and arithmetic skills, and in some instances, earn certificates in higher degrees, as well as obtain a multitude of broad-brush education skills that target whole populations (e.g., governance skills, life skills, AIDS education aimed at preventing and reducing its spread, improved farming techniques, etc.).

It is in recognition of the above that the University of Ibadan (a dual mode university) was the first university in Nigeria to establish a Diploma program in HIV/AIDS Education at the Distance Learning Centre to assist in developing the capacity of workers on HIV prevention. This challenge was soon taken over by NOUN (a single mode university) to introduce a postgraduate diploma in HIV/AIDS Education and Management. The success of this program has informed the decision of the University to introduce the program at the diploma level.

In another study, Pridmore and Yates (2006) examined the strengths of open, distance, and flexible education in HIV/AIDS prevention and mitigation. These scholars argue that to confront AIDS and meet Millennium Development Goals in countries where HIV/AIDS is prevalent, governments must go beyond current efforts and accelerate conventional responses. This can be achieved by increasing access and quality of education and schooling, raising public consciousness, and encouraging people to practice healthy behavior, through emerging accessible, flexible, and cost effective DE. Furthermore, growing evidence indicates that in SubSaharan Africa (SSA), a geography where teachers are in short supply and institutional capacity to support teaching training is inadequate; so where new teacher graduates replace those teachers who have fallen victim to the AIDS pandemic, DE remains an effective strategy for teacher training (Aderinoye \& Ojokheta, 2004; UNESCO, 2002; 2001; Pridmore \& Nduba 2000).

The question that demands our attention here is, 'To what extent have universities recognized this 'window of opportunity' and have included HIV/AIDS not only in their curriculum, but also developed effective institutional policies to combat the epidemic?' Available evidence suggests that universities are yet to take up this challenge fully. As noted by Kelly (2002), although there has been considerable tinkering around the edges, universities have yet to take the 'bull by the horn' to gain control over the HIV/AIDS epidemic. In some cases, universities have undergone what would be the medical equivalent to a botched heart operation. Moreover, none has received the heart transplant that they really need.

This study was conducted to shed light on the following questions:

1) How does education influence the HIV/AIDS epidemic? In addition, how has education itself been affected by HIV/AIDS?

2) What role can universities play in the fight against HIV/AIDS?

3) What efforts have NOUN, a single mode DE university, made in the fight against HIV/AIDS? 
Ambe-Uva

\section{Research Approach}

This study follows an interpretive and case-based research approach. Walsham and Waema (1994), who noted that the use of a single case as a basis for drawing inferences on a particular area of study is related to an interpretive epistemological stance, illustrate the qualitative and inductive nature of case-based research. Orlikowsi and Baroundi (1991) also maintained that case-based interpretive analysis involves inductive reasoning, which is guided and couched within a theoretical framework, which in turn, leads from the concrete case situation to the social totality beyond the individual case. Stake (1994) has listed the attributes of a case study to include uniqueness, functional specificity, integrated bounded system, and consistency. Noting that case studies can be either qualitative or quantitative, Stake adds that a case study is not a methodological choice, but a choice of objects to study. Given the research questions, the case study design research methodology was selected for this study.

Lincoln and Guba (1985) argue that the primary instrument in qualitative research is human - i.e., the researcher might pose certain problems in evaluating their study's objectives as the 'author.' This situation is what B odker and Pedersen (1991) termed being a 'cultural insider.' However, by employing focus discussion groups and analyzing secondary data, it was determined that objectivity could be enhanced, because the focus of the research centered on the validity of the interpretation as distinct from qualitative research, which focus on questions and methods.

\section{Background to the Study}

HIV and AIDS constitute one of the biggest threats to the global agenda. HIV/AIDS have been noted to imperil not only humankind, but also humankind's institutions. In short, HIV/AIDS undermines the very institutions that are designed to protect communities (UNESCO, 2000a), including educational institutions. Indeed, the epidemic is presenting enormous challenges to the higher education sector by weakening demand for - and access to - education by depleting institutional and human capacity, reducing availability of financial resources, and by impeding the delivery of quality education (UNESCO, 2006). Nonetheless, the World Education Forum, held in Dakar in April 2000, noted that a key objective of any international strategy must be to realize the enormous potential that the education system offers as a vehicle to help reduce the incidence of HIV/AIDS and to alleviate its impact on society (UNESCO, 2000a). Growing evidence indicates that education is one of the best defenses against HIV infection, because it equips young people with invaluable tools that increase self-confidence, social and negotiation skills, to improve earning capacity and family well-being, which in turn, fights poverty and promotes social progress.

From across the 15 countries surveyed in Round Two of the 'Afrobarometer,' (http://www.afrobarometer.org/) evidence indicates that large proportions of Africa's people have either lost family or friends to AIDS, or suffer under the burdens of AIDS by caring for sick family members or orphans (Afrobarometer, 2004). In most of these countries cited in the Afrobarometer, the HIV prevalence rate exceeds five percent, numbers that indicates that the epidemic is now undermining every aspect of society, including families, health, education, industry, and economic development (Kelly, 2003).

According to Piot (cited in Katjavivi \& Otaala, 2003), education is at the core of one of the great challenges facing humanity, namely winning the fight against AIDS. Education is life sustaining because it gives children and young people the life-skills and tools they need to carve out their lives. Clearly, education is a lifelong source of comfort, renewal, and strength for people. Piot 
Ambe-Uva

also noted that the world's goals in promoting 'Education for All' and in turning back the AIDS epidemic are mutually dependent. Without education, AIDS will continue to spread. If AIDS remains out of control, education will be out of reach. The focus of this study is placed on the synergy between distance education and HIV/AIDS.

\section{Education and HIV Infection}

Studies by Vandemoortele and Delamonica (2002) show the inverse association between disease burden and the level of education that exists for most infectious diseases. The incidence of malaria and cholera, for instance, are known to be negatively associated with the level of education - those who know less about malaria and cholera are more apt to become infected. For HIV/AIDS, however, there may be an exception during its initial introduction into a society because of its main propagation channel, but further down the road, the 'education vaccine' theory works. Indeed, it is often said that people 'who wear a tie, do not die of cholera.' Combined with macroeconomic policies, education is a key tool in promoting social wellbeing and contributing to poverty reduction. This is because education directly affects national productivity, which in turn determines overall living standards and a country's ability to compete in the global economy (Krueger \& Mikael, 2000). Investment in education is vital simply because it helps countries, like Nigeria, to achieve six of the eight-millennium development goals: 1) poverty reduction, 2) access to universal primary education, 3) gender equality, 4) reduced infant mortality, 5) improved maternal health, and 6) lower prevalence of HIV/AIDS. Making education available to both genders, boys and girls alike, has been proven to provide protection against HIV infection (World Bank, 1999). Evidence that education itself protects against HIV is strong. Data from the late 1980s and early 1990s, when the epidemic was just emerging, shows a positive correlation between the level of education and rates of infection. Kelly (2000) in a study in Zimbabwe found a marked decline in HIV prevalence rates in 15-19 year old males and females with a medium to higher-level education, compared to increases among those with lower educational levels.

Education is a central tool required to reduce the social and economic vulnerability of women. Evidence shows that education aimed specifically at girls and women can slow and even reverse the spread of HIV. Education does this by arming women with valuable life and decision-making skills - which all contribute to poverty reduction, gender equality, personal empowerment, and increased awareness of human rights issues. Women can then pass on to their children, partners, and friends these valuable skills and knowledge. Education enables women's economic independence by delaying marriage, proactive family planning, and by increasing their ability to engage in paid work to support themselves and their families (UNAIDS, 2000; Gregson, Waddell, \& Chandiwana, 2001).

\section{The Impact of HIV Infection on Education}

HIV/AIDS has had a pronounced affect on both the supply and demand for education. The epidemic can affect the performance of educators through increased deaths, absence, and the financial and emotional burden they face in caring for relatives and friends stricken by AIDS. For instance, it has been shown that the death of one teacher deprives a whole classroom of children. In 1999 alone, an estimated 860,000 children in SSA lost teachers to AIDS (Kelly, 2000b). In a recent survey in Nigeria, it was discovered that illness (of one's self, relatives, or friends) combined with attending funerals, accounted for more teachers' reported work absences than any other reason ( Ssengonzi, Schlegel, Anyamele \& Olson, 2004). Death and illness are thus affecting education sector administrators, finance and planning officials, inspectors, and 
Ambe-Uva

managers in many countries. These losses represent the loss of sector knowledge, and holds major negative consequences.

Table 1. School administrators’ reasons cited for the number of days missed

\begin{tabular}{lcc}
\hline Reasons for Absence & $\begin{array}{c}\text { \% Responding } \\
\text { "Yes" }\end{array}$ & $\begin{array}{c}\text { Mean number of } \\
\text { days missed }\end{array}$ \\
\hline Illness (self, relatives, \& friends) & 33.8 & 1.1 \\
Funerals & 27.1 & 0.6 \\
Training & 47.4 & 2.6 \\
To do other non-teaching work & 14.9 & 0.4 \\
Other factors & 22.6 & 0.8 \\
\hline Total & & 5.4 \\
\hline
\end{tabular}

Source: Ssengozi et al., 2004, p. 30

The impact of the epidemic on the demand for education is less clear, however. While Africa's school age population will be smaller, it will nonetheless continue to grow. AIDS mortality does not have its primary effect on school-age children. And while an estimated 3.8 million children have been infected since the epidemic began, more than two-thirds have died. UNAIDS reports that in 1999, 570,000 children under 14 died of AIDS, the vast majority of them in SSA (UNAIDS, 2000). During this same time frame, approximately four times as many adults (age 15 to 49) died of AIDS. This fundamentally generates a cohort of AIDS orphans (a huge population that will require education) which will be put a further at risk of infection and death. In terms of monetary impact, HIV/AIDS is estimated to add between US \$450 million and \$550 million per year (US dollar values for 2000) to the cost of achieving the mandate set out in 'Education For All' (UNESCO, n.d.) in 33 African countries. This implies that the epidemic increases the total 'Education for All' financing gap for the countries by about one-third (World Bank, 2002).

\section{HIV/AIDS and Universities}

When a society needs to face a problem, it typically turns to its schools and asks what they are doing about it. In the context of HIV/AIDS, schools are expected not only to teach, but also instill in their students the skills, knowledge, and values that promote safe behaviors in order to protect themselves against HIV infection. Yet, there are more challenges to these responses from the universities, which themselves are not HIV-free. Kelly (2003) argues that despite the high prevalence of HIV/AIDS inside university populations (i.e., staff and students), it is apparent they have no institutionalized response to slow the scourge. Indeed, formal responses to the epidemic have not yet been integrated into their core operations. Universities instead are slow to react simply because they are embracing a 'hush-up' response to the epidemic.

A growing body of literature, however, shows that it is imperative that universities implement systemic institutional responses to stem the epidemic (Kelly, 2003; Katjavivi \& Otaala, 2003; 
Ambe-Uva

ACU, 2001; Anarfi, 2000; Mwape \& Kathuria, 2000). Listed below are nine reasons that outline the demand for universities to reposition themselves to respond to this growing epidemic:

1) No university is immune to the disease

2) The disease has the potential to impair institutional functioning

3) The long lead time between initial HIV infection and the development of AIDS has major implications for universities

4) Their mandate of 'service to society' demands the engagement of every university to fight HIV/AIDS

5) Universities have a special responsibility for the development of human resources

6) Universities are crucial agents of change and provide leadership to effect such social change

7) Universities must be at the forefront in developing deeper understandings of HIV/AIDS

8) HIV/AIDS raises a host of complex moral, ethical, human rights, and legal issues that cry out for the kind of knowledge, understanding, and insights that universities are specially equipped to provide

9) HIV/AIDS is not a passing phenomenon, but one that is likely to negatively impact society for the remainder of this century

Recent literature shows that African universities are coming to the realization that HIV/AIDS is real and that death is now a daily reality for their staff, their students, and the communities they serve. Pioneering efforts by the Association of African Universities (AAU), the Association of Commonwealth Universities (ACU), and the South African Universities of Vice-Chancellors Association (SAUVCA), have impressed upon African universities the need to adopt a holistic response to the epidemic within their institutions and across the entire higher education sector. The Working Group on Higher Education (WGHE) for the Association for the Development of Education in Africa (ADEA) decided to undertake case studies that examine the ways HIV/AIDS affects several universities in Africa, and to document these universities' particular responses and coping mechanisms. Out of these case studies emerged a synthesis entitled 'Challenging the Challenger: Understanding and expanding the response of universities in Africa to HIV/AIDS' (Kelly, 2001). This report acknowledges that a thick cloak of ignorance surrounds the presence of the disease in the universities - a cloak of death that is lined with layers of secrecy, silence, denial, and fear of stigmatization and discrimination.

\section{Responses from the Educational Sector in Nigeria}

The above challenge from Kelly (2001) has spurred many African universities and the larger educational sector to respond to the HIV/AIDS epidemic. In Nigeria, the Educational Research Network for West and Central Africa contains elaborate review of policy and research documents for the educational sector's response to the epidemic. The alarming spread of HIV/AIDS, which saw the prevalence rate skyrocket from 1.8 percent in 1998 to 5.8 percent in 2001, compelled the Nigerian Government to shift its mechanisms and strategies to prevent the spread of HIV, 
Ambe-Uva

mitigate its consequences, and provide care and support for those living with, or affected by, AIDS. It is within this context that education was identified as a central method for achieving the requisite behaviorial changes needed to stem the epidemic, both inside and outside the classroom. Consequently, the first national workshop on HIV/AIDS and education organized by UNESCO and Federal Ministry of Education (FME) with support from UNAIDS and UK's Department for International Development, was held in Abuja, Nigeria, with the aim of identifying appropriate preventive education response to HIV/AIDS challenges in Nigeria (Ohiri-Anichi \& Odukoya, 2004). As a demonstration of its commitment to addressing the epidemic on continental Africa, Nigeria hosted the Organisation of African Unity (OAU) Summit on HIV/AIDS in June 2001, during which the Abuja Declaration (2001) was made.

The Nigerian government also established an elaborate multi-sector response that focuses on prevention, treatment, and intervention. It established the Presidential Council on AIDS and the National Action Committee on AIDS, the latter comprised representatives from the Presidency, Federal Ministry of Health, Federal Ministry of Education, Federal Ministry of Youths and Sports, Federal Ministry of Finance, and other relevant federal, state, and local parastatals, NGOs, and international organizations working on HIV/AIDS in Nigeria. The HIV/AIDS Emergency Action Plan, coordinated by National Action Committee on AIDS, is the country's current HIV/AIDS policy.

Tangible efforts have since been recorded by the educational sector in Nigeria in prevention, treatment, and intervention. A few worth mentioning in this study are:

a) The Federal Ministry of Education has a full-fledged HIV/AIDS Unit, which supervises and coordinates all HIV/AIDS activities in Nigeria's schools

b) Following the approval of the National Council on Education in March 1999 at its 46th session for the incorporation of sex education into Nigeria's national school curriculum, the Nigerian Educational Research and Development Council (NERDC) collaborated with other government agencies, NGOs, and UN agencies, to develop curriculum on sex education. Sex education is deemed critical in helping young people acquire adequate knowledge, skills, and responsible attitudes, needed to prevent sexually transmitted infections, including HIV/AIDS.

c) In 2002, the National Youth Service Corps (NYSC) in collaboration with UNICEF introduced a peer education program entitled, 'Empowering Youth through Young People.' The objective of this program was to reach new graduates of university programs serving the oneyear compulsory NYSC program with reproductive health and HIV/AIDS messages, train some to be trainers themselves, and for all to act as 'peer educators' in and out of school.

d) Many NGOs, faith-based organizations, and educational institutions have been active in outreach programs, setting up youth counseling centers, promotion of behavior change via radio and television programming, peer education, discussions, awareness, and so forth.

e) eUNESCO supported the establishment of a Preventive Education Unit at the National Teachers Institute (NTI), Kaduna (another single mode DE institution in Nigeria), to assist in the training of teachers in HIV/AIDS.

f) In 2003, the National Institute for Educational Planning and Development (NIEPA) held two seminars in Abuja and Ondo to accelerate Nigeria's educational sector's response to HIV/AIDS pandemic in sub-Saharan Africa. The objectives of these seminars was to develop 
Ambe-Uva

managerial capacity, prevention, planning and impact mitigation, and facilitate access to education for vulnerable children and orphans.

g) In 2003, National Universities Commission/UNESCO/ National Action Committee on AIDS, established 'Youth Friendly Centers' in three universities: Ahmadu Bello University Zaria, University of Nigeria Nsukka, and University of Ibadan.

h) The MacArthur Foundation grant funding to Nigerian universities such as University of Ibadan, Bayero University Kano, and others, to support and strengthen their human capital, institutional facilities, and university systems. The Foundation and the Association of African Universitis, gave the University of Ibadan, to conduct a 'situation analysis' of HIV/AIDS and the development of HIV/AIDS policy. AUU has since extended this grant to University of Ilorin.

i) The National Universities Commission and UNESCO introduced HIV/AIDS training program for all staff of educational institutions in SSA, including primary, secondary, universities, polytechnics/tecnikons, and colleges of education. This program specifically targets teachers and teacher-trainers involved in the delivery of basic and higher education in Africa.

j) Nigerian universities have also benefited from the initiative from African universities Training of Trainers Course (TOT) involving the UNDP and University of Natal for three individuals from each of 31 African universities identified on HIV/AIDS and development. The overall aim of TOT is to contribute to the prevention of HIV/AIDS amongst students and staff within a broader vision/framework designed to address issues of prevention, care and mitigation of the pandemic. The specific aims include: 1) train academic staff in methodology and methods of curriculum development and teaching HIV/AIDS; 2) empower university teachers to integrate HIV/AIDS into their own teaching and provide similar training to colleagues; and 3) enhance research related to HIV/AIDS within the university and among other related stakeholders.

k) Some Nigerian universities have developed and implemented systematic programs to fight HIV/AIDS through the development of HIV/AIDS curriculum for inclusion in a compulsory general studies course.

As commendable as these efforts from the educational sector are, the former Minister of Education, O. Ezekwesili (2007), stated that HIV/AIDS requires imaginative and creative solutions, which demand that the regulatory agencies, the National Action Committee on AIDS, and the educational sector to think outside-the-box. Nigeria's universities, therefore, are being called upon to show more commitment through the development of a comprehensive HIV/AIDS policies designed to fight HIV/AIDS.

\section{National Open University of Nigeria: Background}

The National Open University of Nigeria (NOUN) is the only single mode, distance education university in Nigeria. The University was established on July 22, 1983, by the Open University Act, which subsists in the Law of the Federation of Nigeria (1980) Appendix III. After being closed for several years, the University was re-opened in 2002, and renamed the National Open University of Nigeria (NOUN). NOUN was re-launched upon Nigeria's realization that distance education was becoming an increasingly important policy option for developing countries (Ambe-Uva, 2006). The adoption of distance education is a ". . . process in which a significant 
Ambe-Uva

proportion of the teaching is conducted by 'someone' removed in space and time from the learner. The link between that 'someone' and the learner is therefore necessarily provided by different means of communication and instruction” (Perraton, 2001, p. 79).

A special case for the sustenance of an open university system in developing countries - and especially Nigeria - was made by Jegede (2007). Jegede noted that " Nigeria is an enigma, displaying a glaring contrast of development and inadequacies cohabiting side by side in many spheres of life.” The inadequacies Jegede identified include:

- Using the human development index (HDI) (an index used to measure a country's performance on four key indicators: life expectancy, GNP per capita, gross primary school enrolment, and access to safe water) Nigeria ranked 151 of 174 nations.

- Nigeria, described as country 'too rich to be poor,' is a land of abounding poverty with more than 70 percent of Nigerians living on less than US \$1 a day.

- Nigeria, since independence, has been known for its quality education and its versatile, mobile, and exceptional people. Despite its 'wealth,' over 55 percent of Nigeria's population is illiterate, while another 10 percent remain illiterate due to declining quality in education, or lack of access they need to acquire new skills, after their primary school education has ended.

Nigeria's current context, therefore, is fertile soil for distance education to take root and thrive. Nigeria is currently characterized by population growth, growing demand for education, dwindling of financial resources, increasing fiscal constraints - all conditions that obstruct Nigerian's access to basic and higher education. NOUN aims to meet Nigerian's demand for higher education without compromising quality. Nonetheless, the majority of Nigerian people remain marginalized and hard to reach, that is the poor, illiterate, women, and those living in remote areas. Considering that Nigeria boast of 131.5 million citizens, with an HDI of 0.453 , of which 52.2 percent live in rural areas (ADB, 2006:93-94), it is easy to see and to conclude that Nigeria needs to increase access to basic and higher education provisions for its people. 


\section{Ambe-Uva}

Table 2. Selected basic demographic and education indicators for Nigeria

\begin{tabular}{|c|c|c|c|c|c|c|c|c|}
\hline \multirow{2}{*}{$\begin{array}{l}\text { Basic Indicators } \\
\text { Area }\left(\mathrm{KM}^{2}\right)\end{array}$} & \multicolumn{8}{|c|}{ Most Recent Year } \\
\hline & \multicolumn{8}{|c|}{923768} \\
\hline Population Density (Per KM²) & \multicolumn{8}{|l|}{142} \\
\hline \multirow[t]{3}{*}{ HDI Value (0-1) } & \multicolumn{8}{|l|}{0.453} \\
\hline & 1998 & 1999 & 2000 & 2001 & 200 & 200 & 2004 & 2005 \\
\hline & & & & & 2 & 3 & & \\
\hline \multirow[t]{2}{*}{ Total Population (Millions) } & 112. & 114. & 117. & 120. & 123. & 125. & 128. & 131. \\
\hline & 1 & 9 & 6 & 4 & 1 & 9 & 7 & 5 \\
\hline Urban (\%) & 41.1 & 42.1 & 43.0 & 44.1 & 45.1 & 46.1 & 47.0 & 47.8 \\
\hline Female (\%) & 49.7 & 49.6 & 49.6 & 49.6 & 49.5 & 49.5 & 49.4 & 49.4 \\
\hline $\begin{array}{l}\text { Gross National Income Per capita } \\
\text { (US \$) }\end{array}$ & 260 & 260 & 260 & 300 & 300 & 350 & & \\
\hline \multicolumn{9}{|l|}{ Demographic \& Education } \\
\hline \multicolumn{9}{|l|}{ Indicators } \\
\hline Annual Population Growth Rate & 2.5 & 2.4 & 2.4 & 2.3 & 2.3 & 2.2 & 2.2 & 2.2 \\
\hline \multicolumn{9}{|l|}{ Total } \\
\hline Urban & 5.1 & 4.9 & 4.6 & 4.9 & 4.6 & 4.4 & 4.2 & 4.1 \\
\hline Female & 2.4 & 2.4 & 2.3 & 2.2 & 2.2 & 2.2 & 2.1 & 2.1 \\
\hline $\begin{array}{l}\text { Life Expectancy at Birth- Total } \\
\text { (Years) }\end{array}$ & 44.3 & 44.0 & 43.8 & 43.6 & 43.3 & 43.5 & 43.7 & 43.8 \\
\hline $\begin{array}{l}\text { Life Expectancy at Birth- Female } \\
\text { (Yrs) }\end{array}$ & 45.0 & 44.6 & 44.3 & 43.9 & 43.5 & 43.7 & 43.8 & 44.0 \\
\hline Infant Mortality Rates (per 1000) & 116. & 115 & 115 & 114 & 114 & 113. & 111 & 110. \\
\hline & 2 & 8 & 3 & 8 & 4 & 1 & 9 & 6 \\
\hline Crude Death Rate (per 1000) & 19.1 & 19.2 & 19.2 & 19.3 & 19.4 & 19.2 & 19.0 & 18.8 \\
\hline Total Fertility Rate (per woman) & 6.2 & 6.1 & 6.0 & 5.9 & 5.8 & 5.7 & 5.6 & 5.5 \\
\hline Gross Enrolment Ratio & & & & & & & & \\
\hline Primary-Total & 91.0 & 98.0 & 103 & 103. & 119. & - & - & - \\
\hline & & & 0 & 0 & 0 & & & \\
\hline Primary-Female & 79.0 & 88.0 & 92.0 & 86.0 & $\begin{array}{l}107 . \\
0\end{array}$ & - & - & - \\
\hline Secondary-Total & 33.8 & 34.4 & 34.9 & 35.5 & 36.0 & - & - & - \\
\hline Secondary-Female & 31.1 & 31.3 & 31.4 & 31.6 & 32.0 & - & - & - \\
\hline Adult Illiteracy Rates-Total & 39.0 & 37.5 & 36.0 & 34.6 & 33.3 & 31.9 & 30.6 & 29.2 \\
\hline Adult Illiteracy Rates- Male & 30.1 & 28.8 & 27.8 & 26.7 & 25.6 & 24.5 & 23.5 & 22.4 \\
\hline Adult Illiteracy Rates-Female & 47.4 & 45.7 & 43.9 & 42.3 & 40.7 & 39.1 & 37.4 & 35.8 \\
\hline
\end{tabular}


Ambe-Uva

Table 2 shows that uncertain health outcomes await most Nigerian youths. Indeed, one-third of Nigeria's population lives on less than US $1 \$$ a day, and they lack human development $(<0.5000)$ according to the UNDP 2004 Human Development Index (HDI) which is a measurement of a given country's achievement in terms of life expectancy, educational attainment, and adjusted real income.

Behind South Africa, Nigeria ranks second with the highest number of persons living with HIV/AIDS in SSA. At the end of 2003, approximately 5.4 percent of Nigerian in the age range of 15-49 were HIV-positive, an increase from 1.8 percent 15 years ago (FMOH, 2001; UNAIDS, 2004). Nigeria also has one of the fastest growth rates of new HIV infections and AIDS cases in West Africa. HIV/AIDS has now reached epidemic proportions in Nigeria, having already crossed the threshold of five percent. This means AIDS will soon be the leading cause of adult morbidity and mortality among those age 15-49, arguably the most productive people needed to support any society. This reality will have a devastating impact on all facets of Nigeria's socioeconomic fiber, and will hinder Nigeria's progress in education - the very tool that Nigeria needs to teach its people and thus stem the spread of HIV/AIDS.

This epidemic's impact is far reaching. At time of writing, HIV/AIDS is the world's fourth largest killer, but it ranks number one in SSA (UNAIDS, 2002). In 2002, the region is home to only 7.5 percent of the world's population, yet it accounts for nearly 70 percent of those living with HIV/AIDS, 70 percent of incident HIV infections, and 77 percent of the AIDS deaths (UNAIDS/WHO, 2002). As of 2002, approximately 29.4 million in SSA between ages 15 to 49 were living with HIV/AIDS, a staggering figure of nine percent of the adult population (UNAIDS/WHO, 2002). Whereas life expectancy in the sub-continent increased from 44 years in the 1950s to 59 years in the early 1990s, it plunged to 49 years and is projected to drop even further as the disease spreads (UNDP, 2000a). According to the World Health Organization (WHO, 2002), life expectancy in the region would currently be 62 years if it had not been for the HIV/AIDS epidemic. This means that Nigerian's reduced life expectancy holds serious implications on the health and functioning of Nigeria's universities.

Table 3. Life expectancy with and without AIDS in selected African countries

\begin{tabular}{|c|c|c|c|c|c|c|}
\hline & 2000 & & & 2010 & & \\
\hline Country & $\begin{array}{l}\text { With } \\
\text { AIDS }\end{array}$ & $\begin{array}{l}\text { Without } \\
\text { AIDS }\end{array}$ & Years Lost & $\begin{array}{l}\text { With } \\
\text { AIDS }\end{array}$ & $\begin{array}{l}\text { Without } \\
\text { AIDS }\end{array}$ & Years Lost \\
\hline Botswana & 39.3 & 70.5 & 31.2 & 29 & 73.2 & 44.2 \\
\hline Ethiopia & 45.2 & 56.1 & 10.9 & 42.1 & 60.1 & 18.0 \\
\hline Kenya & 48 & 64.9 & 16.9 & 44.3 & 68.4 & 24.1 \\
\hline Nigeria & 53.6 & 57.8 & 4.2 & 38.9 & 64.9 & 26.0 \\
\hline South Africa & 51.1 & 65.7 & 14.6 & 35.5 & 68.3 & 32.8 \\
\hline Swaziland & 40.4 & 57.7 & 17.3 & 29.7 & 61.5 & 31.8 \\
\hline Zimbabwe & 37.8 & 69.9 & 32.1 & 32.5 & 72.8 & 40.3 \\
\hline Zambia & 37.2 & 58.7 & 21.5 & 38.9 & 72.8 & 33.9 \\
\hline
\end{tabular}


Ambe-Uva

With the gloomy picture painted above, what basic structures does NOUN possesses that will position it to address the HIV/AIDS epidemic? How is NOUN positioned to deal with the epidemic within the university itself? And how can NOUN be of 'service' to the community it serves?

\section{Basic Structures in Noun}

The University has embraced a 'learner-centered' approach to learning. A learner-centered educational process is a departure from the conventional teaching and learning culture, in that one now employs a wide range of tools to effect learning outcomes. These tools recognize and are designed to support self-learning. They include printed course materials, tutor marked assignments, self assessment exercises and feedback systems, radio and television broadcasts, audio and video tapes, CDRoms, help from tutors, and individualized counseling and help, via telephone, facsimile, or electronic mail. These tools enable remote distant delivery to an ever increasing number of learners, despite physical distances.

Equally important, in a relatively large country such as Nigeria, the University's geographic penetration of 18 study centers in 2003, to 27 study centers in 2007, shows that NOUN now services some of remotest the regions in Nigeria. It also shows the geographic extent to which the epidemic can attack the University, especially if concerted efforts are not made to stem the epidemic. As of 2007, NOUN has 35,000 students enrolled and is projected to grow to more than 100,000 by the year's end (Jegede, 2007). The University is therefore an essential means of meeting the needs of Nigerians who, for reasons of distance, work or family commitment, cannot otherwise engage in educational opportunities. In other words, the University reaches people in communities in which they would otherwise be deprived of opportunities to learn. Moreover, NOUN's expansion of its service area is expected to make a significant contribution in stemming the epidemic by increasing people's access to education. Moreover, NOUN's educational programmes are designed in such a way as to enable people to start applying what they have learned immediately (Jegede, 2003).

Table 4. Regional Distribution of NOUN Study Centers

\begin{tabular}{cccccc}
\hline $\begin{array}{c}\text { North- } \\
\text { Central }\end{array}$ & $\begin{array}{c}\text { North- } \\
\text { East }\end{array}$ & North-West & $\begin{array}{c}\text { South- } \\
\text { East }\end{array}$ & South-South & South- West \\
\hline Ilorin & Bauchi & Kano & Akwa & Benin & Akure \\
Jos & Maiduguri & Katsina & Enugu & Calabar & Ibadan \\
Abuja & Yola & Sokoto & Owerri & $\begin{array}{c}\text { Port } \\
\text { Harcourt }\end{array}$ & Lagos \\
Makurdi & Damaturu & Kaduna & Umudike & Yenogoa & Osogbo \\
Minna & & & & & \\
\hline Lokoja & & & & & \\
\hline
\end{tabular}

The University also strives to ensure that those educated will remain in their local communities, thereby reducing localized unemployment rates which, in turn, will help to alleviate rural poverty, increase literacy, and hopefully stimulate and invigorate local economies (Jegede 2003).

The main strength of the University is that it is a fundamental tool needed to break the vicious cycle of poverty that has gripped many areas of Nigeria. NOUN aims to achieve this goal by increasing access to affordable, yet quality education that transcends all barriers. 
Ambe-Uva

\section{Efforts of NOUN in Fighting HIV/AIDS}

The University's response to the HIV/AIDS epidemic is guided by NOUN's Draft Strategic Plan (January, 2005 to December, 2009). This plan identifies the need to provide effective strategies to combat the epidemic, not only within the University itself, but to all the communities it serves. Even before the plan was drafted, however, NOUN was mobilizing against the scourge. In 2004, the School of Science and Technology organized a workshop on HIV/AIDS awareness. This workshop created awareness that underscored the fact that if left unchecked, HIV could very well impair the functioning of the University's workforce.

Table 5. Economic impact of HIV/AIDS on NOUN's workforce

\begin{tabular}{lll}
\hline Direct Costs & Indirect Costs & Systemic Costs \\
\hline Benefit packages & Absenteeism & Loss of workplace cohesion \\
Recruitment & Morbidity on the job & Loss of productivity \\
Training & Management resources & Loss of skills \& experience \\
\hline
\end{tabular}

HIV/AIDS programs

Adapted from: Whiteside and Sunter, 2000.

The Draft Strategic Plan contains two areas related to fighting HIV/AIDS epidemic. First, the University mandate is to foster a conducive working environment for staff, students, and visitors. It will achieve this by embarking on internal training and retraining. Second, the Draft Strategic Plan spells out that the University must utilize its resources to enhance community development. Emphasis has been placed on the provision of educational opportunities for marginalized groups (i.e., youth and women), which is necessary to help them acquire relevant skills to deal with the HIV/AIDS epidemic. 
Ambe-Uva

Table 6. Selected sections of NOUN's Strategic Plan related to HIV/AIDS

\begin{tabular}{|c|c|c|c|c|}
\hline Activities & $\begin{array}{l}\text { Expected } \\
\text { Outcomes }\end{array}$ & Indicators & Targets & $\begin{array}{l}\text { Official(s) } \\
\text { Responsible }\end{array}$ \\
\hline $\begin{array}{l}\text { Devise } \\
\text { effective } \\
\text { strategies to } \\
\text { combat HIV } \\
\text { and AIDS } \\
\text { pandemic }\end{array}$ & $\begin{array}{l}\text { Improved } \\
\text { service and } \\
\text { healthy } \\
\text { workforce }\end{array}$ & 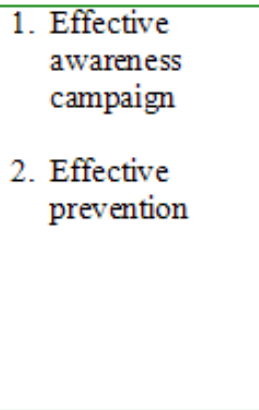 & $\begin{array}{l}\sqrt{\text { NOUN HIV and }} \\
\text { AIDS policy } \\
\text { finalized by } \\
\text { Oct/November, } \\
2006 . \\
\sqrt{\text { HIV/ADS }} \\
\text { workshops } \\
\text { conducted by } \\
\text { Nov/December, } \\
2006\end{array}$ & $\begin{array}{l}\text { Vice-Chance- } \\
\text { llor } \\
\text { DVC (Admin } \\
\text { \& Finance) }\end{array}$ \\
\hline $\begin{array}{l}\text { Encourage } \\
\text { community } \\
\text { development } \\
\text { initiatives and } \\
\text { collaborative } \\
\text { ventures. }\end{array}$ & $\begin{array}{l}\text { Active } \\
\text { presence of } \\
\text { NOUN in } \\
\text { Federal, state } \\
\text { \& local govt. } \\
\text { affairs. } \\
\\
\checkmark \text { Productive } \\
\text { links between } \\
\text { NOUN and the } \\
\text { country's } \\
\text { social } \\
\text { institutions for } \\
\text { development } \\
\text { purposes }\end{array}$ & $\begin{array}{l}\text { Strategic Plan for } \\
\text { community-based } \\
\text { projects \& } \\
\text { collaborative } \\
\text { partnerships }\end{array}$ & $\begin{array}{l}\text { Implementation of } \\
\text { projects involving } \\
\text { Federal Government } \\
\text { skill development } \\
\text { and youth and } \\
\text { women } \\
\text { empowement } \\
\text { program. }\end{array}$ & $\begin{array}{l}\text { Vice- Chance- } \\
\text { llor } \\
\text { DVC } \\
\text { (Instructional } \\
\text { Services) } \\
\text { Dir., Learner } \\
\text { Support } \\
\text { Services }\end{array}$ \\
\hline
\end{tabular}

NOUN DRAFT Strategic Plan: January 2005 to December 2009

While the University is certainly on the right track, it must remain committed to the goals and targets set. For instance, while the HIV/AIDS policy is expected to be ready at the time of writing, that deadline has come and gone. For a young institution like NOUN, such a delay can be pardoned. Yet as NOUN extends its institutional reach and increases its enrolment, such a delay could mean that opportunities are being missed, that NOUN is not addressing the epidemic in a timely manner. The development of an institutional policy on HIV/AIDS should be on the front burner of the University's plan of action. As noted by Saint (2004), a written institutional policy provides explanation for internal decisions and legitimacy for actions taken in the process of AIDS control and prevention. Such a policy, however, can only be as effective as the leadership that owns and supports it. Luckily, NOUN does not need to start from the scratch, as a major resource for preparing an institutional HIV/AIDS response can be found in the work of Chetty (2004), and the guidelines developed by ACU (2002). In addition, the Paris-based International Institute for Educational Planning has established a reference clearing house on AIDS and education (see http:/hivaidsclearinghouse.unesco.org/ev/php ). These can serve as reference documents for Universities engaged in drafting institutional policies on HIV/AIDS.

Since the University has yet to formally institutionalize an HIV/AIDS policy, staff and students response during a recent focus discussion group (FDG) indicated a lack of commitment on the part of staff and students, and a discontinuation in awareness and workshops. For instance, most staff (FDG-A) employed at NOUN after 2004 admitted that they have never heard about or discussed HIV/AIDS at the office. The staff focus group indicated that the University must adopt a scientific approach towards the fight against HIV/AIDS, because 'prose alone' - namely 
Ambe-Uva

rhetoric - will not solve the problem. The freshmen (FDG-B) focus group noted that the HIV/AIDS program was not integrated into the students' curriculum. The freshmen in this focus group admitted, however, that open dialogue between NOUN and students can facilitate this process. Lastly, the focus group comprised of students who have spent a minimum of two semesters at NOUN (FDG-C) either ignorantly - or apathetically - indicated that they do not need more education about the disease. One telling response was, "We do not have a student union, and our study groups are not only inept, but grossly inadequate to discuss with the university authority.”

Table 7. Focus Group Responses

\begin{tabular}{|c|c|}
\hline Focus Group & Responses \\
\hline \multirow[t]{2}{*}{ FG-A } & $\begin{array}{l}\text { "In the College of Education where I came from, HIV/AIDS awareness } \\
\text { and talk shop were organized at least twice every semester; the lack of } \\
\text { it in NOUN may be because NOUN is non-campus based". }\end{array}$ \\
\hline & $\begin{array}{l}\text { "Yes, the University needs to take a second look at the HIV/AIDS } \\
\text { issue. We need both the introduction of HIV/AIDS awareness society } \\
\text { and HIV/AIDS Coordinating Unit. . We need facts and statistics to } \\
\text { put on the table. Prose only won't do?" }\end{array}$ \\
\hline \multirow[t]{2}{*}{ FG-B } & $\begin{array}{l}\text { "We have not been taught about HIV/AIDS. I think because my } \\
\text { program is not HIV/AIDS Education and Management." }\end{array}$ \\
\hline & $\begin{array}{l}\text { "There is a two-way communication between we students and the } \\
\text { University Management. The same open dialogue applies to the } \\
\text { formulation of goals. I therefore think that the University when } \\
\text { reminded by us students can take up the AIDS business seriously." }\end{array}$ \\
\hline \multirow[t]{2}{*}{ FG-C } & $\begin{array}{l}\text { "In this era, you do not need NOUN to educate you about the } \\
\text { epidemic, as some one who has basic education, the handwriting on } \\
\text { the wall is all you need to take care of yourself" }\end{array}$ \\
\hline & $\begin{array}{l}\text { "We do not have the wherewithal to discuss with the university about } \\
\text { such issues; we do not have a student union, and our study groups are } \\
\text { not only inept, but grossly inadequate to discuss with the university } \\
\text { authority." }\end{array}$ \\
\hline
\end{tabular}

Source: Author's field work, April, 2007

The focus groups responses buttress the investigation made by the ADEA on Universities in Africa, and what the AAU synthesis report confirms to be true. Both acknowledged that universities in Africa have little knowledge about their HIV/AIDS status, and do not consider the epidemic as being relevant to their institution's guiding mission and vision, and the challenges it faces. These reports also argued that no rigorous impact assessments by the universities themselves have been undertaken, and in cases where there are pockets of assessments, they are sporadic and uncoordinated responses that rely heavily on the initiative of concerned staff or students. This fact is frustrating efforts to 'mainstream' the institutional response across Africa's 
Ambe-Uva

universities, which in turn, limits understanding of the need to institutionalize such needed responses, thereby creating a vicious cycle of reification. And in many cases, uncertain leadership by top management is at the root of the problem (UNESCO, 2006).

NOUN has a Post-Graduate Diploma (PGD) in HIV/AIDS Education and Management, which aims at providing students with in-depth knowledge in HIV/AIDS education and management. NOUN delivers this diploma via open and distance learning. The program is designed to raise the level of awareness of different segments of the Nigerian society to the reality of HIV/AIDS epidemic, by stressing the need for education and management of this fatal disease. Specifically, the program seeks to:

a) Increase awareness and sensitization among the general population and strategically target stakeholders

b) Develop institutional and national capacity to cope with the training, knowledge sharing, and management, required to educate Nigerians about HIV/AIDS

c) Enable the students to be very resourceful and possesses broader scope of knowledge in HIV/AIDS

d) Equip students with relevant skills they need to impart knowledge professionally to people they serve

e) Equip students with relevant skills needed to impart healthy habits to target populations

f) Equip students with counseling abilities, so they can have a more positive influence to those infected with the HIV/AIDS virus

As noted by Peters and Olugbemiro (2005), however, the program is currently being 'patronized' mostly by those already working in the healthcare sector. If the objectives of the program are to be realized, there must be a shift in clienteles and this can be achieved by adopting a more rigorous approach for marketing the program, that targets audiences beyond healthcare practitioners.

In addition, in recognition of the special needs of distance learners, NOUN has established the Directorate of Learner Support Services (DLSS). The DLSS plays a supportive role and provides the much needed people, structures, and environment for both students and staff. The director also serves as the intermediary between students and the institution. Student counselors are important arm of NOUN's Learner Support Services. Apart from supporting students through their academic work, Learner Support Services provides counseling and guidance related to Sexuality Education, HIV/AIDS awareness, Peer Education, and other professional consultations to staff and students who are engaged in distance education. Counselors are also responsible for keeping in touch with distance learners, and provide 'early warning signals' regarding difficulties with studies and behavioral problems. NOUN has since pushed ahead of conventional universities, through its provision of two counselors for each NOUN study centre, a move that was recently applauded by the Nigerian Psychological Association (NPA).

There is also a growing number of published and unpublished research works on HIV/AIDS in NOUN. Some of those dedicated individuals who have researched and published works in this area come from NOUN's School of Education, Directorate of Examinations and Evaluation, and 
Ambe-Uva

the Vice-Chancellery. An institutional effort, however, needs to be put in place by the Regional Training and Research Institute for Open and Distance Learning (RETRIDAL) to promote research on the nexus between HIV/AIDS and the distance mode of learning.

Despite these invaluable efforts, in the absence of a holistic HIV/AIDS policy, the efforts of the University in the realm of teaching, research, and services can become sporadic, uncoordinated, and reliant on the initiatives of a few dedicated staff and students (UNESCO, 2006). NOUN must also build a bridge to link and coordinate with the university's internal environment with its external environments where the virus is flourishing and gaining an upper hand. In an environment that traditionally fosters discussion and debate, challenges timeworn ways of thinking and being, and offers responses to some of society's most pressing concerns, NOUN is in a good position to ask much needed questions about the epidemic and explore ways in which distance education can be used to create a difference in the fight against HIV/AIDS.

Observations show that NOUN has identified the impact that HIV/AIDS has had, and will continue to have, on society. Identifying a problem does not guarantee a solution, however. Diagnosis and prognosis are only the first steps in the right direction. Therefore, this article urgently calls for the institutionalization of a policy framework for a comprehensive response addressing prevention, treatment, care, and social support.

\section{Conclusion}

As the HIV/AIDS epidemic continues to spread in Nigeria, the emerging literature on HIV and education seems to have reached the consensus that HIV/AIDS can both have a devastating impact on education and can be positively impacted by education. It also shows that distance education can respond flexibly to the needs of working adults to help them obtain the training they need and to provide opportunities for even the most disadvantaged populations (Pridmore \& Yates, 2006; Pridmore \& Nduba, 2000).

Furthermore, it has been shown that the capacity of open and distance learning to support largescale campaigns - i.e., HIV/AIDS education - is significant in the context of continuing education (UNESCO, 2002).

This article attempts to provide a systematic approach to universities' response to the epidemic, using NOUN as a case study. Although the issue of universities' response to the epidemic began to draw attention from scholars and commentators (Kelly, 2003; Katjavivi \& Otaala, 2003; ACU, 2001; Mwape \& Kathuria, 2000), these studies tended to centre on the institutional efficacy of universities. Whereas the current literature informs us of the need for universities to advance the frontiers of knowledge in the fight against HIV/AIDS, this paper places the research issue into a much narrower perspective by considering NOUN's basic structures, which naturally better positions it to fight this destructive epidemic. This research strategy generated insightful findings, some of which have been reported here. Findings show that within a few years of establishment, NOUN had already committed itself to the fight against HIV/AIDS via workshops and awareness creation, and had put in place Learner Support Services, where student counselors provide knowledge to students about HIV/AIDS and behavioral change, and has introduced a PGD program in HIV/AIDS Education and Management. NOUN's failure to institutionalize its HIV/AIDS policy, however, shows that it has not addressed HIV and AIDS in depth and scope, even though its structure as a distance education provider positions it better to wage such a war. Failure to take a leadership role may also endanger NOUN, considering the number of students it serves and it far flung geographical distribution and impact. Findings also suggest that NOUN has 
Ambe-Uva

not yet made concerted efforts to provide knowledge about HIV/AIDS among its own staff and students, although its PGD program is instructive and a positive step forward. Across Africa, studies have repeatedly shown that universities have been inept in the fight against HIV/AIDS, and most have made very little effort to draw-up a policy framework that adequately addresses the epidemic (ACU, 2001; Kelly, 2003). Clearly, new policy initiatives concerning these issues are needed (ACU, 2002). In considering these initiatives, it would be helpful to consider five key components:

- Responsibility of staff and students

- Provision of prevention, care, and support services

- Employment policy

- Enrolment policy

- Integration of HIV/AIDS education into teaching, research, services, and activities in all schools, centers, institutes, units, and departments

It is important to introduce a caveat in conclusion. Institutionalizing an HIV and AIDS response in NOUN would require it to do much more than just producing high quality research and supporting peer education and awareness raising campaigns. It will require serious self-reflection and analysis on the impact the epidemic can have on NOUN - specifically the extent student and staff illness and death can have on the inner workings of the institution, and how this will affect the 'supply and demand' side in NOUN's provision of quality education. Moreover, will NOUN be able to keep in place the much needed mechanism required to provide prevention, care, and support services to its staff, students, and the surrounding community it serves (UNESCO, 2006).

\section{References}

Abuja Declaration (2001, April). Abuja declaration on HIV/AIDS, tuberculosis, and other related infectious diseases. Retrieved November 13, 2007 from: http://www.uneca.org/ADF2000/Abuja\%20Declaration.htm

ACU (2002). Commonwealth Universities in the Age of HIV/AIDS: Guidelines towards a strategic response and good practice. London: Association of Commonwealth Universities.

ACU (2001). HIV/AIDS: Towards a Strategy for Commonwealth Universities: Report of the Lusaka Workshop. London: Association of Commonwealth Universities.

Aderinoye, R., \& Ojokheta, K. (2004). Open Distance Education as a Mechanism for Sustainable Development: Reflections on the Nigerian Experience. International Review of Research in Open and Distance Learning, 5(1), 1-12. Retrieved November 13, 2007 from: http://www.irrodl.org/index.php/irrodl/article/view/174/256

ADB (2006). African Development Bank Statistics Pocket Book, 8, 93-94

Afrobarometer (2002, April). Key Findings about Public Opinion in Africa. Afrobarometer Briefing Paper No. 1. Retrieved November 13, 2007 from: http://www.afrobarometer.org/ 
Ambe-Uva

Ambe-Uva, T. N. (2006). Interactivity in Distance Education: The National Open University of Nigeria (NOUN) experience. Turkish Online Journal of Distance Education, 7(4), 101109.

Anarfi, J. H. (2000). Universities and HIV/AIDS in Sub-Saharan Africa: A case study of the University of Ghana, Legon. Paper Prepared for ADEA Working Group on Higher Education.

Bodker, K., \& Pedersen, J. (1991). Workplace Cultures: Looking at artifacts, symbols and practices. In J. Greenbaum \& M. King (Eds.), Design at Work: Collaborative design of computer systems, (pp. 121-136). Mahwah, NJ.: Lawrence Erlbaum.

Chetty, D. (2004). An HIV/AIDS Toolkit for Tertiary Institutions. In W. Saint (Ed.), Crafting Institutional Policies to HIV/AIDS: Guidelines and resources for tertiary institutions in Sub-Saharan Africa. Africa Region Human Development Working Paper Series. Retrieved November 13, 2007 from: http://siteresources.worldbank.org/AFRICAEXT/Resources/no_64.pdf

Ezekwesili, O. (2007). Madam Minister Charges Tertiary Institutions to Evolve Strategies to Control the Spread of HIV and AIDS. A Publication of the Office of the Executive Secretary, National Universities Commission 2(15). Retrieved November 13, 2007 from: http://www.nuc.edu.ng/Bulletins/9\%20April\%202007.pdf

FMOH (2001). National HIV/Syphilis Sentinel Survey Report. Abuja, Nigeria: Federal Ministry of Health.

Gregson, S., Waddell, H., \& Chandiwana, S. (2001). School Education and HIV Control in SubSaharan Africa: From discourse to harmony? Journal of International Development, 13, 467-485.

Jegede,O. J. (2007, March 13). Free from Ignorance, Empowered by Knowledge. A convocation address of the vice chancellor at the special convocation ceremony held for the formal grand opening and commissioning of the National Open University of Nigeria.

Jegede, O. J. (2003). Taking the Distance Out of Higher Education in 21 st Century Nigeria. An Invited Convocation Lecture Presented at the Federal Polytechnic Oko, Anambra State, on the November 28.

Jegede, O. J. (2002). Celebration of Teacher Education and Open and Distance Learning in Nigeria. Attainments, challenges, and strategies in teacher education in Nigeria: Past, present and future. Kaduna, Nigeria: NTI.

Katjavivi, H. P., \& Otaala, B (2003). African Higher Education Responding to the HIV/AIDS Pandemic. Paper Presented at the AAU Conference of Rectors, Vice Chancellors and Presidents of African Universities (COREVIP) March, 17. Mauritius.

Kelly, M. J. (2003). The Significance of HIV/AIDS for Universities in Africa. JHEA/RESA, 1(1), $1-23$. 
Ambe-Uva

Kelly, J. M. (2002). Standing Education on its Head: Aspects of schooling in a world with HIV/AIDS. Current Issues in Comparative Education, 3(1), 28-38.

Kelly, M. J. (2001). Challenging the Challenger: Understanding and expanding the response of universities in Africa to HIV/AIDS. Washington DC.: ADEA Working Group on Higher Education. Retrieved November 13, 2007 from: http://hivaidsclearinghouse.unesco.org/ev.php?ID=1454_201\&ID2=DO_TOPIC

Kelly, M. J. (2000a). The Encounter Between HIV/AIDS and Education. Harare, Zimbabwe: UNESCO, Sub-Regional Office for South Africa.

Kelly, M. J. (2000b). HIV/AIDS and Education in Eastern and Southern Africa. The Leadership Challenge and the Way Forward. Report for the African Development Forum.

Krueger, A. B., \& L. Mikael, L. (2000). Education for Growth: Why and for whom? Journal of Economic Literature, 39, 1101-1036. Retrieved November 13, 2007 from: http://www.krueger.princeton.edu/krueger.pdf

Mwape, G., \& Kathuria, R. (2000). Universities and HIV/AIDS in Sub-Saharan Africa. University of Zimbabwe: ADEA.

Ohiri-Anichi, C., \& Odukoya, D. (2004). HIV/AIDS and the Education Sector in Nigeria: A review of policy and research documents. Lagos: ERNWA-Nigeria.

Orlikowski, W. J., \& Baroudi, J. J. (1991). Studying Information Technology in Organizations: Research approaches and assumptions. Information System Research, 2(1), 10-28.

Perraton, H. (2001). Models of Open Learning. OSAC Journal of Open Schooling, 1(1), 2.

Peters, F., \& Olugbemiro, J. (2005) The Development of an Academic Programme on HIV/AIDS Education Management by the National Open University of Nigeria. Paper Presented at the First Regional Conference of Vice-Chancellors, Provosts and Deans of Science, Engineering and Technology (COVIDSET), November 15-17, Accra, Ghana.

Pridmore, P., \& Nduba, S. (2000). The power of open and distance learning for basic education for health and the environment. In C. Yates, \& J. Bradley (Eds.), Basic education at a distance. London: Routledge.

Pridmore, P., \& Yates, C. (2006). The role of open, distance, and flexible learning (ODFL) in HIV/AIDS prevention and mitigation for affected youth in South Africa and Mozambique. Department for International Development: Educational Papers. Retrieved November 13, 2007 from: http://www.dfid.gov.uk/pubs/files/odfl-safrica-mozambique-61.pdf

Ssengonzi, R., Schlegel, A., Anyamele, C., \& Olson, K. (2004). Assessing educators views on the impact of HIV/AIDS on primary education in Nigeria: Implications for future programs. Triangle Park, NC.: USAID \& RTI International. Retrieved November 13, 2007 from: http://www.rti.org/pubs/Nigeria_HIV-AIDS_Final_Report.pdf 
Stake, R. E. (1994). Case Studies. In N. K. Denzin \& Y. S. Lincoln (Eds), Handbook of Qualitative Research. Thousand Oaks, CA.: Sage.

UNAIDS (2000). Report on the Global HIV/AIDS Epidemic. Geneva.

UNDP (2004). Human Development Report on Nigeria: A challenge to sustainable human development. UNDP.

UNAIDS/WHO (2002). AIDS Epidemic Update. Geneva, Switzerland.

UNESCO (n.d.). Education for All homepage. Retrieved November 13, 2007 from: http://portal.unesco.org/education/en/ev.php-

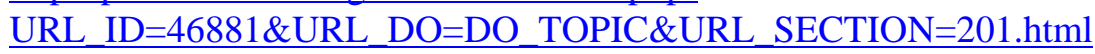

UNESCO (2006). Expanding the Field of Inquiry: A cross-country study of higher education institutions' response to HIV and AIDS. Paris. UNESCO.

UNESCO (2002). Open and Distance Learning: Trends, policy, and strategy considerations. Paris: UNESCO.

UNESCO (2001). Teacher education through distance learning. Paris: UNESCO.

UNESCO (2000). World Education Forum Dakar: Final report. Paris: UNESCO.

Walsham, G., \& Waema, T. (1994). Information Systems Strategy Implementation: A case of a building society. ACM Transactions on Information Systems, 12(2), 150-173.

Whiteside, A., \& Sunter, C. (2000). The Challenge for South Africa. Cape Town: Human Rousseau and Tafelberg.

World Bank (1999). Confronting AIDS: Public priorities in a global epidemic. A World Bank Policy Research Report. New York: Oxford University Press.

World Bank (2002). Education and HIV/AIDS: A window of hope. Washington DC.: The International Bank for Reconstruction and Development (IBRD). 
November - 2007

\title{
Research Notes
}

\section{Lessons from an International e-Learning Project}

\author{
Paul Breen \\ Holborn College, London, UK
}

\begin{abstract}
This paper offers a critical examination of an e-learning project in the context of a Distance Education training program delivered to teacher trainers by an external university in Rwanda. In examining the successes and failures of the project, it uses a framework based on ideas promulgated by Moore (1995) and strives to provide guidance and reference for future projects in this field.
\end{abstract}

\section{Introduction}

Moore (1995) describes how, in May 1995, The American Center for the Study of Distance Education hosted the Third Distance Education Research Symposium Conference, in which a group of researchers were asked to consider "the effect of research on improving the quality of distance education practice" (p. 1). In setting out a framework for analysis, they identified "four key research areas: course design, instruction, policy and administration, and learners and learning” (p. 4).

By Moore's (1995) own admission, there is a considerable degree of overlap within these four key research areas, but they serve to offer structure in a field where so much research is autonomous and unconnected. Although all online learning and development projects should be implemented on a case-by-case basis, there is a clear need for comparative studies. This is advocated in the work of Gourley (2004), and Keniston (2001) who in writing about the Indian context, notes that India abounds with pilot projects that rarely form part of any larger plan and which include little thought or consideration of how they might be replicated on a larger scale beyond the boundaries of the individual projects.

\section{Skepticism at the Outset}

Unfortunately, what Keniston (2001) says about India is not limited to that region alone, and in the same article, he goes on to make another significant point, specifically that few of these projects are analyzed independently and that, invariably, they become success stories, as if in competition against one another.

This is a point echoed by Asmal (2004) who speaks about the need to avoid the "uncritical introduction and adoption of distance education and the associated new technologies" (p. 37). 
Asmal's view is reiterated by Davis (2004) who describes many of these projects as being “doomed to succeed” (p. 8) and, echoing Keniston (2001), warns against any false sense of accomplishment in having re-invented the online learning wheel.

In the African context, in particular, there is a great deal of skepticism about the introduction of so-called 'agenda free' assistance from western agencies or educators who appear to 'brand' technology as the panacea for all the continent's educational ailments. This is a view strongly expressed by Asmal (2004) and many other speakers at the All Africa Ministers' Conference on Distance Education in 2004. Among the critical, but constructive, voices at the conference was Gourley (2004) who questioned, whether or not, either information or education can be seen as value free.

Asmal (2004) spoke of Africa having a history of being used as a "laboratory for educational experiments for external agencies” (p. 37). Africa's history, stretching down from the Islamic north to the sub-Saharan south, has left the continent skeptical of the intentions of outsiders and this is a feeling that pervades much of the literature. One detailed example of this is found in Taylor's seminal (1995) paper on education in South Africa, in which there is a description of events before and after the colonization of the sub-Saharan region and details of the colonial influence upon African education. Taylor argues that the great age-old African tradition of cooperative learning (which is now ironically fashionable in western pedagogy) was almost irreparably destroyed by the influence of missionary and colonial education. He asserts that this is why a current discrepancy exists "between African culture, which may be seen as defining some form of cooperative learning, and the present school culture” (p. 240).

From reading Taylor's article, one can get a clear sense of why Africans might be cynical about western intentions and, indeed, see within them echoes of a 'we broke it, but we're coming back to fix it' attitude.

\section{An African e-Learning Venture}

It was against this backdrop of skepticism and historical abuse of the term 'agenda-free assistance' that an Italian university recently completed the provision of a teacher education program to Rwandan teacher trainers by means of distance education through a blended learning approach. This project, organized by a university in Rome, provided a fourth generation distance education training course for postgraduate students at a technical university in the Rwandan city of Kibungo. The project began as an investigation and an experiment into the feasibility of crosscontinent collaboration and gradually evolved into a full-scale distance education project with the critical aspiration of mutual partnership. The original aim was that both universities would be involved in the design and implementation of the training program so that within a short space of time, Rwandans could manage these courses independently in the future.

The motives of the project were certainly pedagogic rather than financial or culturally imperialistic. They were also driven by a desire to research and prove the effectiveness of constructivism and the blended learning approach. Moore (2002) might argue that this position is flawed from the outset, however. This is because of his assertion that constructivism is largely a philosophical position rather than an empirically supported approach, and less developed than the theories of Mezirow (1991) who coined a 'transformation' theory of five interacting contexts which suggests that people actually learn through a combination of learning styles, from behaviorist right through to constructive, rather than in any one absolutist manner. 
Despite this, however, it is possible to analyze the effectiveness of the blended learning approach, which can be basically defined as the combination of multiple approaches to pedagogy or teaching, which in this case was a combination of face-to-face teaching with online distance education delivered through the medium of a Virtual Learning Environment. It should also be added that blended learning in itself is not new because it can already be seen in the work of Volunteer Services Overseas (VSO), The British Council, and UNESCO, who have all used blended learning approaches in their overseas teaching programs in the developing world. It is also commonly used in cyber schools and universities in developing countries throughout the world. Some prime examples of this are the Cyber University of North Korea described by Im and Lee (2003) and the University of Botswana's blended learning and online programs detailed by Giannini-Gachago and Seleka (2005).

The reason for making the above points is to clarify exactly what place this project has in the broader field of distance education in the African and the broader global context. The manner of its delivery is neither revolutionary nor powerfully innovative, but what makes it interesting is that the organizers set out with a specific goal of delivering the program in such a way that it could be autonomously replicated by the Rwandans themselves in the future. In setting out this goal, they deemed their project to be 'agenda-free assistance' in the purest form of the term but actually, in doing so, unwittingly and unintentionally added themselves to the list of projects defined by Keniston (2001) and Davis (2006). The reason for my saying this is that unfortunately projects that call themselves 'agenda-free' at the outset feel almost duty-bound to portray themselves in the most glowing light possible upon completion of their task. Few projects set out with the aim of being doomed to succeed but usually end up unwilling to be analyzed and open to comparative study. Indeed, it is easier to shelve them away safely in a box labeled 'successfully completed.'

\section{Using Moore's Framework of Analysis}

Having pointed out that the main weakness of this project was in its trying to define itself as 'agenda-free,' it is important to stress that there were many strong points in the delivery of the course and the contribution that it can make to the fields of electronic learning and distance education. Perhaps the main contribution that it can make is to offer answers to those voices in the African context and the broader literature who have asked probing questions about western motives and benefits. These include a number of non-governmental organizations such as UNESCO and the World Development Bank who repeatedly stress the view that technology will only provide viable long-term solutions for the problems of the developing world if foresight is used effectively in its implementation.

In my opinion, the best way to ensure that this foresight takes place is for projects such as this to be open and accountable from the outset, and to make use of comparative studies and research to analyze their eventual contribution to the field. For this reason, I have used Moore's (1995) criteria to evaluate the successes, failures, and lessons of this project.

\section{Course Design}

From the outset, this teacher training project cited key objectives as being that participants should "acquire the expertise which should enable trainees to manage their self-training process," "acquire theoretical notions on the main training models, particularly on cooperative learning," and "acquire project design and management skills for a training course along all its phases." These objectives demonstrate that, in pedagogic terms, this was a course based around the 
acquisition needs of its participants, designed by an external agency giving to rather than taking away from the African continent, and avoiding the traditional tendency of western agencies to manage rather than to share. In order to increase the chances of the Rwandan teacher trainers meeting these objectives, the project used blended cooperative learning methodology as described in the literature of Harasim, Hiltz, Teles, and Turoff (1995), Salmon (1998; 2000), Valiathan (2002), and Gonzalez (2004). In practical terms, this entailed the combination of an online learning platform, with a set of formal academic lessons.

The training course ran for 35 weeks, for a total of approximately 210 hours. This was broken down into three hours per week of formal academic training in the classroom, provided by lecturers from the Rwandan university, and then 105 hours of more flexible, self-paced online training managed by the online tutors from the Italian university. In the formal classroom-based lessons, the lecturer explained theoretical and methodological aspects of the course whilst online activities, supported by the project's learning platform provided deeper insight into those theories explained during formal class work and provided opportunities for interaction and collaboration among participants.

This course, taught half in distance mode and half in real time, had echoes of the 'deep learning' approach referred to in the literature of Toohey (1999), and Motteram, (2001). It needed to possess such characteristics because it was being delivered to 15 adult Rwandese teacher trainers who (in theory) would autonomously deliver this course to other teachers in the future. The first batch of aspiring course managers of the future ranged in age from early 20 s to middle $30 \mathrm{~s}$, unanimously described their ethnic background as black African and were a mix of both genders, although predominantly male.

Of course, in order to deliver the online aspect of the program, a suitable learning platform was required. Originally, the designers opted for a future learning platform named Synergia, a software system that combines an asynchronous component (BSCL) with a synchronous component named MapTool. This was a satisfactory choice and would have served as a good medium for delivering the course. The designers, however, then decided on the more mainstream and internationally recognized Moodle learning platform which is an acronym for Modular Object Oriented Dynamic Learning Environment, detailed on the website http://moodle.org.

Part of the reason Moodle was chosen was that designers wanted to give the course international standing so that it looked as professional and contemporary as possible in the eyes of their Rwandan partners. It is also a flexible platform, which allows teachers to put a wide range of materials online, including lesson notes, PowerPoint presentations, discussion forums, and bulletin boards. In this way, it serves as a forum for interactivity for both students and teachers, and allows students to work at the course in their own time and pace while keeping to a broader schedule, as detailed in Valiathan (2002).

Aside from the pacing and presentation considerations, Moodle also allows tutors to build-up a wide and varied range of complimentary technologies around the core technology of the virtual learning environment (VLE) as advocated by Collis and Moonen (2001). It allows students themselves to build-up an online library of resources over time, which was one of the key aims of the venture, and stated in the project literature as the desire "to set up a shared virtual library to smooth and reduce the barriers (economic, geographical and technological) to knowledge access for students and lecturers of both universities.” 


\section{Instruction}

The second key area of Moore's framework is the process of instruction, which is where the effectiveness of the course design is tested in practical terms. However, it is important to keep in mind critical voices such as Davis (2004) who writes that "building the infrastructure for online learning requires that many factors be considered, so it is difficult to provide a straightforward checklist or recipe to follow" (\$ 3). Davis goes on to cite Lu (2002), writing about gases, who says that "scientists often classify systems as 'ideal' versus 'non ideal', (more commonly understood as 'real')" and "if we apply this concept (to the project in hand) we can define the ideal and then look at the deviations from ideality that manifest themselves in the real” (I 4).

Davis (2004) goes on to say that "an understanding of the technological background of the intended students is crucial” ( 9 9) and thankfully all of the participants in the project had (or at least claimed to have) prior experience of using computers so they were able, in his words, to "participate equally and fully in the learning experience" (ף 9). In order to facilitate ease of use and engagement and to build-up comfort in terms of access and motivation, the program started off at a slow pace with introductions from the online tutors and an invitation to students to explore the learning platform, making sure that all of their peers had passwords and access. This tactic of encouraging the students to work together and consider the needs of their peers created a constructivist sense of teamwork from the outset in the hope that it would make cooperation "a core element of learning” as espoused by Taylor (1995,. p. 252).

However, as in Davis' (2004) writings on 'ideal' and 'real' systems, things did not run quite as smoothly as had been planned in theory. In an email at the start of March 2006, reporting on the progress of the course, one of the five online tutors wrote:

"The project is just starting in these days. We have problems in making the students enter the platform. They probably have no confidence with technologies and the Internet connection is not available every day. That's why they have started attending lessons in the classroom with their Rwandese teachers from UNATEK but haven't as yet started collaborating online with us.

Our role is to coordinate and manage the online activities which as I've said should start in a while...

Regarding questions about the socialisation phase I think we can answer these properly in a few weeks . . . when students really start to use the platform we can say something about their socialisation with the platform and with other students."

From the students' perspective, one of the problems seemed to be a lack of confidence and fear of making mistakes. They appeared to be apprehensive about using the technology and bashful about sharing their ideas in such a public space. Therefore, they had to be coaxed into using the platform and tutors did this with a gentle form of persuasion through a friendly approach and one that built familiarity at their own pace. This was done through using what Salmon $(1998 ; 2000)$ describes as the 'online socialisation' phase where a sense of community is built-up amongst the participants so that they progress to the stages of 'information exchange' and 'knowledge construction' where participants give information relevant to the course to each other and where course related group discussions occur and the interaction becomes more collaborative.

At these stages of information exchange and knowledge construction, things became more demanding for the students and there was actually a lower instance of responses than there had been during the first two phases. Students found it difficult to 'get to grips' with the idea of collaborative learning and doing things for and by themselves; so unfortunately they got trapped 
in the third and fourth stages without ever really progressing to the fifth stage of Salmon's (1998; 2000) framework, namely the 'development' stage where they are able to work independently, with the aim of replicating the course autonomously in the future. Students never quite came to terms with the self management aspect because, in the perception of the online tutors whom I interviewed in the process of writing this article, a period of 35 weeks, or 210 hours, was too short to radically alter the mindset of adult learners who had been trained in a system diametrically opposed to the one they were trying to introduce.

Yet that is not to say that the Instruction phase was a failure. On the contrary, it brought students up to a level where they would be able to progress further with the right time and resources. Their only error was in assuming that things would happen much faster than they did in reality, which shows the importance of using comparative studies and sound research to give course designers a better sense of foresight. In essence, the Rwandan teacher trainers learned a great deal from this course, especially in learning to collaborate with their western counterparts. In the end, actually the Rwandans were the ones who wanted the western agency to remain longer than intended, rather than the opposite scenario which many critics such as Asmal (2004) have complained about in the past.

\section{Policy and Administration}

Butcher (2004), in writing about the financial logic of distance education, argues that ideological arguments are made for open learning, whilst economic ones are commonly used to justify distance education projects. This is true, especially in the African context where there is little room for economic spillage. This, however, does not mean that distance education programs should be put in the hands of economists rather than educators. Badat (2004) has suggested that problems arise when developments are, or seem to be, driven by technologists and business interests rather than by educators. This type of scenario generally places corporate representatives at the top of the hierarchical pyramid and teachers in a position of struggle at the bottom in what White (2003) terms a 'bifurcated system' in a quote taken from Warschauer (2000).

Of course one may argue that, in open learning, teachers often find themselves caught in a position of struggle at the bottom of the institutional ladder, but the problem that Badat and White are trying to highlight is one of image presentation. As Davis (2004) has said, many of these projects are 'doomed to succeed' and if that is the case then it can be costly for those who have to bear the consequences of their failures.

Certainly the project in this paper, while not doomed to succeed, did have elements of people at the top feeding off the hard work of those at the bottom. The good thing about this project, however, was that there was an accreditation procedure in place, which meant that there was criteria that had to be met at each stage of the process, which reduced the chances of teachers being left isolated and working in a vacuum. There was a good administration system in place, though it did depend on a great deal of excess work by the online tutors who bore the brunt of the workload. The problem is that, from my qualitative observations, the higher one goes up these institutional ladders there is less chance of people putting in the same workload for nothing. Therefore, financially these projects cannot survive in the long term because people will not work for nothing forever, and even if the western agency can find a steady stream of willing recruits, much of the expertise and quality will be lost as a direct consequence.

Yet, it is important to stress that even small scale projects, such as this one, make a vital contribution because, in the words of Namibia's Policy Framework for Education (2004), "as we 
develop our own ideas and technologies we become less dependent on imported innovations and the conditions that often accompany them." The problem though is that the timeframe needed for development may be longer than educators can afford to offer, which means that it gives rise to these projects being funded and driven by economists rather than educators, in the future.

\section{Learners and Learning}

In Moore's (1995) framework this section is used to address the success of the project in the whole context of the learning process, not just in terms of the learners in a particular venture, but also the broader context of distance education learners as a whole. Having already explained how the learners in this project did not quite reach the desired level, due to a lack of time, I will therefore focus on how this project can contribute to the broader field of distance education as a whole, reviewing areas that I have touched on before, such as economics and the African/ developing society context. The reason for focusing specifically on learning at this stage is that this particular project placed the learning experience at its core and used that as the fundamental barometer to measure its own successes and failures. Thus, firstly, it is important to ask how projects such as this can fund themselves in such a way to provide an enriching learning experience for students. Perhaps, the answer is by relying heavily on sponsorship and by integrating the project into existing areas of work within the western agency so that it is being automatically financed. The Italian university did this by working on this project in conjunction with others, so that it was benefiting from a run-off of spare funds and time within the Faculty of the Sciences of Communication. A total budget of 39,000€ was spent on the project of which $23,000 €$ was written off through this process of auto financing. Of course, 16,000€ was spent on set-up costs, so that meant funding had to be gained and this is where the biggest problem lay. Around $16,000 €$ was gained from funds made available through the university itself, but this was one-off sponsorship that could not be repeated time-and-time again. Still, approximately 40,000 € for a course such as this is relatively inexpensive, in that it works out to 2,500 € per student. In the event of the Rwandans running the course autonomously, these costs would be further reduced, particularly in the area of paying the labour costs of online tutors, and those responsible for course consultancy.

So, if a system can be worked out where the learning process itself is more effective and students reach that fifth key stage in Salmon's framework, then projects such as this are truly beneficial. Yet, if the project has to close at the end of one session because of financial problems, the trainees will not actually have achieved their goals, will be unable to replicate the course successfully, and will not really have gained too much from it.

Despite the problem of funding, this project does offer evidence that it is possible for western agencies to establish projects that are initially based on partnership and collaboration, and can eventually be passed into a state of total ownership by those developing countries who utilize the benefits of this evolving medium. In saying this, I also agree with the assertions of Asmal (2004), and Butcher (2004), who point out that there is a need to remember that one cannot assume that something which is successful in one context will surely work in another.

Despite their concerns, I believe that it is possible to use a project such as this, to look beyond continental boundaries and consider other developing nations that might benefit from this type of project, such as Bangladesh recently described in an article by Islam and Selim (2006), where the tone was one of slight dejection that online learning is "still a dream for the less developed countries because of poor ICT infrastructure and other socioeconomic reasons ” (\$ 16), particularly in more rural areas. 
Also, the idea of universities working together in partnership through the medium of online learning platforms is something that could serve as a useful base for forging closer links between the developed and developing worlds, as well as in divided societies. For example, universities in Iraq, Afghanistan, Palestine, and North Korea, are all in need of outside assistance in one way or another. Indeed, all of these countries have recently set-up English learning programs in various universities that may, unfortunately, have great difficulty in attracting qualified instructors to meet their demands. Online learning can solve this and, as in this project, can provide them with the means to manage their own education in the future, through a process of partnership rather than dictation from outside agencies. This is surely a selling point of distance education, and hopefully the long-term profits for the western agencies are pedagogic rather than economic. In that way, fewer will be skeptical of our motives in the future.

\section{References}

Asmal, K. (2004). Prospects, Possibilities and Perils: Distance education's response to Africa's development needs. Paper Presented at the 2004 All Africa Ministers Conference on Distance Education, Cape Town, South Africa. Retrieved November 8, 2007 from: http://www.polity.org.za/article.php?a_id=46293

Badat, S. (2004). The diversity of higher educational provision: propositions on distance higher education policy and regulation towards equity, access, quality and social and economic responsiveness. Paper Presented at the 2004 All Africa Ministers Conference on Distance Education, Cape Town, South Africa.

Butcher, N. (2004). Financing Distance Education Programmes in African Education: A guide for sound investment. Paper presented at the 2004 All-Africa Minister's Conference on Open Learning and Distance Education, Cape Town, South Africa.

Collis, B., \& Moonen, J. (2001). Flexible learning in the digital age. London: Kogan Page.

Davis, A. ( 2004).Developing an infrastructure for online learning. T. Anderson \& F. Elloumi (Eds.), Theory and Practice of Online Learning. Athabasca, AB: AUPress. Retrieved April 7, 2007 from: http://cde.athabascau.ca/online book/ch4.html

Giannini-Gachago, D., \& Seleka, G. (2005). Experiences with International Online Discussions: Participation patterns of Botswana and American students in an adult education and development course at the University of Botswana. International Journal of Education and Development using ICT, 1(2). Retrieved November 7, 2007 from: http://ijedict.dec.uwi.edu/viewarticle.php?id=42\&layout=html

Gonzalez, C. (2004). The role of blended learning in the world of technology. Benchmarks online website. Retrieved November 7, 2007 from: http://www.unt.edu/benchmarks/archives/2004/september04/eis.htm

Gourley, B. (2004). 'The Digital Divide: Solution or problem.’ Paper presented at the 2004 All Africa Ministers Conference on Distance Education. Cape Town, South Africa.

Harasim, L., Hiltz, S. R., Teles, L., \& Turoff, M. (1995). Learning Networks: A field guide to teaching and learning online. Cambridge, MA.: MIT Press. 
Lessons from an International e-Learning Project Breen

Im, Y., \& Lee, O. (2003) Pedagogical implications of online discussion for pre-service teacher training. Journal on Technology in Education, 36 (2).

Islam, T., \& Selim, A. S. (2006). Current status and prospects for e-learning in the promotion of distance education in Bangladesh. Turkish Online Journal of Distance Education, 7(1). Retrieved November 8, 2007 from: http://tojde.anadolu.edu.tr/tojde21/articles/islam.htm

Keniston, K. (2001, December). IT for the Common Man: Lessons from India, MN Srinivas Memorial Lecture. Bangalore : National Institute of Advanced Studies, India Institute of Science. [MIT published as a working paper in 2002].

Mezirow, J. (1991). Transformative dimensions of adult learning. San Francisco: Josey Bass.

Moore, G. M. (1995). Editorial: The 1995 Distance Education Research Symposium: A Research Agenda. The American Journal of Distance Education, 9(2). 1- 6.

Moore, G. M. (2002). 'A Personal View: Distance education, development, and the problem of culture in the information age. In V. V. Reddy \& S. Manjulika, S. (Eds.), Towards Virtualization: Open and distance learning. (pp. 633-640). New Delhi: Kogan Page India.

Motteram, G. (2001). The role of synchronous communication in fully distance education. Australian Journal of Educational Technology, 17(2), 131-149.

Namibia 's Policy Framework for Education (2004). Toward Education for All: A development brief for education, culture and training. Namibian Government.

Salmon, G. (2000). E-moderating: The key to teaching and learning online. London: Kogan Page.

Salmon, G. (1998). Developing learning through effective online moderation.Active Learning 9, 3-8.

Taylor, C. (1995). Cooperative learning in an African context. International Journal of Educational Research, 23(3), 239-252.

Toohey, S. (1999). Designing Courses for higher education. In Motteram, G. (2001). The role of synchronous communication in fully distance education. Australian Journal of Educational Technology, 17/2: 131-149.

UNESCO (1988). World Education Report: Teachers and teaching in a changing world. Paris: UNESCO. In C. Yates (Ed.), Teacher education at a Distance: Lessons and Experience from Sub Saharan Africa.

Valiathan, P. (2002). Blended learning models. Learning Circuits: ASTD’s Source for ELearning. Retrieved July 13, 2006 from: http://www.learningcircuits.org/2002/aug2002/valiathan.html

Warschauer, M. (2000). The changing global economy and the future of English teaching. TESOL Quarterly, 34(3), 511-535. 
Lessons from an International e-Learning Project Breen

White, C. (2003). Language learning in distance education. Cambridge: Cambridge University Press.

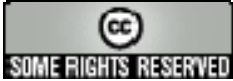




\title{
Research Notes
}

\section{Incorporating Screencasts in Online Teaching}

\author{
Elaine Peterson \\ Montana State University, USA
}

\begin{abstract}
Despite success in teaching the class 'Organization of Information in a School Library Media Center' (EDCI 545) online, one component continued to be a problem for students, the Dewey Decimal Classification System. To supplement the instruction, a set of simple screencasts was developed to assist distance education students. Benchmarks were established and a beta test conducted. It is expected that the next online class of students will have increased success because of the addition of screencasts. It is suggested that screencasts be considered as an additional tool for online learners across other disciplines, particularly when using databases that have layered sets of information, requiring multiple mouse clicks.
\end{abstract}

Keywords: Screencasts; cataloging; classification; online learning

\section{Introduction}

For several years, EDCI 545, 'Organization of Information in a School Library Media Center' has been offered by the College of Education at Montana State University as an online course as part of the university's Extended University. The course has been offered over the summer as a seven week intensive course, but it is usually a semester long class. In both the intensive and semesterlength course, the main components include:

- Professional concepts and tools

- Understanding the online public access catalog

- Intellectual access (authority records and subject headings)

- Classification (Dewey Decimal Classification System)

- Physical description, access, and tagging

- Digital collections

- Future trends

Student success has been high in EDCI 545. Perhaps the main factor is that the students enrolled in this course are graduate students and are highly motivated. Students are usually full-time employees in a school library, either a grade school or high school. What they learn in class is directly applicable to their workplace. Additionally, class size has been limited to 25 students, allowing for individualized attention. Most students were already familiar with the intricacies of online learning, such as submitting assignments as attachments, participating in online 
discussions, or retrieving electronic reserves. Despite the overall technical knowledge and success of these online learners, one component has consistently been a problem for students, even for those that achieve the highest grades.

The problem unit is 'Classification,' specifically, instruction in the Dewey Decimal Classification System. Perhaps viewed by some as arcane in the online environment, the Dewey system does have its uses, particularly in the K-12 school library environment. Although revised over many editions, the classification system remains a classic example of 'nested' or 'embedded' information. For example, a book about Queen Elizabeth would be placed in the classification number 942.055. Each number more thoroughly defines the detailed placement of the book and its relation to other books. That portion of the Dewey schedule shows the following:

\author{
900 History \& geography \\ 940-990 History of the modem world \\ 940 \\ 942 \\ 942.05 \\ 942.055 \\ Europe \\ British Isles \\ Tudor England \\ Queen Elizabeth I
}

With instruction in the traditional classroom, it is possible to flip through the paper volumes of the Dewey schedules and physically point down the pages to show students that they need to keep refining the classification numbers to arrive at the most exact classification number. To complicate matters, the schedules also include references to separate tables with yet other layers of classification numbers.

Obviously scanning the pages of the paperbound Dewey schedules is not possible in the online environment for the distance education students. In the last semester the course was offered, students enrolled were from seven different states and one foreign country. Most had no access to a paper edition of the Dewey schedules. Instead, all registered students were given temporary student access to the online version of the Dewey Decimal Classification schedule through the Online Computer Library Center (OCLC) network (see www.oclc.org). Since the Dewey schedules are the most widely used throughout the world, online access to 'WebDewey' is becoming increasingly popular for a variety of users.

The most widespread student problem was not clicking far enough into the schedules in order to refine the Dewey number. Like many online databases with several layers of information, multiple clicks were necessary to arrive at the correct information. Other students missed notes of instruction within the Dewey schedules with directions to separate online tables. Although many students asked for individual assistance through email, it was still not possible to show them physically where to click in the online schedule, and email responses included complicated written instructions.

\title{
Theory Behind Screencasts
}

Screencasts are a relatively new phenomena, described only twice in the library literature and used primarily for library tutorials (Notess, 2005; Roberts, 2005). Outside of Library and

Information Science, a review of the Education literature revealed no use of screencasts in online 
teaching. While attending a workshop for library tutorials, screencasts relevance to assist distance education students became apparent.

What are screencasts? Screencasts are recordings of a video of screen activities, including mouse movements and clicks. An audio commentary can be added to the video to explain the process. The clear advantage to a screencast is that it can visually show students what the screen should look like and where to click. Another definite advantage is that screencasts are relatively quick to prepare and easy to update and change. Additionally, screencasts can contain sound along with the video, interactive features that help hold students' interest. Because of the licensing restrictions outside of the instructional use of the OCLC network, it is not possible to post specific Dewey examples in this article. For multiple examples, a collection of screencast examples using a variety of software is available at http://www.notess.com/screencasting/examples/. Examples include those for searching complicated databases such as WebDewey.

There are at least four good options in developing useful screencasts. Screencast-O-Matic and Wink are both free software options. Camtasia (developed by TechSmith) and Captivate (developed by Macromedia) come with a charge, but each offers a substantial educational discount. As one might expect, the fee-based software options have additional features with more detailed user instructions.

\section{Research}

For the last class of EDCI 545, overall class grades were very high. Of those 25 students, however, only one received the full 20 points for the Dewey classification assignment. These very capable students were lacking something other than their normal acumen for the class in the online environment. Comments after the assignment and in the final course evaluation specifically pointed to the problems with WebDewey. One student succinctly stated the problem. "Besides using the WebDewey, I also went to our public library and looked up the following class numbers with the Dewey Classification volumes. It seemed that I couldn't go very far on the WebDewey so I thought if I used the print version I might find more information which I did." However, it was this comment that prompted further action to supplement the assignment. "The Dewey assignment was very confusing and more explanation would have been helpful. Possibly a video lecture about Dewey with some visuals to help with understanding all the nuances of the system (tables, etc.).”

In response to student comments, the author began exploring a video production or screencasts to supplement the Dewey assignment. Screencasts were chosen because they can be assembled with free software, and can take less than 20 minutes to complete. Since EDCI 545 will not be offered again until 2008, a beta group of three students was assembled to test the Dewey screencasts. All students affirmed that they were much more capable of navigating the Dewey database online because of the screencasts. Although reaction was extremely positive, the true test of the Dewey screencasts can only be made when a new class is assembled for the 2008 semester. Student grades on the Dewey assignment will be compared to those from the last semester and the same course evaluation will be administered. 
Incorporating Screencasts in Online Teaching

Peterson

\section{Conclusion}

Screencasts can be used to supplement teaching materials or as an insert to email inquiries from distance education students. Although often used for library tutorials, such as explaining an online database, they hold great potential for distance education students using those and other online tools. Certainly as online classes proliferate, the need to give students assistance with online databases will increase. Screencasts can be created to assist with a particular online resource, such as the OCLC database. Screencasts can also be prepared in response to student email queries, then saved and sent to other students with the same question. Certainly screencasts can be applicable across all disciplines for online learners.

\section{References}

Camtasia Studio (n.d.). Techsmith.com product website. Retrieved October 4, 2007 from: http://www.techsmith.com/camtasia

Captivate (n.d.). Macromedia.com product website. Retrieved October 4, 2007 from: http://www.macropedia.com/captivate

Notess, G. R. (2005). Casting the Net: podcasting and screencasting. Online, 29(6), 43-45.

Roberts, G. (2005). Instructional technology that's hip high-tech. Computers in Libraries,25(10), 26-28.

Screencast-O-Matic (n.d.). Screencast-o-matic website. Retrieved October 4, 2007 from: http://www.screencast-o-matic

Wink (n.d.). debugmode.com website. Retrieved October 4, 2007 from: http://debugmode.com/wink

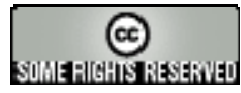


November - 2007

\title{
Book Review - Good Video Games + Good Learning: Collected essays on video games, learning and literacy
}

\author{
Author: James Paul Gee (2007). Good Video Games + Good Learning: Collected essays on \\ video games, learning and literacy. New York: Peter Lang. ISBN: 978-0-8204-9703-7, \\ paperback, 208 pages, \$29.95.
}

Reviewed by: Sharon Stoerger, Indiana University, USA

Teachers teach that knowledge waits. Bob Dylan, It's Alright, Ma (I'm Only Bleeding)

The perfect is the enemy of the good.

Voltaire

A common 'technology' associated with traditional educational environments is the chalkboard. The teacher stands in front of it and lectures to the students sitting in the classroom. Today's students, though, are experiential learners who multitask and prefer to learn by "seeking, sieving, and synthesizing” (Dede, 2005, p. 7) rather than passively listening. In other words, these individuals learn by doing and are actively seeking out the cognitive challenges presented in video games (Steinkuehler, 2005). Because these students have been exposed to technologies, like video games, educational theories that worked in the past may not in a technology-focused world (Prenksy, 2001).

James Paul Gee could have used Good Video Games + Good Learning as a vehicle to examine educational games or the serious game movement. Instead, he concentrates on well-designed games and the ways in which they can become a context for learning. Gee also examines the lessons that can be learned from video games, including violent ones like Mortal Kombat or Doom. While the media often focus on the violence in these games, Gee argues that they are just like any other technology - alone they are neither good nor bad. Moreover, he asserts, "Effects (good or bad) flow not from the game but from game + context” (p. 3).

In this collection of essays that range in topic from pleasure and learning to the human mind to 'being a professional', Gee's intention is not to suggest that video games can, or should, replace books and teachers. In fact, he believes that the immersive experiences touted by liberal education are not enough; guidance is needed otherwise the learner is "simply left to an infinity of choices with no good way to tell them apart" (p. 79). This is not to say that Gee is advocating for a conservative education approach - one that focuses on the acquisition of facts and standardized tests. Rather, Gee contends that good video games are ones that are challenging yet doable, and through guidance can help learners "prepare for action” (p. 80). 
Book Review - Good Video Games + Good Learning: Collected essays on video games, learning and literacy

One of the strongest sections is Gee's discussion of affinity spaces in Chapter 8. He describes the concept of affinity spaces as an alternative to "communities of practice" that are presented by scholars such as Lave (1996) and Wenger (1998). As Kling and Courtright (2003) astutely point out, the term "community" is one that is often uncritically used in layman's terms to connote "a group which shares warm, caring, and reciprocal social relationships among its members" (p. 224). Gee agrees with this assessment, and asserts that one of the main concerns is that notions like communities and communities of practice imply that the intention is to label individuals who is included and who is excluded. In contrast, Gee's affinity space concept is one where, "people 'bond' first and foremost to an endeavor or interest and secondly, if at all, to each other" (p. 98).

Another section worth noting is the discussion on specialist language learning. In Chapter 9, Gee makes a distinction between everyday language, the "vernacular style," versus speaking technically or the "specialist style" (p. 106). Through an example of a mother having a conversation with her child about dinosaurs, fossils, and eggs, Gee reinforces the notion that even native English speakers need language learning in order to acquire and apply specialist language. He continues by stressing that until one has "played the game" the specialist language has no situated meaning. Further, Gee states, "School is too often about reading the manual before you get to play the game, if you ever do” (p. 116).

According to Gee, Chapter 10 is the "main piece in the book" (p. 6) in that it summarizes what he has been working on since his 2003 book, What Video Games have to Teach Us about Learning and Literacy. Gee hopes that this section will further the discussion and expand on the ideas presented in previous portions of this book. Unfortunately, Chapter 10 is repetitive not only in terms of his earlier work, but more importantly of this particular collection of essays. Gee acknowledges this and suggests that this review is designed to bring "together in one place the key themes, ideas, and issues” (p. 129). Because sections are copied verbatim from earlier chapters in this book, though, this style can be frustrating from a reader's perspective. Therefore, those who "fear repetition” (p. 130) should take Gee's advice and skip this portion of the book.

Repetition is not the only troublesome feature of this collection. While Gee makes a strong case for the use of affinity spaces instead of communities in Chapter 8, he loses sight of that message in Chapter 10. In this portion of the book, Gee makes no reference to affinity spaces, but continues to characterize these groupings as communities and communities of practice. This is evident in statements such as the one found in the section, "Video Games and Learning: A New Field." In this portion of the book, Gee states that games like World of WarCraft "are introducing new 'states' or 'communities' into the world” (p. 133). It is not clear why Gee defaults back to communities, but it does raise questions as to the applicability of the affinity spaces concept he so convincingly argues for in a prior chapter.

Gee suggests that gamers may agree that a particular game is good, but they "rarely think any one game is perfect" (p. 8). The discussion presented throughout this book, for the most part, is a good one, but like the video games Gee promotes, it is not perfect. While Gee's assessment of video games is thought provoking, the substantial amount of repetitive content is disappointing, particularly to individuals who are familiar with his earlier work. Those who are new to this topic, however, may find this tactic helpful in reinforcing the fundamental concepts associated with games and learning. Overall, this book and the ideas presented within its covers are accessible to a wide audience; this includes practitioners, college students, and academics alike. 


\section{References}

Gee, J. P. (2003). What video games have to teach us about learning and literacy. New York: Palgrave/ St. Martin’s.

Gee, J. P. (2007). Good video games + good learning: Collected essays on video games, learning and literacy. New York: Peter Lang.

Dede, C. (2005). Planning for neomillennial learning styles. Educause Quarterly, 28(1), 7-12. Retrieved October 31, 2007, from: http://www.educause.edu/ir/library/pdf/eqm0511.pdf

Kling, R., \& Courtright, C. (2003). Group Behavior and Learning in Electronic Forums: A sociotechnical approach. The Information Society, 19(3), 221-236.

Lave, J. (1996). Teaching, as learning, in practice. Mind, Culture, and Activity, 3, 149-164.

Prensky, M. (2001). Digital game-based learning. New York: McGraw-Hill.

Steinkuehler, C. A. (2005). Cognition and literacy in massively multiplayer online games. In D. Leu, J. Coiro, C. Lankshear \& K. Knobel (Eds.), Handbook of research on new literacies. Mahwah, NJ.: Erlbaum. Retrieved September 15, 2007, from http://labweb.education.wisc.edu/curric606/readings/Steinkuehler2005.pdf

Wenger, E. (1998). Communities of Practice: Learning, meaning, and identity. Cambridge: Cambridge University Press.

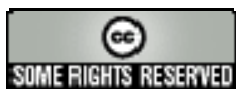


November - 2007

\section{Book Review - The Virtual University - Models and Messages: Lessons from case studies}

Editor: Susan D'Antoni (2006). UNESCO edition; Education on the Move series. 452 pages. ISBN: 10-92-3-104026-X, paperback. This book is also available online at: http://www.unesco.org/iiep/virtualuniversity/home.php

Reviewed by: Denis Mayer, Laurentian University, Canada

\section{General Comments}

Considering that virtual universities have been in existence for several years and that online learning partnerships around the world are growing, it is timely to publish the experiences and lessons learned from the institutions that have pioneered this development. The editor of this book, Susan D’Antoni, provides a valuable resource to those considering establishing a virtual university, or to those already in existence and looking to tweak their approach or model.

A selection of case studies is a practical way to present the various types of institutional models and recent developments in virtual education. This book presents the economic conditions and political considerations that provide impetus for the creation of the virtual institutions worldwide.

The first chapter, The Virtual University: Models and Messages, provides readers with context and background needed to illustrate the inherent nature of online education - specifically, that it will be essentially borderless when fully operational. This chapter underscores the fact that globalization and world economic conditions can and do have an impact - either positively or negatively.

The idea of using an established format for the case studies is helpful because it facilitates readers' comprehension of the various comparisons that can be made of the different cases. However, in the next edition, I highly recommend incorporating what has occurred since 2003.

\section{Comments by Chapter}

Chapter 2, 'The new century: societal paradoxes and major trends,' offers readers valuable context driving the virtual university movement. Topics such as world wealth, technology gains and gaps, restricted access to education, urbanization, globalization, the growth of knowledge, provide readers with the requisite background and foundation to help them mentally situate the rise of virtual institutions.

Chapter 3, 'The university - current challenges and opportunities,' narrows the book's focus even further to higher education and presents current challenges, fundamental roles of 
universities, and societal expectations. The perspective in this chapter is that technology is transforming the availability and accessibility of information, and that this is having an impact on timeworn teaching and learning approaches. The concepts of lifelong learning, digital divide, mobile learning, and learner-driven systems are crucial to the future of education. Flexibility, connectivity, the changing role of the teacher tutor/ trainer is evolving into a higher level of the teaching and learning process. Convergence between learning and working, learning and communicating, and learning and entertainment, are also key points to keep in mind as we attend to the needs of new millennium students.

Chapter 4, 'A world of borderless higher education - impact and implications,' shows that education delivered through virtual universities crosses conventional boundaries of time, space, and geography. This dynamic, in turn, brings with it both great opportunities and great challenges - and consequences particularly in terms of 'quality assurance.' The rise of corporate universities, consortiums, partnerships, and networks, are a result of available technology, and this dynamic is driving the need of institutions to internationalize to increase enrolment and provide learners with increased access and flexibility. These points are the crux of what motivates countries - and even certain governments - to launch virtual university projects.

Chapter 5 examines Universiti Tun Abdul Razak (UNITAR), and provides readers with a solid example of a virtual university operating as a private enterprise in Malaysia, a country that is working to transform its economy into that of a knowledge economy. This chapter provides a description of the start-up processes, the investments required, the operating and management system needed to launch this operation, and the influence of market forces in Malaysia. Describing lessons learned at critical stages of progress through the establishment of UNITAR provides readers with interesting and worthwhile insights.

This chapter could be consolidated, however, because several topics could be organized in such a way as to avoid overlap and repetition. While these headings reappear at different points of evolution of UNITAR, organizing the material differently could reduce some of the repetition.

Chapter 6 examines the context and justification for the creation of the digital campus, Campus Numérique Francophone, in Dakar, Sénégal. This chapter outlines public and private sector institutions, government, and the socio-economic realities in Sénégal, and explores the difficulties faced in higher education in Africa. In sum, this chapter helps readers to gain an appreciation of the complex challenges faced by educational institutions in African countries as they seek to expand capacity and increase access. The specific role of Campus Numérique francophone within the African higher education system, although limited in scope, is situated clearly as an outgrowth of the African Virtual University.

In my opinion, some detail pertaining to course administration, requirements, and technology could have be trimmed to allow for more descriptive information on lessons that have been learned with this type of set-up, especially in terms of student support services and system-wide collaboration.

Chapter 7 examines Universitat Virtual de Quilmes (UVQ), Argentina. International and national contexts are examined to inform readers about state of private university development in Argentina. The rationale to create UVQ is touched upon, and discussions surrounding the concepts of 'no tuition' and 'unrestricted admission' are extremely interesting perspectives examined. Also explored are challenges, arguably faced by most virtual universities, in terms of low graduation rates and the role of part-time faculty members - both issues are clearly important 
considerations in any virtual university structure. The importance of a national technology infrastructure and the Internet use in course delivery are likewise investigated in this chapter. For example, the partnership with a private Internet provider, viewed as an investment in this context, is worthy of readers' time and consideration, along with discussion on finding ways to assist poor, cash-strapped students. UVQ's strategy for continuous improvement is also informative.

Overall, this chapter could use some editing in certain parts. Nonetheless, future developments based on the creation of strategic alliances, joint venture agreements, sub-contracting of services, and so forth, are all excellent points touched upon in this chapter.

Chapter 8 examines the University of Southern Queensland (USQ), Online. USQ is a dual mode institution that, unlike most dual mode institutions, has a larger proportion of off campus operations than that of on campus. The USQ case provides a thorough description of infrastructure needs, content development processes, services to students, investment requirements, and organizational structure.The key lesson to be learned in the USQ case is that it is incredibly helpful to assists learners at key junctures in their learning journey to ensure they do well. In addition, the costing information related to off campus versus on campus operations is also provided. I personally found the 'evolution models' for distance education in a table format to be very helpful, particularly as a quick reference. A very strong argument for proper instructional design, which is a fundamental building block for distance education and online courses, is also made. The part examining 'e-application' was insightful and refreshing.

In terms of editing, some mention of newly emerging and rapidly evolving social networks such as Facebook, Myspace, Second Life, Wikipedia, etc., should have been made simply because these environments are likely going to have an impact on distance learners. Nevertheless, despite this shortcoming, overall, I found this chapter to be well written, clearly organized, and a good example to follow.

Chapter 9 examines Athabasca University (AU), Canada. The AU case provides readers with a good working example of a single mode - that is online and distance education - postsecondary institution. AU's unique single mode structure allows for a strategic focus on customer (i.e., student) service - more specifically students studying at a distance from home. Sharing AU's student demographic details helps readers appreciate the need for comprehensive 'student services' in an online environment that caters to students studying at home in Canada or abroad. The course completion rate of 65 percent is a reality in this type of institution, but a graduation rate of 75 percent is a success story.

Also explored in this chapter is today's shifting teaching and learning model as it transitions from a 'solitary professor' to a 'team of professionals' model. This 'team of professionals' model is central to a single mode distance education university; it also clearly underscores the need for first-rate student support services. This chapter also examines how AU established its 'best practices' in responding to student enquiries, facilitating administrative services, etc. AU's flexible residency requirement (i.e., the ability to transfer credits and study from outside Canada) was also an important point raised in this case study. Readers are also cautioned, however, to the emergence of 'degree mills.' As such, this chapter emphasizes the importance of 'branding' in an online environment. 'Credibility' builds 'brand,' and such 'branding' based on reputation is typically achieved via provincial and national accreditation of the institution. In sum, this level of institutional 'branding' helps AU to differentiate itself in a world where 'degree mills' abound. This case also explores the groundwork that takes place prior to enrolling students at AU, specifically by AU's 'student readiness assessment' procedure that is designed to evaluate 
whether or not a given student is ready to study a given course or program of study at a distance. In sharing AU's 'lesson learned' about managing partnerships also provides valuable insights for readers. Establishing goals for enrolment (growth) targets within existing programs and establishing parameters around international (off shore) growth provides insight on how to manage such growth domestically and internationally. The AU case also accurately shows readers that the main thing students seek from a virtual university are quality, flexibility, and cost. Nonetheless, students must also be assured that studying at a distance will not hinder future employment. Helping students understanding the credibility of the degree they are seeking to earn will work to reificate the overall market perception and hence, ultimate recognition of the degree as credible.

Overall, this chapter is well written and I am confident readers will find it insightful.

Chapter 10, explores the world of Kenyatta University - African Virtual University (AVU) Initially funded by the World Bank to get off the ground, the AVU case offers numerous interesting insights. The primary objective of the AVU project differs from the many other virtual university models covered in this book. Moreover, the AVU case illustrates the multiple and ongoing challenges African countries face in bringing education opportunities to its people. This chapter shows that the traditional model of distributed learning and course brokering remains fraught with challenges and that there remains a serious mismatch between delivery institutions operating in totally different contextual realities versus that of their learners, who are largely desperate for certification and in need of education that is relevant to their world. This case also shows that the concept of exporting education because the technology can enable it is not always the best way forward. This chapter also outlines the steps of development and the difficulties associated with these steps, and illustrate the difficulties faced and efforts needed to keep partnerships alive. Partnerships, without doubt, are essential to virtual universities. This case explores the issue gender, which in itself is clearly a consideration in curriculum development and the provision of student services. The dependency and difficulties of the AVU administrative model impresses upon readers that the 'learning centre model' currently plays second fiddle to the host institution, and that institutional 'branding' is often very difficult to achieve when you are perceived to be 'second fiddle'. In addition, although real and perceived competition is taking place between AVU and its partner universities, the virtual university model is evolving and it is gaining momentum, and as a result, has much greater potential to positively influence many students in Africa.

The chapter is well written and easy to follow and exposes clearly the challenges that must be overcome.

Chapter 11 explores the world of L'Université virtuelle en pays de la Loire, France. This case describes an interesting collaboration comprised of several universities across France. The overall context and the international contexts, however, were extensive and somewhat hard to follow and as such, some clarity could have been helpful. The section outlining the institutional context, including purpose of the consortium, its strengths, and the opportunity to capitalize on the savoirfaire that exists within these institutions is coherently presented. The section describing the creation of the consortium, organizational structure, technological structure and intellectual property contain some detail that could be edited down, however. The description of the UVPL's development and management shows these to be complex structures that seem somewhat unwieldy. The outline on UVPL's teaching and learning processes could also be shortened. The lessons learned and the recommendation section on policy development, planning and management nonetheless was insightful and clearly important to include. This chapter also 
explores the financial needs of such a comprehensive structure, and impresses upon readers the need for periodical assessment of its purpose and value.

Chapter 12 focuses on the case of Netvarsity, India. This chapter examines Netvarsity international context along with its relationship with its creator, India's National Institute of Information Technology (NIIT). Unlike previous chapters, this particular chapter reveals a much different type of intuitional entity - specifically that this particular virtual university is the child of a leading, worldwide information technology training company. And it is clear that NIIT enjoys a handsome profit margin that enables it to fund such an initiative! Netvarsity's creation of a sizable 'student loan program' is commendable, and is shown to support increased enrolment and ensure access. This funding strategy also demonstrates that profit found in 'tuition fees' are a major factor driving the decision to support skill-building and higher education. However, this institution has no degree granting authority, and the credentialing and its market recognition are not well documented in this case study. Moreover, while NIIT's vision and ambition is clearly described, its reputation and 'branding' in the larger market place remains undefined. Nonetheless, including a privately owned, technology skill-building institution in this book's mix of chapters provides readers opportunity to compare and contrast, draw parallels and differences. Still the bottom line is that Netvarsity, without articulation agreements or recognition of training by formal higher education institutions in place, would likely have less market value in, say, North America. Indeed, the lesson to be gained from this chapter is all about the viability of a purely Internet-based skill building organization that operates without direct links to the formal education system. On another note, I found the concept of developing "skillets" - something akin to learning objects - very interesting. Also, the comment made that the Internet can make traditional instructor-led training more effective, but that it does not replace, was an astute point to raise.

Chapter 13 entitled 'Messages and lessons learned,' is the final chapter in Susan D'Antoni's collection of very enlightening case studies. Having a summary chapter was a great idea. However, the next edition of this book could benefit by pulling together more of the key learnings and commonalities, and help reader to draw clear differences between the various case studies.This chapter could also have benefited by including remarks about the international context of the countries involved, and draw conclusions about the potential for e-learning within this highly diversified, global mix.A commentary section or observations from those charged with peer reviewing this book, could also enrich it greatly. For example, such comments and observations could be organized under themes such as: 1) institutional models; 2) leadership; 3) policy and political context; 4) economic realities; 5) human resources availability; 6) sustainability; 7) societal readiness; 8) international perspective etc.

Overall, I found this book to be an excellent resource, and would recommend it to those working in a virtual university or those trying to introduce e-learning in a traditional university. 